\title{
Understanding the Mechanism of Hard Metal (WC-Co) Toxicity: In vitro Studies and In vivo Exploration
}

Andrea Lynn Armstead

Follow this and additional works at: https://researchrepository.wvu.edu/etd

\section{Recommended Citation}

Armstead, Andrea Lynn, "Understanding the Mechanism of Hard Metal (WC-Co) Toxicity: In vitro Studies and In vivo Exploration" (2014). Graduate Theses, Dissertations, and Problem Reports. 5122.

https://researchrepository.wvu.edu/etd/5122

This Dissertation is protected by copyright and/or related rights. It has been brought to you by the The Research Repository @ WVU with permission from the rights-holder(s). You are free to use this Dissertation in any way that is permitted by the copyright and related rights legislation that applies to your use. For other uses you must obtain permission from the rights-holder(s) directly, unless additional rights are indicated by a Creative Commons license in the record and/ or on the work itself. This Dissertation has been accepted for inclusion in WVU Graduate Theses, Dissertations, and Problem Reports collection by an authorized administrator of The Research Repository @ WVU.

For more information, please contact researchrepository@mail.wvu.edu. 


\title{
Understanding the Mechanism of Hard Metal (WC-Co) Toxicity: \\ In vitro Studies and In vivo Exploration
}

\author{
Andrea Lynn Armstead \\ Dissertation submitted to the School of Pharmacy at West Virginia University \\ in partial fulfillment of the requirements for the degree of
}

\section{Doctor of Philosophy}

In

\section{Pharmaceutical \& Pharmacological Sciences}

\author{
Bingyun Li, PhD. (Mentor \& Chair) \\ Peter Gannett, $\mathrm{PhD}$. \\ Rae Matsumoto, PhD. \\ Yon Rojanasakul, $\mathrm{PhD}$. \\ Timothy Nurkiewicz, PhD. (External member) \\ Pharmaceutical \& Pharmacological Sciences Graduate Program \\ Department of Basic Pharmaceutical Science \\ Morgantown, WV 26506
}

2014

Keywords: nanoparticle, nanotoxicity, pulmonary exposure, lung disease, inflammation, particle inhalation, internalization, immune response, hard metal, toxicity 


\section{ABSTRACT \\ Understanding the Mechanism of Hard Metal (WC-Co) Toxicity: In vitro Studies and In vivo Exploration}

\section{Andrea Lynn Armstead}

Hard metals, such as tungsten carbide cobalt (WC-Co), are frequently used for a number of industrial applications such as surface coatings for heavy machinery and tools. In particular, WC-Co coatings are prevalent in mining and drilling applications where extensive, repetitive use of these tools causes wear over time. In enclosed environments, WC-Co wear particles become airborne and present an occupational inhalation hazard. It is known that inhalation of WC-Co "dusts", composed of nano- and micro-sized WC-Co particles, contributes to the development of hard metal lung disease and increased risk for lung cancer; however, the relationship between acute WC-Co toxicity and disease progression remains poorly understood. To address this gap in knowledge, we systematically evaluated nano-WC-Co particle toxicity using a combination of in vitro and in vivo models. In Aim 1, we determined the toxicity of nano-WC-Co particles in BEAS2B lung epithelial cells over concentrations ranging 0.1 to $1000 \mu \mathrm{g} / \mathrm{mL}$ and exposure periods from 0.5 to $48 \mathrm{hr}$. Our MTT-based cell viability assay indicated that nano-WC-Co exhibits greater toxicity than micro-WC-Co at concentrations $\geq 10 \mu \mathrm{g} / \mathrm{mL}$. We also found that nano-WC-Co exposure induces oxidative stress at the highest particle concentration tested $(1000 \mu \mathrm{g} / \mathrm{mL}) \mathrm{using}$ a fluorescence-based (DCF/DHE) assay and that WC-Co particle exposure induced cellular apoptosis, marked by increased annexin-V staining in our flow cytometry apoptosis assay. The potential for nano-WC-Co particle internalization was also investigated using transmission electron microscopy (TEM) and confirmed that nano-WC-Co particles are capable of being internalized by BEAS-2B cells. In Aim 2, we determined the inflammatory response toward nanoWC-Co particles in a co-culture model of BEAS-2B cells and macrophages, to more closely represent the dynamic tissue environment of the lung. The results of our viability assay indicated that macrophages attenuated the toxicity of nano-WC-Co in the co-culture model compared to BEAS-2B alone, which indicated a protective effect of the macrophages. We found that nano-WCCo exposure caused macrophage polarization toward the M1 pro-inflammatory phenotype and determined that nano-WC-Co exposure also stimulates the secretion of cytokines such as IL-12 and IL- $1 \beta$ in macrophages, consistent with a pro-inflammatory response. In Aim 3, we investigated the potential systemic (extra-pulmonary) effects of nano-WC-Co exposure in an intra-tracheal instillation (IT) rat model and compared the outcomes with a known pulmonary irritant, cerium dioxide $\left(\mathrm{CeO}_{2}\right)$. After $24 \mathrm{hr}$ exposure, nano-WC-Co exposure did not induce pulmonary or systemic inflammation at a dose of 50,250 or $500 \mu \mathrm{g}$ compared to control or $\mathrm{CeO}_{2}$; this outcome highlights the need for future in vivo studies which examine the inflammatory effects of chronic or repeated nano-WC-Co exposure. Taken together, the results of our studies improve the current understanding of hard metal WC-Co toxicity and may point toward potential therapeutic or diagnostic strategies for the future. 


\section{ACKNOWLEDGEMENTS}

"Believe in yourself and all that you are. Know that there is something inside you that is greater than any obstacle." -Christian D. Larson

My personal journey towards earning my doctoral degree has been filled with steep obstacles, deep valleys and seemingly endless tangents, but I know without a doubt, that if you believe in yourself, work hard and persevere, you'll find great rewards in the end. A heartfelt thank you goes out to my incredible network of family, friends and mentors whom have helped guide me at various times down this long and challenging path:

First, I would like to thank my mentor, Bingyun $\mathrm{Li}$, and my dissertation committee members, Rae Matsumoto, Peter Gannett, Yon Rojanasakul and Tim Nurkiewicz, for allowing me to pursue my own research ideas, encouraging me to think critically and for providing critical commentary and suggestions along the way. A special thank you to Tim and Rae, for lending an extra shoulder to lean on during my times of frustration and for always reminding me that it will turn out great in the end.

To my "Morgantown Friends"- Alaina Smith, Amanda Suchanek, Katherine Hickey, Brian Train and Lance Wollenberg- thank you for being my outlet for the good, the bad and the ugly, at the times I needed it the most. The friendships we have built and memories we've created over the past five years mean the world to me and I'm so grateful that I connected with each and every one of you. I'd also like to thank my long-time friends and partners in crime, Renae Solko and Paul Harrison, for always being there and fetching those occasional, stress relieving margaritas.

Back home in the land of Oz, I'd like to thank my parents, Becky and Rusty Walters, for making a fantastic, honest effort to really understand what my research is about (nanopartawhat?), spending countless hours on the phone, sharing in my joys, celebrating my achievements and encouraging me when I was down and frustrated; to the rest of my family, Deanna, Uncle Ronnerd, Grandma Marge \& Mallory, thank you for doing what you could to help out from many miles away.

Additionally, I'd like to thank Suzanne Smith, for always having an open office door, providing an outside perspective, ordering my research supplies and proofreading all of my written work. The experiments composing this dissertation would not have been possible without you! I would also like to thank Ellen Woods and the American Foundation for Pharmaceutical Education; my appointment as an AFPE fellow has provided a number of exciting experiences and opportunities that I wouldn't have had otherwise during my time here at WVU.

Most importantly, I want to acknowledge my incredible husband, Brian Armstead, for all of his love and constant support over the last five years. It takes a special kind of strong, dedicated man to marry a woman, pack everything up and drive across the country so his wife can start graduate school two weeks after saying "I Do”. Words cannot express how grateful I am to have you in my life and how much it means to me that you've been there for me every step of the way. You've made this dissertation possible in more ways than you know. This is not just for me, it's also for you and for us. I cannot wait to see what the future holds..... (:) 


\section{TABLE OF CONTENTS}

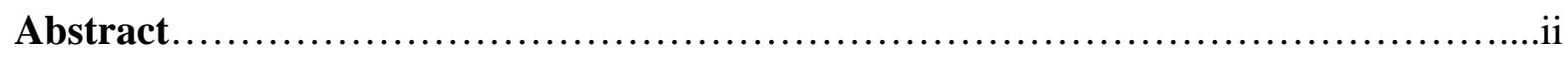

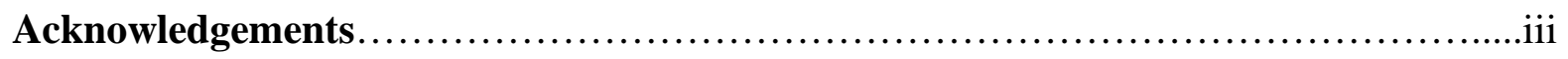

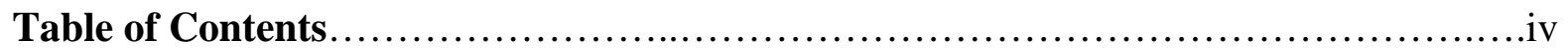

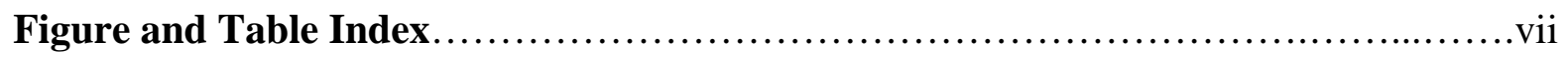

Chapter 1: Nanotoxicity: Emerging Concerns Regarding Nanomaterial Safety \& Occupational Hard Metal (WC-Co) Nanoparticle Exposure

1.1: Engineered Nanomaterials, Nanotoxicity \& Means of Exposure..................3

1.2: Industrial Hard Metal (WC-Co) Applications \& Exposure......................10

1.3: Risk of WC-Co Exposure: Hard Metal Lung Disease (HMLD) Prognosis \& Cancer Risk..........................................................11

1.4: Defining Hard Metal (WC-Co) Toxicity: In vitro and In vivo Studies............12

1.5: Specific Aims of Dissertation Research.................................20

\section{Chapter 2: Exploring the Potential Role of Tungsten Carbide Cobalt (WC-Co)}

Nanoparticle Internalization in Observed Toxicity toward Lung Epithelial Cells in vitro

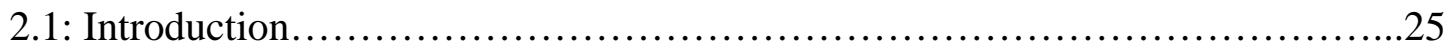

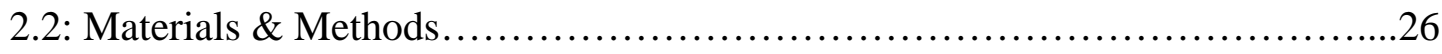

2.3: Results..........................................................30

2.4: Discussion...................................................... 38

2.5: Conclusion.................................................... 42

2.6: Supplementary Material.............................................44

Chapter 3: Inflammatory Effects of Hard Metal (WC-Co) Nanoparticle Exposure in vitro: Mono-culture vs. Co-culture Models 


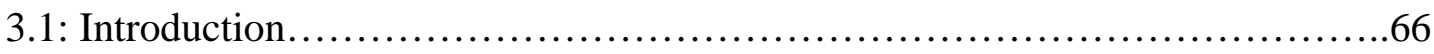

3.2: Materials \& Methods ....................................................68

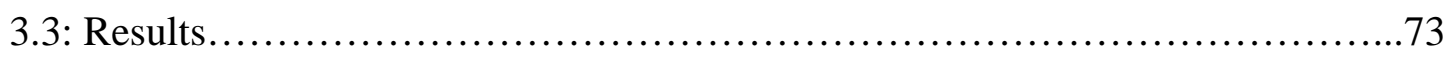

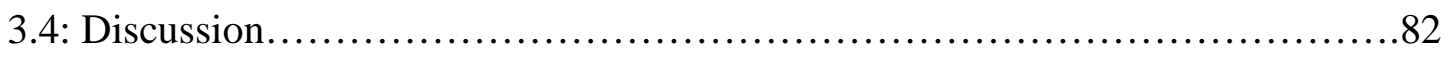

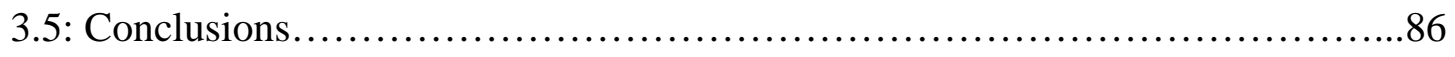

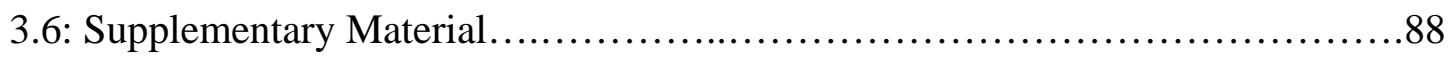

\section{Chapter 4: Acute Inflammatory Responses of Nanoparticles in an Intra-tracheal Instillation Rat Model}

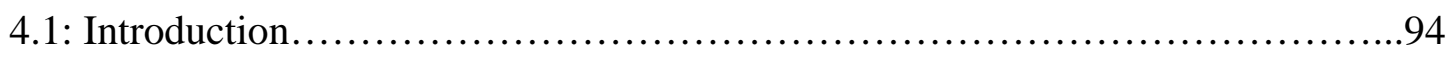

4.2: Materials \& Methods....................................................96

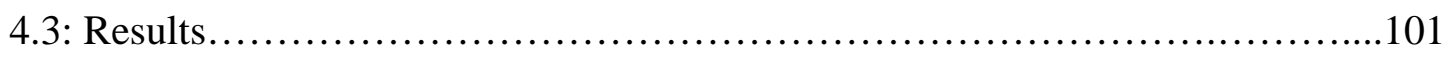

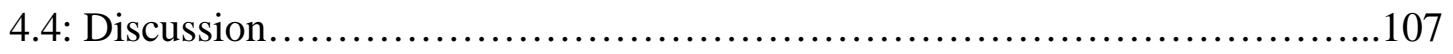

4.5: Conclusions...............................................................

\section{Chapter 5: Toxicity of Cobalt Chromium Molybdenum (CoCrMo) Toward Lung}

\section{Epithelial Cells in vitro}

6.1: Introduction.............................................................

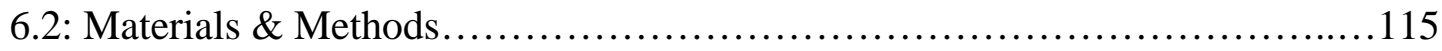

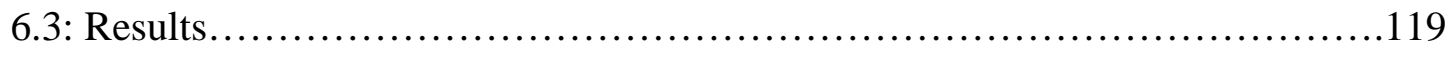

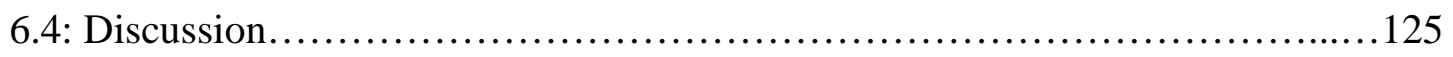

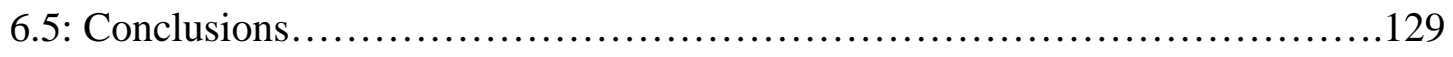

6.6: Supplementary Material...................................................131

\section{Chapter 6: Research Summary \& General Discussion}

5.1: Summary of Research Findings.............................................135 


\section{Chapter 7: References}

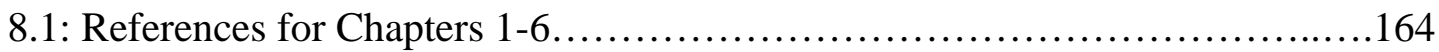

\section{Appendix I: Curriculum Vitae}

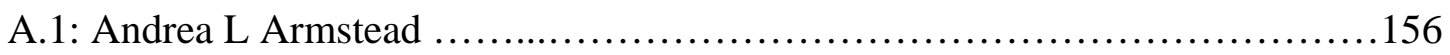

\section{Appendix 2: Nanomedicine as an Emerging Approach against Intracellular Pathogens}

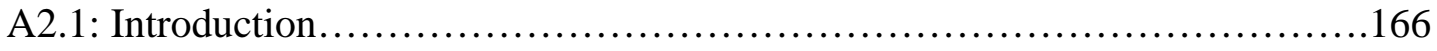

A2.2: Intracellular Pathogens and Current Treatment Approaches..................166

A2.3: Major Challenges in Treating Intracellular Pathogens......................172

A2.4: Nanomedicine as an Emerging Therapeutic Approach........................177

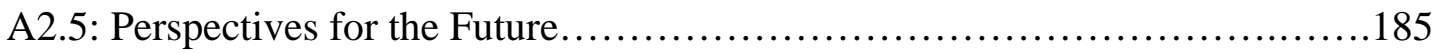

A2.6: Concluding Remarks..............................................189

A.2.7: References.....................................................191 


\section{INDEX OF FIGURES \& TABLES}

\section{Chapter 1: Introduction \& Literature Review}

Table 1.1: Important components of NP toxicity testing..........................................5

Table 1.2: Examples of in vitro cell models used for nanotoxicity testing.................7

Table 1.3: Examples of in vivo animal models used for nanotoxicity testing..............9

Table 1.4: Summary of in vitro studies regarding WC-Co toxicity......................14

Table 1.5: Summary of in vivo studies regarding WC-Co toxicity.......................18

Figure 1.1 Routes and potential detrimental effects of NP exposure...................4

Figure 1.2 Schematic representation of dissertation research project..........................22

\section{Chapter 2: Exploring the Potential Role of Tungsten Carbide Cobalt (WC-Co)}

Nanoparticle Internalization in Observed Toxicity Toward Lung Epithelial Cells in vitro

Table 2.1: Elemental composition of WC-Co particles by EDX.....................31

Figure 2.1: WC-Co particle characterization via DLS and TEM.......................31

Figure 2.2: Cell viability after WC-Co nano/micro-particle exposure..................32

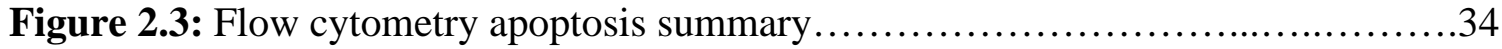

Figure 2.4: Cell viability after WC-Co exposure in presence of inhibitors................36

Figure 2.5: WC-Co particle internalization via TEM.............................38

Chapter 3: Inflammatory Effects of Hard Metal (WC-Co) Nanoparticle Exposure in vitro: Mono-culture vs. Co-culture Models

Figure 3.1: Cell viability after nano-WC-Co exposure in mono- and co-culture.........74

Figure 3.2: Summary of macrophage polarization flow cytometry staining..............76

Figure 3.3-3.5: Representative dot plots for macrophages exposed to nano-WC-Co.....77

Figure 3.4: Levels of pro-inflammatory cytokines...............................81

\section{Chapter 4: Acute Inflammatory Responses of Nanoparticles in an Intra-tracheal} Instillation Rat Model

Figure 4.1: Pulmonary inflammation in the BAL fluid............................102

Figure 4.2: Inflammatory cells in the BAL fluid.................................104

Figure 4.3: Inflammatory cytokine concentration in BAL fluid and plasma.............105

Figure 4.4: Isolated BAL cell histology ................................... 106

Chapter 5: Toxicity of Cobalt Chromium Molybdenum (CoCrMo) Particles Toward Lung Epithelial Cells in vitro

Figure 5.1: CoCrMo particle characterization via SEM...........................119

Figure 5.2: Cell viability after exposure to CoCrMo particles.......................121

Figure 5.3: Comparison of cell viability after CoCrMo and WC-Co exposure.............122

Figure 5.4: DCF fluorescence after CoCrMo particle exposure.....................123

Figure 5.5: DHE fluorescence after CoCrMo particle exposure.....................124 
Figure 5.6: Comparison of CoCrMo and WC-Co oxidative stress...................125

\section{Appendix II: Nanomedicine as an Emerging Approach against Intracellular Pathogens}

Table A2.1 Summary of Disease-Causing Pathogens................................167

Table A2.2-A Current therapeutic strategies against selected viral pathogens............174

Table A2.2-B Current therapeutic strategies against intracellular bacterial pathogens..176

Table A2.3 Examples of biocompatible nanoparticles in this review...................189

Figure A2.1 Potential locations of intracellular pathogens...........................173

Figure A.2 Components of an ideal nanoparticle for intracellular drug delivery.........187 


\section{CHAPTER 1:}

Nano-Toxicity: Emerging Concerns Regarding Nanomaterial Safety

\&

Occupational Hard Metal (WC-Co) Nanoparticle Exposure 


\section{ABSTRACT}

As the number of commercial and consumer products containing engineered nanomaterials (ENMs) continually rises, the increased use and production of these ENMs presents an important toxicological concern. While ENMs offer a number of advantages over traditional materials, their extremely small size and associated characteristics greatly enhance their toxic potential. ENM exposure can occur in a variety of consumer and industrial settings via inhalation, ingestion or dermal routes. While the importance of accurate ENM characterization, effective dosage metrics and selection of appropriate cell or animal-based models are universally agreed upon as important factors in ENM research, at present, there is no "standardized" approach used to assess ENM toxicity in the research community. Of particular interest is occupational exposure to tungsten carbide cobalt (WC-Co) "dusts", composed of nano- and micro-sized particles, in hard metal manufacturing facilities and mining and drilling industries. Inhalation of WC-Co dust is known to cause "hard metal lung disease" and an increased risk of lung cancer; however, the mechanisms underlying WC-Co toxicity, the inflammatory disease state and progression to cancer are poorly understood. Herein, a discussion of ENM toxicity is followed by a review of the known literature regarding the effects of WC-Co particle exposure and an original dissertation research project, focusing on the mechanisms of WC-Co mediated toxicity in vitro and in vivo, is proposed.

Keywords: engineered nanomaterial, nanotoxicity, nanoparticle, occupational exposure, hard metal, lung disease, cancer 


\section{ENGINEERED NANOMATERIALS, NANOTOXICITY \& MEANS of EXPOSURE}

Due to recent technological and manufacturing advancements, the production and use of engineered nanomaterials (ENMs) is increasing at a rapid pace. The term ENM broadly encompasses a number of nano-sized materials that vary in shape, such as nanotubes, nanowires, or nanoparticles (NPs), which are generally defined as "any material having at least one dimension smaller than $100 \mathrm{~nm} "[1,2]$. Due to their extremely small size and high surface area, NPs offer a number of advantages over traditional "bulk" materials and are suitable for a wide variety of applications in consumer goods [3-5], medical devices and diagnostics [6-9], pharmaceutical products [8, 10-14], fuel additives [15-17] and other industrial uses [18]. As a result, the number of manufactured goods containing NPs is continually rising; in 2006, manufacturers reported that NPs were incorporated in over 600 consumer products worth $\$ 50$ billion in market value [3], a number which more than doubled to greater than $1600 \mathrm{NP}-$ containing consumer products in 2013 [19].

With the increased use of NPs in such diverse applications, a concomitant risk of exposure exists across consumer households and in commercial occupational settings. NPs exist in our daily environments and are often referred to as "contaminants" of important air, water and soil resources [20-24]. Because these NPs are all around us, exposure can occur via mechanisms such as inhalation, ingestion and dermal exposure [25]. Additionally, emerging evidence suggests that humans may also be exposed to NPs internally, which may be generated in situ due to orthopedic surgical implant wear [26-29]. These potential routes of NP exposure are summarized graphically in Figure 1. Importantly, the route of exposure ultimately determines which body system or specific tissues the NPs interact with which in turn, determines the effects of NP exposure such as toxicity [30-32] or alterations in physiological function [33, 34]. 


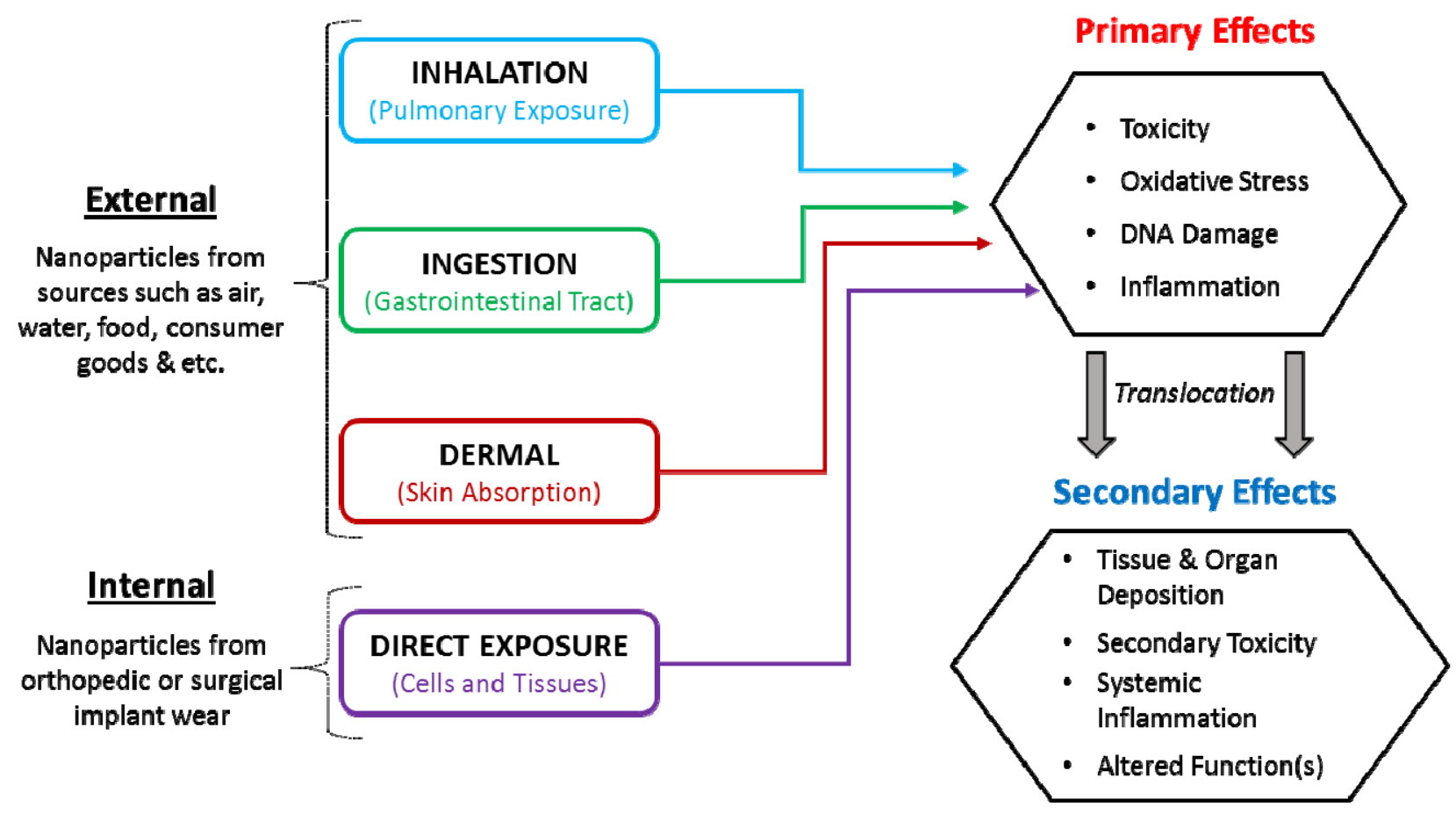

Figure 1. Routes and potential detrimental effects of NP exposure.

The effects of NP exposure can be divided into primary and secondary categories (Figure 1), depending upon the extent of exposure. Primary effects resulting from direct cellular NP contact may include toxicity, oxidative stress, DNA damage and inflammation $[1,2,35]$. Due to their small size, NPs may translocate through tissue barriers into the blood, where they can circulate and eventually deposit in other organs, thereby generating a secondary NP exposure. Secondary effects may include toxicity at the site of NP deposition, in organs such as the liver, spleen or kidneys, systemic inflammation or alterations in systemic function [1, 2, 33, 35-37]. The first three routes of exposure occur via external NP sources, but there is emerging evidence which indicates that humans may also be exposed internally, when orthopedic or surgical implant wear NPs are released locally from the implant site [26, 38, 39]. Most commonly, humans are exposed to NPs in their environments through the pulmonary route, by inhaling airborne NPs during normal breathing $[33,34,40,41]$. 
Despite their potential toxic properties, it is worth mentioning that certain NPs have distinct advantages which outweigh the risk of use and have greatly improved a consumer products on the market today such as sunscreens and cosmetics [25]. For example, titanium dioxide NPs present in sunscreens and cosmetic products are highly beneficial, offering excellent protection from sun exposure, therefore protecting the skin against UV damage and preventing sunburn. NPs have been approved for use under these conditions; however, the long-term effects of titanium dioxide NPs on aquatic life in contaminated water sources (lakes, oceans, etc) remain an important concern for future research.

\section{Table 1: Important Components of NP Toxicity Testing}

\begin{tabular}{|c|c|}
\hline \multirow{6}{*}{ Characterization } & Primary particle size \\
\hline & Agglomerate size in suspension \\
\hline & Size distribution range \\
\hline & Elemental composition \& contaminant levels \\
\hline & Zeta potential \\
\hline & Particle shape/morphology \& density \\
\hline \multirow{4}{*}{ Dosage Metrlcs } & Mass per volume $(\mathrm{mg} / \mathrm{mL})$ \\
\hline & Surface area $\left(\mu \mathrm{m}^{3}\right)$ \\
\hline & Particle number \\
\hline & Single or multi-dose \& dose frequency \\
\hline \multirow{5}{*}{ Model System } & In vitro: cell selection, mono- or co-culture model \\
\hline & In vitro assay selection (MTT, LDH, etc.) \\
\hline & In vivo: animal selection (rat, mouse, etc.) \\
\hline & $\begin{array}{l}\text { In vivo: method of exposure (inhalation, intra-tracheal instillation, } \\
\text { injection, internal wear debris, etc.) \& exposure duration }\end{array}$ \\
\hline & In vivo sample collection (fluid, tissue, organ, etc.) \\
\hline
\end{tabular}

Table 1. Important components of NP toxicity testing. 
As a direct result of the increased use of NPs and likelihood of exposure, the study of the acute and chronic effects of NP exposure has recently emerged as the field of 'nanotoxicology' [42]. Currently, there is no standard approach for NP toxicity testing and a number of arguments support the implementation of a standard testing procedure, so that results and outcomes can be directly comparable amongst all NPs tested. However, this remains a difficult task because the route and realistic amount of exposure (dose) vary greatly depending on the particular NP in question [43]. In order to define the toxic potential of NPs, several key factors must be addressed (summarized in Table 1) [1, 2, 42]. First, it is imperative to characterize NPs in terms of size, shape and properties, so that the observed effects can be attributed to a particular property or characteristic $[44,45]$. Next, an appropriate dosage metric must be selected for the NPs to be examined. In the literature, NP dosages have been reported as concentration per volume or mass $(\mathrm{mg} / \mathrm{mL}$ or $\mathrm{mg} / \mathrm{kg})$, as reactive surface area $\left(\mathrm{cm}^{2}\right)$ or as particle number in solution, calculated based on NP size [43].

In addition to particle characterization and selection of the dosing metric, an appropriate model must be selected for toxicity testing [32, 41, 46]. Typically, in vitro cell-based models are the starting point due to lower cost and relative ease of execution compared to in vivo animalbased model systems [47]. In vitro systems require small amounts of NP for testing and allow for dose-response testing and sample collection over time in a variety of systems such as cells or tissues [47]. Primary or commercial cells are commonly used for ENM toxicity testing and cell selection for a given assay is frequently based on the potential route of NP exposure; some examples of in vitro models are summarized in Table 2. Aside from the advantage of being "fast and cheap", in vitro models can be used to estimate toxico-kinetic parameters, target organ 
toxicity and help define appropriate NP dosages for in vivo studies, which helps to reduce the number of experimental animals required for nanotoxicity research.

\section{Table 2: Examples of In Vitro Cell Models used for Nanotoxicity Testing}

\begin{tabular}{|c|c|c|c|c|}
\hline Cell Type & NPs Studied & NP Size & NP Dose & [Ref] \\
\hline Human lung carcinoma (A549) & $\begin{array}{l}\text { Cerium Dioxide } \\
\left(\mathrm{CeO}_{2}\right)\end{array}$ & $10 \mathrm{~nm}$ & $\begin{array}{c}6.25,25 \text { or } 100 \\
\mu \mathrm{g} / \mathrm{mL}\end{array}$ & [17] \\
\hline $\begin{array}{l}\text { Human hepatocyte }(\mathrm{C} 3 \mathrm{~A}) \text {, human } \\
\text { colon adenocarcinoma }(\mathrm{CaCo}-2) \text {, } \\
\text { primary trout hepatocytes }\end{array}$ & $\begin{array}{l}\text { Gold }(\mathrm{Au}) \\
\text { Cerium Dioxide } \\
\left(\mathrm{CeO}_{2}\right)\end{array}$ & $\begin{array}{l}35 \mathrm{~nm} \\
25 \mathrm{~nm}\end{array}$ & $0-1000 \mu \mathrm{g} / \mathrm{mL}$ & {$[24]$} \\
\hline $\begin{array}{l}\text { Human fibroblasts, peripheral } \\
\text { blood mononuclear cells, } \\
\text { macrophages }\end{array}$ & $\begin{array}{l}\text { Cobalt Chromium } \\
\text { (CoCr) }\end{array}$ & $\begin{array}{l}30 \mathrm{~nm} \\
3 \mu \mathrm{m}\end{array}$ & $1-5000 \mu \mathrm{m}^{3} /$ well & $\begin{array}{l}{[48-} \\
50]\end{array}$ \\
\hline Hepatocellular carcinoma (HepG2) & $\begin{array}{l}\text { Silicon Dioxide } \\
\left(\mathrm{SiO}_{2}\right)\end{array}$ & $43 \mathrm{~nm}$ & $\begin{array}{c}25,50,100,200 \\
\mu \mathrm{g} / \mathrm{mL}\end{array}$ & {$[51]$} \\
\hline $\begin{array}{l}\text { Human lung epithelial cells } \\
\text { (BEAS-2B) }\end{array}$ & $\begin{array}{l}\text { Titanium Dioxide } \\
\text { (TiO2) }\end{array}$ & $25 \mathrm{~nm}$ & $5,10,20,40 \mu \mathrm{g} / \mathrm{mL}$ & {$[52]$} \\
\hline $\begin{array}{l}\text { Rat alveolar macrophages (RAW } \\
264.7 \text { ) }\end{array}$ & $\begin{array}{l}\text { Crystalline Silica } \\
\text { Zinc Oxide } \\
\text { Magnesium Oxide } \\
\text { (DQ12, ZnO, MgO) }\end{array}$ & $\begin{array}{l}960 \mathrm{~nm} \\
10 \mathrm{~nm} \\
8 \mathrm{~nm}\end{array}$ & $1,5,10,40 \mu \mathrm{g} / \mathrm{cm}^{2}$ & [53] \\
\hline
\end{tabular}

Table 2. Examples of in vitro models used in NP toxicity testing.

Although in vitro models and toxicity assays are reliable and used frequently, several groups have reported NP interference with commonly used cell-based assays [54-57], bringing into question whether the results are accurate or if they are simply artifacts generated due to NP interference with the assay mechanism $[57,58]$. To address this issue, a number of control 
experiments are required to identify any potential NP assay interference and these effects must be considered when interpreting the final results.

Although they offer a number of advantages, cell-based systems are limited and generally demonstrate the effects of NPs within a very specific and small compartment compared to whole-animal in vivo models [59-61]. Animal models may offer more realistic insights as to the effects of NP exposure in humans because the body systems can be utilized as a whole, with all of its cells, tissues and organs interacting with the NPs as would be encountered in a realistic exposure scenario [59-61].

Since there are a number of NP exposure routes for humans, a number of in vivo exposure approaches must be used such that the effects of the NP on the appropriate tissue or organ system can be identified. Commonly used in vivo NP exposure routes are summarized Table 3, including NP inhalation, intra-tracheal instillation (IT), injection and ingestion or gavage. As mentioned earlier, NP inhalation and pulmonary exposure is the most common in humans and is therefore the most frequent route by which experimental animals are exposed in nanotoxicity studies. However, not all NPs are suitable for aerosolization for the purposes of an inhalation chamber, so alternatively, pulmonary NP exposure can be achieved via intra-tracheal instillation (IT) [62]. IT is a highly reproducible, direct method for depositing NP within the lungs and NP delivered in this manner have very similar lung distribution to NP inhalation [62]; therefore, IT is considered an excellent approach for the pulmonary delivery of NP. In addition to pulmonary routes of exposure, animals may also be exposed to NP via injection for the purposes of systemic or local NP exposure. Intra-peritoneal (IP) or intravenous (IV) NP injections can be used to achieve systemic NP exposure, as the NP will circulate through the vasculature and may deposit in organs such as the liver, spleen or kidneys. Injection may also be 
used to achieve localized NP exposure within articular locations, such as the knee or hip, or may be used to target subcutaneous tumors.

\section{Table 3: Examples of In Vivo Animal Models Used for Nanotoxicity Testing}

\begin{tabular}{|c|c|c|c|c|c|}
\hline $\begin{array}{l}\text { NP Delivery } \\
\text { Method }\end{array}$ & Animal Model & NPs Studied & NP Size & NP Dose & [Ref] \\
\hline \multirow[t]{2}{*}{ Inhalation } & Mouse & $\begin{array}{l}\text { Cadmium } \\
\text { Oxide }(\mathrm{CdO})\end{array}$ & $15 \mathrm{~nm}$ & $\begin{array}{l}250 \mu \mathrm{g} / \mathrm{m}^{3} \text { for } 3 \mathrm{hr} / \\
\text { day } \times 7 \text { days }\end{array}$ & [63] \\
\hline & Rat & $\begin{array}{l}\text { Magnetite } \\
\left(\mathrm{Fe}_{3} \mathrm{O}_{4}\right)\end{array}$ & $1.3 \mu \mathrm{m}$ & $\begin{array}{l}4.7,16.6,52.1 \\
\mu \mathrm{g} / \mathrm{m}^{3} \text { for } 6 \mathrm{hr} / \text { day } \times \\
5 \text { days } / \text { week } \times 13 \\
\text { weeks }\end{array}$ & [64] \\
\hline \multirow[t]{2}{*}{$\begin{array}{l}\text { Intra-tracheal } \\
\text { Instillation (IT) }\end{array}$} & Rat & $\begin{array}{l}\text { Cerium Dioxide } \\
\left(\mathrm{CeO}_{2}\right)\end{array}$ & $191 \mathrm{~nm}$ & $\begin{array}{l}10,100,400 \mu \mathrm{g} \text { per } \\
\text { rat }\end{array}$ & {$[65]$} \\
\hline & Mouse & Chitosan & $633 \mathrm{~nm}$ & $2 \mathrm{mg} / \mathrm{kg}$ & [66] \\
\hline \multirow[t]{2}{*}{ Injection } & $\begin{array}{l}\text { Mouse } \\
\text { (periarticular } \\
\text { injection) }\end{array}$ & $\begin{array}{l}\text { Cobalt } \\
\text { Chromium } \\
(\mathrm{CoCr})\end{array}$ & $\begin{array}{l}32 \mathrm{~nm} \\
2.9 \mu \mathrm{m}\end{array}$ & $\begin{array}{l}1.2 \times 10^{6} \mu \mathrm{m}^{3} / 25 \mathrm{~g} \\
1 \text { injection/week } \times 2 \\
\text { weeks }\end{array}$ & [67] \\
\hline & $\begin{array}{l}\text { Rats (articular } \\
\text { injection) }\end{array}$ & $\begin{array}{l}\text { Cobalt } \\
\text { Chromium } \\
(\mathrm{CoCr})\end{array}$ & $60 \mathrm{~nm}$ & $\begin{array}{l}0.05,0.25,1.25 \\
\mu \mathrm{g} / \mathrm{mL} \\
1 \text { injection/week } \times \\
10 \text { weeks }\end{array}$ & [68] \\
\hline $\begin{array}{l}\text { Ingestion } \\
\text { (via GI tract) }\end{array}$ & $\begin{array}{l}\text { Daphnia magna, } \\
\text { Cyprius carpo } \\
\text { (fish species) }\end{array}$ & $\begin{array}{l}\text { Gold }(\mathrm{Au}) \\
\text { Cerium Dioxide } \\
\left(\mathrm{CeO}_{2}\right)\end{array}$ & $\begin{array}{l}35 \mathrm{~nm} \\
25 \mathrm{~nm}\end{array}$ & $0-10 \mu \mathrm{g} / \mathrm{mL}$ & $\begin{array}{r}{[24,} \\
69]\end{array}$ \\
\hline
\end{tabular}

Table 3. Examples of in vivo exposure models used in NP toxicity testing. 


\section{INDUSTRIAL HARD METAL (WC-Co) APPLICATIONS \& EXPOSURE}

Among the plethora of NPs gaining industrial use and popularity is tungsten carbide cobalt (WC-Co), which is a hard composite metal known for its extreme hardness, stability and sharpness $[70,71]$. The use of WC-Co NPs as a spray coating on heavy machinery, drill bits and saw blades substantially increases strength, durability and resistance to wear, which drastically improves the operating lifetimes in industrial applications [70, 71]. In particular, WC-Co coatings are popular in the mining and drilling industries, where maintenance of sharp saw blades and drills is of critical importance.

Despite the improved durability and strength of WC-Co NP coatings compared to other conventional materials, these coatings do not last forever and eventually wear over extended use and time. As a result, airborne WC-Co dusts containing particles of varying size can be generated during use [72]. These airborne WC-Co "dusts" present an occupational exposure hazard not only in hard metal manufacturing facilities, but also in mining and drilling industries where these WC-Co coated implements are used extensively in enclosed environments [73-78]. Typical WC-Co dusts encountered in industrial environments have a reported size range of several microns down to highly respirable particles in the nano-size range $[78,79]$.

While exposure to WC-Co containing dusts has been identified as an occupational workplace hazard by the National Institutes of Occupational Safety and Health (NIOSH) [80], exposure limits for WC-Co dusts and powders remain undefined. Existing exposure limits for cobalt metal and ionic cobalt [81-83] are difficult to translate to WC-Co exposure, as cobalt content can vary, depending on the application, and generated dusts may not have uniform composition between multiple industrial sites [77]. More importantly, the combination of WCCo is more toxic than $\mathrm{Co}, \mathrm{W}$ or $\mathrm{WC}$ particles alone (see page 11). Therefore, understanding the 
toxic effects of hard metal WC-Co particles is crucial so that occupational exposure guidelines can be developed.

\section{RISK OF WC-Co EXPOSURE: HARD METAL LUNG DISEASE (HMLD) PROGNOSIS \& CANCER RISK}

Exposure to "hard metal dust" containing WC-Co is well associated with the occurrence of occupational asthma and is a known prerequisite for the development of hard metal lung disease (HMLD) [70, 72, 81, 84-109]. Diagnosis of HMLD is a challenge, as symptoms are general and often mistaken for other respiratory ailments: patients often report difficulty breathing and present with reduced lung capacity, progressive lung inflammation and eventual fibrosis $[101,102,105,110,111]$. HMLD has been reported in hard metal manufacturing, oil and mining/drilling industries, where workers were exposed to WC-Co dusts or fumes on a daily basis for a number of years prior to diagnosis [72, 84, 101, 105, 112-118]. Currently, treatments are limited and no disease-specific therapy or diagnostic tool exists. There has been some success in treating HMLD with corticosteroids or immuno-suppressive therapies [119-122], but in most cases, avoidance of further hard metal exposure is the recommended course of action.

It has recently been established that the defining characteristic of HMLD is the presence of "bizarre, cannibalistic, multinucleated giant cells" in lung biopsy specimens of workers exposed to WC-Co [102, 111, 114, 117, 123-127]. These giant cell complexes are thought to originate from macrophages which have engulfed WC-Co particles, which then stimulate inflammatory and fibrotic processes in the surrounding lung tissue [99, 102, 114, 124, 125]. In

some cases, WC-Co particle "deposits" have been found in biopsy specimens, confirming causative exposure to WC-Co dust and HMLD diagnosis [113, 114, 124, 126]. It has been 
hypothesized that there may be an allergic reaction or a genetic predisposition which may contribute to the development of HMLD in certain individuals $[89,128,129]$.

There is also accumulating evidence that patients with HMLD are at a two-fold increased risk of developing lung cancer $[95,97,100,101]$. It has been argued that the generation of reactive oxygen species by WC-Co particles, which may directly cause DNA damage, along with the ability of cobalt ions to inhibit DNA repair mechanisms, may play a synergistic role in the development of lung cancer in HMLD patients [100]. However, this hypothesis has yet to be verified in vivo and the relationship between the inflammatory disease state and development of lung cancer remains unclear.

\section{DEFINING HARD METAL (WC-Co) TOXICITY: In Vitro and In Vivo STUDIES}

Early data concerning the effects of inhaled WC-Co dusts first emerged in the 1960s and continued through the 1980s, providing researchers the foundation to further explore the toxic effects of hard metal exposure using in vitro [128, 130-153] and in vivo [130, 154-161] models. Although cobalt itself was originally considered the causative agent of HMLD, several studies demonstrated that this is not the case and the disease is mainly developed due to the simultaneous presence of WC with Co $[128,132,134-136,138,140,141,145,146,155,156$, $162,163]$. It is currently understood that the combination of WC-Co is more toxic than Co, W or WC particles alone, both in vitro and in vivo $[128,130,132,134,138-149,152,153,155-160]$, but the reason for this enhanced toxicity is still not well defined.

On the in vitro side, the effects of direct WC-Co particle exposure were examined by a number of research groups in terms of cell viability, apoptogenic potential, genotoxicity, 
oxidative stress and DNA damage in multiple cell lines of various origins. The major outcomes of these early in vitro studies are summarized in Table 4, where the cell type, particle size and dosage parameter is noted for each study. In alveolar macrophages, $2 \mu \mathrm{m}$ WC-Co particles caused significant toxicity after $24 \mathrm{hr}$ of exposure at concentrations ranging from 50 to 1667 $\mu \mathrm{g} / \mathrm{mL}$, but were less toxic toward type II pneumocytes under these conditions [130, 152], confirming pulmonary WC-Co toxicity in a relevant in vitro model. Toxicity has also been reported in mouse peritoneal macrophages, where WC-Co particles ranging from 2-4 $\mu \mathrm{m}$ caused toxicity after as little as $6 \mathrm{hr}$ of exposure at concentrations ranging 50 to $300 \mu \mathrm{g} / \mathrm{mL}$ [140-146]. In human peripheral blood mononuclear cells, exposure to micron-sized WC-Co particles caused apoptosis, DNA damage, genotoxicity and alterations in gene expression after exposure times as short as $15 \mathrm{~min}$ and up to $6 \mathrm{hr}[147-149,157]$. Additionally, a number of these studies compared the toxicity of WC-Co, WC or Co particles and determined that the interaction of WC with Co significantly enhances the toxicity of the composite compared to either component alone [128, $132,134,140,141,146,148]$.

There are fewer studies which have examined the effects of nano-WC-Co particles; however, nano-WC-Co toxicity has been reported in human keratinocytes, liver carcinoma cells, oligodendroglial precursor cells and neurons, at concentrations ranging from 3 to $30 \mu \mathrm{g} / \mathrm{mL}$ and exposure times from $1 \mathrm{hr}$ up to 3 days [132, 133, 138]. Internalization of nano-WC-Co has been reported in the keratinocytes (epidermal cells) after 2 days of exposure, which suggested that nano-WC-Co could potentially be absorbed through the skin $[132,133]$. Nano-WC-Co toxicity has also been reported in rainbow trout gill cells, murine epidermal cells and fibroblasts at concentrations $<100 \mu \mathrm{g} / \mathrm{mL}$ for $3 \mathrm{hr}$ and up to 3 days [137, 150,151]. Nano-WC-Co has also 
been shown to exert genotoxic effects by affecting the expression of genes involved in cellular apoptosis and stress responses [133, 134].

While the effects of WC-Co particles have been established in multiple cell lines of varying origin, these studies used mono-culture systems in their examination of WC-Co particle toxicity, which may not provide an accurate assessment of what happens during/after WC-Co exposure since the local environment of the lung is highly dynamic and contains more than a single cell type. Additionally, amongst these studies, there was little information regarding the effects of WC-Co exposure in lung epithelial cells (non-carcinoma), which line the airway and are highly likely to directly encounter WC-Co particles or dust during an occupational exposure. Despite these limitations, this body of research clearly demonstrates that WC-Co particles are highly toxic and are capable of inducing oxidative stress and genotoxicity following exposure, highlighting the need for further investigation into the relationship between acute WC-Co toxicity and development of HMLD.

\section{Table 4: Summary of In Vitro Studies Regarding WC-Co Particle Toxicity}

\begin{tabular}{|c|c|c|c|}
\hline Cell Type & $\begin{array}{c}\text { Particle Size } \\
\text { \& Dosage }\end{array}$ & Major Outcome(s) & [Ref] \\
\hline $\begin{array}{l}\text { Primary rat type II } \\
\text { pneumocytes }\end{array}$ & $\begin{array}{l}2 \mu \mathrm{m} \\
50 \mu \mathrm{g} / \mathrm{mL} \mathrm{WC}- \\
\text { Co }\end{array}$ & $\begin{array}{l}\text { No changes in the levels of TNFa, IL-1, fibronectin or } \\
\text { cystatin-C (compared to control) were observed after } \\
\text { WC-Co exposure for } 12 \text { or } 24 \mathrm{hr} \text { in isolated rat type II } \\
\text { pneumocytes. }\end{array}$ & [130] \\
\hline $\begin{array}{l}\text { Human colon } \\
\text { adenocarcinoma } \\
\text { (CaCo-2), human } \\
\text { keratinocytes } \\
\text { (HaCaT), human lung } \\
\text { carcinoma (A549), } \\
\text { OLN-93 oligodendro- } \\
\text { glial precursor cells, } \\
\text { rat neurons, astrocytes }\end{array}$ & $\begin{array}{l}145 \mathrm{~nm} \\
3.3,6.6,8.25 \\
11,16.5 \text { or } 33 \\
\mu \mathrm{g} / \mathrm{mL} \text { WC-Co }\end{array}$ & $\begin{array}{l}\text { WC-Co particles exhibited significant toxicity at a } \\
\text { concentration of } 33 \mu \mathrm{g} / \mathrm{mL} \text { after } 3 \text { days exposure to } \\
\text { CaCo- } 2, \mathrm{HaCaT} \text { and A549 cells. Significant toxicity } \\
\text { was also observed in astrocytes after exposure to } \\
3.3 \mu \mathrm{g} / \mathrm{mL} \text { and higher WC-Co concentration after } 1 \\
\text { and } 3 \text { days. Primary rat neurons were not sensitive } \\
\text { to WC-Co toxicity. Additionally, WC-Co particles } \\
\text { were internalized into the cytoplasm of HaCaT, A549 } \\
\text { and OLN-93 cells after } 2 \text { days. }\end{array}$ & [132] \\
\hline
\end{tabular}


Table 4. Summary of in vitro WC-Co toxicity studies.

\section{Table 4: Summary of In Vitro Studies Regarding WC-Co Particle Toxicity (continued)}

\begin{tabular}{|c|c|c|c|}
\hline Cell Type & $\begin{array}{l}\text { Particle Size } \\
\text { \& Dosage }\end{array}$ & Major Outcome(s) & [Ref] \\
\hline $\begin{array}{l}\text { Human peripheral } \\
\text { blood mononucleated } \\
\text { cells (PMBC) }\end{array}$ & $\begin{array}{l}1 \mu \mathrm{m} \\
10,50 \text { or } 100 \\
\mu \mathrm{g} / \mathrm{mL} \text { WC-Co } \\
\text { or Co }\end{array}$ & $\begin{array}{l}\text { After } 15 \text { min exposure to WC-Co, PMBC } \\
\text { demonstrated } 1.5 \text {-fold increase in DNA damage, } \\
\text { marked by increased formation of micronuclei due to } \\
\text { oxidative stress, compared to control and Co particle } \\
\text { treatment alone. }\end{array}$ & [134] \\
\hline $\begin{array}{l}\text { Rainbow trout gill cells } \\
\text { (RTgill-W1) }\end{array}$ & $\begin{array}{l}145 \mathrm{~nm} \\
8.25,16.5 \text { or } \\
33 \mu \mathrm{g} / \mathrm{mL} \text { WC- } \\
\text { Co }\end{array}$ & $\begin{array}{l}\text { WC-Co caused significant reduction in cell viability } \\
\text { after } 3 \mathrm{hr} \text { and } 3 \text { day of exposure in RT gill cells. WC- } \\
\text { Co particles were also found to be internalized into } \\
\text { the cytoplasm after } 2 \text { days. }\end{array}$ & [137] \\
\hline $\begin{array}{l}\text { Human keratinocyte } \\
\text { (HaCaT) and hepato- } \\
\text { cellular liver } \\
\text { carcinoma (HepG2) } \\
\text { cells }\end{array}$ & $\begin{array}{l}145 \mathrm{~nm} \\
7.5,15 \text { or } 30 \\
\mu \mathrm{g} / \mathrm{mL}\end{array}$ & $\begin{array}{l}\text { WC-Co internalization in HaCaT was confirmed; } \\
\text { however, WC-Co did not cause significant toxicity at } \\
\text { the concentrations studied after } 1 \mathrm{hr}, 3 \mathrm{hr} \text { or } 3 \text { days. } \\
\text { WC-Co particles did not induce reactive oxygen } \\
\text { species (ROS) or DNA micronuclei under the } \\
\text { conditions tested. }\end{array}$ & [138] \\
\hline $\begin{array}{l}\text { Mouse peritoneal } \\
\text { macrophages }\end{array}$ & $\begin{array}{l}2 \mu \mathrm{m} \\
50,100,200 \\
\text { or } 300 \mu \mathrm{g} / \mathrm{mL} \\
\text { of } \mathrm{WC}-\mathrm{Co}, \mathrm{Co} \\
\text { or WC }\end{array}$ & $\begin{array}{l}\text { After } 18-24 \text { hr of exposure, WC-Co caused } \\
\text { significant toxicity, marked by increased LDH release } \\
\text { and significant induction of oxidative stress } \\
\text { compared to control. Activated oxygen species were } \\
\text { implicated in associated DNA damage (micronuclei) } \\
\text { in macrophages. }\end{array}$ & $\begin{array}{r}{[140-} \\
144]\end{array}$ \\
\hline $\begin{array}{l}\text { Human keratinocytes } \\
(\mathrm{HaCaT})\end{array}$ & $\begin{array}{l}62 \mathrm{~nm} \\
33 \mu \mathrm{g} / \mathrm{mL} \text { WC- } \\
\text { Co }\end{array}$ & $\begin{array}{l}\text { WC-Co exposure caused significant changes in gene } \\
\text { expression, such as HIF } 1 \text {, after } 3 \mathrm{hr} \text { and } 3 \text { days of } \\
\text { exposure. WC-Co responsive genes were involved } \\
\text { in cellular death and stress responses. }\end{array}$ & [133] \\
\hline $\begin{array}{l}\text { Mouse peritoneal } \\
\text { macrophages }\end{array}$ & $\begin{array}{l}2-4 \mu \mathrm{m} \\
0-500 \mu \mathrm{g} / \mathrm{mL} \\
\text { of carbides: } \\
\mathrm{WC}, \mathrm{TaC}, \mathrm{SiC}, \\
\mathrm{NbC}, \mathrm{Fe}, \mathrm{TiC}, \\
\mathrm{Mo}_{2} \mathrm{C} \text {; all plus } \\
6 \% \mathrm{Co}\end{array}$ & $\begin{array}{l}\text { The addition of } 6 \% \text { Co particles to each of the } \\
\text { "carbide" particles significantly enhanced the toxicity } \\
\text { of WC, TiC and NbC in macrophages after } 18 \mathrm{hr} \\
\text { exposure, marked by increased levels of LDH } \\
\text { release compared to control and the various carbide } \\
\text { particles alone. Enhanced toxicity was attributed to } \\
\text { the interaction of Co with the carbides. }\end{array}$ & [146] \\
\hline
\end{tabular}


Table 4: Summary of In Vitro Studies Regarding WC-Co Particle Toxicity (continued)

\begin{tabular}{|c|c|c|c|}
\hline Cell Type & $\begin{array}{l}\text { Particle Size } \\
\text { \& Dosage }\end{array}$ & Major Outcome(s) & [Ref] \\
\hline $\begin{array}{l}\text { Human peripheral } \\
\text { blood mononuclear } \\
\text { cells (PMBC) }\end{array}$ & $\begin{array}{l}<1 \mu \mathrm{m} \\
100 \mu \mathrm{g} / \mathrm{mL} \text { WC- } \\
\text { Co }\end{array}$ & $\begin{array}{l}\text { Exposure to WC-Co particles for } 15 \text { min caused } \\
\text { altered gene expression after } 6 \text { and up to } 24 \mathrm{hr} \\
\text { post-exposure in PMBC, including activation of } \\
\text { HIF-1a, p53 and altered expression of HMOX1 } \\
\text { which is involved in oxidative stress response } \\
\text { mechanisms. }\end{array}$ & [147] \\
\hline $\begin{array}{l}\text { Human peripheral } \\
\text { blood mononuclear } \\
\text { cells (PMBC) }\end{array}$ & $\begin{array}{l}<1 \mu \mathrm{m} \\
33.3,45 \text { or } 100 \\
\mu \mathrm{g} / \mathrm{mL} \mathrm{WC}-\mathrm{Co} \\
\text { or WC }\end{array}$ & $\begin{array}{l}\text { WC-Co particles caused cellular apoptosis, marked } \\
\text { by annexin-V staining, after } 15 \text { min and } 6 \text { hr of } \\
\text { exposure. Apoptosis was induced via the caspase- } \\
9 \text { pathway and DNA fragmentation was significantly } \\
\text { elevated in WC-Co exposed cells compared to WC } \\
\text { alone. }\end{array}$ & [148] \\
\hline $\begin{array}{l}\text { Human peripheral } \\
\text { blood mononuclear } \\
\text { cells (PMBC) and } \\
\text { human monocytes }\end{array}$ & $\begin{array}{l}<1 \mu \mathrm{m} \\
100 \mu \mathrm{g} / \mathrm{mL} \text { WC- } \\
\text { Co or WC }\end{array}$ & $\begin{array}{l}\text { A } 24 \text { hr exposure to WC-Co caused significant up- } \\
\text { regulation of apoptosis and stress response genes } \\
\text { in both PMBC and monocytes, namely BNIP3, } \\
\text { which is involved in mitochondrial mediated cell } \\
\text { death. }\end{array}$ & [149] \\
\hline $\begin{array}{l}\text { Human peripheral } \\
\text { lymphocytes and } \\
\text { mouse fibroblast (3T3) }\end{array}$ & $\begin{array}{l}2 \mu \mathrm{m} \\
100 \mu \mathrm{g} / \mathrm{mL} \text { WC- } \\
\text { Co, WC or Co }\end{array}$ & $\begin{array}{l}\text { In lymphocytes, WC-Co caused significant } \\
\text { induction of DNA strand breaks after } 15 \text { min of } \\
\text { exposure, attributed to oxidative stress damage, } \\
\text { and caused extensive DNA damage in isolated 3T3 } \\
\text { cellular DNA compared to WC or Co particles } \\
\text { alone. }\end{array}$ & {$[150]$} \\
\hline $\begin{array}{l}\text { Mouse epidermal cells } \\
\text { (JB6) }\end{array}$ & $\begin{array}{l}80 \mathrm{~nm}, 4 \mu \mathrm{m} \\
25,37.5,50,75 \\
\text { or } 150 \mu \mathrm{g} / \mathrm{mL} \\
\text { WC-Co }\end{array}$ & $\begin{array}{l}\text { Nano-WC-Co induced greater oxidative stress and } \\
\text { hydroxyl radicals, marked by significantly } \\
\text { decreased cellular GSH levels, in JB6 cells } \\
\text { compared to micro-WC-Co. Nano-WC-Co also } \\
\text { stimulated induction of AP-1 and NF-kappaB and } \\
\text { increased cellular proliferation in JB6 cells } \\
\text { compared to micro-WC-Co under identical } \\
\text { conditions. }\end{array}$ & {$[151]$} \\
\hline $\begin{array}{l}\text { Rat alveolar } \\
\text { macrophages (AM) } \\
\text { and type II } \\
\text { pneumocytes }\end{array}$ & $\begin{array}{l}2 \mu \mathrm{m} \\
83,417 \text { or } 1667 \\
\mu \mathrm{g} / \mathrm{mL} \text { WC-Co } \\
\text { or Co }\end{array}$ & $\begin{array}{l}\text { After } 24 \text { hr exposure to WC-Co, significant toxicity } \\
\text { was observed in AM, but not in type II } \\
\text { pneumocytes, compared to controls. However, type } \\
\text { II cells were more sensitive toward Co toxicity than } \\
\text { AM, in the absence of WC components. }\end{array}$ & {$[152]$} \\
\hline
\end{tabular}


The large majority of previous WC-Co animal studies summarized in Table 5 employed the intra-tracheal installation (IT) exposure model, as the preferred means of delivery for hard metal particles and 'dust' in vivo [130, 154-157, 159, 161]. Inhalation studies regarding pure Co dust have been published [160], but to our knowledge, an in vivo study which employs inhalation as the means of delivery for WC-Co particles has yet to be reported. As noted in Table 5, the previous in vivo studies examined the effects of WC-Co particles in the micron-size range, using the mass-per-body weight dosing scheme (i.e. $\mathrm{mg} / \mathrm{kg}$ or $\mathrm{mg} / \mathrm{g}$ ), although some variation in particle size was noted in most cases (overall, WC-Co size ranging from 0.1 to $6 \mu \mathrm{m}$ ). Specifically, micro-sized WC-Co particle exposure caused significant pulmonary inflammation in rats, marked by increased broncho-alveolar lavage (BAL) fluid parameters such as lactate dehydrogenase (LDH) and albumin content, compared to control animals, as little as $24 \mathrm{hr}$ after delivery of the WC-Co IT bolus $[130,156,157,161]$. Significant pulmonary edema, interstitial lung fibrosis, alveolar congestion and alveolitis were also reported in micro-sized WC-Co exposed animals at 1 and 6 months following a single IT exposure [154, 155, 161]. Given this body of literature, the local effects of micro-sized WC-Co following pulmonary exposure have been well characterized and it is understood that micro-sized WC-Co exerts both acute and chronic effects in vivo.

However, since it is now understood that inhaled particulate matter can exert extrapulmonary effects and alter systemic functions [37, 66, 164-175], these studies provide limited insight as to the potential systemic effects of WC-Co after pulmonary exposure. The overall lack of in vivo toxicity data regarding nano-sized WC-Co is also concerning, since nano-sized WC-Co particles are likely to penetrate deeper into the lungs and cause more tissue damage than microsized WC-Co particles. Further, the pathology of HMLD and presence of the "hallmark" 
multinucleated giant cells have yet to be successfully reproduced in an animal model, so the mechanism underlying WC-Co mediated toxicity and progression to HMLD in exposed workers needs further investigation.

\section{Table 5: Summary of In Vivo Studies Regarding WC-Co Particle Toxicity}

\begin{tabular}{|c|c|c|c|c|}
\hline $\begin{array}{c}\text { Method of } \\
\text { Delivery }\end{array}$ & $\begin{array}{c}\text { Animal Model \& } \\
\text { Particle Size }\end{array}$ & $\begin{array}{l}\text { WC-Co } \\
\text { Dosage }\end{array}$ & Major Outcome(s) & [Ref] \\
\hline $\begin{array}{l}\text { Intra- } \\
\text { tracheal } \\
\text { Instillation } \\
\text { (IT) }\end{array}$ & $\begin{array}{l}\text { Rat } \\
\text { Mixed WC-Co } \\
\text { dusts } \sim 0.1 \text { to } 6 \\
\mu \mathrm{m}\end{array}$ & $\begin{array}{l}\text { Single IT } \\
\text { bolus at high } \\
\text { dose ( } \geq 1 \\
\mathrm{mg} / \mathrm{kg} \text { body } \\
\text { weight) }\end{array}$ & $\begin{array}{l}\text { At } 6 \text { months following single IT WC- } \\
\text { Co exposure, rats presented with } \\
\text { pulmonary edema, alveolar } \\
\text { congestion and lung fibrosis in } \\
\text { regions of deposited WC-Co dusts. }\end{array}$ & [154] \\
\hline IT & $\begin{array}{l}\text { Rat } \\
5 \mu \mathrm{m} \text { WC-Co }\end{array}$ & $\begin{array}{l}\text { Single IT } \\
\text { bolus at } 1 \\
\mathrm{mg} / 100 \mathrm{~g} \\
\text { body weight }\end{array}$ & $\begin{array}{l}\text { WC-Co caused high mortality with } \\
\text { massive pulmonary edema, } \\
\text { increased macrophage counts, } \\
\text { LDH, albumin and total protein } \\
\text { content at } 24 \mathrm{hr} \text { post-exposure. }\end{array}$ & [155] \\
\hline IT & $\begin{array}{l}\text { Rat } \\
5 \mu \mathrm{m} \text { WC-Co }\end{array}$ & $\begin{array}{l}\text { Single and } \\
\text { repeated IT } \\
\text { bolus at } 1,5 \\
\text { or } 10 \mathrm{mg} / \mathrm{kg} \\
\text { body weight }\end{array}$ & $\begin{array}{l}\text { Single IT WC-Co exposure caused } \\
\text { acute alveolitis which persisted for } \\
\text { about } 1 \text { month following the IT } \\
\text { bolus. Repeated weekly exposure } \\
\text { ( } 4 x / 1 \text { month) caused interstitial lung } \\
\text { fibrosis and increased lung } \\
\text { hydroxyproline levels in exposed } \\
\text { rats. }\end{array}$ & {$[156]$} \\
\hline IT & $\begin{array}{l}\text { Rat } \\
2 \mu \mathrm{m} \text { WC-Co }\end{array}$ & $\begin{array}{l}\text { Single IT } \\
\text { bolus at } 16.6 \\
\mathrm{mg} / \mathrm{kg} \text { body } \\
\text { weight }\end{array}$ & $\begin{array}{l}\text { WC-Co exposure caused significant } \\
\text { elevation of LDH, total protein \& } \\
\text { albumin in BAL fluids after } 12 \mathrm{hr} \\
\text { and up to } 72 \mathrm{hr} \text { following exposure. } \\
\text { In rat type II pneumocytes isolated } \\
\text { after IT exposure, increased } \\
\text { induction of micronuclei were } \\
\text { observed, indicating genotoxicity } \\
\text { and DNA damage. }\end{array}$ & [157] \\
\hline
\end{tabular}




\section{Table 5: Summary of In Vivo Studies Regarding WC-Co Particle Toxicity}

\begin{tabular}{|c|c|c|c|c|}
\hline $\begin{array}{l}\text { Method } \\
\text { of } \\
\text { Delivery }\end{array}$ & $\begin{array}{c}\text { Animal Model \& } \\
\text { Particle Size }\end{array}$ & $\begin{array}{l}\text { WC-Co } \\
\text { Dosage }\end{array}$ & Major Outcome(s) & [Ref] \\
\hline IT & $\begin{array}{l}\text { Rat } \\
2 \mu \mathrm{m} \text { WC-Co }\end{array}$ & $\begin{array}{l}\text { Single IT } \\
\text { bolus at } 1 \\
\mathrm{mg} / 100 \mathrm{~g} \\
\text { body weight }\end{array}$ & $\begin{array}{l}24 \mathrm{hr} \text { after single IT WC-Co } \\
\text { exposure, significant increases in } \\
\text { LDH, total protein and albumin were } \\
\text { found in BAL fluids. WC-Co did not } \\
\text { exert any effects on the levels of IL- } \\
1 \text {, TNFa, fibronectin or cystatin-C in } \\
\text { BAL fluids of exposed animals. }\end{array}$ & [130] \\
\hline IT & $\begin{array}{l}\text { Rat } \\
3 \mu \mathrm{m} \text { WC-Co }\end{array}$ & $\begin{array}{l}\text { Single IT } \\
\text { bolus at } 2.5,5 \\
\text { or } 10 \mathrm{mg} / 100 \\
\mathrm{~g} \text { body weight }\end{array}$ & $\begin{array}{l}\text { Pulmonary edema, fibrin formation } \\
\text { and increased number of } \\
\text { inflammatory cells were observed in } \\
\text { WC-Co exposed rat lungs, along } \\
\text { with decreased reactivity to } \\
\text { methacholine, increased levels of } \\
\text { nitric oxide synthase (NOS), LDH, } \\
\text { total protein and albumin in BAL } \\
\text { fluids. }\end{array}$ & [159] \\
\hline IT & $\begin{array}{l}\text { Rat } \\
1 \mu \mathrm{m} \text { WC-Co }\end{array}$ & $\begin{array}{l}\text { Single IT } \\
\text { bolus at } 1 \text { or } 3 \\
\text { mg per rat }\end{array}$ & $\begin{array}{l}\text { A significant increase in LDH was } \\
\text { observed after } 1,4,7 \text { and } 30 \text { days } \\
\text { of WC-Co exposure and fibrosing } \\
\text { alveolitis was developed in rats after } \\
30 \text { days post-IT exposure. }\end{array}$ & [161] \\
\hline
\end{tabular}

Table 5. Summary of in vivo WC-Co toxicity studies. 


\section{SPECIFIC AIMS of DISSERTATION RESEARCH}

The long-term goal of this dissertation research project is to identify the mechanisms by which NPs exert their toxic effects and how these effects may contribute toward the development of respiratory diseases, such as HMLD. Since our focus is hard metal NP exposure in particular, the overall objective of this research project was to identify the mechanism underlying nanoWC-Co toxicity in vitro and to establish an in vivo model to assess the potential systemic effects caused by pulmonary exposure to nano-WC-Co.

Our central hypothesis is that nano-WC-Co particle exposure causes toxicity in vitro via induction of oxidative stress and activation of apoptosis, induces inflammation and exerts systemic effects in vivo which may be contributing factors in the progression of HMLD in patients. This hypothesis was generated upon review of the existing literature regarding hard metal toxicity and emerging data highlighting the potential extra-pulmonary (systemic) effects of inhaled NPs. Our rationale is that this dissertation research will improve our knowledge regarding the mechanism of nano-WC-Co toxicity at the cellular level, which may offer new insights into the progression of HMLD and direct us toward improved disease diagnosis, therapeutic treatments or potential prophylactic strategies in the future.

In pursuit of our long-term goal and to systematically test our central hypothesis, the

proposed research was divided into three attainable specific aims, presented graphically in Figure 2:

Specific Aim 1: Determine the toxicity and identify the internalization mechanism of nanoand micro-sized tungsten carbide cobalt (WC-Co) particles in lung epithelial cells (BEAS-2B). Our working hypothesis for Aim 1 is that nano-WC-Co causes dose-dependent toxicity via 
induction of oxidative stress and stimulation of cellular apoptosis due to particle internalization in vitro.

Specific Aim 2: Determine the inflammatory response to tungsten-carbide cobalt (WC-Co) NPs using a co-culture model composed of lung epithelial cells (BEAS-2B) and macrophages

(THP-1). Our working hypothesis for Aim 2 is that exposure to nano-WC-Co stimulates the release of pro-inflammatory cytokines and induces M2 macrophage polarization in a co-culture model using lung epithelial cells and macrophages.

Specific Aim 3: Design and conduct an in vivo pilot study to determine the systemic effects of pulmonary tungsten carbide-cobalt (WC-Co) exposure in rats. Our working hypothesis for Aim 3 is that, in addition to local toxic effects in the lung tissue, acute nano-WC-Co exposure induces a systemic response marked by increased levels of inflammatory markers in the blood plasma.

Our proposed research is of importance because we will address the weaknesses of previous studies by examining the effects of WC-Co exposure on lung epithelial cells and macrophages using co-culture in vitro and establish an in vivo model for the assessment of systemic effects caused by pulmonary nano-WC-Co exposure. This research will have a positive impact on the realm of hard metal toxicity research, which may facilitate the discovery of molecular markers which could be used for improved diagnostic and treatment strategies which, in turn, could greatly reduce the impact of HMLD on healthcare costs and improve long-term patient outcomes. Additionally, the approach described herein could be further applied to other NPs or ENMs; therefore, this research may contribute toward the development of a standard model and approach for nanotoxicity and safety testing. 


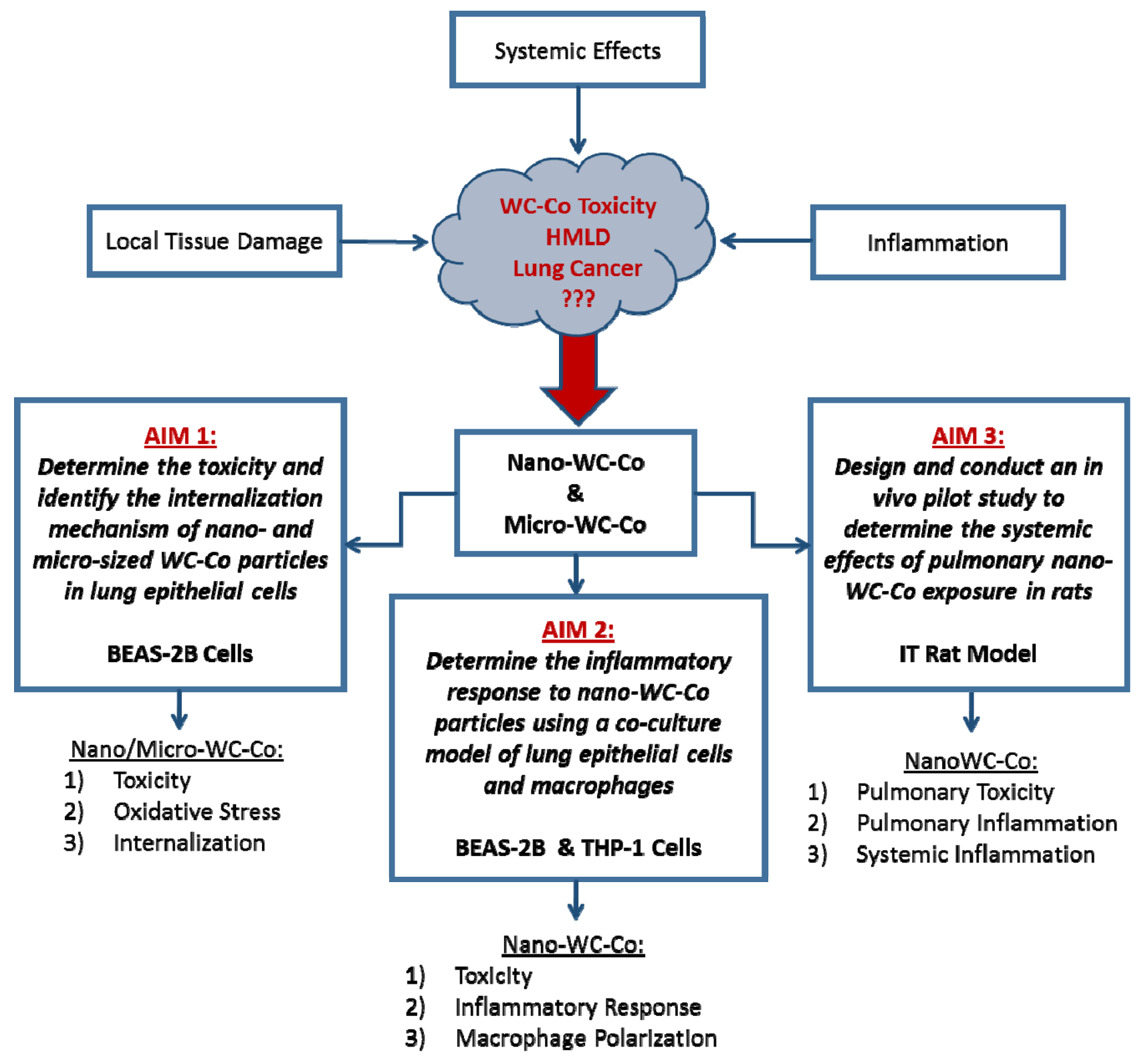

Figure 2. Schematic representation of the proposed WC-Co dissertation research project. 


\section{CHAPTER 2:}

\section{Exploring the Potential Role of Tungsten Carbide Cobalt (WC-Co) Nanoparticle Internalization in Observed Toxicity toward Lung Epithelial Cells in vitro}

First-Author manuscript published in fulfillment of

Specific Aim \#1

Armstead, A.L; Arena, C.B; Li, B. 2014. Exploring the potential role of tungsten carbide cobalt (WC-Co) nanoparticle internalization in observed toxicity toward lung epithelial cells in vitro. Tox App Pharmacol 278, 1-8. http://dx.doi.org/10.1016/j.taap.2014.04.008 


\section{ABSTRACT}

Tungsten carbide cobalt (WC-Co) has been recognized as a workplace inhalation hazard in the manufacturing, mining and drilling industries by the National Institute of Occupational Safety and Health. Exposure to WC-Co is known to cause "hard metal lung disease" but the relationship between exposure, toxicity and development of disease remain poorly understood. To better understand this relationship, the present study examined the role of WC-Co particle size and internalization on toxicity using lung epithelial cells. We demonstrated that nano- and micro-WC-Co particles exerted toxicity in a dose- and time-dependent manner and that nanoWC-Co particles caused significantly greater toxicity at lower concentrations and shorter exposure times compared to micro-WC-Co particles. WC-Co particles in the nano-size range (not micron-sized) were internalized by lung epithelial cells, which suggested that internalization may play a key role in the enhanced toxicity of nano-WC-Co particles over micro-WC-Co particles. Further exploration of the internalization process indicated that there may be multiple mechanisms involved in WC-Co internalization such as actin and microtubule based cytoskeletal rearrangements. These findings support our hypothesis that WC-Co particle internalization contributes to cellular toxicity and suggests that therapeutic treatments inhibiting particle internalization may serve as prophylactic approaches for those at risk of WC-Co particle exposure.

Keywords: nanotoxicity, nanoparticle, hard metal, lung disease, pulmonary exposure, particle internalization 


\section{INTRODUCTION}

The effects of nanomaterial inhalation and pulmonary exposure are intense areas of research, as this is one of the most common routes by which humans are exposed to nanomaterials or nanoparticles in their environments [30, 37]. Although the effects of exposure vary due to the material and composition of the particles, pulmonary effects of nanoparticle exposure are known to include lung toxicity, inflammation, asthma, pleural effusion, pulmonary fibrosis, granuloma formation, etc $[40,176]$. Inhalation of nanoparticles is a concern not only for the casual consumer, but also as an occupational hazard for industry workers whose daily tasks include the manufacture, production or repeated use of nanoparticle-containing goods, tools and equipment.

In particular, occupational exposure to tungsten carbide cobalt (WC-Co), a hard composite metal commonly used as a material or coating for tools and machinery in mining and drilling industries [70] is a concern. Exposure typically occurs via inhalation in the workplace, as WC-Co "dusts" are released into the air upon extensive and repeated use of these tools, such as drills, in a closed environment. Inhalation of WC-Co "dusts", composed of various-sized WC-Co particles, is well-documented to cause occupational asthma, hard metal lung disease (HMLD) and an increased (e.g. two-fold) risk for lung cancer $[70,73,75,77,85,97,100,101,114,124$, 163, 177]. Among pulmonary diseases, HMLD is difficult to diagnose as its symptoms are similar to other respiratory ailments. HMLD usually manifests as progressive inflammation and fibrosis of the lung, with some cases progressing to lung cancer [101, 102, 104, 107, 114, 124]. At present, the relationship between WC-Co exposure, toxicity and development of HMLD remains poorly understood. 
Since the first recognition of adverse health effects from WC-Co exposure in the 1960s [178-182], there have been a number of reports regarding the toxicity of WC-Co in the literature both in vitro $[131-135,137,140,141,143,144,147,149-153,158]$ and in vivo $[130,154-157$, 159-161]. While it is well established that composite WC-Co particles are more toxic than tungsten (W), tungsten carbide (WC) or cobalt (Co) alone, the potential contribution of WC-Co particle internalization toward observed toxicity and the mechanism by which WC-Co particles could be internalized by relevant cells has not been well-addressed. The present study examined the toxic effects and explored potential internalization mechanism(s) of nano- and micro-sized WC-Co particles in lung epithelial cells.

\section{MATERIALS and METHODS}

Materials and Reagents: Micro-sized WC-Co particles (micro-WC-Co; $4 \mu \mathrm{m}$ ) were purchased from Alfa Aesar (Ward Hill, MA) and nano-sized WC-Co particles (nano-WC-Co; $80 \mathrm{~nm}$ ) were purchased from Inframat Advanced Materials (Manchester, CT). BEAS-2B lung epithelial cells were obtained from the laboratory of Yon Rojansakul. Dulbecco's Modified Eagle Media (DMEM), sterile phosphate buffered saline (PBS), $0.25 \%$ trypsin/ethylenediaminetetraacetic acid (EDTA), fetal bovine serum (FBS) and penicillin/streptomycin were purchased from Lonza (Allendale, NJ). The MTT cell viability kit (TOX-1), 2',7'-dichlorofluorescein diacetate (DCF), dihydroethidium (DHE), monodansylcadaverine (MDC), colchicine and cytochalasin-D, glutaraldehyde, paraformaldehyde, agarose and osmium tetroxide were purchased from SigmaAldrich (St. Louis, MO). ApoScreen flow cytometry kit, including annexin-V-FITC (AV-FITC) 
and propidium iodide (PI), was purchased from Southern Biotech Inc. (Birmingham, AL). SPIPON 812 for electron microscopy was purchased from SPI Supplies (West Chester, PA).

Particle Preparation: For cell culture experiments, stock WC-Co particle suspensions (5 $\mathrm{mg} / \mathrm{mL}$ ) were prepared in sterile PBS containing 10\% FBS and sonicated using an Omni International Sonic Ruptor 250 Ultrasonic Homogenizer (Kennesaw, GA). Stock particle suspensions were sonicated under 120 watts power output, at a frequency of $20 \mathrm{kHz}$, in two 30second intervals to ensure particle dispersion. Sonication was performed in $30 \mathrm{~mL}$ plastic vials immobilized in an ice bath to minimize heating of the suspension during the sonication process. Dilute particle suspensions ( 0.1 to $1000 \mu \mathrm{g} / \mathrm{mL}$ ) were prepared in DMEM containing $10 \%$ FBS from the $5 \mathrm{mg} / \mathrm{mL}$ stock particle suspension on the day of each experiment.

Particle Characterization: Micro- and nano-WC-Co particles were characterized after preparation in suspension for cell culture, described above, via dynamic light scattering (DLS, Malvern Zetasizer version 7.01, Malvern Instruments Ltd, Malvern, UK), transmission electron microscopy (TEM; Zeiss Libra 120 electron microscope, Carl Zeiss Microscopy, Jena, Germany), scanning electron microscopy and energy-dispersive x-ray for the determination of elemental composition (SEM/EDX; JEOL JSM 7600F, Jeol USA, Inc, Peabody, MA). Further detail provided in Supplementary Material.

Cell Culture and Exposure to WC-Co Particles: BEAS-2B cells were cultured in DMEM supplemented with $10 \%$ FBS and $1 \%$ penicillin-streptomycin and maintained at $37^{\circ} \mathrm{C}$ and $5 \%$ $\mathrm{CO}_{2}$. Briefly, confluent monolayers were rinsed with $\mathrm{PBS}$, trypsinized, transferred to $5 \mathrm{~mL}$ polystyrene tubes and centrifuged at $1200 \mathrm{rpm}$ for $7 \mathrm{~min}$ to pellet. The cell pellet was resuspended at the desired plating density, transferred to a tissue culture plate and allowed to 
adhere overnight. 96 well plates were seeded at $1.5 \times 10^{5}$ cells $/ \mathrm{mL}$ for viability, oxidative stress and inhibitor assays; 24 well plates were seeded at $2 \times 10^{5}$ cells $/ \mathrm{mL}$ for apoptosis and TEM examination of particle internalization.

Cell Viability Assay: For the viability assay, cells were exposed to either nano- or micro-WCCo particles at concentrations of $0.1,1,10,100$ and $1000 \mu \mathrm{g} / \mathrm{mL}$ for exposure periods of $0.5,1$, 2, 6, 12 and $48 \mathrm{hr}$. Following particle treatment, cells were rinsed once with sterile PBS to remove traces of media and excess particles. The MTT cell viability assay was performed per kit instructions (TOX-1, Sigma-Aldrich) in a 96 well cell culture plate.The absorbance of each well was recorded at $570 \mathrm{~nm}$ using a Bio-Tek $\mu$ Quant microplate reader (Winooski, VT). Blank values were subtracted from absorbance readings. Cell viability was calculated by dividing the absorbance of particle treated cells (Absexptl) by the absorbance of the negative control cells (media treatment only; Abscontrol) and converted to percentage according to the following equation: Cell Viability $(\%)=($ Absexptl $/$ Abscontrol $) \times 100 \%$.

Oxidative Stress Assay: Oxidative stress was examined at select nano- and micro-WC-Co particle concentrations of $0.1,10$ and $1000 \mu \mathrm{g} / \mathrm{mL}$ after exposure periods of $0.5,1,2,6,12$ and $48 \mathrm{hr}$. Following particle treatment, cells were rinsed once with sterile PBS to remove traces of media and excess particles. Oxidative stress was then determined by the addition of $10 \mu \mathrm{M}$ DCF or DHE in PBS following particle treatment. Plates were incubated for $15 \mathrm{~min}$ in the dark and then fluorescence intensity of each well was quantified at $520 \mathrm{~nm}$ for DCF or $620 \mathrm{~nm}$ for DHE. The relative fluorescence of particle-treated cells was calculated as fold over control.

Annexin-V Apoptosis Assay: Cells were treated with WC-Co particles at select concentrations of 10,100 and $1000 \mu \mathrm{g} / \mathrm{mL}$ for $12 \mathrm{hr}$. Positive control (apoptotic) cells were prepared by heat- 
shock for $5 \mathrm{~min}$ at $56^{\circ} \mathrm{C}$ to induce apoptosis. Following particle exposure/heat treatment, cells were rinsed once with PBS, trypsinized, transferred to $5 \mathrm{~mL}$ polystyrene tubes and centrifuged at $1200 \mathrm{rpm}$ for $7 \mathrm{~min}$ to pellet. Cell pellets were re-suspended and rinsed twice with $1 \mathrm{~mL}$ of PBS to remove traces of media that may interfere with staining. After rinsing, cells were re-suspended in ice-cold binding buffer and stained with AV-FITC and PI according to manufacturer instructions. Samples were analyzed immediately by flow cytometry using a BD FACSCalibur flow cytometer (Franklin Lakes, NJ).

Particle Internalization and Inhibition Assay: Three cytoskeletal inhibitors, each affecting a specific pathway, were studied to explore the potential mechanism(s) by which WC-Co particles could be internalized: 1) MDC; an inhibitor of clathrin-coated pit endocytosis [183], 2) colchicine; an inhibitor of microtubule polymerization [184] and 3) cytochalasin-D; an inhibitor of actin filament polymerization [185]. WC-Co particle suspensions were prepared as described above with the addition of $10 \mu \mathrm{g} / \mathrm{mL}$ MDC, colchicine or cytochalasin-D. Cell viability was calculated as described above; in this case, control cells received inhibitor treatment only (media $+10 \mu \mathrm{g} / \mathrm{mL}$ inhibitor) such that any background toxicity of the inhibitor itself was accounted for in the resulting cell viability calculation.

Transmission Electron Microscopy (TEM): Following $12 \mathrm{hr}, 100 \mu \mathrm{g} / \mathrm{mL}$ WC-Co particle exposure, cells were washed once with PBS, detached using trypsin/EDTA and collected by centrifugation at $1200 \mathrm{rpm}$. Cell pellets were washed twice with PBS and fixed with $2 \%$ paraformaldehyde and $2.5 \%$ glutaraldehyde in PBS for $0.5 \mathrm{hr}$ at room temperature. Fixed cell samples were transferred to the West Virginia University Tissue Processing \& Imaging Core Facility for additional processing. Briefly, fixed cell pellets were washed 3 times with PBS, resuspended in warm $2 \%$ low-melting point agarose solution and centrifuged at $2000 \times \mathrm{g}$ for 5 
min. The resulting gelled pellet was post-fixed in a $1 \%$ osmium tetroxide for $2 \mathrm{hr}$ at room temperature. Post-fixation, the cell pellet was washed 3 times with PBS and dehydrated in a graded ethanol series followed by propylene oxide. Next, the cells were embedded in SPI-PON 812 solution and polymerized at $60^{\circ} \mathrm{C}$ for $48 \mathrm{hr}$. Thin sections $(50 \mathrm{~nm})$ were cut and mounted on copper grids and subsequently imaged using a Zeiss Libra 120 electron microscope at $120 \mathrm{kV}$ (Carl Zeiss Microscopy, Jena, Germany). A minimum of 200 cells were examined for the presence of WC-Co particles per mounted sample, with at least 20 sample grids examined per treatment group. The presence of tungsten (W) in cells showing internalized WC-Co particles was confirmed using electron energy loss spectroscopy (EELS; see Supplementary Material).

Statistical Analyses: All experiments were performed in triplicate and data are presented as mean \pm standard deviation. Statistical analysis was carried out by 2-way analysis of variance (ANOVA) using GraphPad Prism software (La Jolla, CA). P values $<0.05$ were considered significant.

\section{RESULTS}

WC-Co Particle Characterization: Dynamic light scattering analysis of WC-Co particles in suspension revealed a narrow nano-WC-Co particle size distribution, with a calculated average particle size of $98 \mathrm{~nm}$ verified by TEM imaging (Figure 1A and C). For the micro-WC-Co particles, size distribution was slightly larger with a calculated average particle size of $3.4 \mu \mathrm{m}$, also confirmed by TEM imaging (Figure 1B and D). EDX analysis of raw WC-Co powder showed that nano-WC-Co contained oxygen in addition to tungsten and cobalt (Table 1 and Figure S1, S2). 
WC-Co Effects on Cell Viability and Oxidative Stress: Lung epithelial BEAS-2B cells were exposed to WC-Co particles at concentrations of $0.1,1,10,100$ and $1000 \mu \mathrm{g} / \mathrm{mL}$ for durations of $0.5,1,2,6,12$ and $48 \mathrm{hr}$. In cells exposed to nano-WC-Co particles (Figure 2A), a significant reduction in viability (compared to control) was observed at concentrations of 10, 100 and 1000 $\mu \mathrm{g} / \mathrm{mL}$ for all the exposure time periods studied. Significant reduction in viability was also observed at concentrations of 0.1 and $1 \mu \mathrm{g} / \mathrm{mL}$ after $48 \mathrm{hr}$ of exposure. In cells exposed to micro-
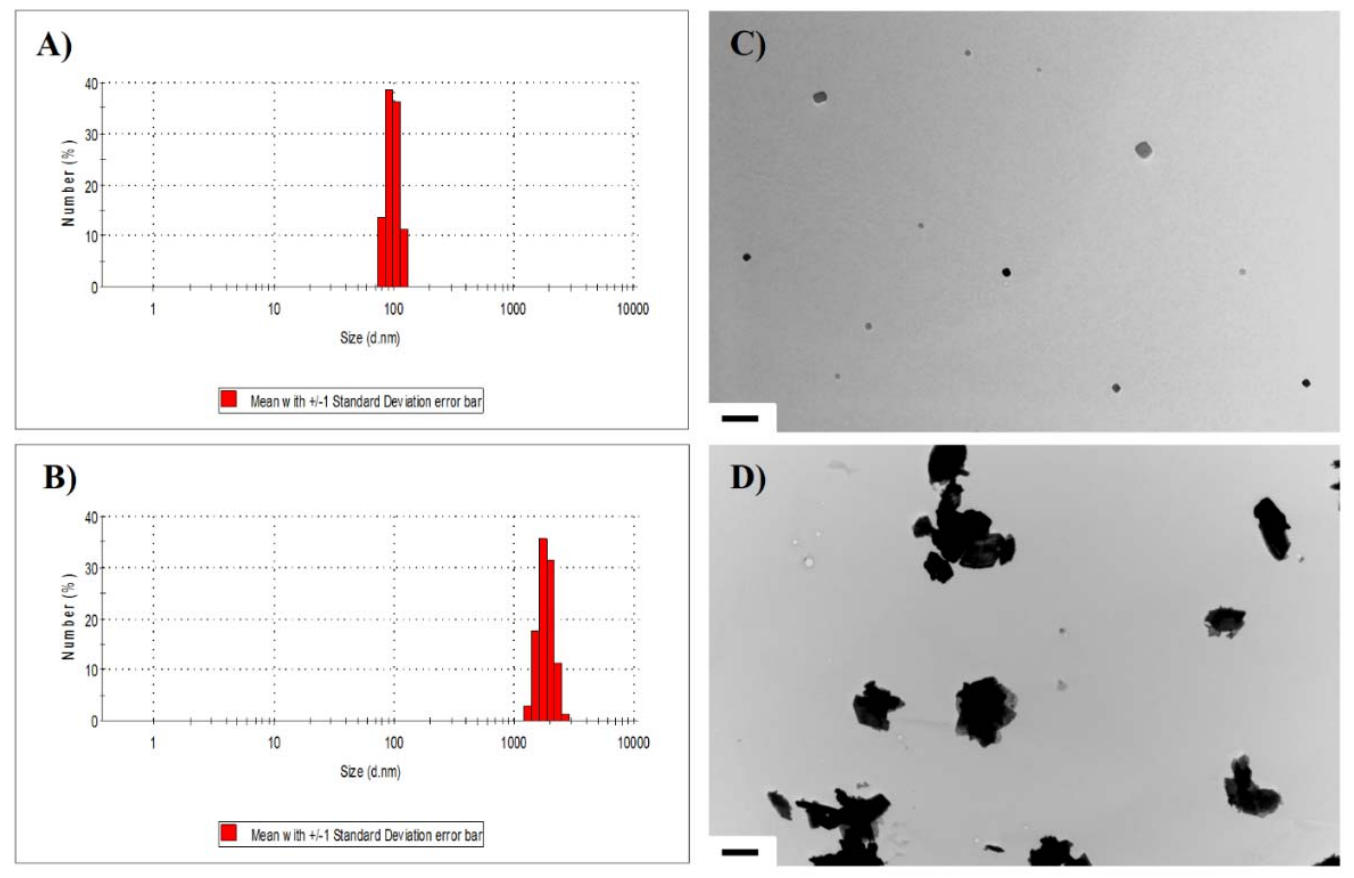

Figure 2.1. WC-Co particle characterization via dynamic light scattering (DLS) of A) nano-WC-Co and B) micro-WC-Co particles suspended in cell culture media (average size $=98 \mathrm{~nm}$ and $3.4 \mu \mathrm{m}$, respectively) and representative TEM images of C) nano-WC-Co (scale bar $=500 \mathrm{~nm}$ ) and D) micro-WCCo $($ scale bar $=2 \mu \mathrm{m})$ particles.

\begin{tabular}{|c|c|c|c|c|}
\hline \multicolumn{5}{|c|}{ Table 1: Elemental Composition of WC-Co Particles by EDX (Weight \%) } \\
\hline Particle Sample & Tungsten (W) & Cobalt (Co) & Carbon (C) & Oxygen (O) \\
\hline $\begin{array}{c}\text { Nano-WC-Co } \\
\text { (avg. size 98 nm) }\end{array}$ & 72.13 & 13.42 & 7.63 & 6.81 \\
\hline $\begin{array}{c}\text { Micro-WC-Co } \\
\text { (avg. size 3.4 } \mu \mathrm{m})\end{array}$ & 86.53 & 5.06 & 8.40 & 0.00 \\
\hline
\end{tabular}

Table 1.1. Elemental composition of nano- and micro-WC-Co particles by weight percentage determined using energy-dispersive X-ray (EDX). 
A)
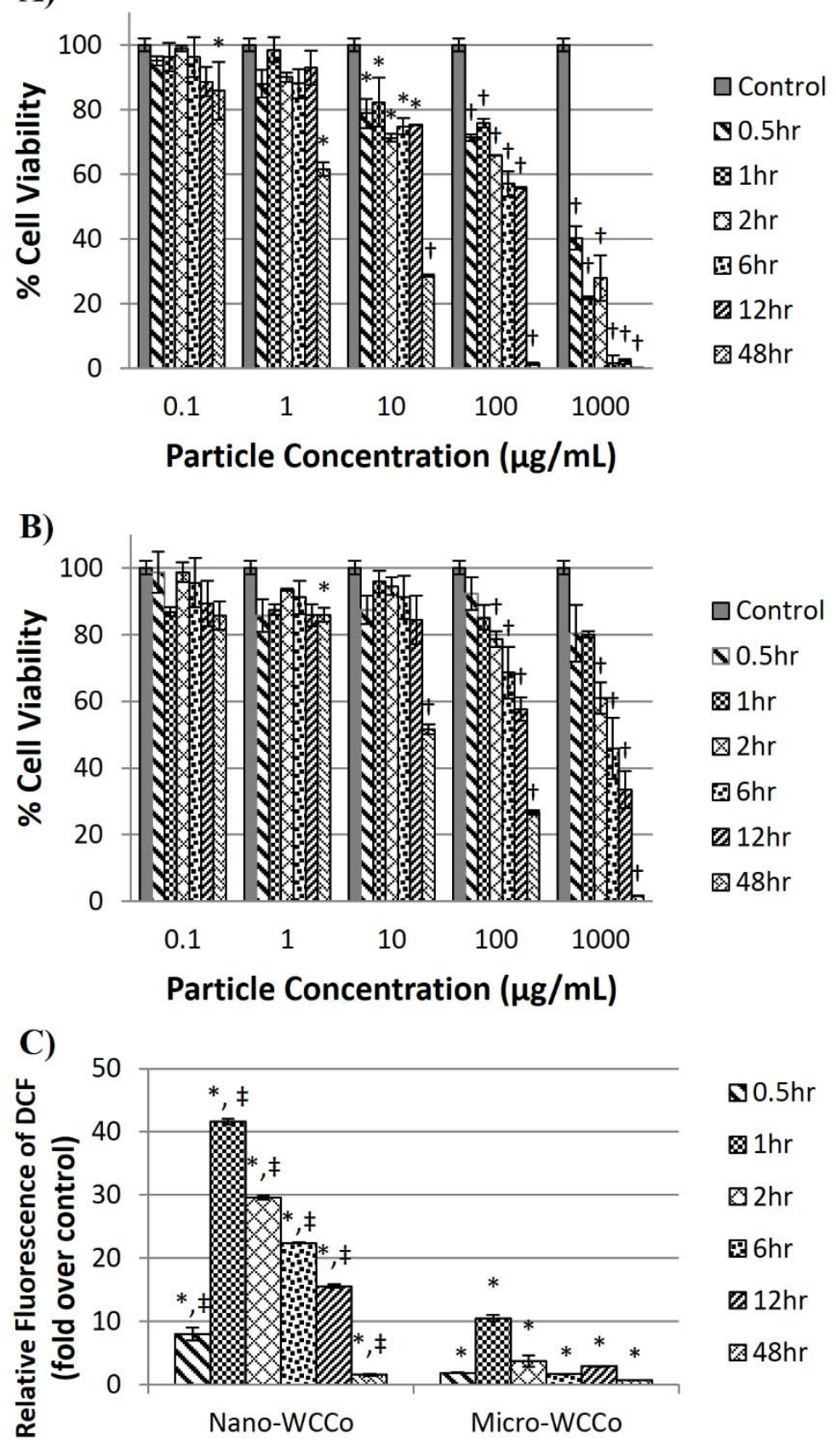

$1000 \mu \mathrm{g} / \mathrm{mL}$ Particles

Figure 2.2. Cell viability after A) nano-WC-Co and B) micro-WC-Co particle exposure and C) oxidative stress indicated by DCF fluorescence after exposure to $1000 \mu \mathrm{g} / \mathrm{mL}$ nano- and micro-WC-Co particles. ( ${ }^{*} \mathrm{P}<0.05,{ }^{\dagger} \mathrm{P}<0.001$ compared to control, ${ }^{\ddagger} \mathrm{P}<0.05$ compared to micro-WC-Co) 
WC-Co (Figure 2B), significant reduction in viability (compared to control) was observed at concentrations of 100 and $1000 \mu \mathrm{g} / \mathrm{mL}$ at 2, 6, 12 and $48 \mathrm{hr}$ of exposure. Significant reduction in viability was also observed at 1 and $10 \mu \mathrm{g} / \mathrm{mL}$ after $48 \mathrm{hr}$ of exposure. Moreover, nano-WC-Co particle exposure resulted in significantly higher reduction in cell viability overall compared to micro-WC-Co particles (Figure S3). For instance, the cell viability following nano-WC-Co exposure was significantly lower than the viability following micro-WC-Co exposure (Figure S3) at $1000 \mu \mathrm{g} / \mathrm{mL}$ for all exposure periods studied except at $48 \mathrm{hr}$, where the cell viability for both particle exposures was very low (Figure S3F). Significantly lower cell viability was also observed in nano-WC-Co compared to micro-WC-Co particle exposure at $0.5 \mathrm{hr}$ from 10 to 1000 $\mu \mathrm{g} / \mathrm{mL}$ (Figure S3A).

Oxidative stress was measured in the form of DCF/DHE fluorescence after exposure to WC-Co particles at $0.1,10,1000 \mu \mathrm{g} / \mathrm{mL}$ at representative low, moderate and highly toxic particle concentrations determined in Figure 2A, B. Compared to control, there was a significant increase in DCF fluorescence in cells exposed to $1000 \mu \mathrm{g} / \mathrm{mL}$ nano- and micro-WC-Co particles over the exposure periods studied $(0.5,1,2,6,12$, and $48 \mathrm{hr})$ and no significant difference when exposed to 0.1 and $10 \mu \mathrm{g} / \mathrm{mL}$ (Figure 2C and S4A). Maximal DCF fluorescence was observed for $1000 \mu \mathrm{g} / \mathrm{mL}$ nano- and micro-WC-Co after $1 \mathrm{hr}$ of exposure, where DCF fluorescence due to nano-WC-Co exposure was significantly higher than micro-WC-Co (Figure 2C). Compared to control, there were no significant differences in DHE fluorescence observed for cells exposed to nano- or micro-WC-Co at any concentration or exposure period tested (Figure S4B).

Induction of Apoptosis in WC-Co Exposed Cells: The total percentage of apoptotic, necrotic or viable BEAS-2B cells determined by flow cytometry after exposure to WC-Co is shown in 
Figure 3. Cells stimulated to undergo apoptosis by heat treatments at $56^{\circ} \mathrm{C}$ were included as a positive control for reference.
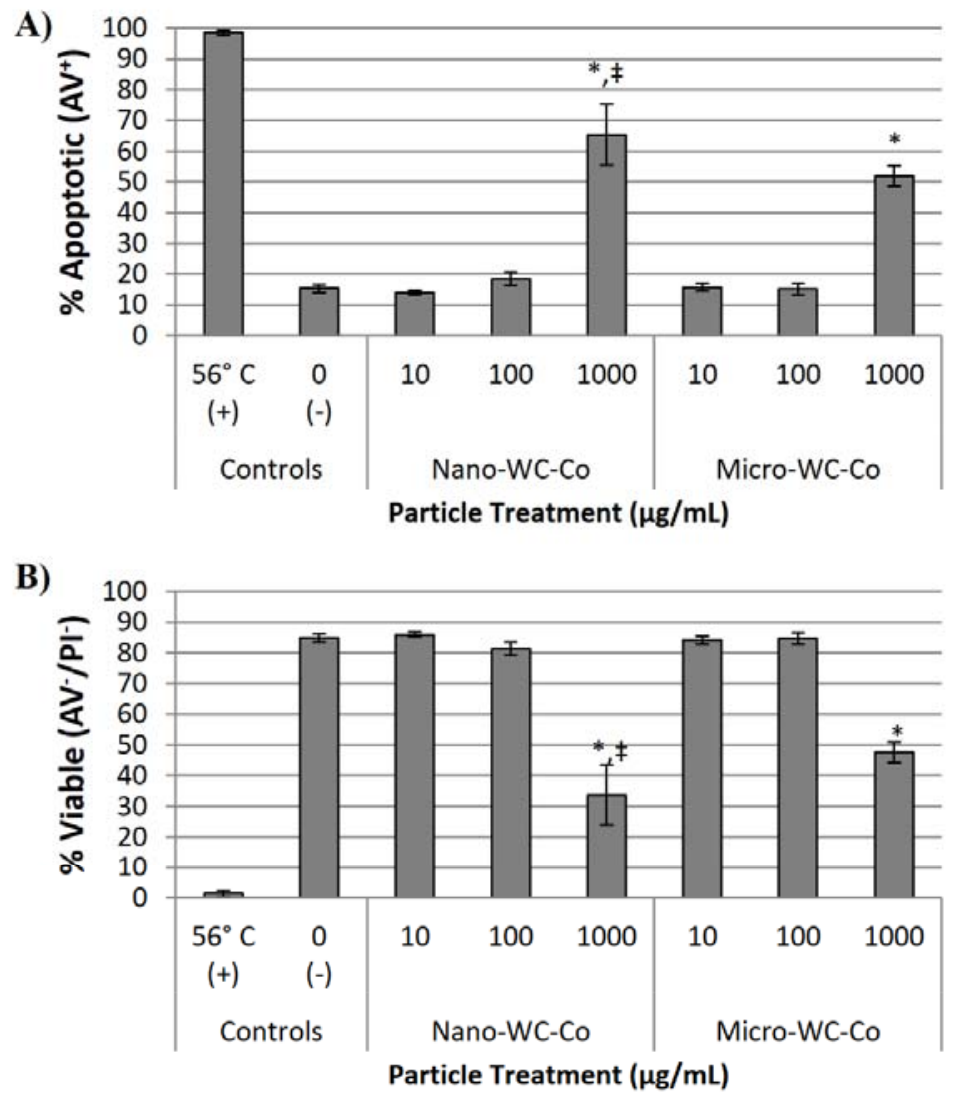

C)

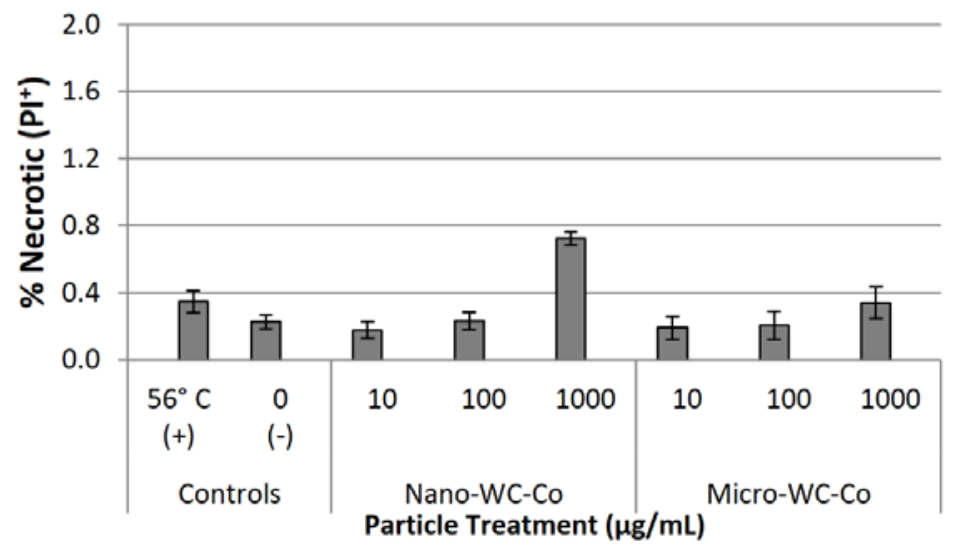

Figure 2.3. Summary of flow cytometry staining profiles after $12 \mathrm{hr}$ WC-Co particle exposure: A) total percentage of apoptotic cells $\left(\mathrm{AV}^{+} / \mathrm{PI}^{+}\right.$and $\mathrm{AV}^{+} / \mathrm{PI}^{-}$; sum total of upper and lower right quadrants), $\mathrm{B}$ ) total percentage of viable cells $\left(\mathrm{AV}^{-} / \mathrm{PI}^{-}\right.$; lower left quadrant) and $\left.\mathrm{C}\right)$ total percentage of necrotic cells ( $\mathrm{PI}^{+} / \mathrm{AV}^{-}$; upper left quadrant) $\left({ }^{*} \mathrm{P}<0.05\right.$ compared to control, ${ }^{\ddagger} \mathrm{P}<0.05$ compared to micro-WC-Co) 
A dose-dependent increase in the total percentage of apoptotic cells was observed with increasing WC-Co particle concentration for nano- and micro-WC-Co particles (Figure 3A). Compared to negative control, a significantly higher percentage of apoptotic cells was observed at $1000 \mu \mathrm{g} / \mathrm{mL}$ for both nano- and micro-WC-Co particles (Figure 3A). A corresponding dosedependent decrease in the percentage of viable cells was also observed and a significantly lower percentage of viable cells, compared to control, was found at $1000 \mu \mathrm{g} / \mathrm{mL}$ for both nano- and micro-WC-Co particles (Figure 3B). The percentage of necrotic cells remained low, less than $1 \%$ for cells exposed to nano- and micro-WC-Co (Figure 3C). A significant difference in the percentage of apoptotic cells was observed at the highest particle concentration of $1000 \mu \mathrm{g} / \mathrm{mL}$, where nano-WC-Co treatment showed significantly higher apoptosis than micro-WC-Co treatment (Figure 3A) and the percentage of viable cells after nano-WC-Co treatment was significantly lower than micro-WC-Co treatment (Figure 3B).

Particle Internalization and Inhibition: After $6 \mathrm{hr}$ of nano-WC-Co exposure, there was a significant increase in cell viability compared to control (cells receiving particle treatment only, no inhibitor) in the presence of MDC, colchicine and cytochalasin D at WC-Co concentrations of 10, 100 and $1000 \mu \mathrm{g} / \mathrm{mL}$ (Figure 4A). After $12 \mathrm{hr}$, significant increases in cell viability were observed in the presence MDC and colchicine at $100 \mu \mathrm{g} / \mathrm{mL}$ nano-WC-Co and in the presence of cytochalasin D at 10, 100 and $1000 \mu \mathrm{g} / \mathrm{mL}$ nano-WC-Co (Figure 4B). After $48 \mathrm{hr}$, significant increases in cell viability were observed for MDC and colchicine at 10 and $100 \mu \mathrm{g} / \mathrm{mL}$ whereas cytochalasin D caused a significant increase in viability for 10,100 and $1000 \mu \mathrm{g} / \mathrm{mL}$ nano-WCCo (Figure 4C). 

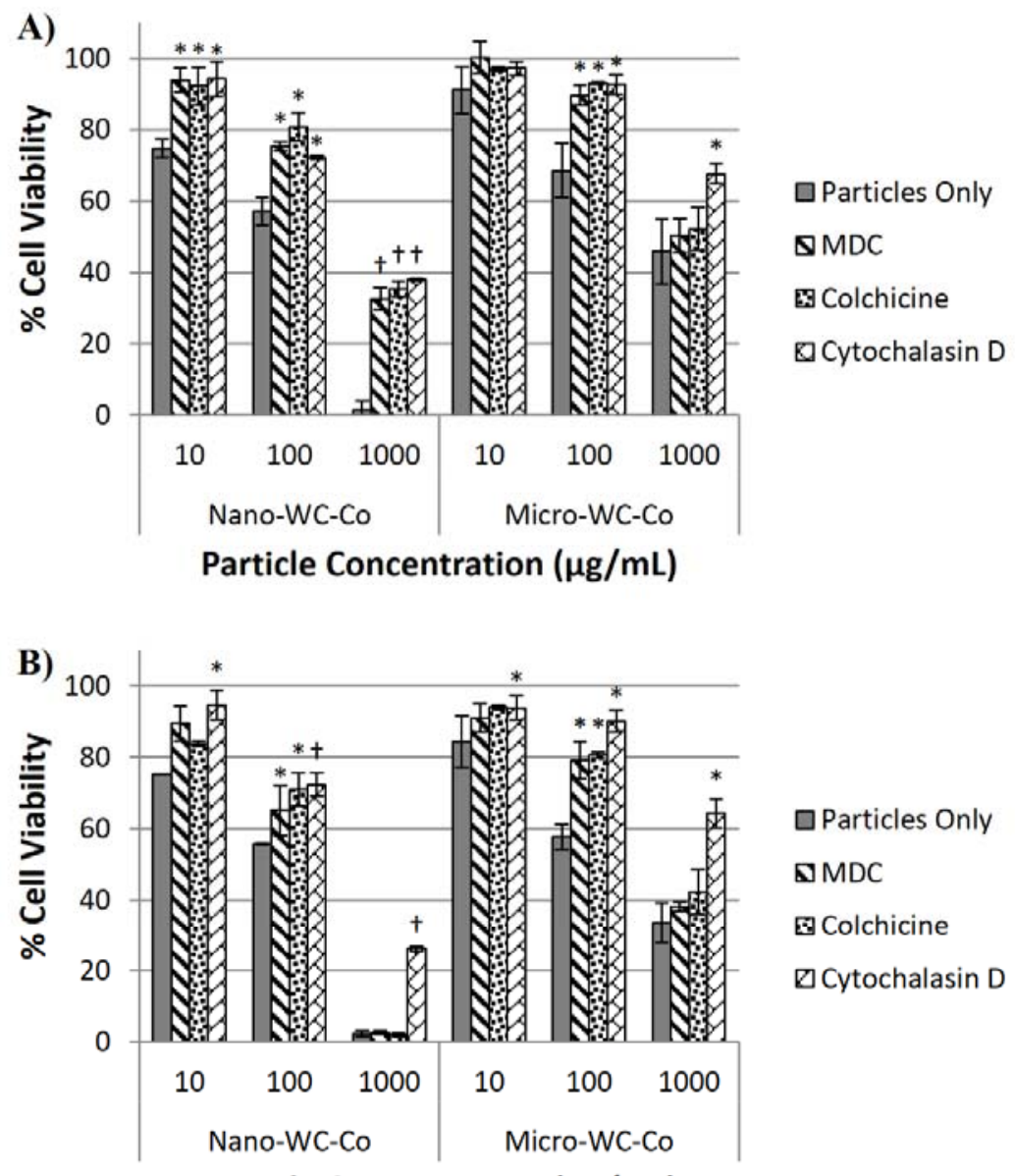

Particle Concentration $(\mu \mathrm{g} / \mathrm{mL})$

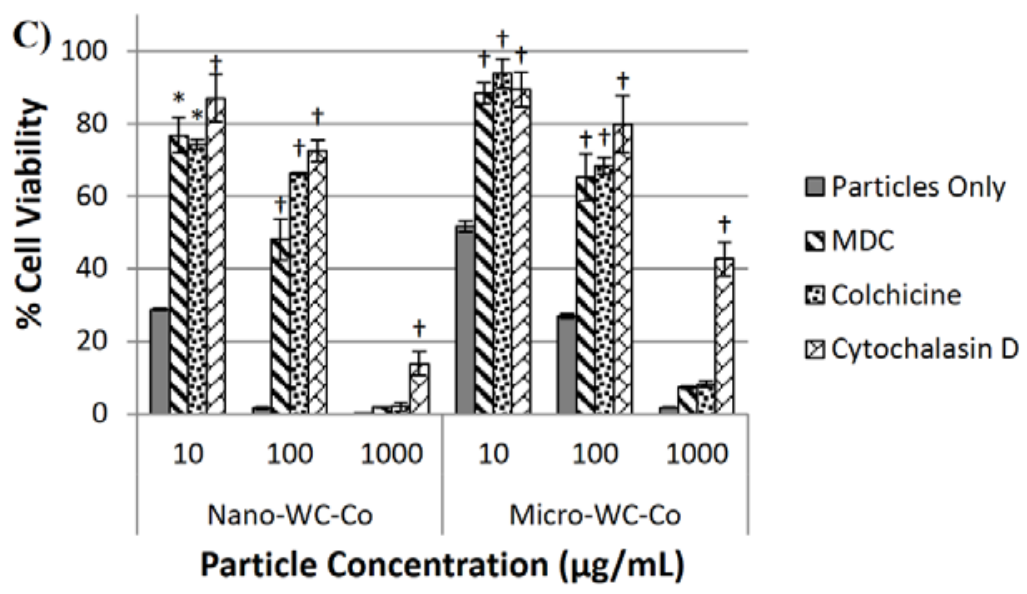

Figure 2.4. Cell viability after exposure to nano- or micro-WC-Co particles in the presence of $10 \mu \mathrm{g} / \mathrm{mL}$ cytoskeletal inhibitors MDC, colchicine or cytochalasin D after A) $6 \mathrm{hr}, \mathrm{B}) 12 \mathrm{hr}$ and C) $48 \mathrm{hr}$. [ ${ }^{*} \mathrm{P}<0.05$, ${ }^{\dagger} \mathrm{P}<0.001$ compared to control (particles only)] 
For cells exposed to micro-WC-Co particles, a significant increase in cell viability was observed after 6 and $12 \mathrm{hr}$ in the presence of MDC and colchicine at $100 \mu \mathrm{g} / \mathrm{mL}$ WC-Co (Figure 4A and B). In the presence of cytochalasin D, significant increases in cell viability were observed after $6 \mathrm{hr}$ for 100 and $1000 \mu \mathrm{g} / \mathrm{mL}$ WC-Co and after $12 \mathrm{hr}$ at 10,100 and $1000 \mu \mathrm{g} / \mathrm{mL}$ micro-WC-Co (Figure 4A and B). After $48 \mathrm{hr}$, significant increases in cell viability were observed for MDC and colchicine at 10 and $100 \mu \mathrm{g} / \mathrm{mL}$ and in the presence of cytochalasin $\mathrm{D}$ at 10, 100 and $1000 \mu \mathrm{g} / \mathrm{mL}$ micro-WC-Co (Figure 4C).

Compared to micro-WC-Co exposure, nano-WC-Co particle exposure led to significantly lower cell viability after $6 \mathrm{hr}$ in the presence of MDC and cytochalasin D at 100 and $1000 \mu \mathrm{g} / \mathrm{mL}$ and in the presence of colchicine at $1000 \mu \mathrm{g} / \mathrm{mL}$ (Figure S6A, S7A, S8A). After $12 \mathrm{hr}$ of exposure, nano-WC-Co particles resulted in significantly lower cell viability than micro-WC-Co particles in the presence of all 3 inhibitors at particle concentration of $1000 \mu \mathrm{g} / \mathrm{mL}$ (Figure S6B, S7B, S8B). After $48 \mathrm{hr}$, the cell viability after nano-WC-Co exposure was significantly lower than that of micro-WC-Co exposure in the presence of MDC at 10 and $100 \mu \mathrm{g} / \mathrm{mL}$, colchicine at $10 \mu \mathrm{g} / \mathrm{mL}$ and cytochalasin D at $1000 \mu \mathrm{g} / \mathrm{mL}$ (Figure S6C, S7C, S8C).

Representative TEM images of BEAS-2B cells exposed to $100 \mu \mathrm{g} / \mathrm{mL}$ WC-Co particles for $12 \mathrm{hr}$ are shown in Figure 5. We found that nano-WC-Co particles had been internalized (visible as distinct black dots, denoted by arrows) and were localized in the cytoplasm within the outer cell membrane (Figure 5B). For cells exposed to micro-WC-Co, no particles of micron size were detected within the cells; however, several particles with diameter of approximately $500 \mathrm{~nm}$ were found localized in the cytoplasm (Figure 5C). In the presence of cytochalasin D, no particles were found within the cytoplasm of nano-WC-Co exposed cells (Figure 5D). The presence of tungsten in representative particle-treated cells (Figure 5) was confirmed using 
EELS, where a definite tungsten peak was identified at $\sim 1850 \mathrm{eV}$ (Figure S9) which confirmed the presence of WC-Co particles within the cytoplasm shown in Figure 5.
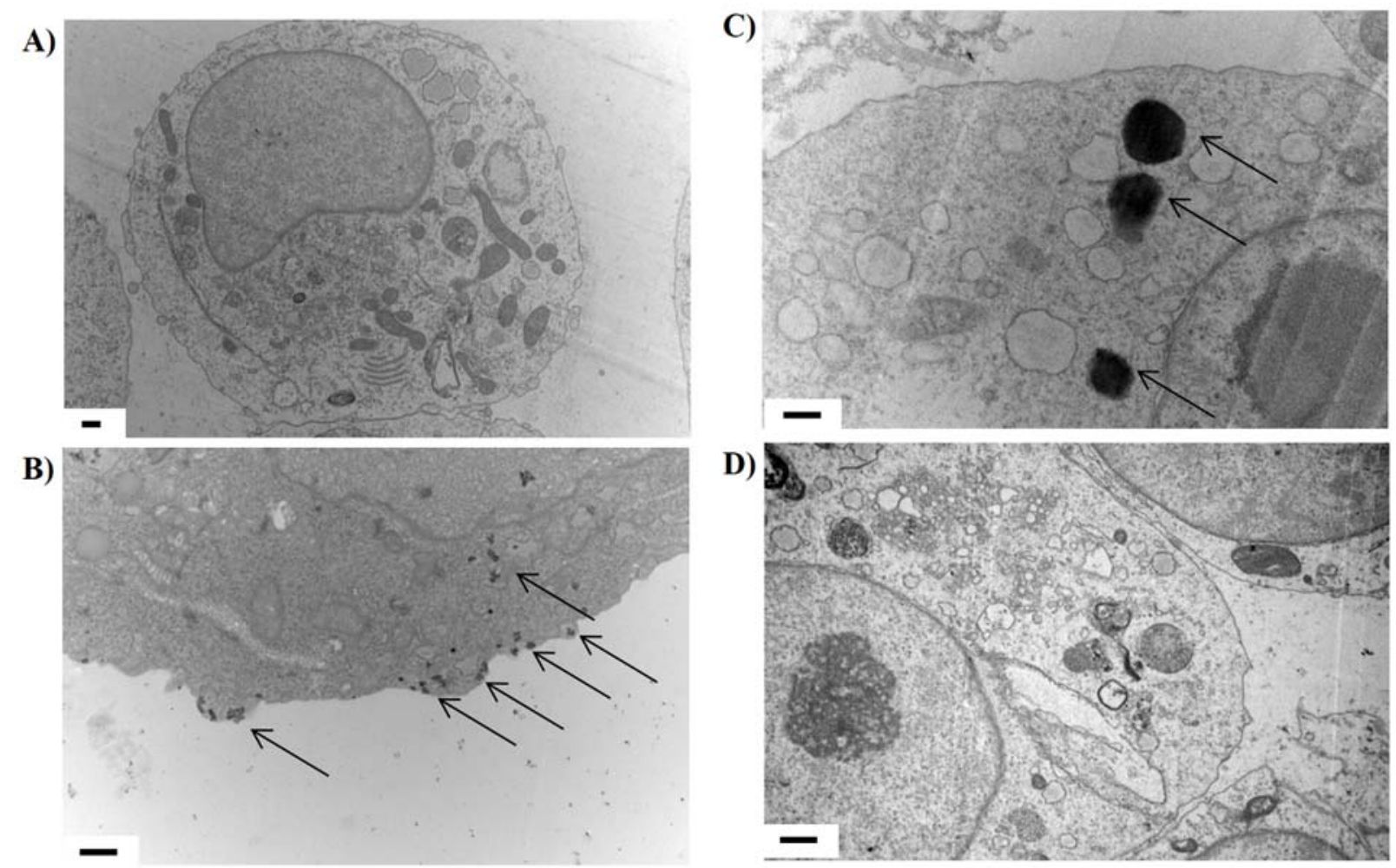

Figure 2.5. Representative TEM images of A) non-exposed control cells, B) cells exposed to $100 \mu \mathrm{g} / \mathrm{mL}$ nano-WC-Co for $12 \mathrm{hr}, \mathrm{C}$ ) cells exposed to $100 \mu \mathrm{g} / \mathrm{mL}$ micro-WC-Co for $12 \mathrm{hr}$ and D) cells exposed to $100 \mu \mathrm{g} / \mathrm{mL}$ nano-WC-Co plus $10 \mu \mathrm{g} / \mathrm{mL}$ cytochalasin D for $12 \mathrm{hr}$. Arrows denote WC-Co particles; scale bars $=0.5 \mu \mathrm{m}$.

\section{DISCUSSION}

While workplace exposure limits are defined for hard metal manufacturing facilities [7779], it is difficult to predict the resulting lung burden of inhaled WC-Co per person [124] and challenging to define a relevant dosing scheme for experimental studies. Since exposure limits are frequently defined on a mass-per-volume basis (i.e. $\mathrm{mg}$ per $\mathrm{m}^{3}$ ), we elected to deliver our 
nano- and micro-WC-Co particles at equivalent mass-per-volume doses and intentionally encompassed a large concentration range, 0.1 to $1000 \mu \mathrm{g} / \mathrm{mL}$, to cover the range in total lung particle mass burden that would be observed in workers exposed through occupational settings. As shown in Figure 2, nano-WC-Co was significantly more toxic than micro-WC-Co at concentrations $\geq 10 \mu \mathrm{g} / \mathrm{mL}$. These data are consistent with our expectations and similar to toxicity reported in the literature (Bastian et al., 2009, De Boeck et al., 2003, Lombaert et al., 2012, Lombaert et al., 2004, Lombaert et al., 2008, Busch et al., 2010, Kuhnel et al., 2009, Kuhnel et al., 2012, Anard et al., 1997). Since reasonable measures were taken to address the potential artifacts (Figures S10-16) due to particle interference with our in vitro assays [53-56, 186], the differences in our observed toxicity were probably to the smaller size, higher resulting particle number and increased surface area of the nano-WC-Co compared to the micro-WC-Co particles. These factors are known to play a critical role in particle toxicity and uptake regardless of material composition [10, 187-191].

The role of apoptosis in hard metal lung disease remains unclear; however, earlier studies have demonstrated the apoptogenic potential of WC-Co particles in vitro [148]. Since there are known roles for the regulation/dysregulation of apoptotic processes in cancer progression [192194] and it is reported that HMLD patients are at a two-fold increased risk of developing lung cancer [97, 100], it seemed appropriate to examine the effects of WC-Co exposure on the induction of apoptosis in our lung epithelial cell model [195]. We confirmed that WC-Co exposure induces apoptosis in exposed cell populations after $12 \mathrm{hr}$ in the present study (Figure 3, S5). We believe in the possibility that WC-Co induced apoptosis may play a role in HMLD progression and contribute to the increased risk of lung cancer; however, the exact mechanism and contribution of these factors remains to be elucidated. 
Interestingly, our apoptosis findings (Figure 3) did not correlate directly with our viability data shown in Figure 2; greater toxicity was determined in the MTT viability assay than was observed by quantification of annexin-V-positive (apoptotic/dead) cells in our flow cytometry assay. We attributed the variance in observed WC-Co toxicity to the differences in assay methodology and approach: while the MTT assay relies on the conversion of the tetrazolinium substrate to formazan by live cells, the annexin-V flow cytometry assay relies on membrane surface staining of exposed phosphatidyl serine (PS) residues, a known marker for apoptotic cells. In this case, we believe that after WC-Co treatment, some of the cells may have reduced metabolic function but are not yet undergoing apoptosis, which would be reflected in the MTT assay as a reduction in viability; however, these same cells would not be quantified as apoptotic (dead) by the AV-FITC apoptosis assay since they may not yet have externalized PS residues available for staining. However, our data confirmed that WC-Co is capable of inducing apoptosis. Additionally, our data regarding the limited capacity of WC-Co particle exposure to stimulate oxidative stress at low concentrations $(<1000 \mu \mathrm{g} / \mathrm{mL}$, Figure S4) appears to be consistent with earlier in vitro studies in other cells [138, 140, 143, 144, 153]. Although oxidative stress has been implicated as the toxic mechanism for other nanomaterials such as silica or titanium dioxide [51, 52], our data suggest that oxidative stress is probably not a primary mechanism of WC-Co toxicity.

Hard metal WC-Co particle internalization is of particular interest because hard metal deposits have been found in lung biopsy specimens from patients with hard metal lung disease $[85,95,101,113,114,196-199]$ which may suggest a potential role for particle internalization and/or deposition in the disease state. Studying how WC-Co particle internalization occurs in vitro may offer a better understanding of how these deposits may form in vivo, which may allow 
for the development of improved HMLD treatment strategies or new prophylactic approaches [200-202] for those at risk of exposure. It has been reported that alveolar epithelial cells are capable of internalizing nanoparticles (Stearns et al., 2001) and we confirmed in this study that WC-Co particles are capable of being internalized [132] in our lung epithelial cell model as shown in Figure 5. Based on our findings from the cytoskeletal inhibitor assay shown in Figure 4, we believe that WC-Co particle internalization plays a role in WC-Co mediated toxicity because a significant increase in cell viability was observed for all three inhibitors tested when compared to cells treated with WC-Co particles only.

The extent of this "rescue" effect varied amongst the inhibitors; however, cytochalasin D appeared to have the most significant effect of the three inhibitors (Figure 4C), so we hypothesized that actin dynamics and polymerization, inhibited by the presence of cytochalasin D $[185,203]$, may play a major role in the internalization of WC-Co particles. Additionally, we did not find any internalized WC-Co particles in cells treated with cytochalasin D shown in Figure 5. A significant increase in cell viability was also observed in the presence of colchicine and MDC, so the potential for multiple mechanisms of internalization cannot be excluded from this study. Colchicine, known to inhibit microtubule polymerization [184, 204], can interrupt the formation of endocytic vesicles which may also play a role in WC-Co internalization as indicated by the increase in cell viability observed in Figure 4. However, colchicine was ineffective at reducing WC-Co toxicity at the highest concentration of particles after $48 \mathrm{hr}$ (Figure 4C), so we believe that microtubule-dependent internalization processes are likely secondary to actinmediated processes affected by cytochalasin D. MDC is an inhibitor of clathrin $[183,204]$ and specifically blocks clathrin-mediated endocytosis. In our study, MDC caused the least significant increase in cell viability following WC-Co exposure so we do not believe that clathrin-pit 
mediated endocytosis is a primary mechanism for WC-Co particle internalization. Taken together, these initial findings suggest a potential role for WC-Co particle internalization in observed toxicity toward lung epithelial cells.

\section{CONCLUSION}

This study examined the toxicity of nano- and micro-sized WC-Co particles and explored the potential role of particle internalization in observed toxicity toward lung epithelial cells. Nano-WC-Co was found to be more toxic than micro-WC-Co as expected and we determined that WC-Co particles are capable of being internalized (via TEM). The presence of cytochalasin $\mathrm{D}$, colchicine and MDC all caused a reduced toxicity, which suggests that there may be multiple mechanisms involved in WC-Co internalization and toxicity. Therefore, internalization of WCCo particles by cells lining the respiratory tract and lung is possible and may be a potential source of hard metal deposits found in HMLD biopsy specimens.

\section{ACKNOWLEDGEMENT}

The authors thank Yon Rojanasakul for providing the BEAS-2B cells and Bing-Hua Jiang for WC-Co particle samples. The authors acknowledge the WVU Biochemistry Shared Facilities, the WVU Flow Cytometry Core facility and Kathy Brundage for instrument use and assistance (National Institutes of Health grant \#P303M103488, P30RR0321R8). Thanks to Dale Porter for assistance with particle characterization and dynamic light scattering. Special thanks to Dr. Ava Dykes for assistance with electron microscopy experiments performed in the West 
Virginia University Tissue Processing and Analysis Core Facility, supported in part by National Institutes of Health grant \#P30RR031155. The authors thank Suzanne Danley for proofreading.

REFERENCES (See Chapter 6) 


\section{SUPPLEMENTARY MATERIAL}

\section{MATERIALS and METHODS}

S1.1 WC-Co Particle Characterization: Micro-WC-Co and nano-WC-Co particles were analyzed using dynamic light scattering (DLS), transmission electron microscopy (TEM) and scanning electron microscopy with energy-dispersive $\mathrm{x}$-ray (SEM/EDX) to determine the average particle/aggregate size in suspension, morphology and elemental composition.

For DLS, stock particle suspensions $(5 \mathrm{mg} / \mathrm{mL})$ were prepared by adding $25 \mathrm{mg}$ dry particle powder to a $20 \mathrm{~mL}$ vial containing $5 \mathrm{~mL}$ sterile PBS with $10 \%$ FBS. The particles were then sonicated using an Omni International Sonic Ruptor (Kennesaw, GA) for two intervals of $30 \mathrm{sec}$ each to ensure particle dispersion. Dilute particle suspension was then prepared in DMEM supplemented with 10\% FBS and analyzed via DLS using a Malvern Zetasizer 7.01 (Malvern Instruments Ltd, Malvern, UK). Background absorbance of DMEM containing 10\% FBS only was used to 'blank' the instrument prior to measurement of the WC-Co particle suspensions.

For TEM, WC-Co particles were re-suspended in distilled water and vortexed for $60 \mathrm{sec}$ to remove traces of salt and protein from the culture media which could interfere with TEM imaging. Five microliters of the resulting suspension was transferred to a carbon-coated copper grid. Excess liquid was wicked away using filter paper after $30 \mathrm{sec}$ and grids were allowed to dry for at least $30 \mathrm{~min}$ before imaging on a Zeiss Libra 120 electron microscope at $120 \mathrm{kV}$ (Carl Zeiss Microscopy, Jena, Germany).

For SEM/EDX, raw particle powder was imaged on a JEOL JSM 7600F setup equipped with an Oxford Instruments energy dispersive x-ray (EDX) system for chemical analysis. EDX 
measurements were carried out in the Point \& ID mode with spectrum acquisition time of $120 \mathrm{~s}$ and spectrum range of $0-10 \mathrm{keV}$.

S1.2 WC-Co Nanoparticle Compatibility with In Vitro Assays: To eliminate potential artifacts due to the presence of WC-Co particles in the absorbance measurement for the MTT cell viability assay, nano- and micro-WC-Co suspensions ranging from 0.1 to $1000 \mu \mathrm{g} / \mathrm{mL}$ in PBS and supplemented DMEM were tested for background absorbance, with and without the addition of the MTT tetrazolinium dye solution, at $570 \mathrm{~nm}$ (primary MTT absorbance wavelength) and $590 \mathrm{~nm}$ (background wavelength). The WC-Co particles did not exhibit any absorbance in the presence of the MTT dye solution after $2 \mathrm{hr}$ of incubation under assay conditions (Figure S10).

Similarly, for the oxidative stress assays using DCF and DHE dye solutions, nano- and micro-WC-Co particles were tested for background fluorescence and interference with the dye solutions. The WC-Co particles did not exhibit any auto-fluorescence at either of the primary fluorescence wavelengths for DCF $(520 \mathrm{~nm})$ or DHE $(620 \mathrm{~nm})$ and did not affect the background fluorescence of the dye solutions themselves (Figure S11). Additionally, we tested whether WCCo particle addition caused increased fluorescence of DCF/DHE in dye-loaded cells. In a separate experiment, cells were loaded with dye solution for 30 minutes, spiked with particle suspensions and resulting fluorescence was read immediately at each wavelength. No changes in DCF/DHE fluorescence were observed in intact cells under these conditions (Figure S12). After initial measurement, cells spiked with WC-Co particles were then lysed by the addition of $0.1 \%$ Triton-X, in order to release the fluorescent DCF/DHE into solution. Resulting fluorescence was read after 15 min at each wavelength to determine if WC-Co caused changes in fluorescence under this condition. No changes in fluorescent DCF/DHE intensity were observed, indicating 
that WC-Co particle are inert toward DCF/DHE and there are no artifacts present as the result of particle-dye interactions (Figure S13).

S1.3 Inhibitor Concentration and Background Toxicity: The selection of inhibitors for this study was based on the existing literature regarding nanoparticle internalization. Inherent toxicity of the inhibitors alone was tested over a concentration range of 2-50 $\mu \mathrm{g} / \mathrm{mL}$ and a $48 \mathrm{hr}$ exposure period for colchicine, cytochalasin-D and monodansylcadaverine (MDC). Each inhibitor exhibited varying effects on cell viability over the course of $48 \mathrm{hr}$ (Figure S14); however, all three inhibitors maintained reasonable cell viability (80\% of control, un-treated cells) at a concentration of $10 \mu \mathrm{g} / \mathrm{mL}$ which was further selected for our studies regarding WC-Co particle internalization. Importantly, for each WC-Co particle internalization experiment, the negative control (non-particle treated) cells were treated with inhibitor only, so that the background toxicity of the inhibitors was considered and did not affect our final viability results.

S1.4 WC-Co Nanoparticle Compatibility with Apoptosis Assay: Prior to examining AV/PI stained cell populations following WC-Co particle exposure, several control tests were performed on the FACs Calibur to confirm that the particles did not bind the stains or otherwise interfere with the determination of cell staining profiles. Experiment parameters were set on the machine using live, unstained cells, positive control (dead, heat-shock) and negative control (live, untreated) AV/PI stained cells (Figure S15). Gating and laser intensity were set and saved for further experiments. Once stain and instrument parameters were finalized, nano- and microWC-Co particles were prepared in assay binding buffer at the maximum concentration tested $(1000 \mu \mathrm{g} / \mathrm{mL})$ and run through the instrument to exclude any potential background or interference of the particles with various assay components (Figure S16). 
S1.5 Electron Energy Loss Spectroscopy (EELS): To confirm the presence of WC-Co nano/micro-particles in cell samples imaged via TEM, EELS measurements were obtained on a Zeiss Libra 120 Transmission Electron Microscope equipped with a Gatan Imaging Filter (GIF) Tridiem spectrometer with an UltraScan 1000 FT detector. Cumulative M5 edge spectra were collected, centered at an energy loss of $1970 \mathrm{eV}$ with a collection time of $10 \mathrm{~s}$. The resulting tungsten (W) peak appears at $\sim 1850 \mathrm{eV}$. The power law background model in Digital Micrograph software (Gatan, Inc., Pleasanton, CA, USA) was used to model the energydependence of the background signal. 


\section{FIGURES}

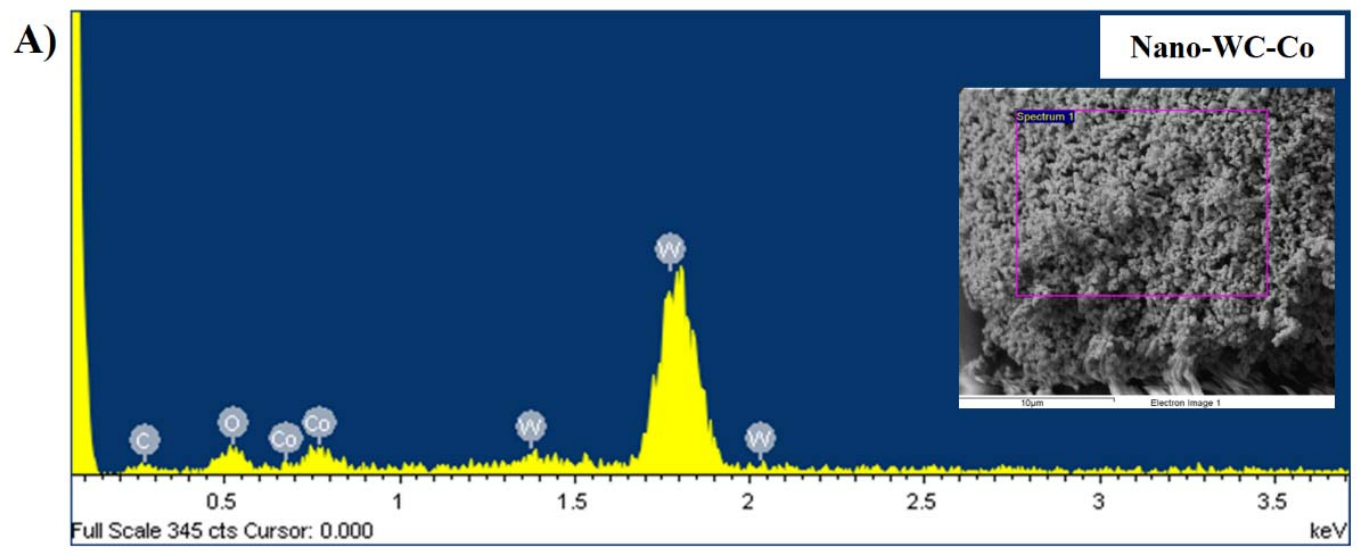

B)

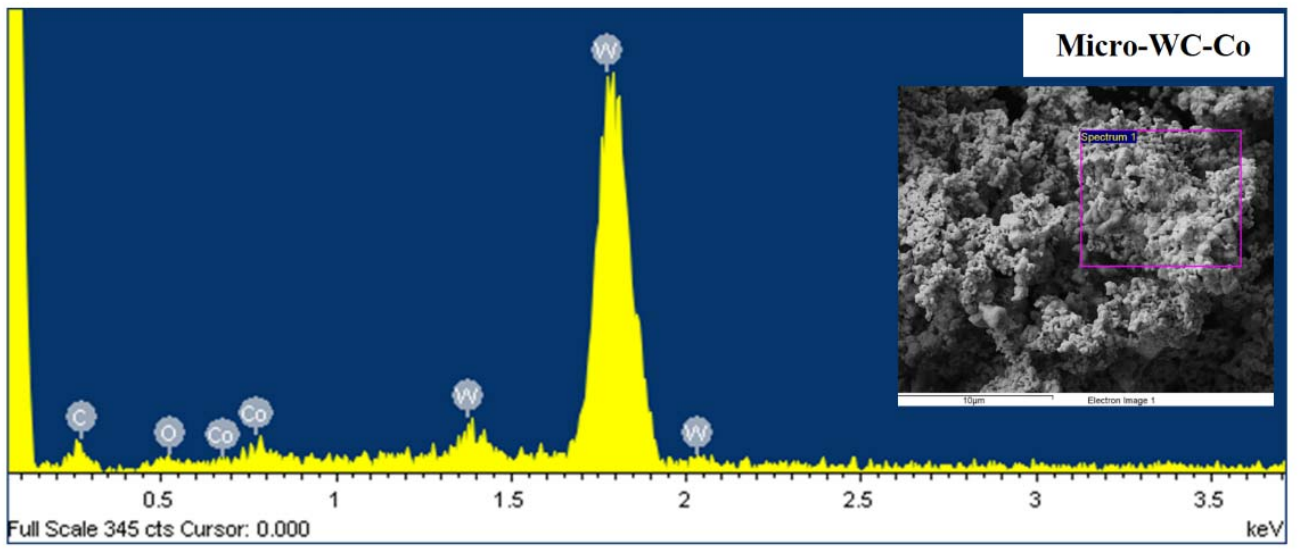

Figure S1. EDX spectra for elemental composition by weight (\%) for A) nano-WC-Co and B) micro-WC-Co; insets depict scanned powder area. 
A)

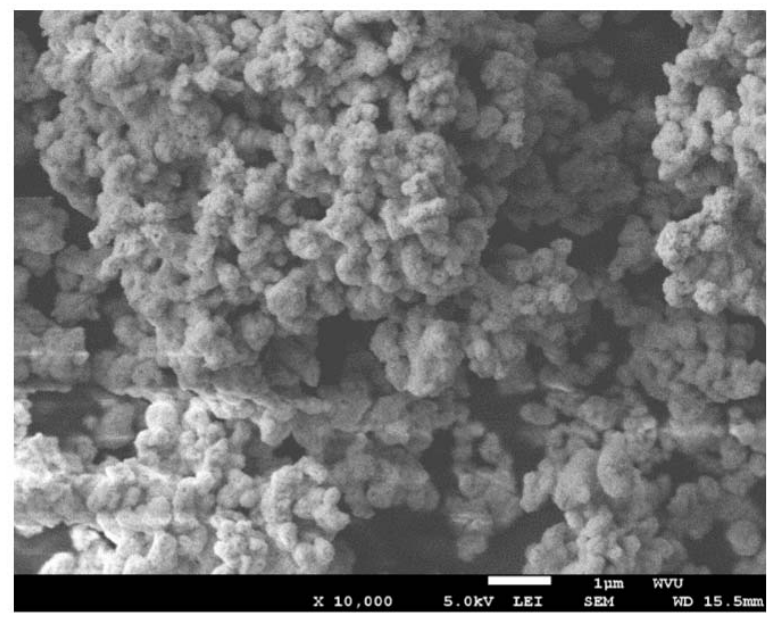

B)

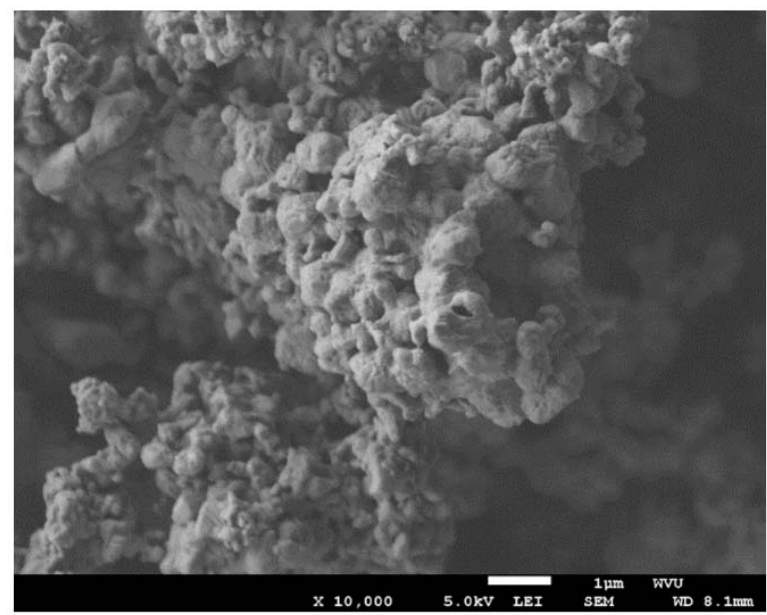

Figure S2. Representative SEM images of raw A) nano-WC-Co and B) micro-WC-Co powders used for EDX compositional analysis; scale bars $=1 \mu \mathrm{m}$. 

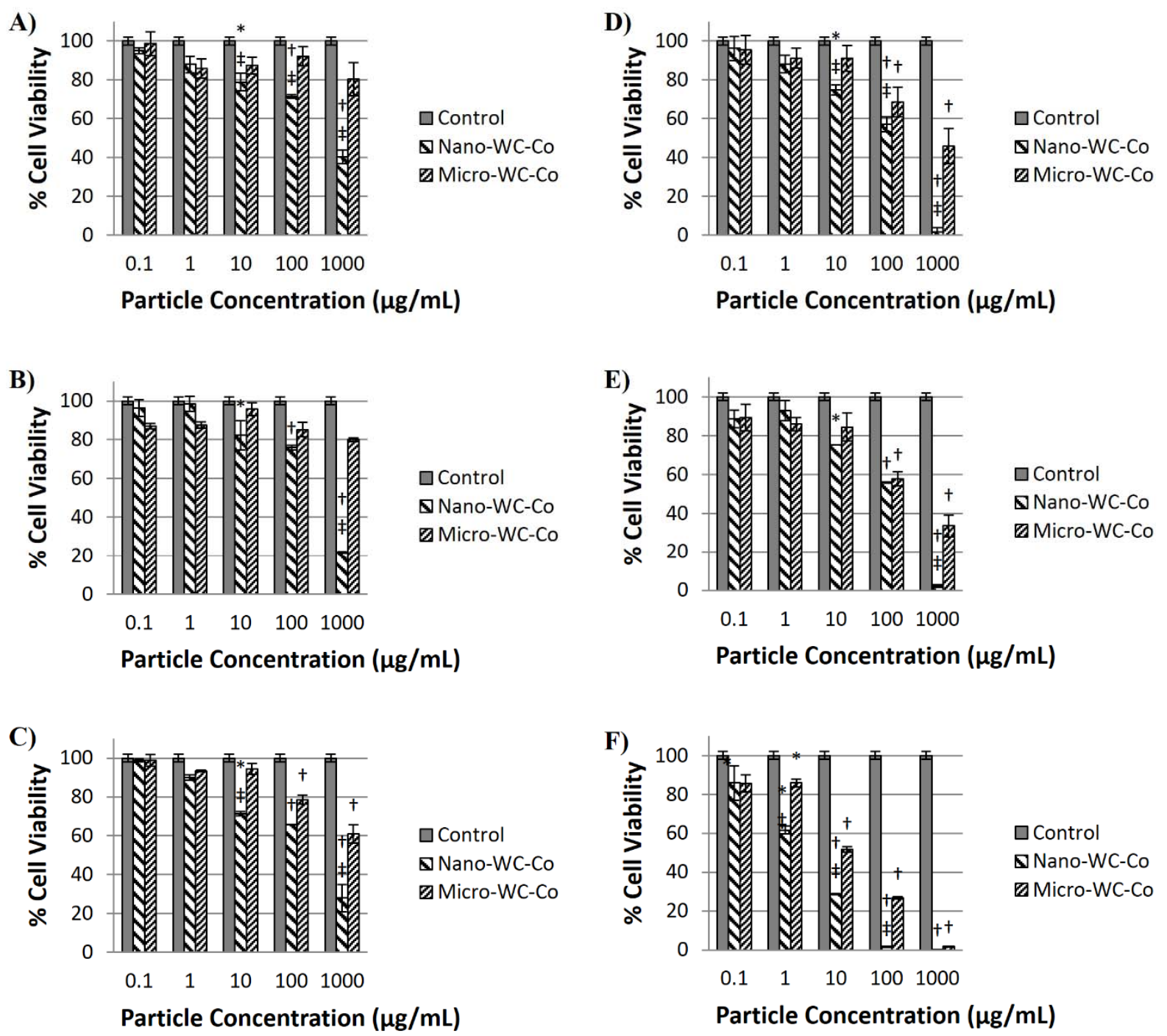

Figure S3. Comparison of cell viability after exposure to nano- and micro-WC-Co for A) $0.5 \mathrm{hr}$, B) $1 \mathrm{hr}, \mathrm{C}) 2 \mathrm{hr}$, D) $6 \mathrm{hr}, \mathrm{E}) 12 \mathrm{hr}$ and F) $48 \mathrm{hr}$. ( ${ }^{*} \mathrm{P}<0.05,{ }^{+} \mathrm{P}<0.001$ compared to control, ${ }^{\ddagger} \mathrm{P}<$ 0.05 compared to micro-WC-Co) 


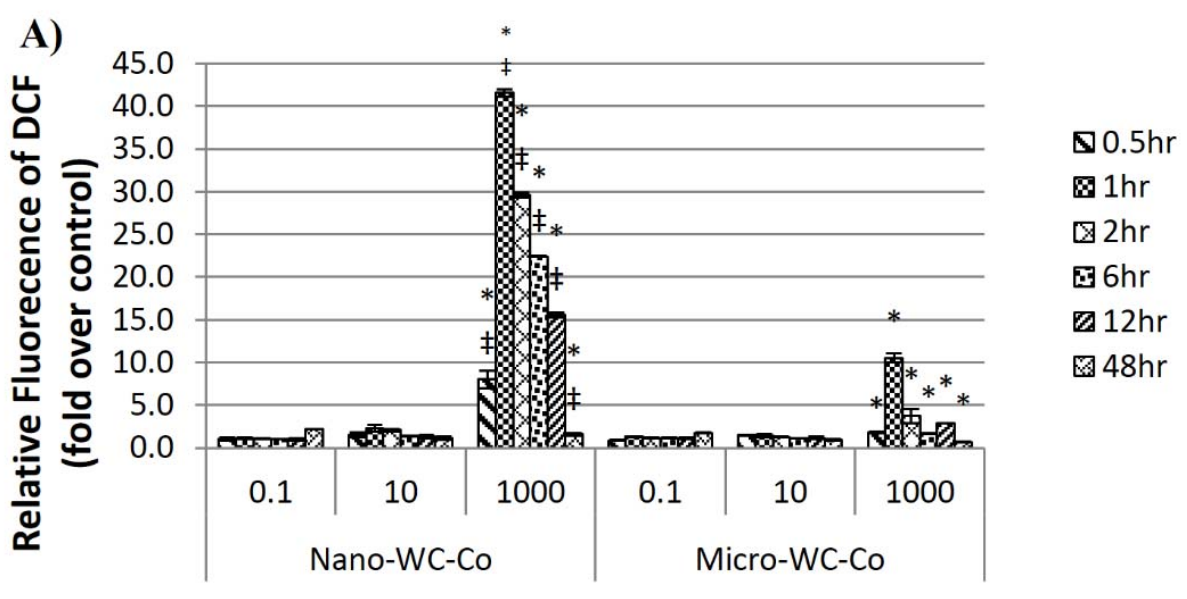

\section{Concentration of Particles $(\mu \mathrm{g} / \mathrm{mL})$}

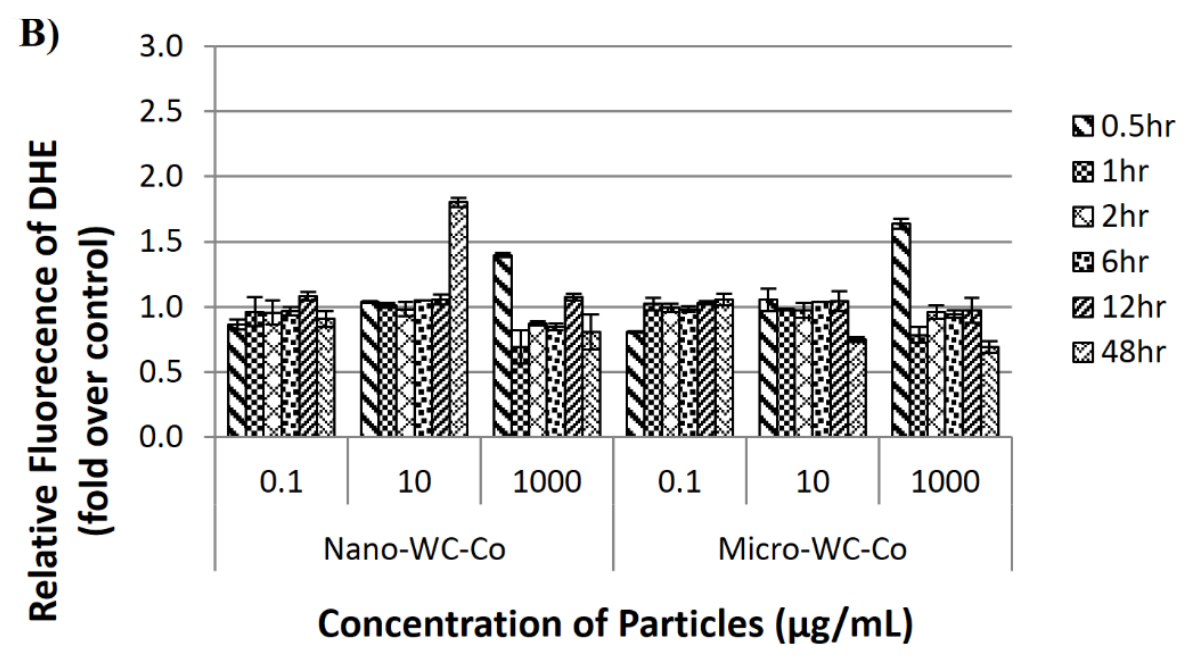

Figure S4. Relative fluorescence of A) DCF and B) DHE as markers of oxidative stress following exposure to nano- and micro-WC-Co particles. ( ${ }^{*} \mathrm{P}<0.05$ compared to control, $¥ \mathrm{P}<$ 0.05 compared to micro-WC-Co at the same exposure time) 

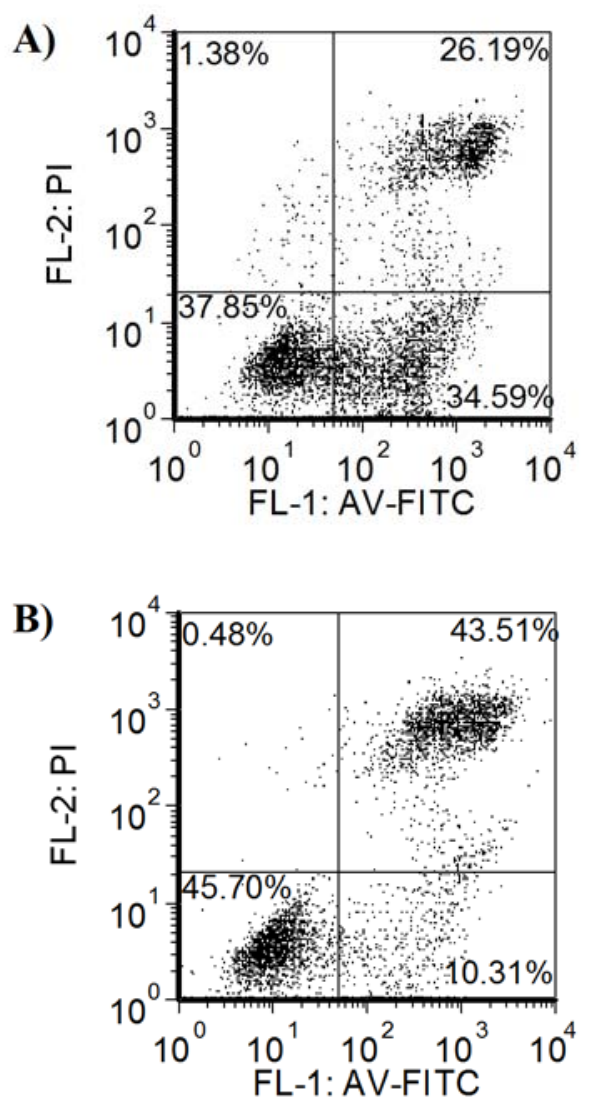

Figure S5. Representative flow cytometry plots illustrating annexin-V (AV) and propdium iodide (PI) stained cell populations following $12 \mathrm{hr}$ exposure to A) $1000 \mu \mathrm{g} / \mathrm{mL}$ nano-WC-Co and B) $1000 \mu \mathrm{g} / \mathrm{mL}$ micro-WC-Co. Percentages of stained cells are listed in each respective quadrant: lower left ( $\mathrm{PI}^{-} / \mathrm{AV}^{-}$; viable), lower right $\left(\mathrm{PI}^{-} / \mathrm{AV}^{+}\right.$; early apoptotic), upper right $\left(\mathrm{PI}^{+} / \mathrm{AV}^{+}\right.$; late apoptotic), upper left $\left(\mathrm{PI}^{+} / \mathrm{AV}^{-}\right.$; necrotic). 
A)

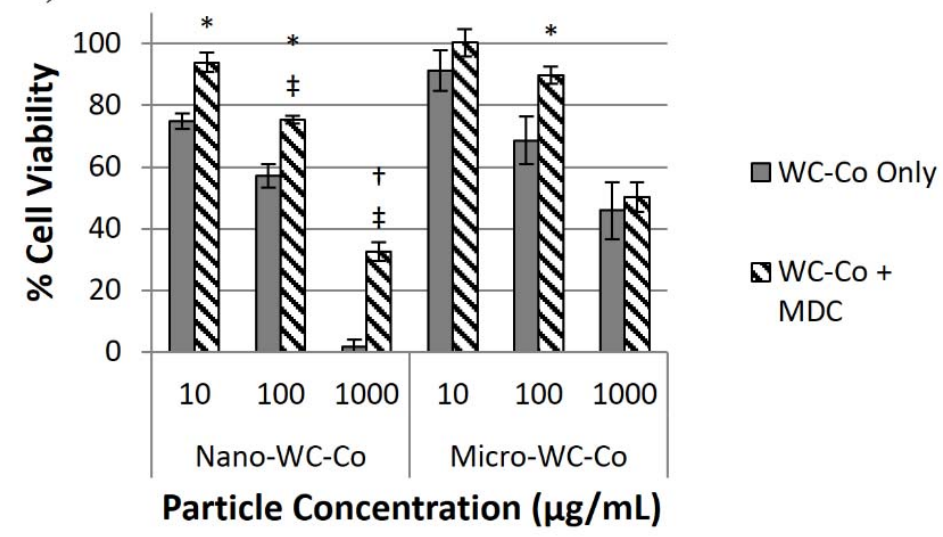

B)

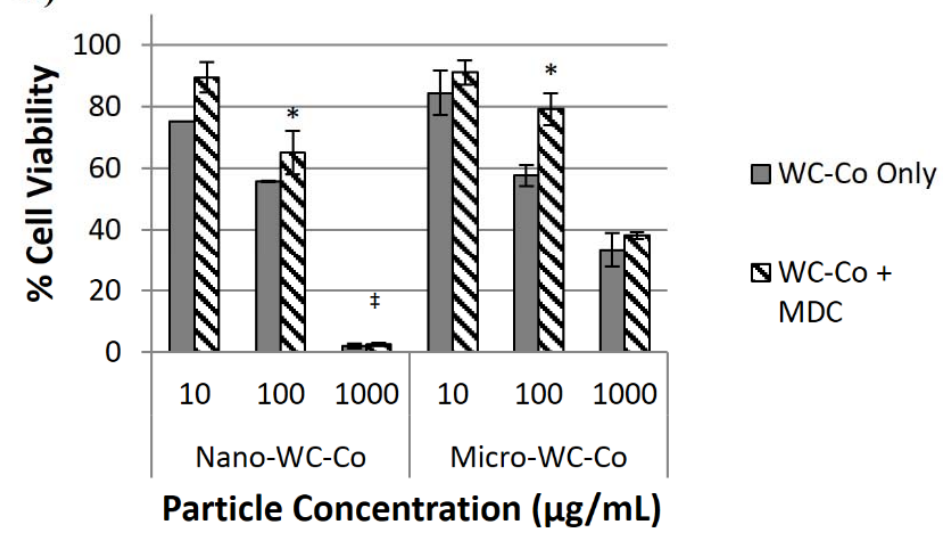

C)

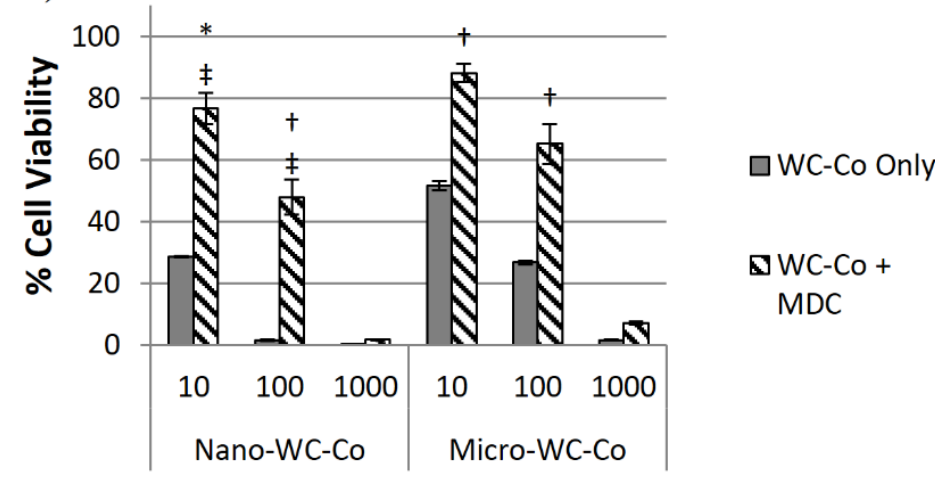

Particle Concentration $(\mu \mathrm{g} / \mathrm{mL})$

Figure S6. Comparison of cell viability in presence of nano- and micro-WC-Co plus $10 \mu \mathrm{g} / \mathrm{mL}$ MDC after A) $6 \mathrm{hr}$, B) $12 \mathrm{hr}$ and C) $48 \mathrm{hr}$ of exposure. $\left[{ }^{*} \mathrm{P}<0.05,{ }^{\dagger} \mathrm{P}<0.001\right.$ compared to control (WC-Co only), ${ }^{\ddagger} \mathrm{P}<0.05$ compared to micro-WC-Co $+\mathrm{MDC}$ ] 
A)

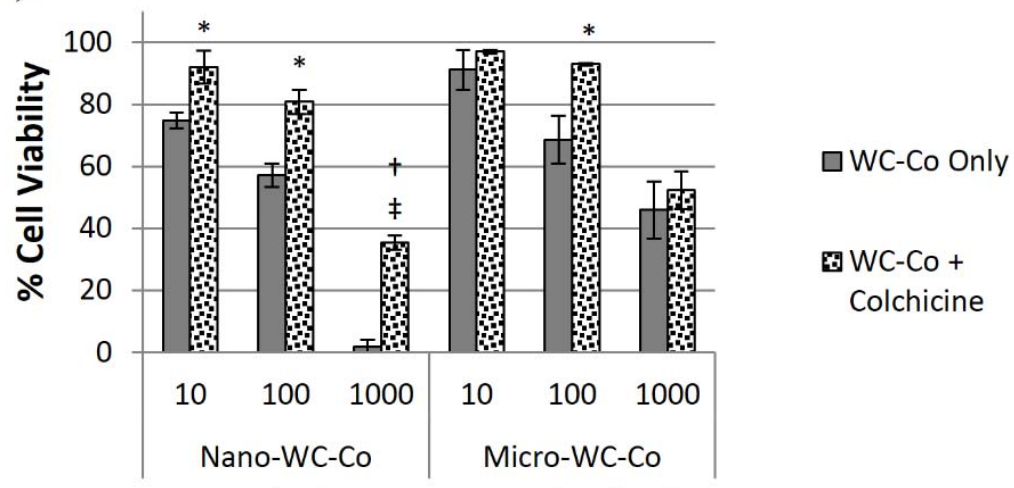

Particle Concentration $(\mu \mathrm{g} / \mathrm{mL})$

B)

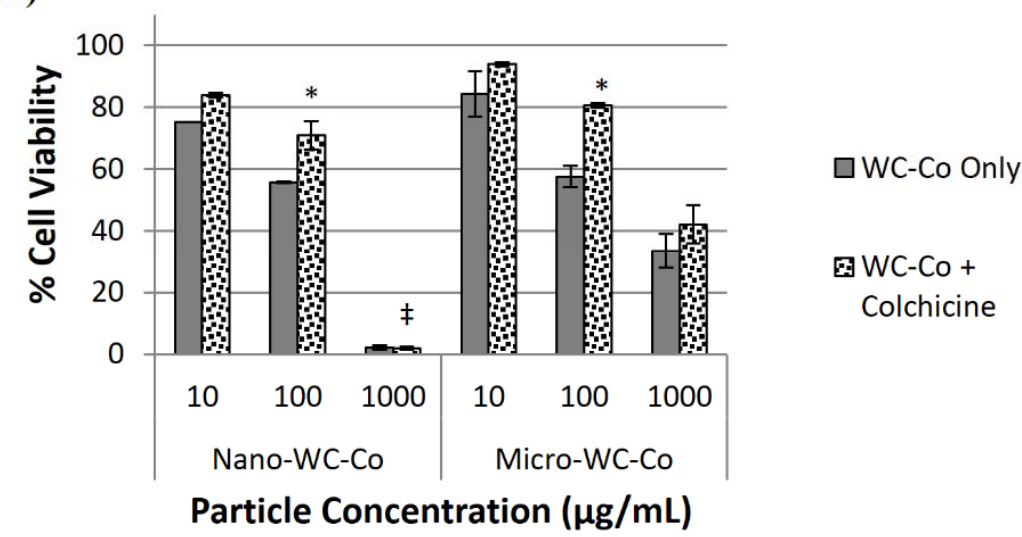

C)

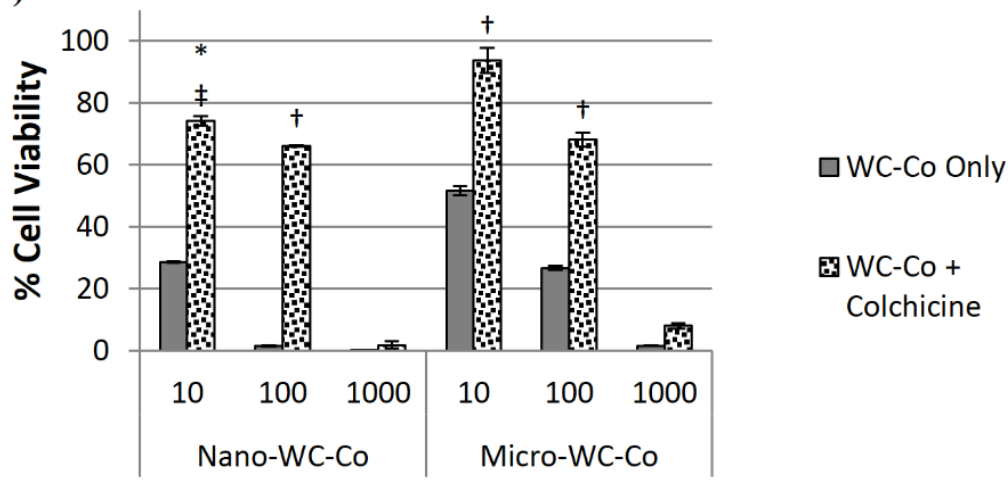

Particle Concentration $(\mu \mathrm{g} / \mathrm{mL})$

Figure S7. Comparison of cell viability in presence of nano- and micro-WC-Co plus $10 \mu \mathrm{g} / \mathrm{mL}$ colchicine after A) $6 \mathrm{hr}, \mathrm{B}) 12 \mathrm{hr}$ and C) $48 \mathrm{hr}$ of exposure. [ ${ }^{*} \mathrm{P}<0.05, \dagger \mathrm{P}<0.001$ compared to control (WC-Co only), $\$ \mathrm{P}<0.05$ compared to micro-WC-Co + colchicine] 
А)

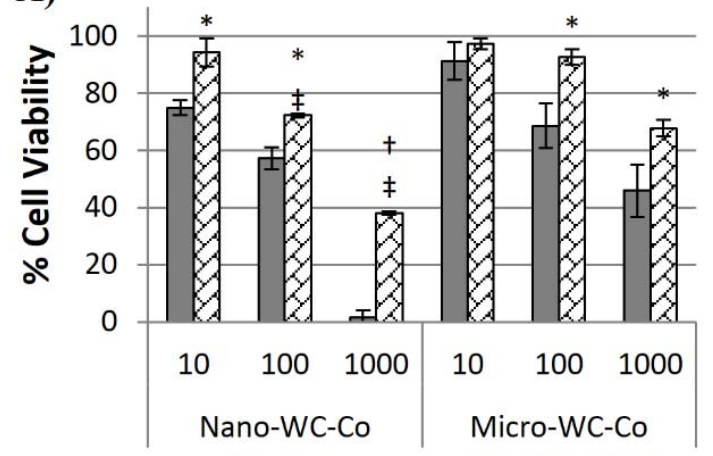

Particle Concentration $(\mu \mathrm{g} / \mathrm{mL})$

B)

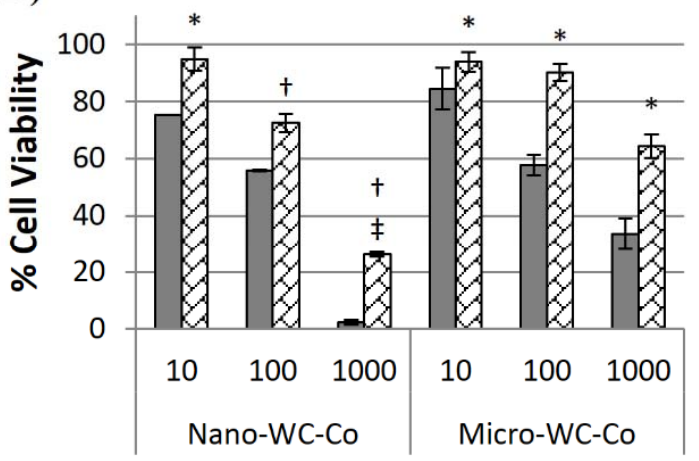

Particle Concentration $(\mu \mathrm{g} / \mathrm{mL})$

C)

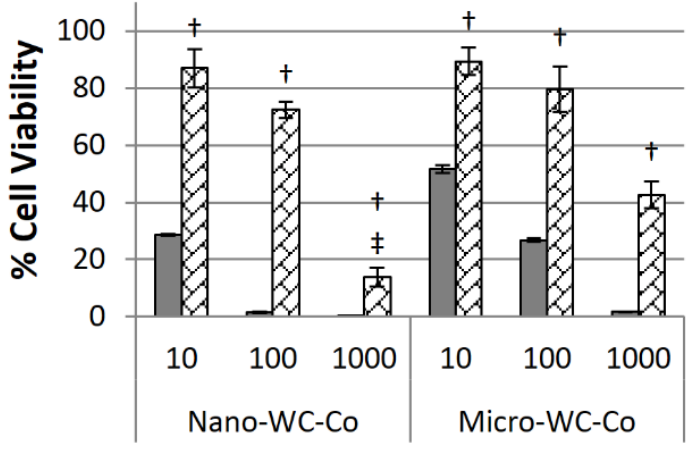

Particle Concentration $(\mu \mathrm{g} / \mathrm{mL})$
aWC-Co Only

DWC-Co+

Cytochalasin D

aWC-Co Only

$\square$ WC-Co+

Cytochalasin D

口WC-Co Only

曰WC-Co+

Cytochalasin D

Figure S8. Comparison of cell viability in presence of nano- and micro-WC-Co plus $10 \mu \mathrm{g} / \mathrm{mL}$ cytochalasin D after A) $6 \mathrm{hr}$, B) $12 \mathrm{hr}$ and C) $48 \mathrm{hr}$ of exposure. $\left[{ }^{*} \mathrm{P}<0.05,{ }^{+} \mathrm{P}<0.001\right.$ compared to control (WC-Co only), ${ }^{\ddagger} \mathrm{P}<0.05$ compared to micro-WC-Co + cytochalasin $\left.\mathrm{D}\right]$ 


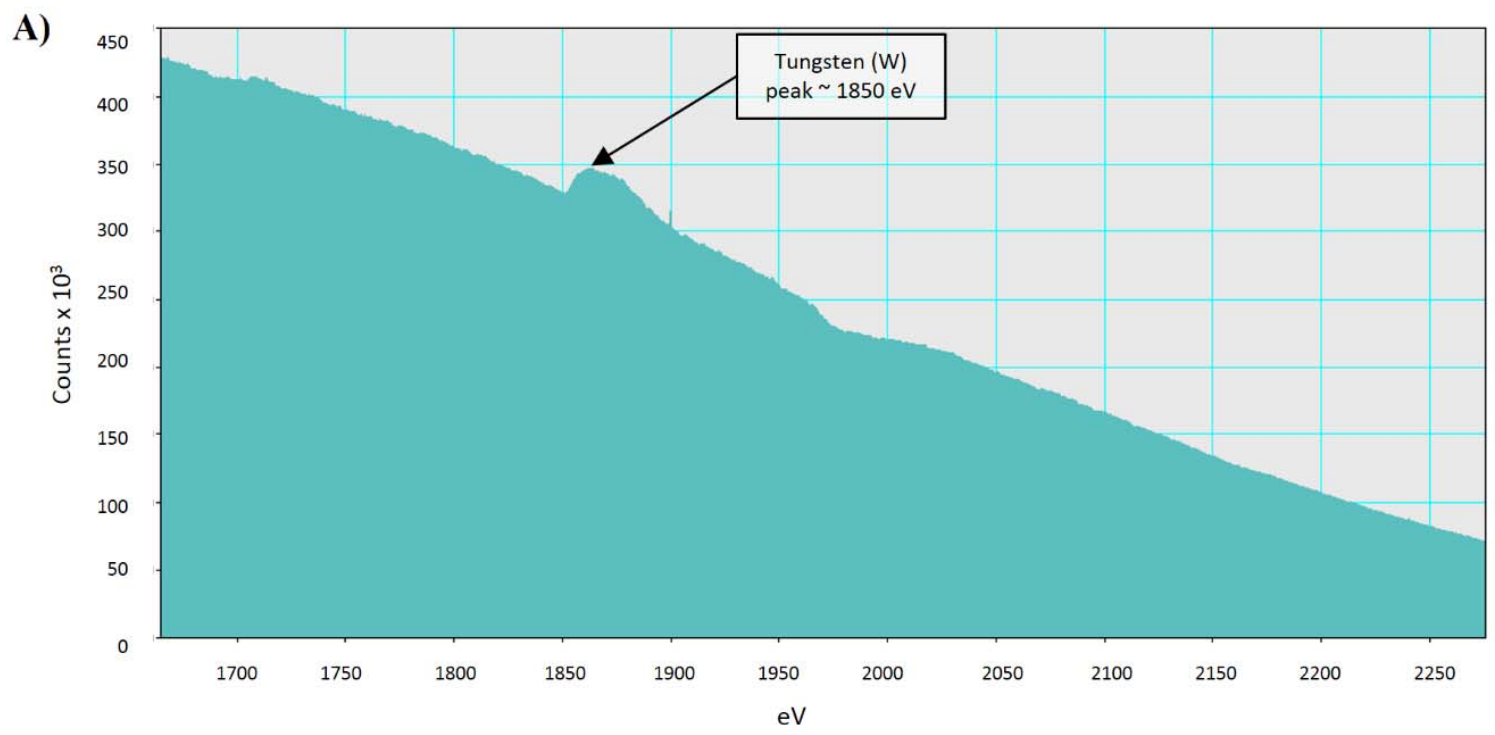

B)

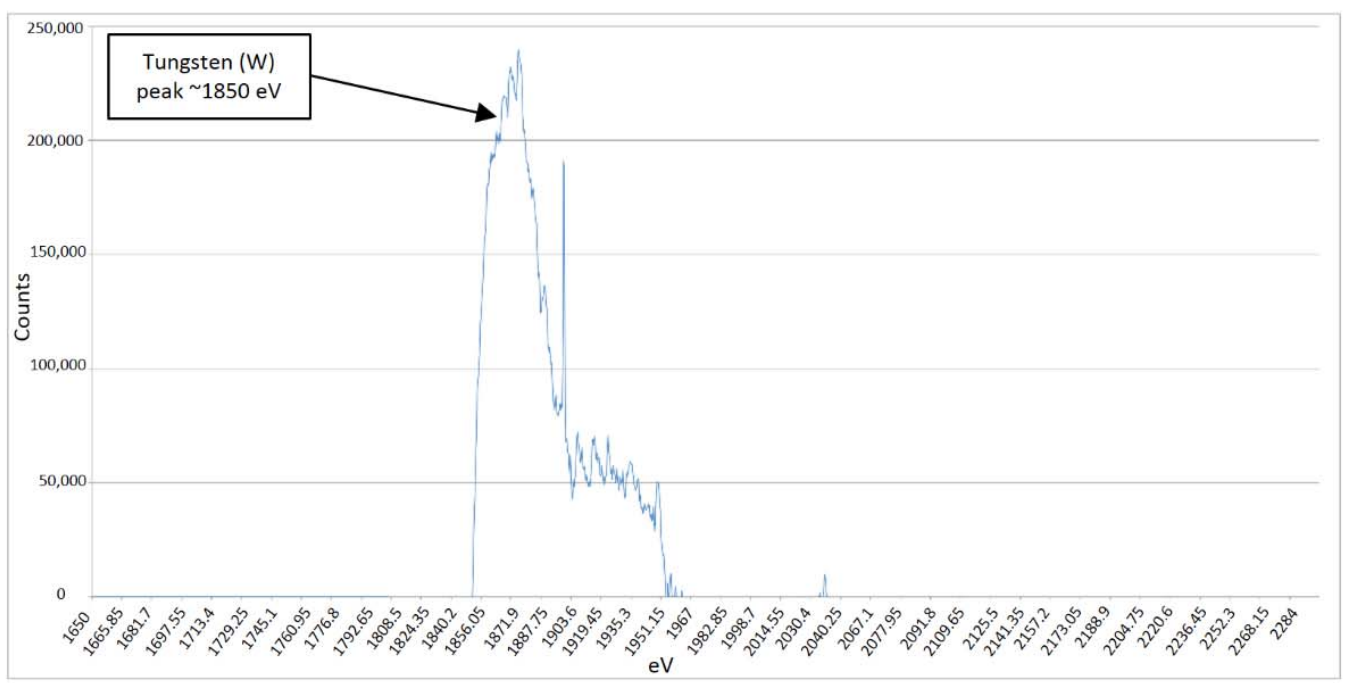

Figure S9. Electron energy loss spectra (EELS) for cell samples scanned for the presence of internalized WC-Co particles using TEM, confirming the presence of tungsten (W) $\sim 1850 \mathrm{cV}$ in the A) cumulative and B) power law fitted curves. 


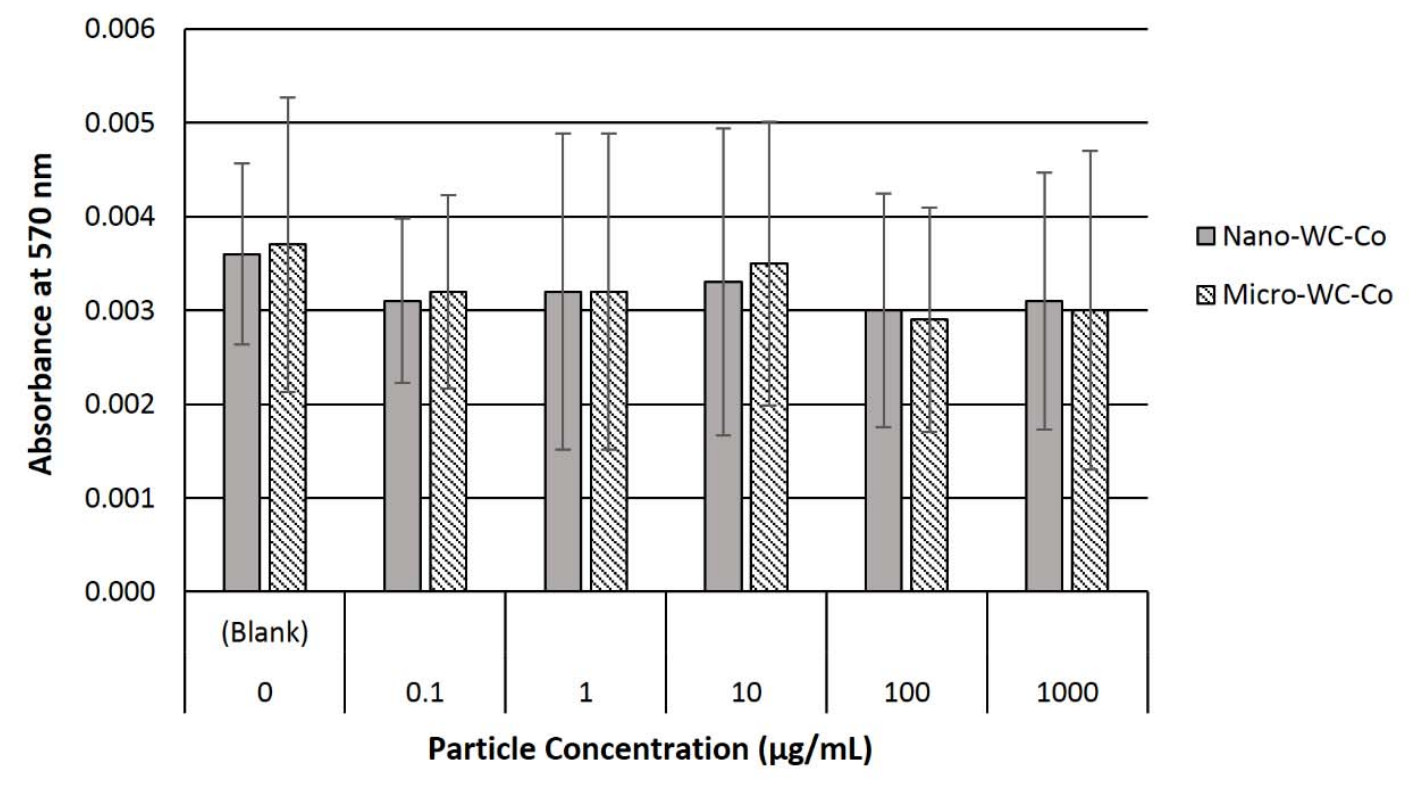

Figure S10. Background absorbance of DMEM containing MTT reagent (tetrazolinium salt) under assay conditions in the absence (blank/0) and presence of WC-Co particles to confirm the absence of artifacts at $570 \mathrm{~nm}$, the primary absorbance wavelength for formazan detection. 
A)

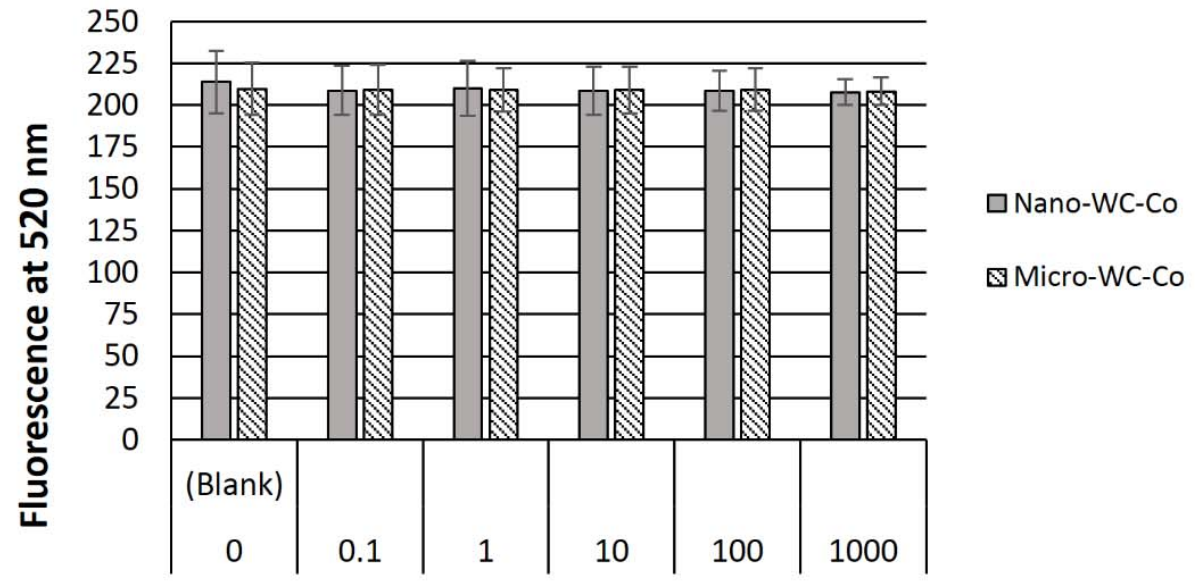

Particle Concentration $(\mu \mathrm{g} / \mathrm{mL})$

B)

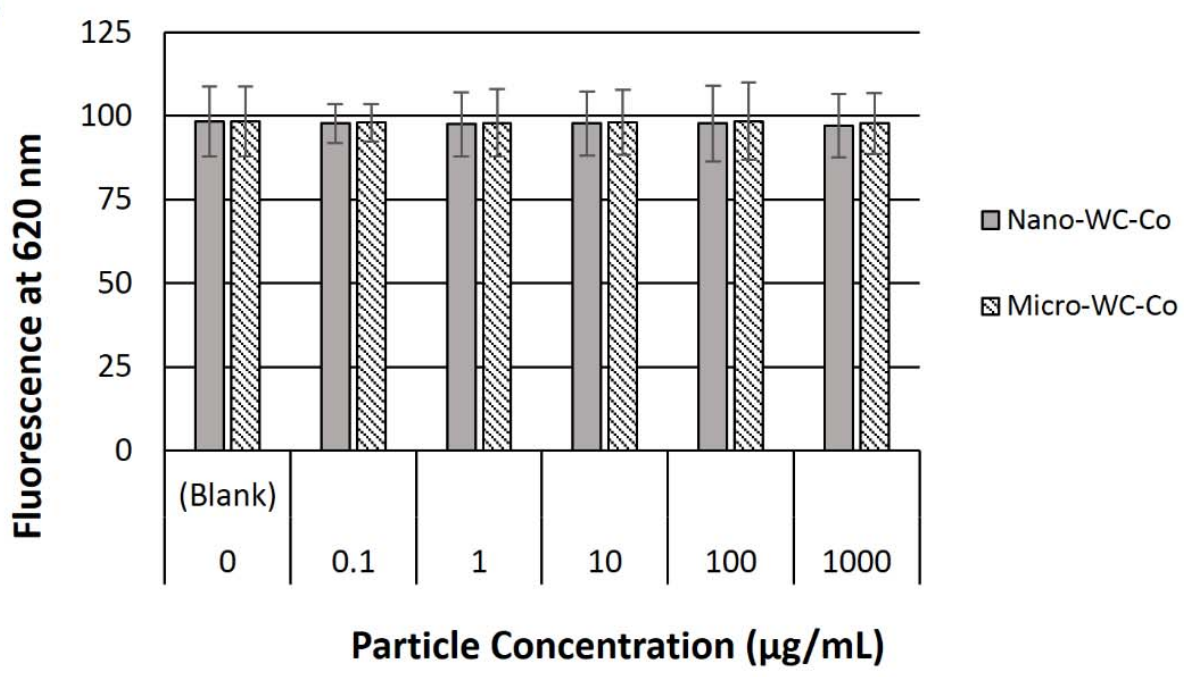

Figure S11. Background fluorescence of blank (PBS + dye only) and WC-Co particle suspensions in the absence of cells to confirm the absence of artifacts at the primary emission wavelengths for A) DCF at $520 \mathrm{~nm}$ and B) DHE at $620 \mathrm{~nm}$. 

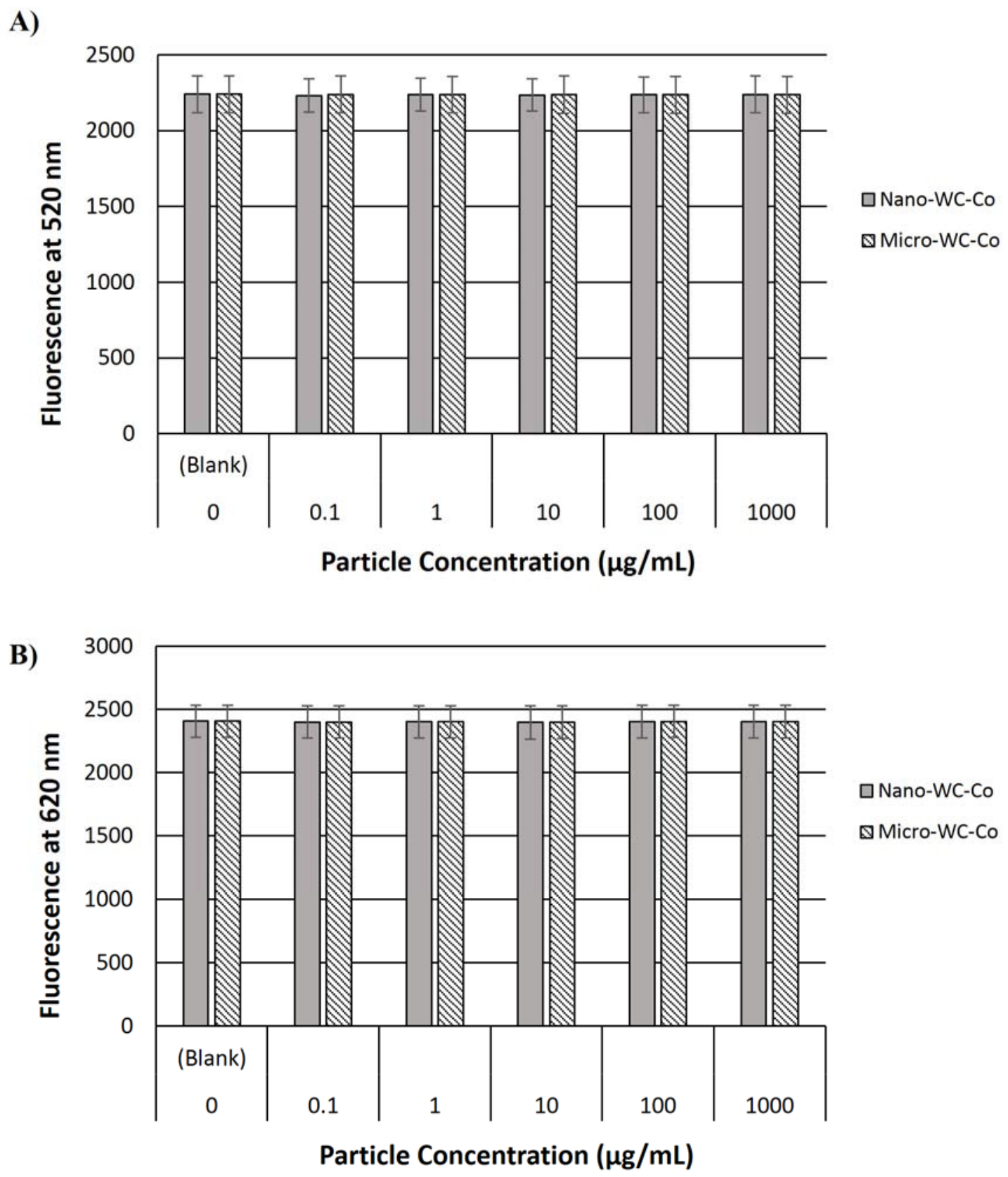

Figure S12. Background fluorescence in dye-loaded cells after being spiked with WC-Co particle suspensions to confirm the absence of artifacts at the primary emission wavelengths for A) DCF at $520 \mathrm{~nm}$ and B) DHE at $620 \mathrm{~nm}$. 

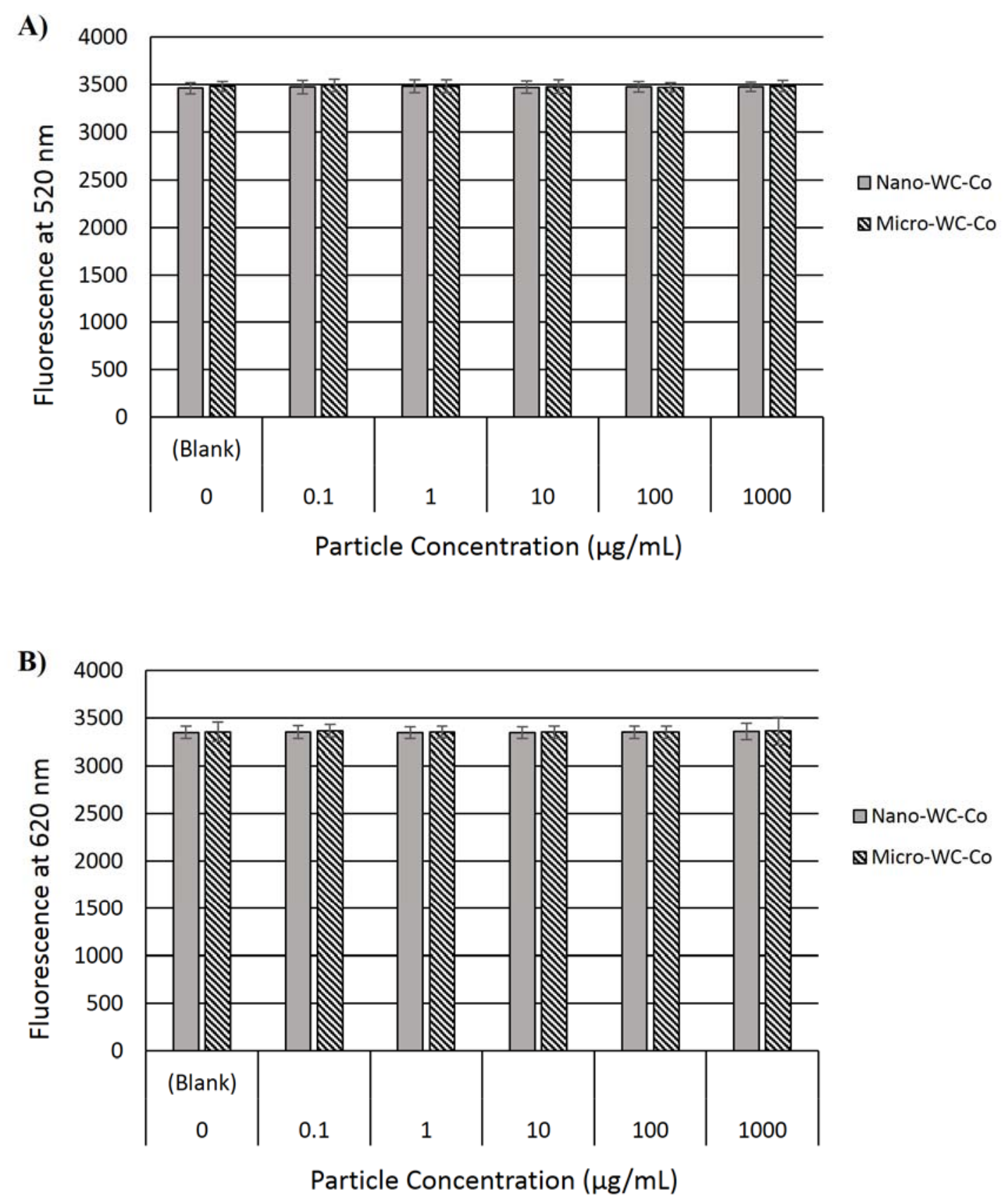

Figure S13. Background fluorescence in dye-loaded cells after being spiked with WC-Co particle suspensions and lysed, releasing fluorescent dyes into solution in order to confirm the absence of artifacts due to particle interference at the primary emission wavelengths for A) DCF at $520 \mathrm{~nm}$ and B) DHE at $620 \mathrm{~nm}$. 


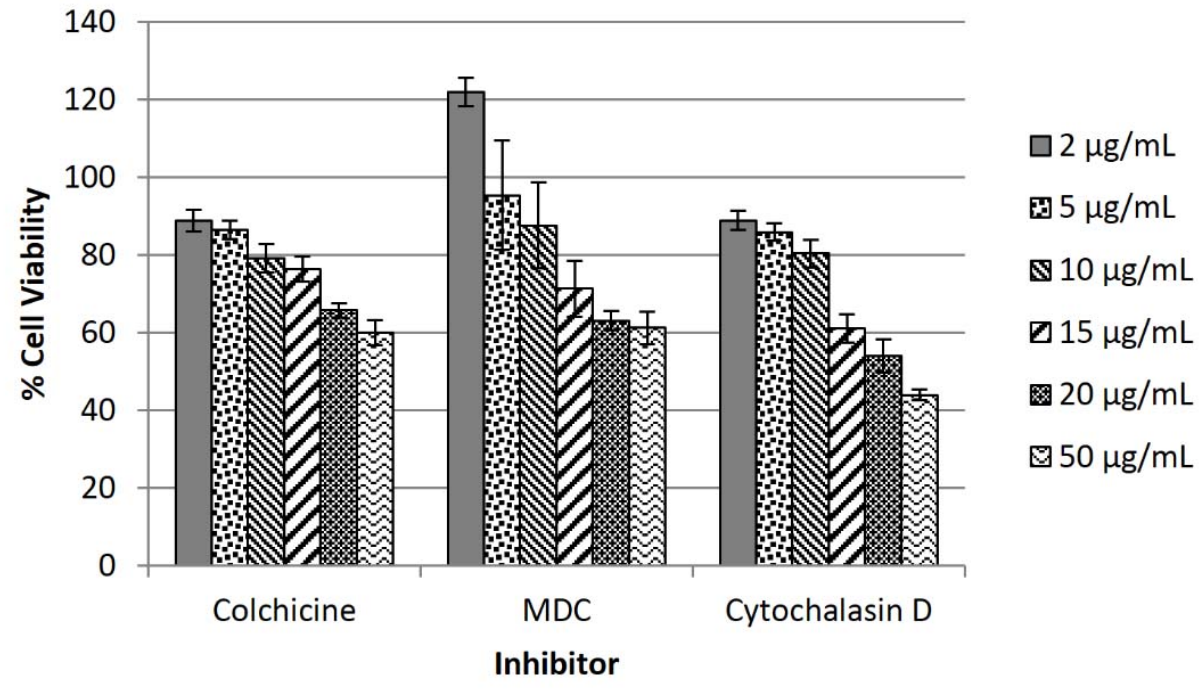

Figure S14. Cell viability in the presence of colchicine, monodansylcadaverine (MDC) and cytochalasin D after $48 \mathrm{hr}$ of exposure. Cell viability in presence of inhibitor calculated based on absorbance of untreated control cells (no inhibitor). 

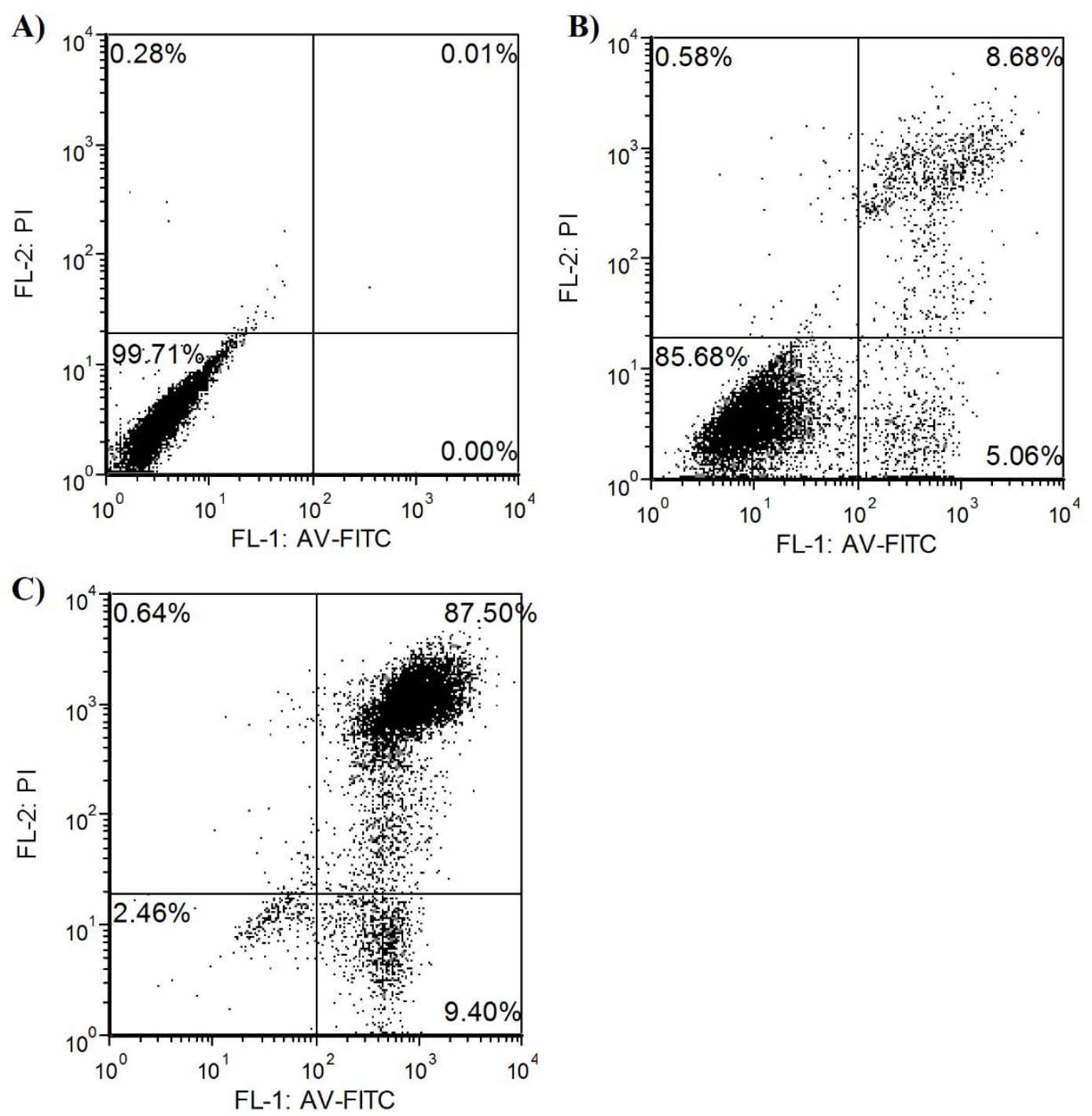

Figure S15: Representative flow cytometry dot plots illustrating gating parameters set for A) live, unstained cells, B) live, stained cells (neg. control; AV + PI) and C) heat-shocked dead cells (pos. control; AV + PI). 
A)

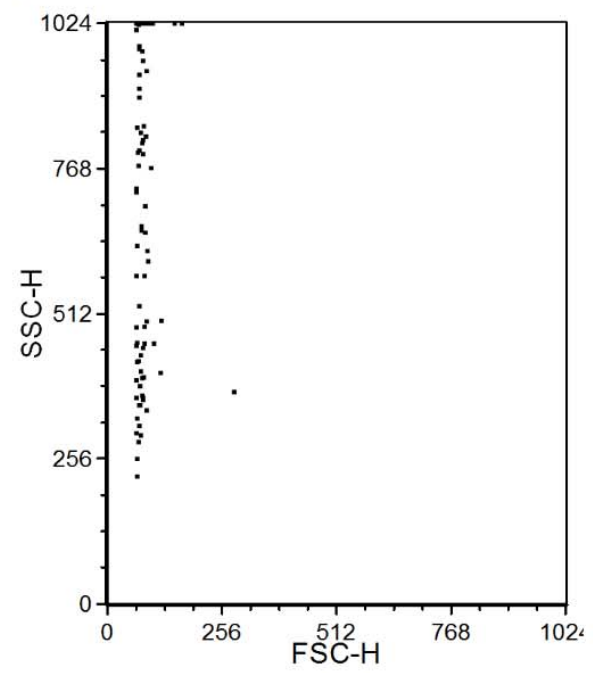

B)

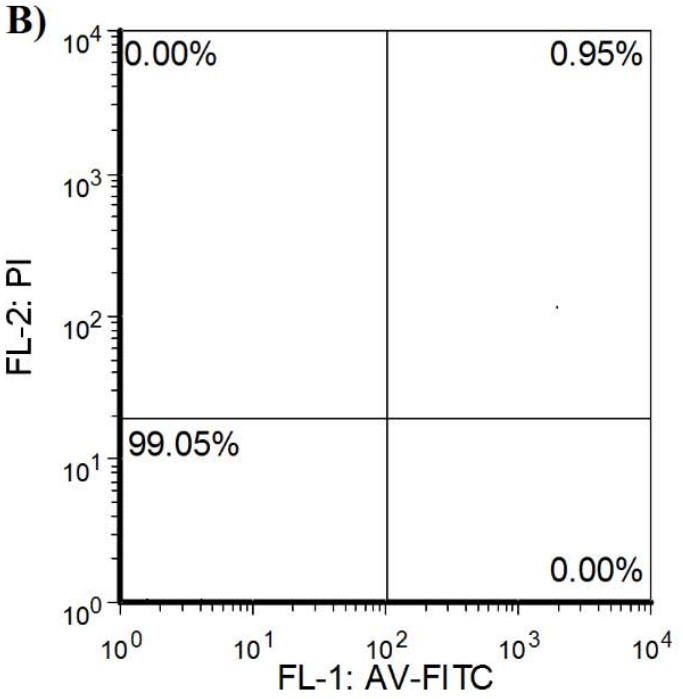

C)
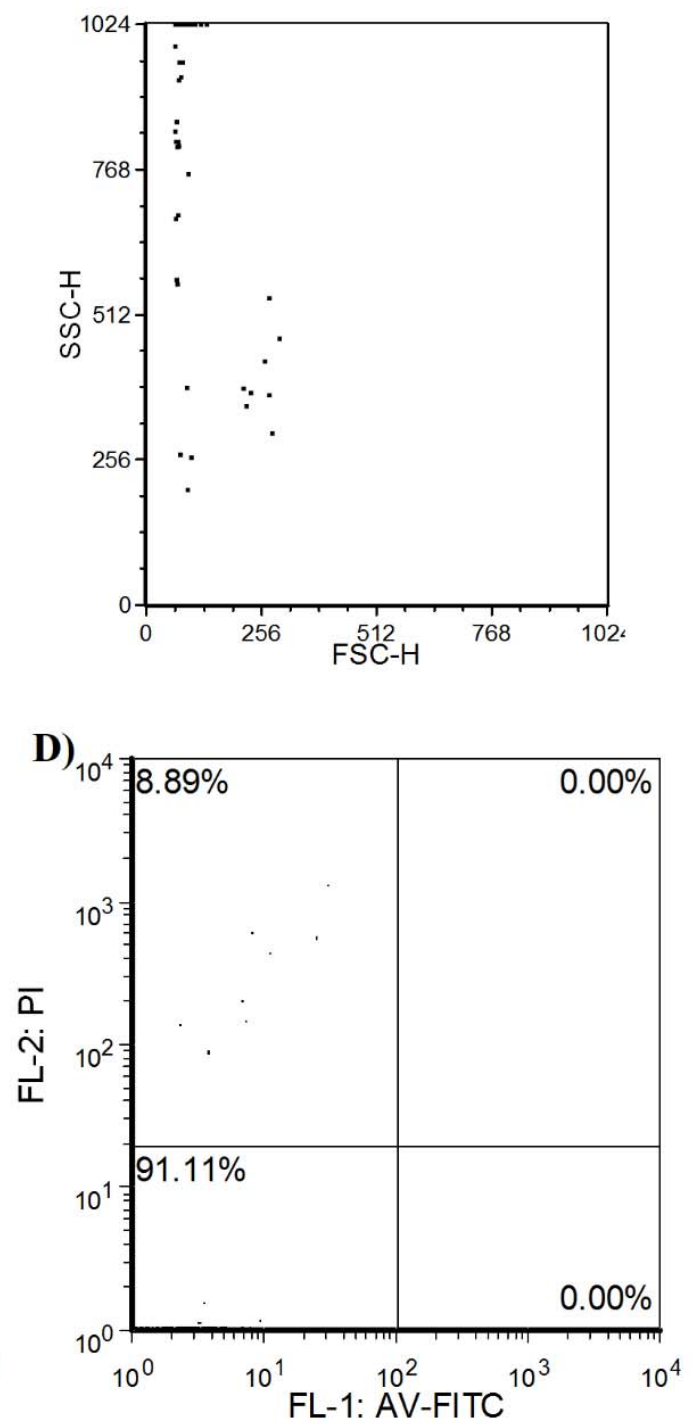

Figure S16: Representative scatter and dot plots showing the background of WC-Co particles in the flow cytometry apoptosis assay in the presence of assay binding buffer, AV-FITC and PI for A-B) nano-WC-Co and C-D) micro-WC-Co. Gates in B, D set based on control parameters shown above in Figure S14. 


\section{CHAPTER 3:}

\section{The Inflammatory Effects of Hard Metal (WC-Co) Nanoparticle Exposure in vitro: Mono-culture vs. Co-culture Models}

Original dissertation research completed in fulfillment of

Specific Aim \#2 


\section{ABSTRACT}

Identifying the toxicity of nanoparticles is an important area of research as the number of nanomaterial-based consumer and industrial products continually rises. In addition, the potential inflammatory effects resulting from pulmonary nanoparticle exposure are emerging as an important aspect of nano-toxicity. In this study, we examined the toxicity and inflammatory state resulting from tungsten carbide cobalt (WC-Co) nanoparticle exposure in macrophages and a coculture of lung epithelial cells (BEAS-2B) and macrophages (THP-1) at a 3:1 ratio. We found that the toxicity of nano-WC-Co was cell dependent; significantly less toxicity was observed in THP-1 compared to BEAS-2B cells. We demonstrated that nano-WC-Co caused reduced toxicity in our co-culture model compared to lung epithelial cell mono-culture, which suggested that macrophages may play a protective role against nano-WC-Co mediated toxicity in co-cultures. Nano-WC-Co exposure in macrophages resulted in increased levels of interleukin-1beta (IL-1 $\beta$ ) and interleukin-12 (IL-12) secretion and decreased levels of tumor necrosis factor (TNF $\alpha$ ). In addition, the polarizing effects of nano-WC-Co exposure toward the M1 (pro-inflammatory) and M2 (anti-inflammatory) macrophage phenotypes were investigated. The results of this assay indicated that nano-WC-Co exposure stimulated the M1 phenotype, marked by high expression of CD40 M1 macrophage surface markers.

Keywords: nanoparticle, nanotoxicity, inflammation, cytokine, macrophage, lung disease, cancer 


\section{INTRODUCTION}

The majority of nanomaterial or nanoparticle (NP) exposure occurs via the pulmonary route $[30,37]$ and, upon inhalation, macrophages are recruited to the area as part of the body's defense mechanism to promote particle clearance from the lungs [205, 206]. Phagocytic by nature, macrophages will quickly identify and engulf the NPs as part of their inherent physiological response mechanism [206, 207]. However, during this process, the macrophage accumulates a large quantity of NPs. Depending on the NP, this accumulation within the cell may cause toxicity or induce a secondary immune response and stimulate a local or systemic inflammatory process [63, 170, 207-209]. Therefore, along with addressing the directly toxic effects of the multitude of NPs currently used in consumer products today, it is important to consider the inflammatory response which these materials may generate upon exposure [207].

Macrophage mediated inflammation typically occurs in response to bacterial or viral infections and tissue injuries as a part of the normal healing process, but it can also occur as a result of foreign particle inhalation [207, 210]. Depending on the stimulus, macrophages differentiate into either a "classically" activated M1 or "alternatively" activated M2 phenotype, which have signature characteristics that distinguish them from one other [211-217]. Classical M1 macrophages play important roles in infection clearance, typically in response to lipopolysaccharide (LPS), which stimulates a high level secretion of pro-inflammatory cytokines such as tumor necrosis factor alpha (TNF $\alpha)$ and interleukin 12 (IL-12) and promotes a type $1 \mathrm{~T}$ helper (Th1) immune response [211-213, 217]. Macrophages activated by other factors, such as endogenous interleukin 4 (IL-4) or glucocorticoid hormones, fall under the alternatively activated M2 phenotype. M2 macrophages generally secrete high levels of interleukin 10 (IL-10)

and interleukin 1-beta (IL-1 $\beta$ ) to promote the type $2 \mathrm{~T}$ helper (Th2) immune response [211-213, 
217]. Additionally, emerging evidence indicates that macrophage activation/polarization toward the M1 or M2 phenotype may play critical roles in tumor growth and cancer progression [210, $211,218,219]$. It is thought that M1 macrophages promote tumor resistance, due to their highlevel secretion of pro-inflammatory cytokines and potent effector cell functions [212, 213]. In contrast, M2 macrophages are believed to possess tumor promoting functions due to their promotion of angiogenesis, tissue remodeling and repair mechanisms [212, 213]. Further, the tumor microenvironment can influence tumor associated macrophages to undergo a "phenotypic switching" from M1 to M2, and thus tumor-promoting, phenotype [212, 218].

Given this body of literature, it has been suggested that inflammation resulting from pulmonary NP exposure may play a role in the toxicity associated with exposure $[33,40,63,66$, $170,176,207-209,220,221]$ and that the inflammatory state resulting from particle exposure may play a role in cancer progression [207, 210]. This is especially concerning in occupational settings $[18,75,78,79]$ where workers undergo pulmonary exposure to NPs on a daily basis $[98$, 176]. In particular, exposure to tungsten carbide cobalt NPs (nano-WC-Co) in occupational settings is known to cause hard metal lung disease (HMLD), characterized by progressive inflammation and fibrosis of the lung $[85,101,104,105,113,114,118,129]$, which is further associated with a two-fold increased risk of lung cancer [97, 100, 107]. While the toxicity of WC-Co particles has been studied [128, 130-134, 137, 139, 141, 143, 147-153, 155-157, 159, $161,222,223]$, the relationship between WC-Co toxicity, inflammation and lung cancer remains poorly understood.

Additionally, there is limited information regarding the interaction of multiple cell types during WC-Co NP exposure (i.e. immune cells and epithelial cells), as the majority of previous in vitro studies employed single cell (mono-culture) models in their examination of WC-Co 
toxicity [130, 132-134, 141-144, 146-149]. This design is a disadvantage, as co-culture models may more closely represent the in vivo environment during a WC-Co NP exposure. To address this gap in understanding, the present study examined the effects of nano-WC-Co particle exposure in vitro using mono- and co-culture cell models composed of macrophages (THP-1) and lung epithelial cells (BEAS-2B) to assess the toxicity, stimulation of inflammatory cytokine secretion and M1/M2 macrophage polarization. We hypothesized that exposure to nano- WC-Co stimulates inflammation in macrophages and may promote polarization toward the M1 proinflammatory macrophage phenotype.

\section{MATERIALS and METHODS}

Materials and Reagents: THP-1 (TIB-202) human monocyte cell line (TIB-202) was purchased from American Type Culture Collection (ATCC; Manassas, VA) and BEAS-2B cells (originally purchased from ATCC) were obtained from the laboratory of Yon Rojanasakul. Nano-WC-Co (tungsten carbide cobalt) composite particles were purchased from Inframat Advanced Materials (Manchester, CT). RPMI-1640 media for THP-1 cell culture was purchased from ATCC. Phosphate buffered saline (PBS), Dulbecco's Modified Eagle Media (DMEM), 0.25\% trypsin/ethylenediaminetetraacetic acid (EDTA), versene (EDTA-based cell detachment reagent), penicillin/streptomycin, beta-mercaptoethanol and fetal bovine serum (FBS) were purchased from Lonza (Allendale, NJ). Isopropanol, hydrochloric acid, Triton-X-100, thiazolyl blue tetrazolinium bromide (MTT reagent), phorbol-12-mystirate-13-acetate (PMA), lipopolysaccharide (LPS) and enzyme-linked immunosorbent assay (ELISA) kits for human IL-

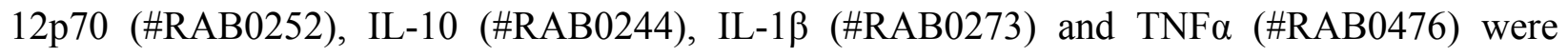

purchased from Sigma-Aldrich (St. Louis, MO). Flow cytometry staining buffer (containing 
$0.2 \%$ bovine serum albumin and sodium azide), recombinant human IL-4, human IgG, antihuman CD-40-APC and anti-human CD-206-FITC antibodies were purchased from BD Biosciences (Franklin Lakes, NJ).

Nano-WC-Co Particle Preparation: Nano-WC-Co stock particle suspensions ( $5 \mathrm{mg} / \mathrm{mL}$ ) were prepared in sterile PBS (containing 10\% FBS to prevent agglomeration) by sonication under 120 watts power output, frequency $20 \mathrm{kHz}$, for 1 min with an Omni International Sonic Ruptor (Kennesaw, GA). Sonication was performed in $30 \mathrm{~mL}$ plastic vials immobilized in an ice bath to prevent heating during particle dispersion. Dilute nano-WC-Co particle suspensions (1 to 1000 $\mu \mathrm{g} / \mathrm{mL}$ ) were prepared on the day of each experiment in DMEM containing $10 \%$ FBS from the 5 $\mathrm{mg} / \mathrm{mL}$ stock particle suspension.

Cell Culture and THP-1 Macrophage (M0) Activation: BEAS-2B cells were maintained and passaged upon confluence in DMEM supplemented with $10 \%$ FBS and $1 \%$ penicillin/streptomycin. THP-1 cells were maintained and passaged upon confluence in RPMI1640 supplemented with $10 \%$ FBS, $1 \%$ penicillin/streptomycin and $0.5 \mathrm{mM}$ betamercaptoethanol. All cells were maintained in an incubator at $37^{\circ} \mathrm{C}$ and $5 \% \mathrm{CO}_{2}$. Differentiation of THP-1 cells to macrophages (M0) was achieved through the addition of $10 \mathrm{ng} / \mathrm{mL}$ PMA. After 48hr, THP-1 to M0 differentiation was confirmed via examination of cell morphology using a light microscope [215, 224], where M0 cells underwent a signature change in morphology and became adherent to the culture dish. For co-culture, M0 cells were rinsed once with PBS and incubated with versene (EDTA-based cell dissociation reagent) for 15 min. M0 were then pipetted gently to ensure detachment from the culture dish and re-suspended in DMEM at the desired concentration for co-culture seeding. 
Macrophage and Epithelial Cell Co-Culture: To establish the co-culture (CC) at a ratio of 3:1 (lung epithelial cell: macrophage), BEAS-2B cells were trypsinized, re-suspended in DMEM and seeded in a 96-well plate at a density of $1.5 \times 10^{5}$ cells $/ \mathrm{mL}$ and allowed to adhere for $1 \mathrm{hr}$. BEAS-2B attachment was confirmed using light microscopy prior to the addition of M0 cells. M0 cells were seeded directly on top of the BEAS-2B monolayer at a density of $5 \times 10^{4}$ cells $/ \mathrm{mL}$ in DMEM and co-cultured for $24 \mathrm{hr}$ to allow attachment and cellular interaction prior to nanoWC-Co exposure.

Nano-WC-Co Particle Exposure: Nano-WC-Co particle exposure was achieved by aspirating the media from each well and replacing immediately with an equivalent volume of nano-WC-Co particle suspension at a concentration of $1,10,100$ or $1000 \mu \mathrm{g} / \mathrm{mL}$ and incubated at $37^{\circ} \mathrm{C}$ and $5 \% \mathrm{CO}_{2}$ for exposure periods of 2, 6, 12, 24 and $48 \mathrm{hr}$; controls were treated with LPS (100 $\mathrm{ng} / \mathrm{mL})$ or IL-4 (20 ng/mL). For the M1/M2 flow cytometery experiments, M0 cells were treated with either control LPS, IL-4 or 0, 1, 10 and $100 \mu \mathrm{g} / \mathrm{mL}$ nano-WC-Co for exposure periods of 1 , 2 and 5 days.

Cell Viability after Nano-WC-Co Exposure: Following nano-WC-Co exposure, the media containing nano-WC-Co was aspirated from each well and cells were rinsed once with PBS to remove excess particles. Then, $100 \mu \mathrm{L}$ un-supplemented DMEM was added to each well, followed by the addition of $10 \mu \mathrm{L}$ MTT reagent to achieve a final concentration of $0.5 \mathrm{mg} / \mathrm{mL}$ MTT per well. Cells were incubated for $2 \mathrm{hr}$ at $37^{\circ} \mathrm{C}$ and $5 \% \mathrm{CO}_{2}$ to allow conversion of the soluble tetrazolinium salt (yellow) to formazan crystals (purple). Crystal formation was confirmed using light microscopy. Next, $100 \mu \mathrm{L}$ of solubilization solution $(0.1 \mathrm{M} \mathrm{HCl}$ in isopropanol containing $10 \%$ Triton-X) was added to each well to dissolve the formazan crystals and the absorbance of each well was recorded immediately at $570 \mathrm{~nm}$ using a Bio-Tek $\mu$ Quant 
microplate reader (Winooski, VT). Blank values were subtracted from all absorbance readings. Cell viability was calculated by dividing the absorbance of nano-WC-Co treated cells by the absorbance of control cells receiving media treatment only and converted to a percentage.

Macrophage Polarization Assay: THP-1 cells were seeded at a density of $5 \times 10^{5}$ cells $/ \mathrm{mL}$ in RPMI-1640 containing $10 \mathrm{ng} / \mathrm{mL}$ PMA in a 12-well culture dish and incubated for $48 \mathrm{hr}$ to stimulate M0 cell differentiation. Media were then aspirated from each well and replaced with DMEM containing $100 \mathrm{ng} / \mathrm{mL}$ LPS (M1 stimulus/positive control), $20 \mathrm{ng} / \mathrm{mL}$ IL-4 (M2 stimulus/positive control) and $0,1,10$ or $100 \mu \mathrm{g} / \mathrm{mL}$ nano-WC-Co particles. M0 cells were incubated with the M1, M2 or nano-WC-Co stimulus for 1,2 and 5 days at $37^{\circ} \mathrm{C}$ and $5 \% \mathrm{CO}_{2}$.

Flow Cytometry: Following M1/M2/WC-Co exposure, M0 cells were rinsed once with PBS, detached with versene (described above) and transferred to $15 \mathrm{~mL}$ polystyrene tubes. Cells were centrifuged at $1200 \mathrm{rpm}$ for $7 \mathrm{~min}$ to pellet and re-suspended in $1 \mathrm{~mL}$ ice-cold flow cytometry staining buffer. M0 cells were counted on a hemocytometer and a total of $3 \times 10^{5}$ cells per sample were transferred to $5 \mathrm{~mL}$ polystyrene tubes for subsequent staining. After centrifugation, cell pellets were re-suspended in $100 \mu \mathrm{L}$ staining buffer containing $10 \mu \mathrm{g}$ human $\operatorname{IgG}$ and incubated for 30 min over ice to block macrophage $\mathrm{Fc}$ receptors and minimize non-specific antibody binding. Next, cells were rinsed with $1 \mathrm{~mL}$ cold staining buffer to remove excess IgG and re-suspended in $80 \mu \mathrm{L}$ buffer. $10 \mu \mathrm{L}$ of each antibody (anti-CD-40-APC or anti-CD-206FITC) was added to each appropriate tube, including positive/negative and single-stain controls and incubated for $1 \mathrm{hr}$ over ice. After staining, cells were rinsed 3 times with $1 \mathrm{~mL}$ cold staining buffer to remove unbound antibodies. After the final rinse, cell pellets were re-suspended in 100 $\mu \mathrm{L} 0.4 \%$ paraformaldehyde to fix and stored overnight at $4^{\circ} \mathrm{C}$. The next day, fixed cells were centrifuged, re-suspended in $300 \mu \mathrm{L}$ staining buffer and analyzed immediately on a BD LSR 
FORTESSA flow cytometer. Instrument settings were defined at the beginning of each experiment using the cells only (no stain) and single-stain controls (CD40-APC only and CD206-FITC only) and applied for all subsequent experimental samples.

Inflammatory Cytokine Secretion in response to Nano-WC-Co Exposure: The concentration of IL-12, IL-10, IL-1 $\beta$ and TNF $\alpha$ in cell culture supernatants was determined using an enzymelinked immunosorbent assay (ELISA) kit. Following nano-WC-Co exposure, cell culture supernatants were collected after $6,12,24$ and $48 \mathrm{hr}$ in $150 \mu \mathrm{L}$ aliquots in a 96-well plate and preserved immediately at $-80^{\circ} \mathrm{C}$ for later analysis. Once all supernatant samples had been collected, the 96-well plates were quickly thawed at room temperature and centrifuged briefly (500 rpm for $5 \mathrm{~min}$ ) to pellet any cell debris or nano-WC-Co particles which may interfere with the assay. The ELISA assays were then carried out according to manufacturer instructions. Briefly, $100 \mu \mathrm{L}$ supernatant or cytokine standard (prepared according to instructions) was transferred to the appropriate well(s) of the 96-well ELISA plate and incubated at room temperature for $2.5 \mathrm{hr}$ with gentle shaking. Next, the solutions were discarded and each well was rinsed 4 times with prepared 1x wash buffer according to instructions. Following the rinse step, $100 \mu \mathrm{L}$ of biotinylated antibody was added to each well and incubated for $1 \mathrm{hr}$ with gentle shaking. Next, solutions were discarded, the rinse step was repeated, followed by the addition of $100 \mu \mathrm{L}$ streptavidin solution to each well and incubated for 45 min with gentle shaking. Then, solutions were discarded, the rinse step was repeated and $100 \mu \mathrm{L}$ of TMB one-step substrate reagent was added to each well. Plates were incubated in the dark for an additional 30 min with gentle shaking, followed by the addition of $50 \mu \mathrm{L}$ stop solution to each well. Plate absorbance was read immediately at $450 \mathrm{~nm}$. Standard curves were prepared in duplicate for each ELISA 
plate. The concentration of cytokine(s) in each supernatant sample was then calculated based on the sample absorbance at $450 \mathrm{~nm}$ and the slope of the standard curve according to instructions.

Statistical analyses: All experiments were performed in triplicate and data are presented as mean \pm standard deviation. Statistical analysis was carried out by 2 -way analysis of variance (ANOVA) using GraphPad Prism software (La Jolla, CA). P values $<0.05$ were considered significant.

\section{RESULTS}

Nano-WC-Co Characterization: Nano-WC-Co particles were prepared and characterized as previously described [222]. Briefly, nano-WC-Co particles averaged $98 \mathrm{~nm}$ in diameter in suspension determined by dynamic light scattering and transmission electron microscopy. Compositional analysis by energy-dispersive x-ray (EDX) determined that nano-WC-Co contained $72.13 \%$ tungsten, $13.42 \%$ cobalt, $7.63 \%$ carbon and $6.81 \%$ oxygen.

Co-Culture Viability: Macrophages (THP-1), lung epithelial cells (BEAS-2B) and a 3:1 coculture of BEAS-2B and THP-1 cells were exposed to nano-WC-Co at concentrations of 1, 10, 100 and $1000 \mu \mathrm{g} / \mathrm{mL}$ for durations of 2, 6, 12, 24 and $48 \mathrm{hr}$. In macrophage mono-culture (THP1), nano-WC-Co exposure did not induce significant changes in cell viability (compared to control) at $1 \mu \mathrm{g} / \mathrm{mL}$ but did induce a significant reduction in cell viability at $10 \mu \mathrm{g} / \mathrm{mL}$ after 48 hr, at $100 \mu \mathrm{g} / \mathrm{mL}$ after $6,12,24$ and $48 \mathrm{hr}$ and at $1000 \mu \mathrm{g} / \mathrm{mL}$ after 2, 6, 12, 24 and $48 \mathrm{hr}$ of exposure (Figure 1). Consistent with our previous report [222], nano-WC-Co exposure caused a significant reduction in cell viability in lung epithelial cells (BEAS-2B) at $1 \mu \mathrm{g} / \mathrm{mL}$ after 24 and $48 \mathrm{hr}$ and at $\geq 10 \mu \mathrm{g} / \mathrm{mL}$ after 2, 6, 12, 24 and $48 \mathrm{hr}$ of exposure (Figure 1). The viability in 
THP-1 cells was significantly higher compared to BEAS-2B mono-culture at $1 \mu \mathrm{g} / \mathrm{mL}$ after 2, 6 and $48 \mathrm{hr}$ and at 10, 100 and $1000 \mu \mathrm{g} / \mathrm{mL}$ after 2, 6, 12, 24 and $48 \mathrm{hr}$ nano-WC-Co exposure (Figure 1).

In the co-culture of BEAS-2B and THP-1 cells, nano-WC-Co exposure did not lead to significant changes in cell viability at $1 \mu \mathrm{g} / \mathrm{mL}$ but caused a significant reduction in cell viability (compared to control) at $10 \mu \mathrm{g} / \mathrm{mL}$ after 24 and $48 \mathrm{hr}$ and at 100 and $1000 \mu \mathrm{g} / \mathrm{mL}$ after 2, 6, 12, 24 and $48 \mathrm{hr}$ of exposure (Figure 1). Compared to BEAS-2B mono-culture, an increased cell viability was observed in the co-culture model at $1 \mu \mathrm{g} / \mathrm{mL}$ after 24 and $48 \mathrm{hr}$, at $10 \mu \mathrm{g} / \mathrm{mL}$ after 2, 6, 12, 24 and $48 \mathrm{hr}$, at $100 \mu \mathrm{g} / \mathrm{mL}$ after 2, 24 and $48 \mathrm{hr}$ and at $1000 \mu \mathrm{g} / \mathrm{mL}$ after 2 and $6 \mathrm{hr}$ of exposure (Figure 1).
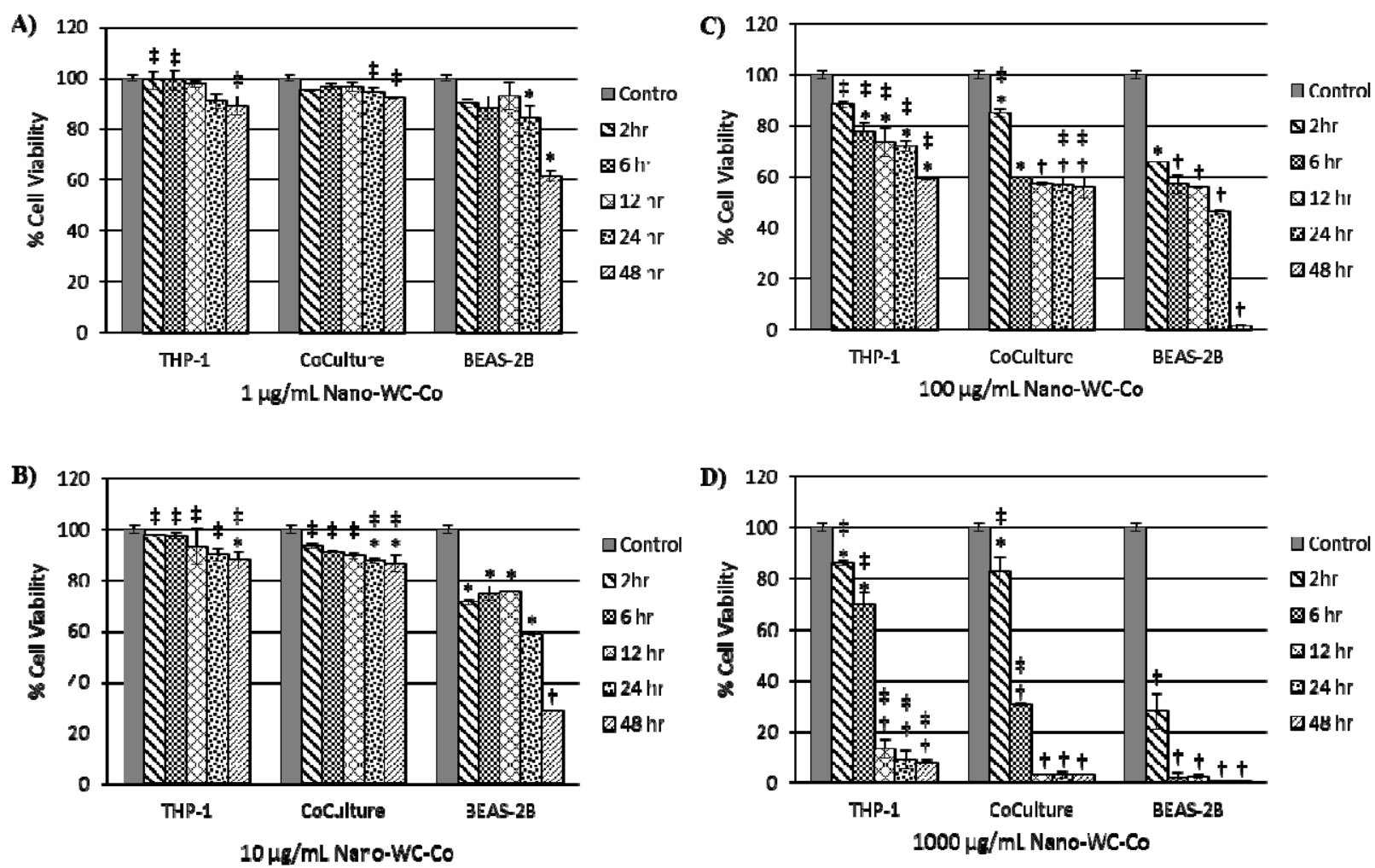

Figure 3.1. Cell viability after exposure to A) $1 \mu \mathrm{g} / \mathrm{mL}$, B) $10 \mu \mathrm{g} / \mathrm{mL}$, C) $100 \mu \mathrm{g} / \mathrm{mL}$ and D) $1000 \mu \mathrm{g} / \mathrm{mL}$ nano-WC-Co particles in macrophages (THP-1), lung epithelial cells (BEAS-2B) and 3:1 co-culture 
(BEAS-2B:THP-1). $(* \mathrm{P}<0.05,+\mathrm{P}<0.01$ compared to control; $¥ \mathrm{P}<0.05$ compared to BEAS-2B monoculture)

Macrophage Polarization: Macrophage polarization toward the M1 and M2 phenotypes was examined after exposure to LPS (M1 positive control), IL-4 (M2 positive control) and 0, 1, 10 or $100 \mu \mathrm{g} / \mathrm{mL}$ nano-WC-Co for 1, 2 and 5 days. Cells staining positive for CD40-APC were considered M1-type macrophages and cells staining positive for CD206-FITC were considered M2-type macrophages. A summary of M1 and M2 flow cytometry staining is presented graphically in Figure 2. Representative dot plots depicting M1/M2 macrophage staining after exposure to nano-WC-Co for 1, 2 and 5 days are shown in Figure $3(1 \mu \mathrm{g} / \mathrm{mL})$, Figure 4 (10 $\mu \mathrm{g} / \mathrm{mL})$ and Figure $5(100 \mu \mathrm{g} / \mathrm{mL})$. Compared to the control group $(0 \mu \mathrm{g} / \mathrm{mL}$ nano-WC-Co $)$, for the staining control samples used to set the instrument gating parameters, a significant increase in CD40+ stained cells was observed following LPS exposure for 1, 2 and 5 days; IL-4 exposure caused a significant increase in CD206+ cells after 2 and 5 day exposure (Figure S2).

In general, CD40+ staining was dominant in all the samples at the exposure periods studied (Figure 2). Compared to the control group ( $0 \mu \mathrm{g} / \mathrm{mL}$ WC-Co), cells exposed to 1 and 10 $\mu \mathrm{g} / \mathrm{mL}$ nano-WC-Co had significantly higher CD40+ staining after 5 days of exposure. Exposure to $10 \mu \mathrm{g} / \mathrm{mL}$ nano-WC-Co also caused a significant increase in CD40+ cells after 1 day and cells exposed to $100 \mu \mathrm{g} / \mathrm{mL}$ demonstrated significantly lower numbers of CD40+ cells after 2 and 5 days of exposure (Figure 2A). Further, cells exposed to 1, 10 and $100 \mu \mathrm{g} / \mathrm{mL}$ nano-WC-Co had significantly less CD206+ cells after 5 days of exposure compared to the control group $(0 \mu \mathrm{g} / \mathrm{mL}$ WC-Co) (Figure 2B). With increasing nano-WC-Co exposure time from day 1 to day 2 and day 5, an increase in the ratio of M2/M1 was found; the ratio of M2/M1 was significantly higher after 5 days compared to 1 day for 1, 10 and $100100 \mu \mathrm{g} / \mathrm{mL}$ nano-WC-Co (Figure 2C). 
A)

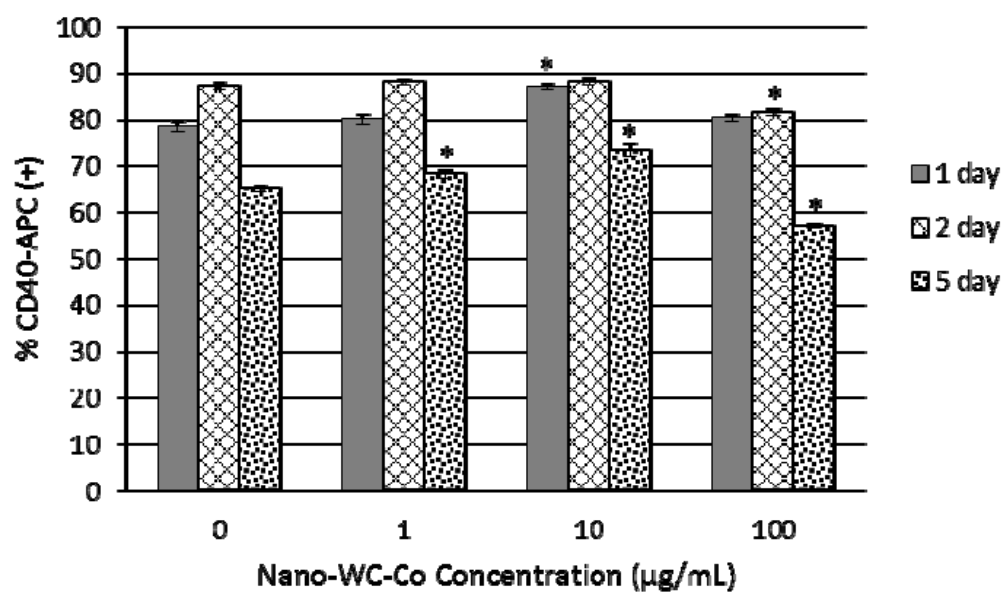

B)
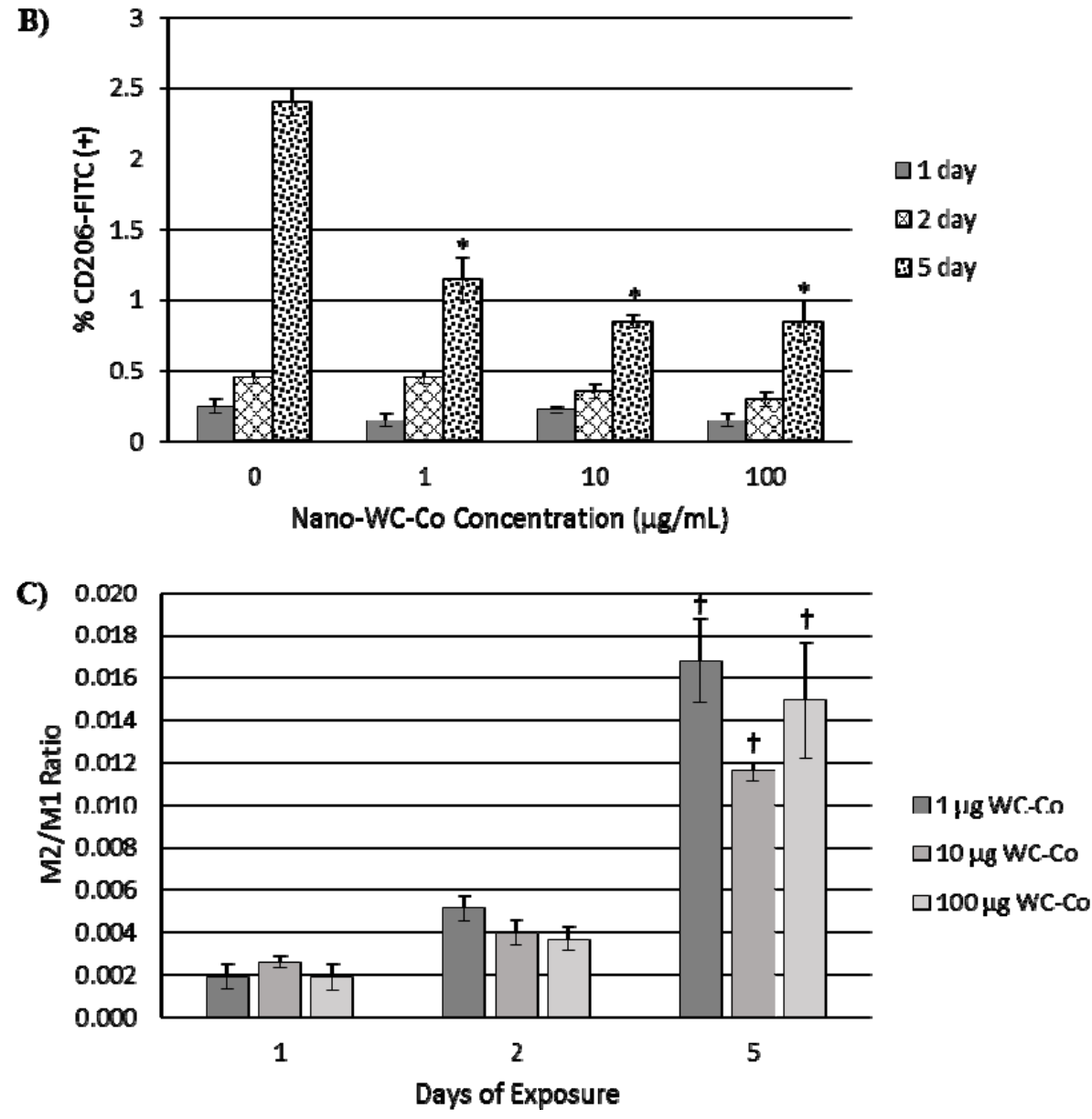

Figure 3.2. Summary of macrophage flow cytometry staining as total percentage of A) CD40+/M1, B) CD206+/M2 and C) M2/M1 ratio after exposure to nano-WC-Co particles for 1, 2 and 5 days. $(* \mathrm{P}<0.05$ compared to $0 \mu \mathrm{g} / \mathrm{mL}$ (M0) control $(2 \mathrm{~A}, \mathrm{~B}$ ) and $\uparrow \mathrm{P}<0.01$ compared to 1 day (2C)) 
A)

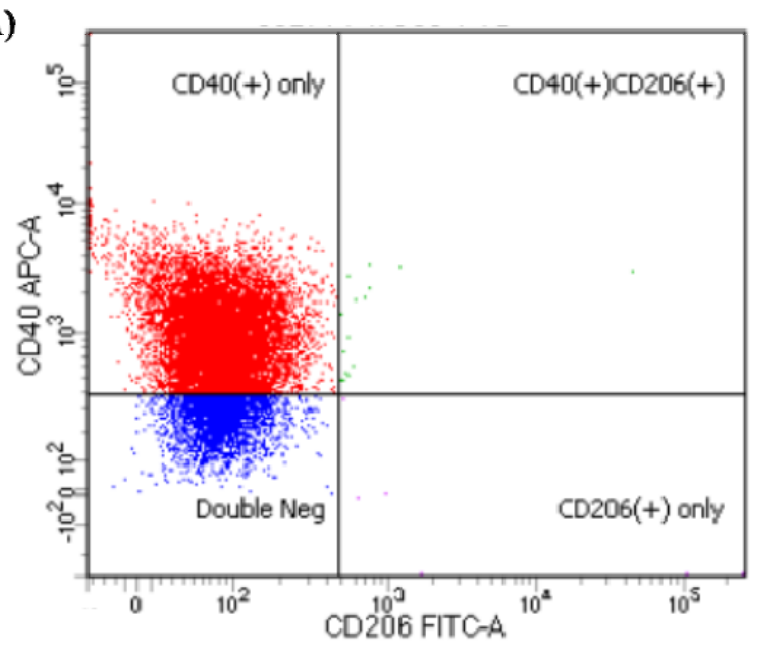

C)

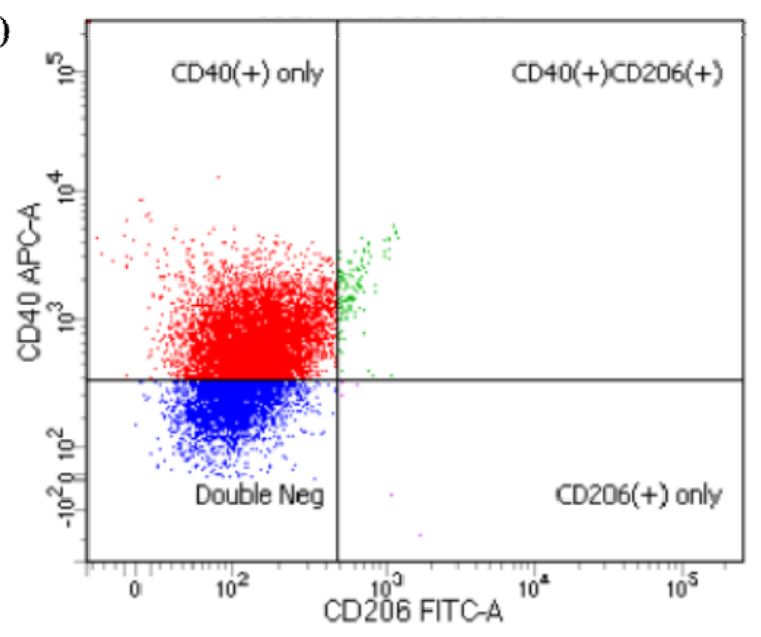

B)

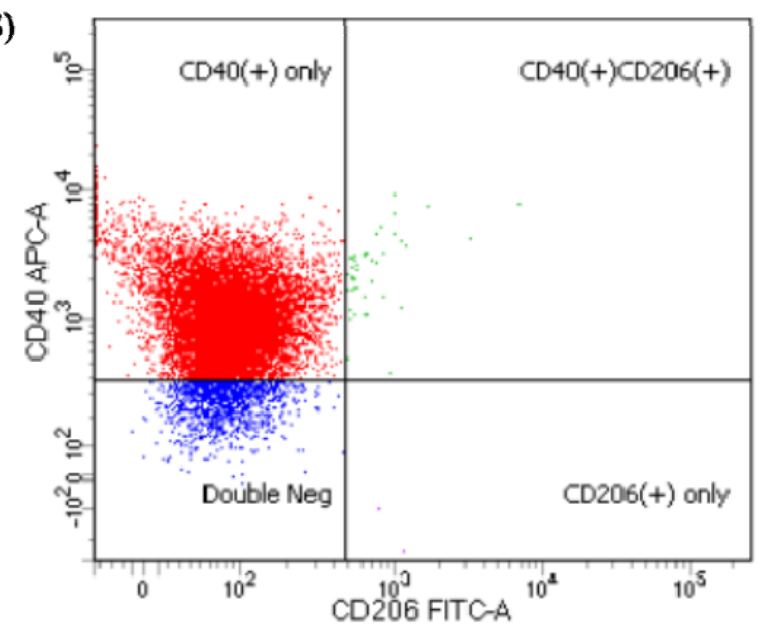

Figure 3.3. Representative flow cytometry dot plots depicting macrophage staining after exposure to 1 $\mu \mathrm{g} / \mathrm{mL}$ nano-WC-Co particles for A) 1 day, B) 2 days and C) 5 days. CD40-APC as surface marker of M1-type macrophages and CD206-FITC as surface marker of M2-type macrophages. 
A)

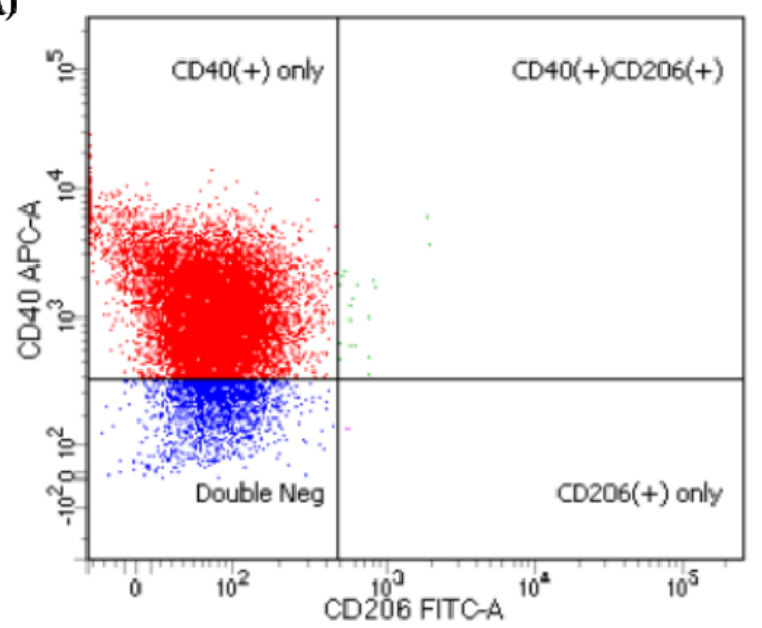

C)

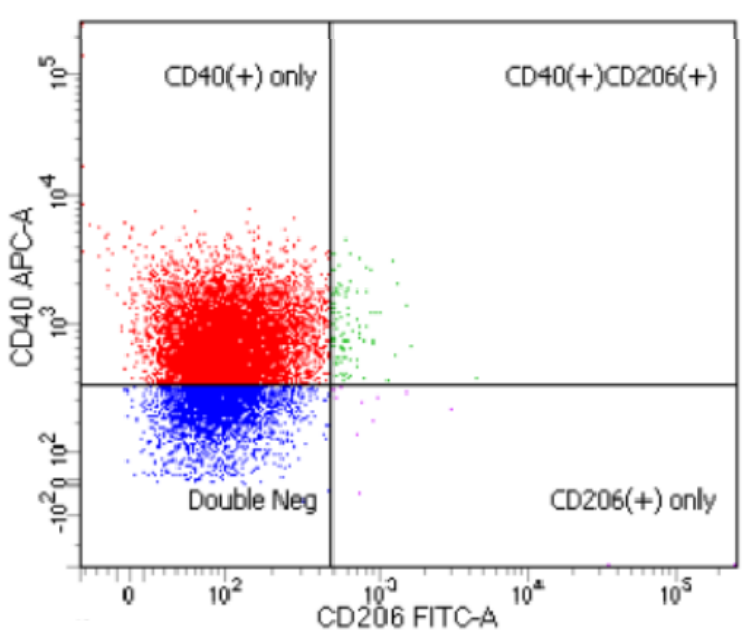

B)

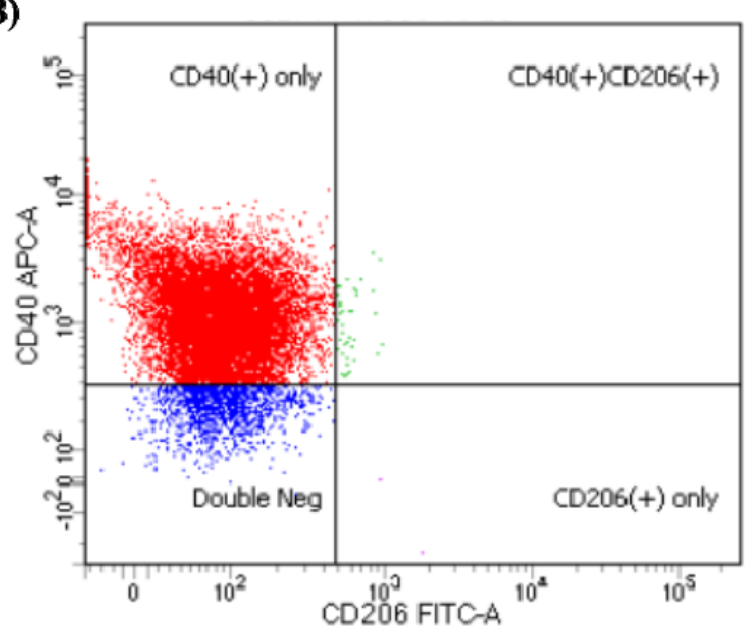

Figure 3.4. Representative flow cytometry dot plots depicting macrophage staining after exposure to 10 $\mu \mathrm{g} / \mathrm{mL}$ nano-WC-Co particles for A) 1 day, B) 2 days and C) 5 days. CD40-APC as surface marker of M1-type macrophages and CD206-FITC as surface marker of M2-type macrophages. 
A)

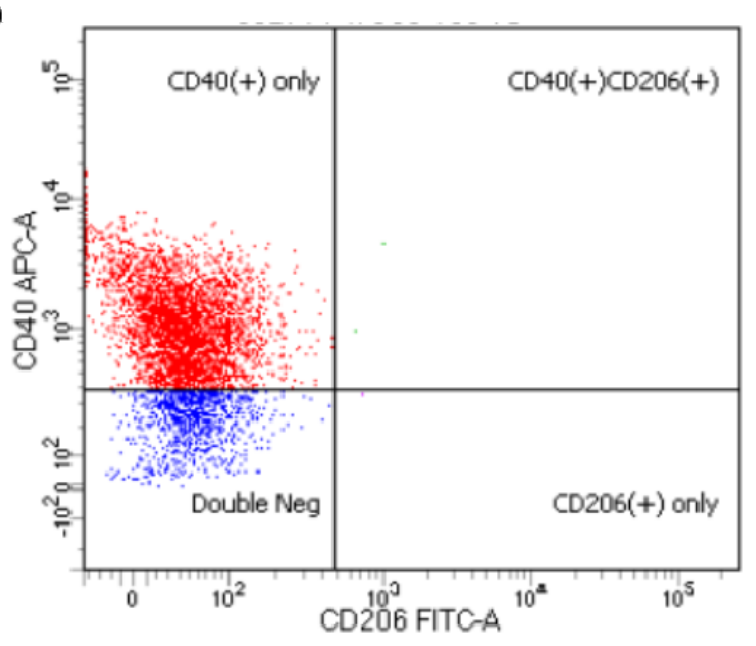

C)

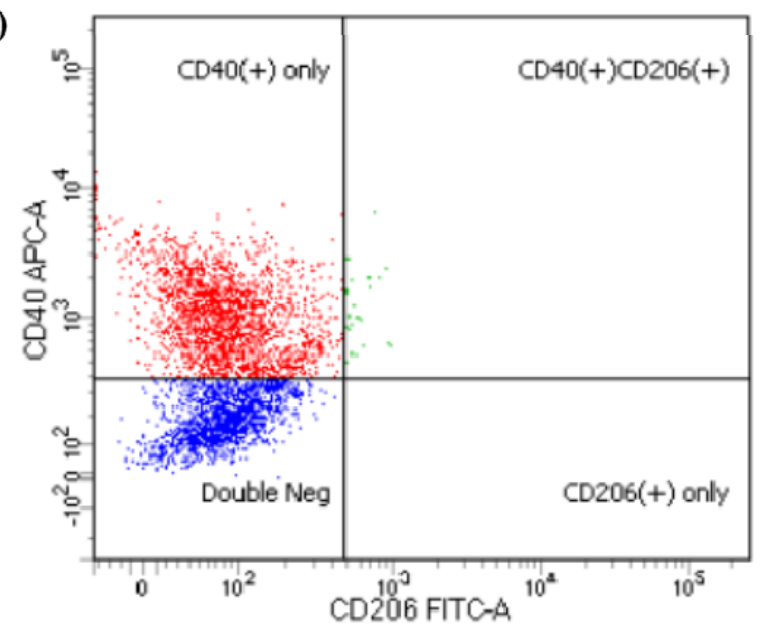

B)

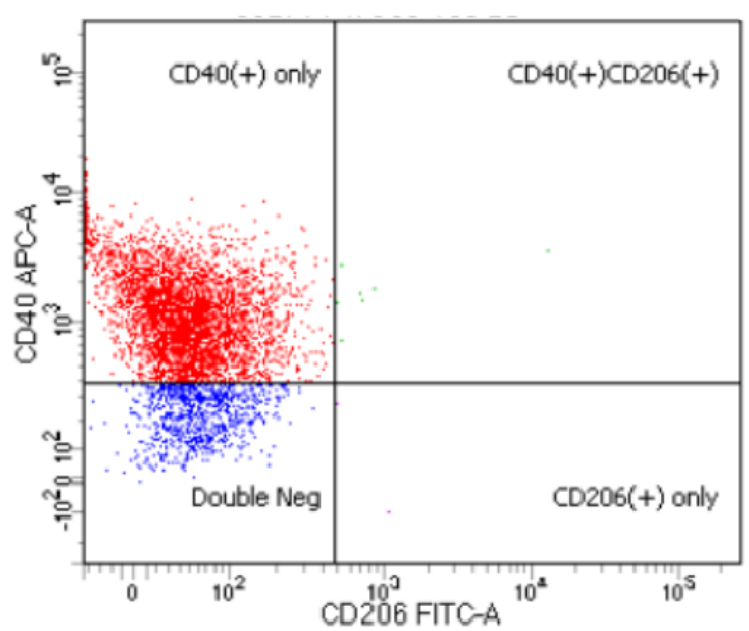

Figure 3.5. Representative flow cytometry dot plots depicting macrophage staining after exposure to 100 $\mu \mathrm{g} / \mathrm{mL}$ nano-WC-Co particles for A) 1 day, B) 2 days and C) 5 days. CD40-APC as surface marker of M1-type macrophages and CD206-FITC as surface marker of M2-type macrophages. 
Inflammatory Cytokine Secretion: The levels of inflammatory cytokines were quantified in the cell culture supernatant via ELISA after 6,12, 24 and $48 \mathrm{hr}$ of exposure to 0,1,10 or $100 \mu \mathrm{g} / \mathrm{mL}$ nano-WC-Co (Figure 6) and either LPS (M1 stimulus) or IL-4 (M2 stimulus) (Figure S3). Nano-WC-Co treatment caused varying effects on TNF $\alpha$ secretion (Figure 6A); $1 \mu \mathrm{g} / \mathrm{mL}$ nanoWC-Co caused a significant increase in TNF $\alpha$ after $6 \mathrm{hr}$ of exposure, compared to control (0 $\mu \mathrm{g} / \mathrm{mL}$ ), but the levels were significantly lower after 12, 24 and $48 \mathrm{hr}$ of exposure. A decrease in $\mathrm{TNF} \alpha$, compared to control $(0 \mu \mathrm{g} / \mathrm{mL})$, was also observed at $10 \mu \mathrm{g} / \mathrm{mL}$ after 24 and $48 \mathrm{hr}$ and at $100 \mu \mathrm{g} / \mathrm{mL}$ after 12, 24 and $48 \mathrm{hr}$ exposure to nano-WC-Co (Figure 6A).

In the IL-1 $\beta$ assay (Figure 6B), $1 \mu \mathrm{g} / \mathrm{mL}$ nano-WC-Co treatment caused a significant increase in IL-1 $\beta$ levels, compared to control $(0 \mu \mathrm{g} / \mathrm{mL})$, after 12 and $24 \mathrm{hr}$ of exposure. In the 10 $\mu \mathrm{g} / \mathrm{mL}$ nano-WC-Co group, a significant increase in IL-1 $\beta$ was found at exposures of 12, 24 and $48 \mathrm{hr}$. Compared to control $(0 \mu \mathrm{g} / \mathrm{mL}), 100 \mu \mathrm{g} / \mathrm{mL}$ nano-WC-Co exposure led to a significant decrease in IL-1 $\beta$ after 6 and $12 \mathrm{hr}$ and a significant increase after $24 \mathrm{hr}$ followed by a significant decrease after $48 \mathrm{hr}$ of exposure (Figure 6B).

For IL-12 (Figure 6C), exposure to $1 \mu \mathrm{g} / \mathrm{mL}$ nano-WC-Co caused a significant increase compared to control $(0 \mu \mathrm{g} / \mathrm{mL})$ after $12 \mathrm{hr}$ exposure. $10 \mu \mathrm{g} / \mathrm{mL}$ nano-WC-Co caused a significant increase in IL-12 after 12 and $48 \mathrm{hr}$ of exposure and $100 \mu \mathrm{g} / \mathrm{mL}$ nano-WC-Co also caused a significant increase in IL-12 (compared to control) after 6,12 and $48 \mathrm{hr}$ of exposure (Figure 6C). 


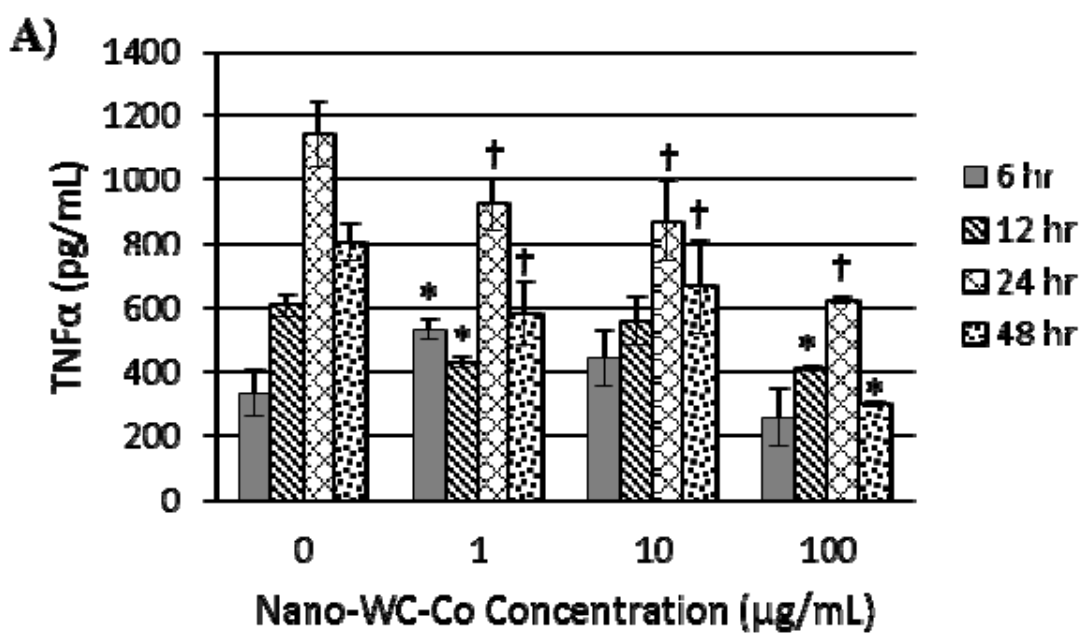

B)

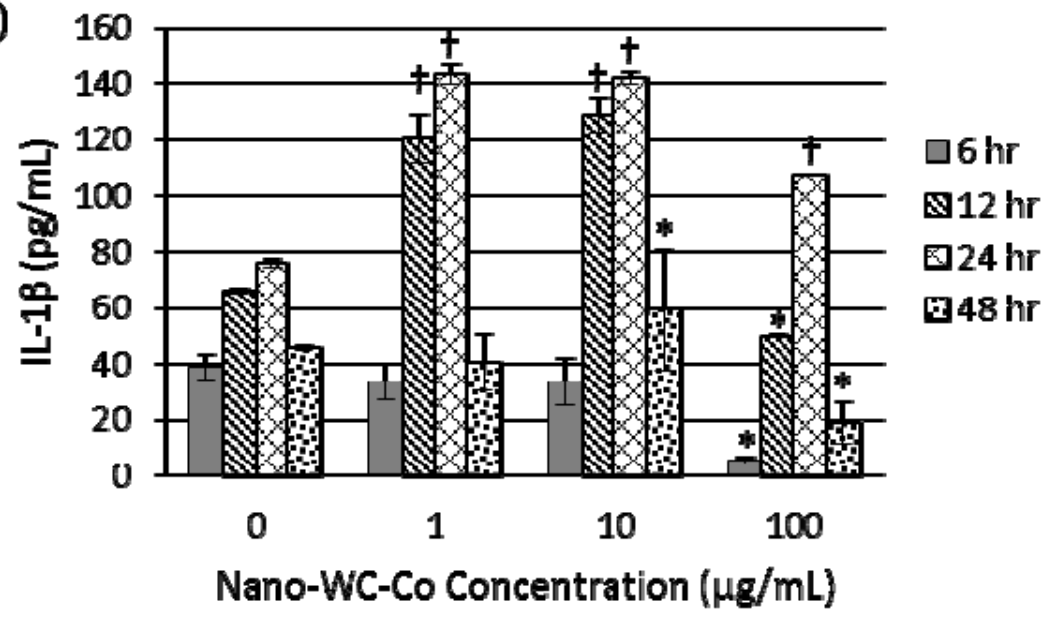

C)

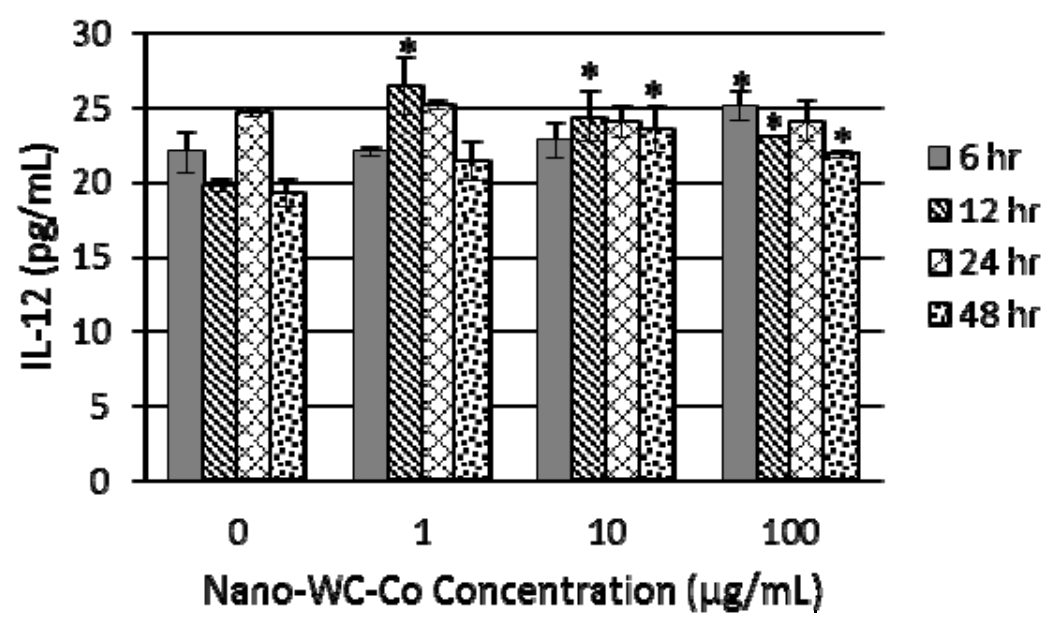

Figure 3.6. Secretion of pro-inflammatory cytokines A) TNF $\alpha, B$ ) IL- $1 \beta$ and C) IL-12 in cell culture supernatant as markers of inflammation following nano-WC-Co exposure. ( ${ }^{*} \mathrm{P}<0.05,+\mathrm{P}<0.01$ compared to $0 \mu \mathrm{g} / \mathrm{mL}$ (M0) control) 


\section{DISCUSSION}

Due to the increased use of nanoparticles (NP) in consumer and industrial applications [3], there is a critical need to clearly define the toxic and inflammatory effects of NP which occur after exposure. We recently reported that commercially prepared nano-WC-Co particles induced a time- and dose-dependent toxicity in human lung epithelial cells (BEAS-2B) and were capable of being internalized, inducing oxidative stress and stimulating apoptotic cell death in vitro [222]. Since macrophages play a critical role in promoting natural pulmonary particle clearance mechanisms, an important aspect of the current study was to define the toxic effects of nanoWC-Co particle exposure on macrophages in both mono- and co-culture settings. To test the effects of nano-WC-Co particle exposure on macrophage-mediated inflammation and M1/M2 polarization, we selected monocyte-derived THP-1 cells as our macrophage model due to their prevalence in the literature and the ease with which THP-1 cells are differentiated toward a macrophage (M0) phenotype with PMA $[215,217,224,225]$. Here, a 3:1 co-culture ratio of BEAS-2B to THP-1 M0 was selected to represent the dynamic tissue environment within the lung during a particle inhalation scenario [226, 227]; the viability was compared between THP-1 and BEAS-2B mono-cultures and the 3:1 co-culture system.

Due to the inherent phagocytic nature of macrophages, we hypothesized that the presence of THP-1 M0 in the co-culture model would offer a "protective effect" against nano-WC-Co toxicity; therefore, increased viability would be observed in the co-culture system compared to BEAS-2B cells alone. In this case, the results of our cell viability study (Figure 1) are consistent with our hypothesis and we believe that macrophage engulfment of nano-WC-Co isolated the particles and prevented direct contact with the BEAS-2B cells, effectively attenuating nano-WCCo toxicity to the extent reported previously in BEAS-2B cells [222]. In fact, the toxicity of 
nano-WC-Co was found to be cell dependent and significantly less toxicity was observed in macrophages compared to BEAS-2B cells (Figure 2). While the $1000 \mu \mathrm{g} / \mathrm{mL}$ dose is very high, we believe that it is relevant because the resulting lifetime accumulation of nano-WC-Co particles in the lung from occupational settings could be substantial. This idea is supported by histological findings in HMLD patients, where large deposits of WC-Co are often visible in lung specimens $[113,114,123,124]$.

Macrophage polarization following exposure to other metal NPs has been reported elsewhere [228], so we explored the effects of nano-WC-Co exposure on macrophage polarization toward the M1 or M2 phenotype using flow cytometry by staining for two wellknown macrophage cell membrane markers: CD40 as an M1 surface marker and for CD206 (mannose receptor), as an M2 macrophage surface marker [214, 215, 217]. Overall, high levels of CD40+/M1 staining were observed in nano-WC-Co particle exposed groups (Figure 2A) and in the LPS-stimulated M1 positive control group (Figure S2A). The prevalence of CD40+/M1 staining was much higher in nano-WC-Co exposed groups than CD206+/M2 staining; while a slight increase in CD206+/M2 staining was observed at 5 days compared to 1 and 2 days after nano-WC-Co exposure, overall, the levels of CD206+/M2 macrophages were significantly lower than the control $(0 \mu \mathrm{g} / \mathrm{mL})$ group (Figure $2 B)$. It seems that the ratio of M2/M1 increased with increasing exposure time (Figure 2C).

Therefore, at least in terms of surface marker expression, nano-WC-Co particles appear to induce strong CD40 expression, typical of an M1 classically activated phenotype, rather than increased levels of CD206 expression associated with M2 alternatively activated macrophages. However, there are a few potential limitations which may have contributed to the lack of CD206+ macrophages in our cell populations. Upon stimulation with PMA, THP-1 macrophages 
became extremely adherent to the culture dish and were difficult to detach for membrane surface staining, so it is possible that CD206 membrane receptors may have been damaged during the detachment process, causing low numbers of CD206+ cells overall. Additionally, in our control $(0 \mu \mathrm{g} / \mathrm{mL})$ group, receiving PMA treatment only, a high level of CD40+/M1 staining was observed, which may indicate a predisposition toward the M1 surface markers in our control cells.

Next, we examined the secretion of pro-inflammatory cytokines including TNF $\alpha$, IL-1 $\beta$ and IL-12 over an exposure period ranging from 6 to $48 \mathrm{hr}$ to determine the effects of nano-WCCo exposure on cytokine expression over time (Figure 6). Given the strong CD40+/M1-type inflammatory macrophage surface marker expression in our flow cytometry assay, we expected to see complimentary induction of pro-inflammatory cytokines in our ELISA assay. Typically, $\mathrm{TNF} \alpha$ is secreted by activated macrophages and plays a primary role in the inflammatory immune response associated with infections due to bacterial or viral pathogens, such as promoting neutrophil chemotaxis and inducing acute phase proteins (C-reactive protein) [229]. A mixed TNF $\alpha$ response was observed in nano-WC-Co macrophages compared to the control group, with higher levels after $6 \mathrm{hr}$ exposure to low concentration $(1 \mu \mathrm{g} / \mathrm{mL})$ but similar or lower levels of TNF $\alpha$ compared to control at 10 and $100 \mu \mathrm{g} / \mathrm{mL}$ (Figure 6A).

IL-1 $\beta$ is a potent inflammatory cytokine that plays a critical role in the immune response to infection by promoting adhesion factors on endothelial cells, which allows for migration of macrophages and neutrophils to the site of infection [230]. IL-1 $\beta$ is known to enhance systemic inflammation and mediate auto-immune disorders, such as rheumatoid arthritis [230, 231]. In contrast to TNF $\alpha$, significantly higher levels of IL-1 $\beta$, compared to control, were observed in all three nano-WC-Co treatment groups after $24 \mathrm{hr}$ of exposure and for the 1 and $10 \mu \mathrm{g} / \mathrm{mL}$ groups 
after $12 \mathrm{hr}$ (Figure 6B). Since IL-1 $\beta$ is produced largely by activated macrophages, the induction of high levels of IL-1 $\beta$ secretion may indicate a pro-inflammatory response and increased activation in macrophages exposed to nano-WC-Co particles.

IL-12 is known to induce phagocytic activation of macrophages, natural killer cells and cytotoxic T-lymphocytes as part of the innate immune response to bacterial, parasitic or intracellular infections [232-237]. IL-12 also acts as an inducer of other cytokines, such as interferon-gamma (IFN $\gamma)$. Like IL-1 $\beta$, IL-12 may also contribute to chronic inflammation in rheumatoid arthritis, psoriasis and other immune disorders [232]. In our THP-1 macrophage model, nano-WC-Co exposure also stimulated IL-12 secretion, since significantly higher IL-12 levels were found in nano-WC-Co treated cells, compared to control, after $12 \mathrm{hr}$ of exposure (Figure 6C).

Additionally, it is worth considering how the toxic effects of nano-WC-Co particles toward THP-1 macrophages (Figure 1) may have impacted the results of our inflammatory cytokine assay. In general, the $1 \mu \mathrm{g} / \mathrm{mL}$ nano-WC-Co dose was non-toxic up to $48 \mathrm{hr}$ in our viability assay, so higher observed levels of TNF $\alpha$, IL-1 $\beta$ and IL-12 at this concentration are likely to reflect increased inflammatory cytokine secretion overall in nano-WC-Co exposed macrophage populations. In contrast, significant toxicity was observed after $48 \mathrm{hr}$ exposure to 10 $\mu \mathrm{g} / \mathrm{mL}$ nano-WC-Co, so the lower levels of secreted inflammatory cytokines at this concentration seem consistent with increased nano-WC-Co toxicity at this time point. $100 \mu \mathrm{g} / \mathrm{mL}$ nano-WC-Co was toxic toward THP-1 macrophages at $6 \mathrm{hr}$ and beyond, so the secretion of increased levels of IL-12 (compared to control) at this concentration are especially significant, indicating that the remaining live macrophages $(<80 \%$ compared to control $)$ are stimulated to undergo a very strong IL-12 mediated inflammatory response. Taken together, these results are 
consistent with our hypothesis and demonstrate that nano-WC-Co particles are capable of inducing a pro-inflammatory response in macrophages marked by high levels of IL-1 $\beta$ and IL-12 secretion and high expression of CD40 M1 surface markers.

\section{CONCLUSION}

This study examined the toxicity of nano-WC-Co in a co-culture of macrophages and lung epithelial cells and explored the effects of nano-WC-Co exposure on M1/M2 polarization and inflammatory cytokine secretion in THP-1 macrophages. The presence of THP-1 cells in the co-culture model was found to reduce the toxicity of nano-WC-Co compared to a mono-culture of BEAS-2B, which suggested a protective role of macrophages against nano-WC-Co particle toxicity. In macrophages, nano-WC-Co exposure induced increased secretion of IL-1 $\beta$ and IL12, which are indicators of a pro-inflammatory response. The M1/M2 polarization assay indicated a strong M1 phenotype (CD40+) in nano-WC-Co treated macrophages after 1, 2 and 5 days of exposure. Overall, the outcomes of our cytokine ELISA and flow cytometry assay indicated that exposure to nano-WC-Co particles in vitro stimulates a pro-inflammatory cytokine response and polarization toward the M1 phenotype in macrophages.

\section{ACKNOWLEDGEMENT}

We acknowledge financial support from the AO Foundation (Project S-13-15L). The authors thank Yon Rojanasakul for providing the BEAS-2B cells and acknowledge the WVU Flow Cytometry Core facility, operated by Kathy Brundage, which is supported by the National Institutes of Health equipment grant number S10OD016165 and the Institutional Development 
Award (IDeA) from the National Institute of General Medical Sciences of the National Institutes of Health under grant numbers P30GM103488 (CoBRE) and P20GM103434 (INBRE).

REFERENCES (See Chapter 7) 


\section{SUPPLEMENTARY MATERIAL}

FIGURES

A)

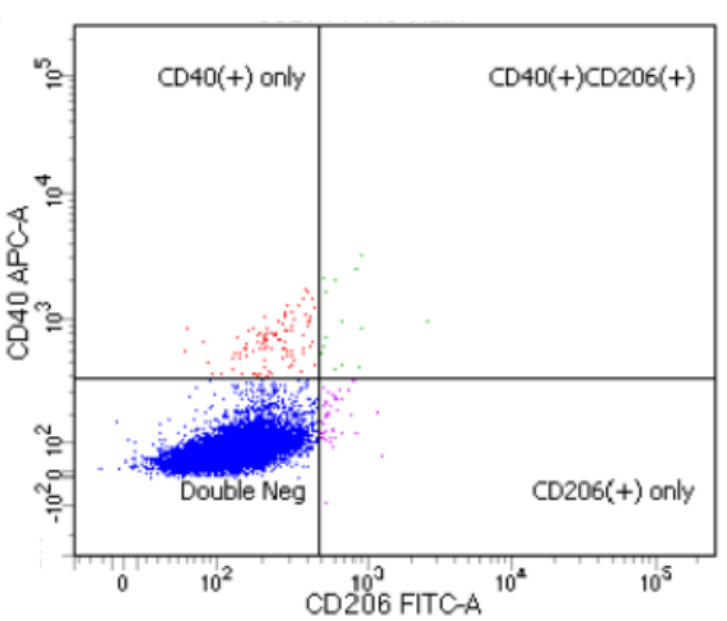

C)

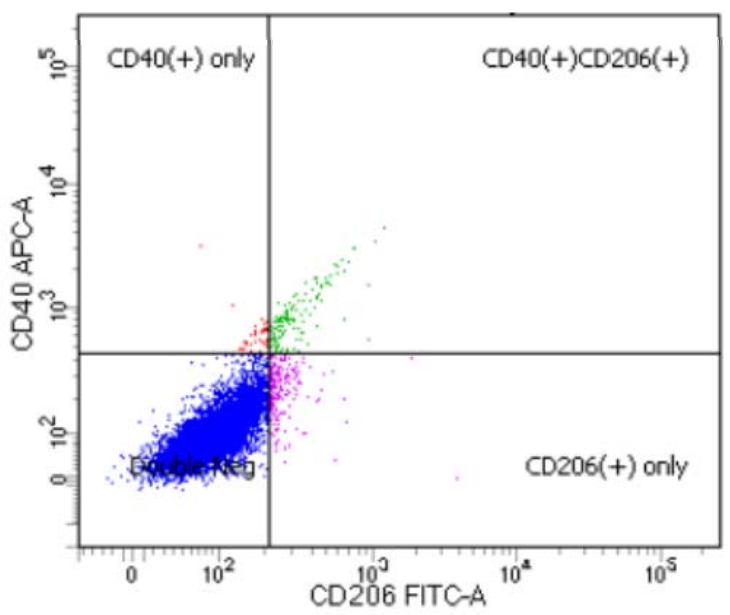

B)

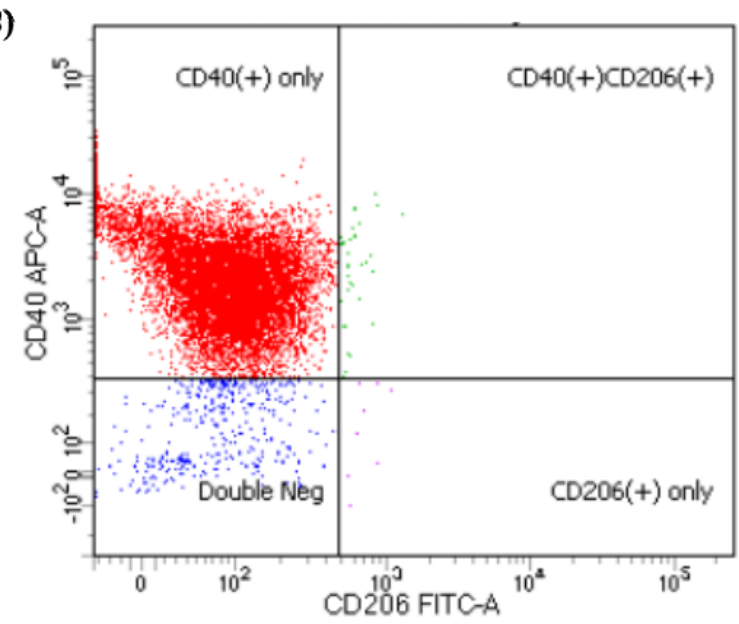

D)

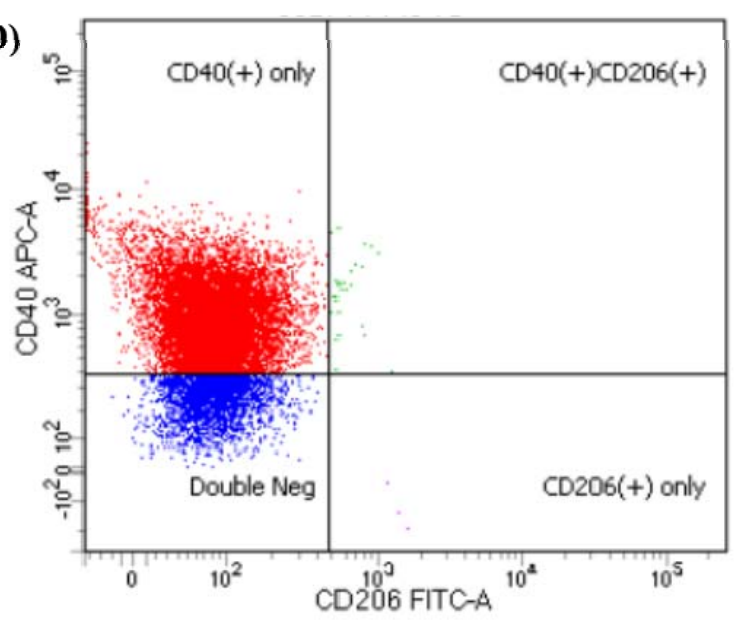

Figure S1. Representative flow cytometry dot plots depicting macrophage staining controls used to set flow cytometer experimental parameters: A) no stain/M0 cells only, B) M1 positive control (LPS) stained with CD40-APC only, C) M2 positive control (IL-4) stained with CD206-FITC only and D) M0 negative control cells stained with both CD40-APC and CD206-FITC. CD40-APC as a surface marker of M1-type macrophages and CD206-FITC as a surface marker of M2-type macrophages. 

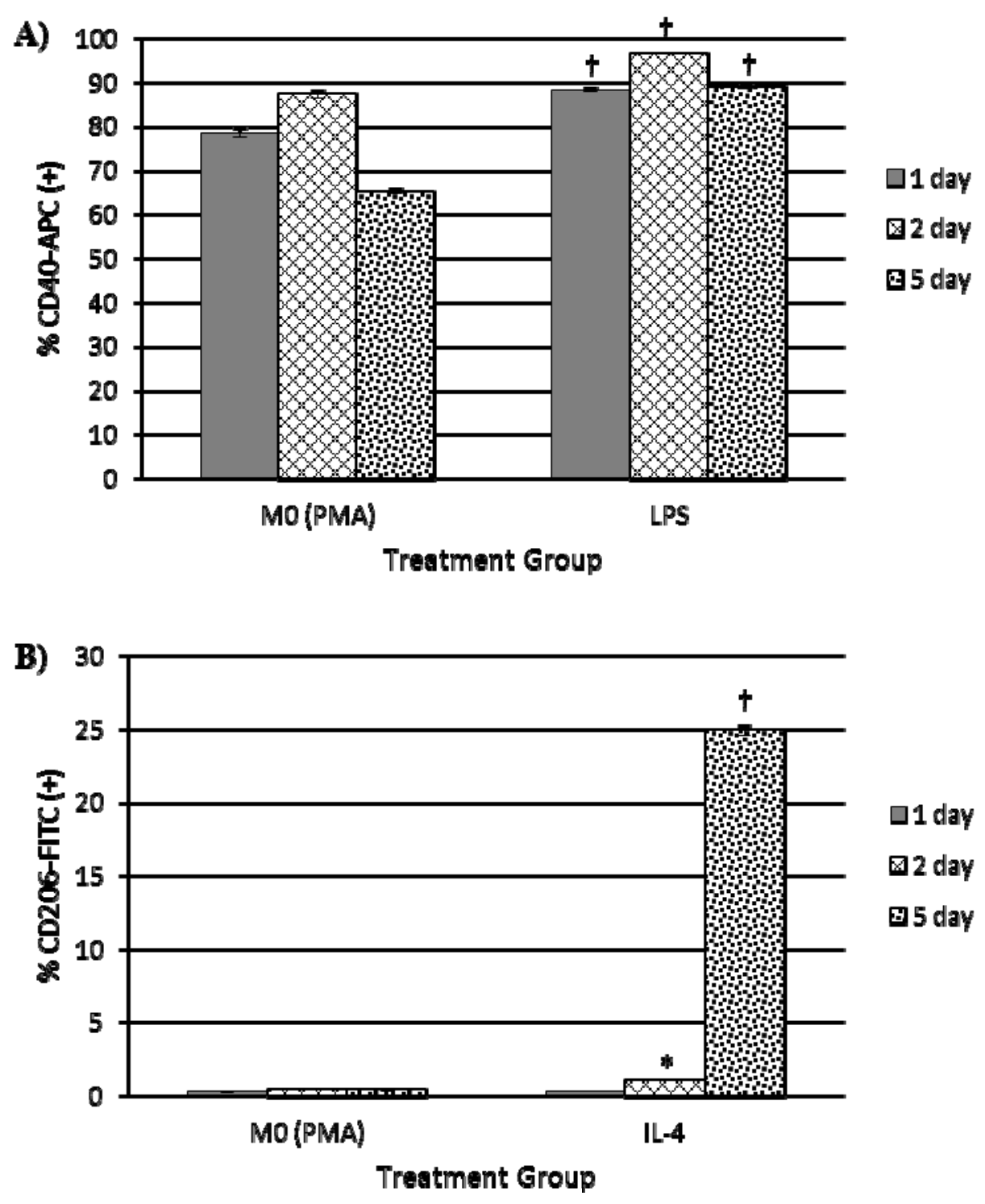

Figure S2. Summary of A) CD40+ M1-type and B) CD206+ M2-type macrophage flow cytometry staining controls. M0 cells received PMA treatment only, M1 positive control received $100 \mathrm{ng} / \mathrm{mL}$ LPS and $\mathrm{M} 2$ positive control received $20 \mathrm{ng} / \mathrm{mL}$ IL-4 for 1,2 or 5 days. $(* \mathrm{P}<0.05,+\mathrm{P}<0.01$ compared M0 control) 

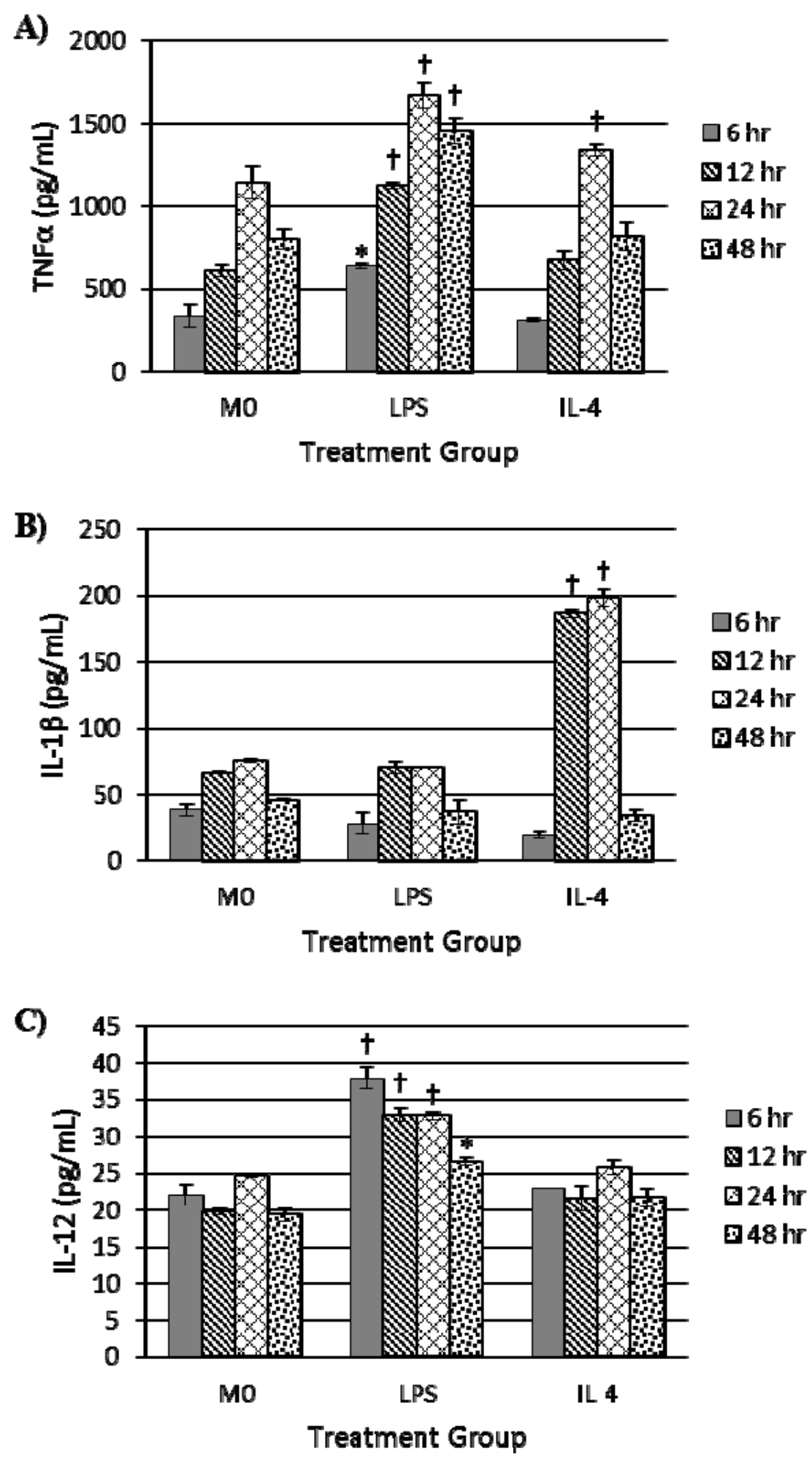

Figure S3. Levels of A) TNF $\alpha$, B) IL-1 $\beta$ and C) IL-12 inflammatory markers in cell culture supernatant for the M0 (negative control), LPS $(100 \mathrm{ng} / \mathrm{mL})$ and IL-4 $(20 \mathrm{ng} / \mathrm{mL})$ control groups. $(* \mathrm{P}<0.05,+\mathrm{P}<$ 0.01 compared to M0 control) 

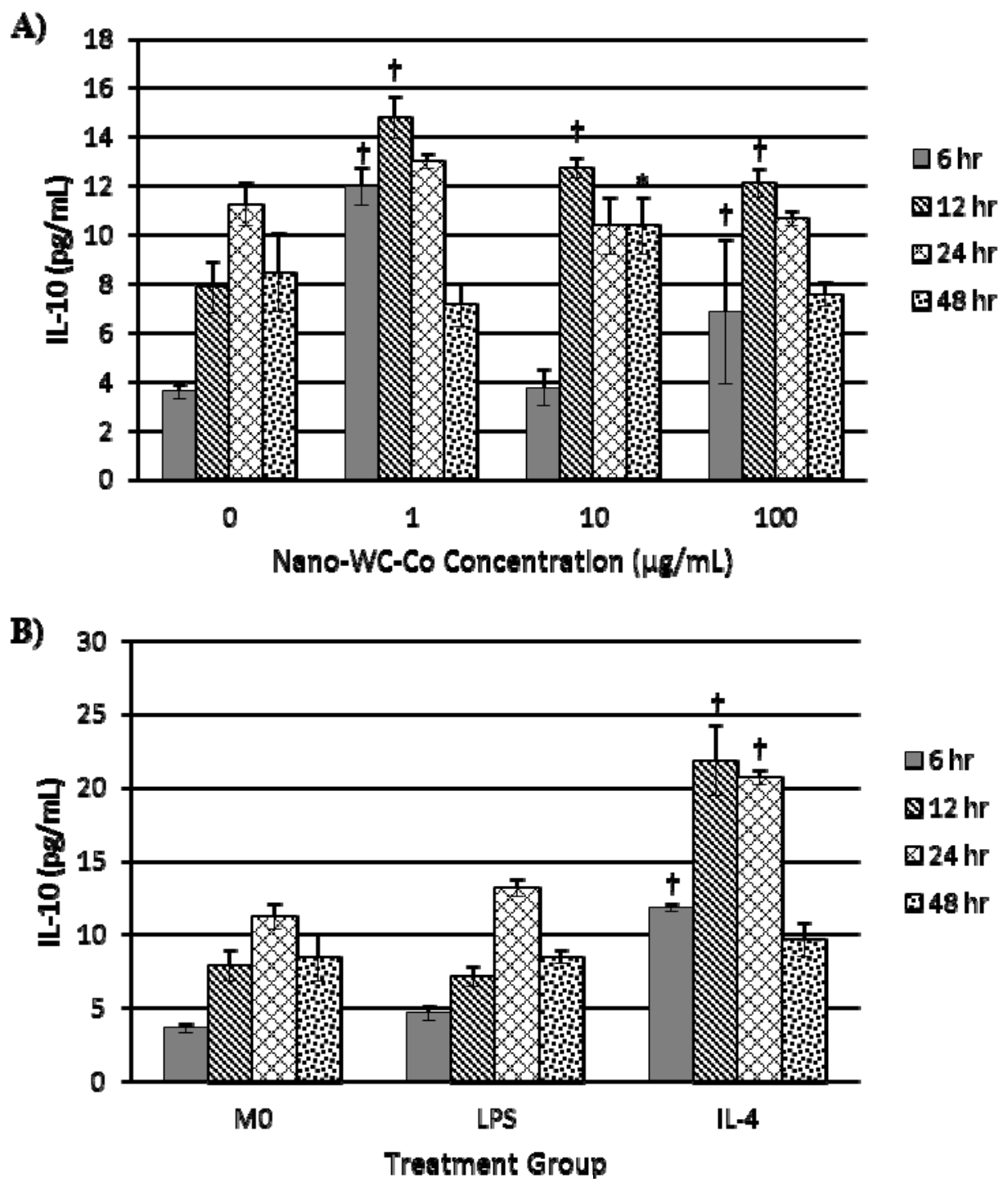

Figure S4. Levels of IL-10 in cell culture supernatants following A) nano-WC-Co exposure and B) M0 (negative control), LPS $(100 \mathrm{ng} / \mathrm{mL})$ and IL-4 $(20 \mathrm{ng} / \mathrm{mL})$ control treatments. $\left({ }^{*} \mathrm{P}<0.05, \uparrow \mathrm{P}<0.01\right.$ compared to M0 control) 


\section{CHAPTER 4:}

\section{Acute Inflammatory Responses of Nanoparticles in an Intra-tracheal Instillation Rat Model}

First-Author research manuscript published in fulfillment of

$$
\text { Specific Aim \#3 }
$$

Armstead, A.L; Minarchick, V.C; Porter, D.W; Nurkiewicz, T.R; Li, B. 2014. Acute inflammatory responses of nanoparticles in an intra-tracheal instillation rat model. PLoS One (under revision) 


\section{ABSTRACT}

Exposure to hard metal tungsten carbide cobalt (WC-Co) "dusts" in enclosed industrial environments is known to contribute to the development of hard metal lung disease and an increased risk for lung cancer. Currently, the influence of local and systemic inflammation on disease progression following WC-Co exposure remains unclear. To better understand the relationship between WC-Co nanoparticle (NP) exposure and its resultant effects, the acute local pulmonary and systemic inflammatory responses caused by WC-Co NPs were explored using an intra-tracheal instillation (IT) model and compared to those of $\mathrm{CeO}_{2}$ (another occupational hazard) NP exposure. Sprague-Dawley rats were given an IT dose (0-500 $\mu$ g per rat) of WC-Co or $\mathrm{CeO}_{2}$ NPs. Following 24-hr exposure, broncho-alveolar lavage fluid and whole blood were collected and analyzed. A consistent lack of acute local pulmonary inflammation was observed in terms of the broncho-alveolar lavage fluid parameters examined (i.e. LDH, albumin, macrophage activation); however, significant acute pulmonary inflammation was observed in the $\mathrm{CeO}_{2} \mathrm{NP}$ group. The lack of acute inflammation following WC-Co NP exposure contrasts with earlier in vivo reports regarding WC-Co toxicity in rats, illuminating the critical role of NP dose and exposure time and bringing into question the potential role of impurities in particle samples. Further, we demonstrated that WC-Co NP exposure does not induce acute systemic effects since no significant increase in circulating inflammatory cytokines were observed. Taken together, the results of this in vivo study illustrate the distinct differences in acute local pulmonary and systemic inflammatory responses to NPs composed of WC-Co and $\mathrm{CeO}_{2}$; therefore, it is important that the outcomes of pulmonary exposure to one type of NPs may not be implicitly extrapolated to other types of NPs.

Keywords: nanoparticle exposure; particle inhalation; pulmonary exposure; inflammation 


\section{INTRODUCTION}

The increased use of engineered nanomaterials (ENMs) in commercial manufacturing and consumer products presents an important toxicological concern. As the ENMs are used repetitively and wear over time, nanoparticles (NPs) are generated and released into the environment, thereby creating a NP exposure hazard. Currently, there are no definitive "standards" for evaluating the toxic effects of NPs, so identifying NP exposure effects remain a challenge for researchers world-wide [32]. It is evident from the literature that the effects of NP exposure effect vary greatly, ranging from non-toxic to carcinogenic, depending upon the particle size, composition, dose, length, and route of exposure [1, 2, 31, 32, 37, 58]. The pulmonary effects of NPs are particularly important, as airborne NPs are inhaled and inhalation is the most frequent route by which workers are exposed in occupational settings $[42,176,238]$.

Recently, it has been reported that inhaled NPs are capable of depositing in the lung and causing systemic effects at sites distant from that of exposure [37, 168, 169]. Translocation of NPs across the lung and into the bloodstream may result NP deposition in other organs (liver, spleen, kidney), with subsequent organ damage or toxicity, and may cause changes in vascular function or permeability $[34,37,65,164,165,168,171,172,239,240]$. It is difficult to predict the long-term impact of these systemic effects, so the extent by which systemic effects of NP exposure may contribute to or alter specific disease states remains unknown.

As mentioned above, occupational inhalation of NPs is of particular concern; specifically, exposure to tungsten carbide cobalt (WC-Co) dusts and particles. WC-Co is a hard composite metal commonly used as a material and coating for equipment used in mining and drilling industries [70]. As these tools are used extensively in a closed environment, WC-Co dusts 
containing particles of respirable range are released, thereby creating an occupational inhalation hazard $[78,79]$. Inhalation of WC-Co containing dusts and particles is known to cause hard metal lung disease (HMLD) and a two-fold increased risk for lung cancer [73, 77, 101, 102, 177]; however, the relationship between acute WC-Co toxicity and the potential role of inflammation on HMLD progression remains unknown. The toxicity of WC-Co particles toward a number of cell types in vitro has been reported in the literature [131, 132, 134, 135, 141, 143, $144,148-150,152,153,158,222,241]$. Specifically, we recently found that WC-Co particles in the nano-size range were internalized by epithelial cells and that exposure to WC-Co NPs resulted in significant toxicity toward lung epithelial cells at concentrations as low as $10 \mu \mathrm{g} / \mathrm{mL}$ for exposure periods as short as $0.5 \mathrm{hr}$, significant toxicity at concentrations of $0.1 \mathrm{and} 1 \mu \mathrm{g} / \mathrm{mL}$ after $48 \mathrm{hr}$ exposure and that overall, WC-Co NPs caused significantly greater toxicity compared to WC-Co micro-particles [222].

Additionally, there have been several studies regarding the toxicity of WC-Co particles in vivo $[130,154-157,159-161]$. These early in vivo studies focused on the local pulmonary responses to WC-Co exposure and confirmed that the composite material of WC-Co was responsible for the observed toxic effects when compared to tungsten (W), carbide (C), or cobalt (Co) exposure alone $[154,160,161]$. The WC-Co particles used for these studies were within the 2-4 $\mu \mathrm{m}$ size range and reported toxicity following single IT exposure was marked by severe alveolitis, pulmonary edema and increased levels of lactate dehydrogenase (LDH), which were observed after $24 \mathrm{hr}$ and up to $72 \mathrm{hr}$ post-exposure [154-156]. While the findings regarding the pulmonary toxicity of WC-Co micro-particles were fairly consistent among these studies, there is a lack of information regarding the toxicity of WC-Co particles in the nano-size range in vivo. 
Given the gap in knowledge regarding nano-sized WC-Co toxicity in vivo and our recent findings demonstrating the enhanced toxicity of nano-sized WC-Co compared to micro-sized WC-Co in vitro, we conducted a pilot study to examine the acute pulmonary and systemic inflammatory effects of WC-Co NP exposure, which have not yet been reported, using an intratracheal instillation rat model and compared the outcomes with cerium dioxide $\left(\mathrm{CeO}_{2}\right) \mathrm{NPs}$. The Nurkiewicz laboratory, including Minarchick, Porter, and Nurkiewicz whom are coauthors of this study, previously reported that $\mathrm{CeO}_{2}$ NPs induced microvascular dysfunction following pulmonary exposure in vivo, characterized by impaired endothelium-dependent and endotheliumindependent dilation and speculated that such microvascular changes may likely contribute to cardiovascular dysfunction associated with particle exposure [65]. In this case, we hypothesized that WC-Co NPs would induce dose-dependent acute pulmonary inflammation, similar to $\mathrm{CeO}_{2}$ NPs $[65,170,242]$ and may cause systemic inflammation marked by increased levels of inflammatory cytokines such as tumor necrosis factor alpha (TNF- $\alpha$ ) and interleukin 6 (IL-6).

\section{MATERIALS and METHODS}

WC-Co and $\mathrm{CeO}_{2}$ NPs: Tungsten carbide cobalt (WC-Co) NPs $(80 \mathrm{~nm})$ were purchased from Inframat Advanced Materials (Manchester, $\mathrm{CT}$ ). Cerium dioxide $\left(\mathrm{CeO}_{2}\right) \mathrm{NPs}$ were synthesized and characterized as previously described [65]. The chemical composition of WC-Co NPs included 72.1 wt.\% W, 13.4 wt.\% Co, 7.6 wt.\% C, and 6.8 wt.\% O [222]. Stock solutions of WC-Co and $\mathrm{CeO}_{2} \mathrm{NPs}$ were prepared as previously reported [65]. Briefly, dry WC-Co or $\mathrm{CeO}_{2}$ NPs were weighed and added to $10 \mathrm{~mL}$ of saline (Normosol) with $10 \%$ fetal bovine serum (FBS). Previous studies showed that saline and FBS reduced particle aggregation and did not induce mechanical artifacts in terms of broncho-alveolar lavage (BAL) and systemic responses in 
rats $[33,36,65]$. The average size of $\mathrm{WC}-\mathrm{Co}$ and $\mathrm{CeO}_{2} \mathrm{NPs}$ in Normosol (isotonic saline) plus $10 \%$ FBS was determined via dynamic light scattering (DLS) using a Malvern Zetasizer version 7.01 (Malvern Instruments Ltd, Malvern, UK). The average sizes of WC-Co and $\mathrm{CeO}_{2} \mathrm{NPs}$ were found to be approximately $100 \mathrm{~nm}$ and $190 \mathrm{~nm}$, respectively.

Animals: Male Sprague-Dawley rats (8-9 weeks old) were purchased from Hilltop Laboratories (Scottdale, PA). The rats were housed at the West Virginia University animal facility in ventilated cages, under controlled humidity and temperature, with a $12 \mathrm{hr}$ light/dark cycle with food and water provided ad libitum. Animals were acclimated for at least 2 days prior to use. Rats were divided randomly into groups (six animals per group) and assigned to either the 0,50 , 250 or $500 \mu \mathrm{g}$ WC-Co or $400 \mu \mathrm{g} \mathrm{CeO}_{2} \mathrm{NP}$ group. All procedures were approved by the West Virginia University Animal Care and Use Committee (Permit Number 12-0414) and carried out in accordance with recommendations set forth in the Guide for the Care and Use of Laboratory Animals by the National Institutes of Health. All efforts were made to ensure minimal suffering during stated procedures.

Intra-tracheal Instillation Rat Model and NP Exposure: The NP stock solutions were sonicated for $5 \mathrm{~min}$ on ice to ensure particle dispersion and used immediately for intra-tracheal (IT) instillation. Rats were lightly sedated with isofluorane gas (5\% induction) and intratracheally instilled with a $300 \mu \mathrm{L}$ bolus dose of the stock NP solutions to achieve final doses of 0, 50, 250, and $500 \mu \mathrm{g}$ WC-Co NPs or $400 \mu \mathrm{g} \mathrm{CeO} 2$ NPs. Rats were monitored after instillation until consciousness was regained. After a $24-\mathrm{hr}$ recovery period, rats were euthanized with thiobutabarbital sodium salt hydrate (Inactin ${ }^{\circledR}$; Sigma-Aldrich, MO) at a dose of $1 \mathrm{mg} / \mathrm{kg}$ via intra-peritoneal (i.p.) injection. Anesthesia was confirmed by testing the toe-pinch reflex. Upon euthanization, the rat abdomen was opened and whole blood was collected in anti-coagulant 
(ethylenediaminetetraacetic acid, EDTA) vacuum tubes via the abdominal aorta until a minimum of $6 \mathrm{~mL}$ blood was obtained. Following blood collection, the aorta was cut for complete exsanguination and broncho-alveolar lavage (BAL) was performed immediately thereafter.

Blood Plasma Isolation: Whole blood samples were kept on ice until all samples were collected and then centrifuged at $2000 \times \mathrm{g}$ for 15 min to separate the plasma from the cellular blood components. The plasma (supernatant) was drawn off using a pipet, transferred to a cryogenic vial in $0.5 \mathrm{~mL}$ aliquots, and flash frozen in liquid nitrogen for later cytokine analysis.

Assessment of Pulmonary Inflammation at 24-hr Post-Exposure: Pulmonary inflammation was assessed in the BAL fluid after NP exposure by evaluating several parameters. First, BAL fluid samples were assessed for cytotoxicity using the LDH assay and second, albumin protein concentration in the BAL fluid was determined to evaluate the integrity of the epithelialendothelial (blood-gas exchange) barrier in the lung. Third, inflammatory cells were isolated from the BAL fluid and differential cell counts performed to identify the number of alveolar macrophages (AM) and polymorphonuclear leukocytes (PMN) present in the lung following NP exposure. Further, isolated macrophage (AM) activation states were examined using a standard chemiluminescence assay. Then, the concentration of inflammatory cytokines (i.e. TNF- $\alpha$, IL-6, and IFN- $\gamma$ ) were determined in BAL fluid samples using ELISA.

BAL Procedure and BAL Fluid Collection: Broncho-alveolar lavage (BAL) was performed with $\mathrm{Ca}^{2+} / \mathrm{Mg}^{2+}$-free phosphate buffered saline (PBS, pH 7.4) plus $5.5 \mathrm{mM}$ D-glucose as previously described [240]. Briefly, a tracheal cannula was inserted and BAL was performed through the cannula using ice-cold PBS. The first BAL fluid, totaling $6 \mathrm{~mL}$ of PBS, was collected and immediately centrifuged $\left(650 \times \mathrm{g}, 10 \mathrm{~min}, 4^{\circ} \mathrm{C}\right)$. The resulting first BAL fluid 
supernatant was then divided for later analysis: two $0.5 \mathrm{~mL}$ aliquots were flash-frozen in liquid nitrogen for cytokine determination by ELISA and the remaining $5 \mathrm{~mL}$ was kept on ice for analysis of LDH and albumin. After the first BAL was collected, BAL was repeated using $8 \mathrm{~mL}$ of PBS until a total of $40 \mathrm{~mL}$ BAL fluid was collected. Next, the $40 \mathrm{~mL}$ of BAL fluid was centrifuged $\left(650 \times \mathrm{g}, 10 \mathrm{~min}, 4^{\circ} \mathrm{C}\right)$ and the resulting cell pellet was pooled with the cell pellet from the first BAL fluid. The pooled cells were re-suspended in HEPES-buffered medium (10 mM N-[2-hydroxyethyl]piperazine-N'-[2-ethanesulfonic acid], $145 \mathrm{mM} \mathrm{NaCl}, 5 \mathrm{mM} \mathrm{KCl}, 1 \mathrm{mM}$ $\mathrm{CaCl}_{2}, 5.5 \mathrm{mM}$ D-glucose, $\left.\mathrm{pH} 7.4\right)$ and centrifuged a second time $\left(650 \times \mathrm{g}, 10 \mathrm{~min}, 4^{\circ} \mathrm{C}\right)$. The resulting supernatant was decanted and a final suspension of the isolated BAL cells was prepared in HEPES-buffered medium.

Albumin Protein Assay and LDH Activity: LDH and albumin assays were performed as previously described $[65,243]$ on the same day as BAL fluid collection using a Roche Cobas c111 (Roche Diagnostic Systems, Indianapolis, IN). In brief, LDH activity was used as a marker of cytotoxicity. A commercial assay kit was purchased from Roche Diagnostic Systems (Indianapolis, IN) and used to measure LDH activity based on the LDH-driven oxidation of pyruvate coupled with the reduction of nictoinamide adenine dinucleotide at $340 \mathrm{~nm}$. Albumin concentration was monitored as an indicator of cellular integrity using a commercially available kit from Sigma Chemical Co (St. Louis, MO) based on albumin binding to bromcresol green and measuring the color change at $628 \mathrm{~nm}$.

Histology: A total of $1.0 \times 10^{6}$ BAL cells were suspended in $200 \mu \mathrm{L}$ HEPES-buffered medium and transferred to microscope slides using the cytospin approach [244]. The resulting cytospin preparations were stained with modified Wright-Giemsa stain and cell differentials 
were determined using light microscopy. Differential cell counts were calculated by multiplying the total cell count by the cell differential percentage obtained from the cytospin preparations.

Macrophage Chemiluminescence: The activation state of alveolar macrophages (AM), previously isolated from the BAL fluid (above), was determined in a total volume of $0.5 \mathrm{~mL}$ HEPES-buffered medium as previously described using a chemiluminescence assay [245]. First, chemiluminescence of resting AM (non-stimulated) was determined by incubating $1.0 \times 10^{6}$ $\mathrm{AM} / \mathrm{mL}$ at $37^{\circ} \mathrm{C}$ for $20 \mathrm{~min}$, followed by the addition of 5-amino-2,3-dihydro-1,4phthalazinedione (luminol) to a final concentration of $0.08 \mu \mathrm{g} / \mathrm{mL}$. The resulting chemiluminescence was measured with an automated luminometer (Berthold Autolumat Plus LB 953, Oakridge, TN) at 390-620 $\mathrm{nm}$ for $15 \mathrm{~min}$, where the integral of counts per minute (cpm) versus time was calculated. Next, zymosan-stimulated chemiluminescence was determined by adding $2 \mathrm{mg} / \mathrm{mL}$ of un-opsonized zymosan just prior to the measurement of chemiluminescence. The use of un-opsonized zymosan in this assay allows for the determination of AM chemiluminescence, which is a reflection of the macrophage activation state, because unopsonized zymosan stimulates AM chemiluminescence [246] but does not stimulate polymorphonuclear leukocyte (PMN) chemiluminescence [62, 247]. Stimulated macrophage chemiluminescence was then calculated by subtracting the cpm from the resting AM measurement from the cpm of the zymosan-stimulated measurement.

Inflammatory Cytokine ELISA: Standard curves for cytokines including TNF- $\alpha$, IL-6, and Interferon $\gamma(\mathrm{IFN}-\gamma)$ were prepared using a dilution series with a commercial ELISA kit (Signosis, Inc, Santa Clara, CA). Previously frozen plasma and BAL fluid samples were thawed and used to determine the cytokine concentrations in each sample. Briefly, $100 \mu \mathrm{L}$ of BAL fluid or plasma sample was added to each well of the 96-well ELISA plate and incubated for $2 \mathrm{hr}$ to 100 
allow sufficient binding to the immobilized antibodies within each well. Samples were then aspirated and wells were rinsed three times with $200 \mu \mathrm{L}$ buffer per wash. Next, $100 \mu \mathrm{L}$ biotinlabeled detection antibody was added to each well and incubated for $1 \mathrm{hr}$. The washing step was repeated followed by the addition of $100 \mu \mathrm{L}$ streptavidin-horseradish peroxidase (HRP) conjugate to each well. After $45 \mathrm{~min}$, the washing step was repeated and $100 \mu \mathrm{L}$ substrate was added to each well. The plate was further incubated for $30 \mathrm{~min}$ in the dark, followed by the addition of $50 \mu \mathrm{L}$ stop solution to each well. The absorbance of each sample was immediately measured at $450 \mathrm{~nm}$. BAL fluid and plasma samples were run in triplicate and the cytokine concentration of each sample was calculated based on the sample absorbance and the slope of the standard curve for each respective cytokine.

Statistical Analysis All data were presented as the mean \pm standard deviation. Statistical significance between experimental groups was determined using one-way analysis of variance (ANOVA) and Dunnett's post-hoc analysis in GraphPad Prism 6 software (San Diego, CA).

\section{RESULTS}

Pulmonary Inflammation: BAL fluid was collected and analyzed to assess pulmonary inflammation following 24-hr exposure to WC-Co or $\mathrm{CeO}_{2} \mathrm{NPs}$. Compared to the vehicle control group, there were no significant differences in LDH activity for WC-Co NP exposed animals at the doses studied. A significant increase in LDH activity was observed in the $\mathrm{CeO}_{2} \mathrm{NP}$ group compared to the vehicle control and all of the WC-Co NP exposed groups (Figure 1A). This indicated a lack of cytotoxicity in the WC-Co NP exposed groups at the doses studied while the exposure to $\mathrm{CeO}_{2}$ NPs caused significant cytotoxicity. Similarly, there were no significant 
differences found in the albumin content in WC-Co NP exposed animals compared to vehicle control, although relatively higher albumin content was observed at the exposure dose of $500 \mu \mathrm{g}$ compared to the other doses (i.e. 50 and $250 \mu \mathrm{g}$ ) (Figure 1B). A significant increase in albumin was found in the $\mathrm{CeO}_{2} \mathrm{NP}$ exposed group compared to the vehicle control and all of the WC-Co NP exposed groups (Figure 1B). This indicated that the epithelial-endothelial barrier remained undisrupted in WC-Co NP exposed animals but was affected in the $\mathrm{CeO}_{2} \mathrm{NP}$ exposed group.

A)

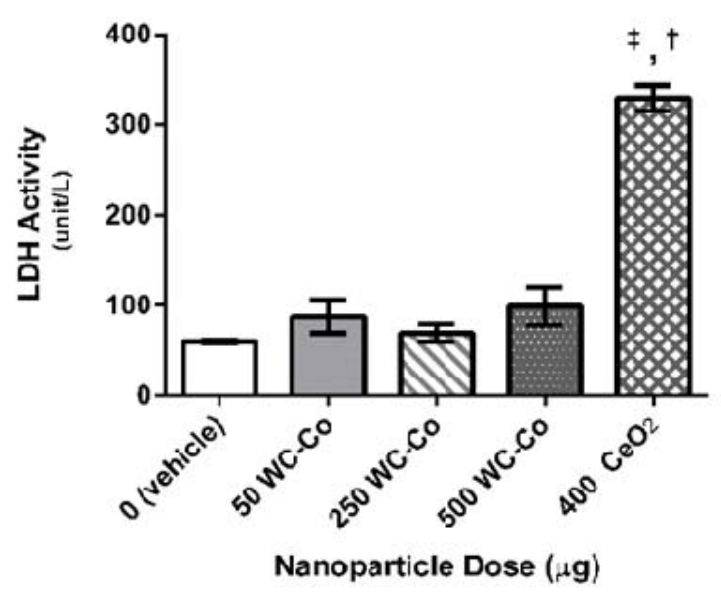

C)

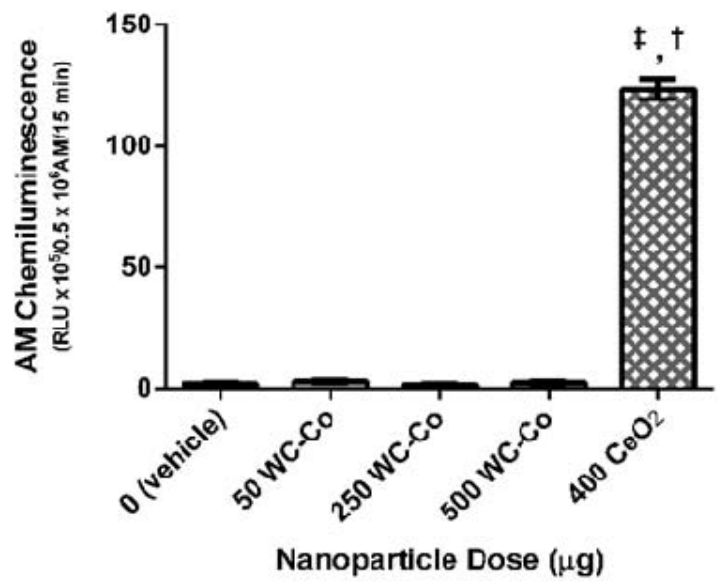

B)

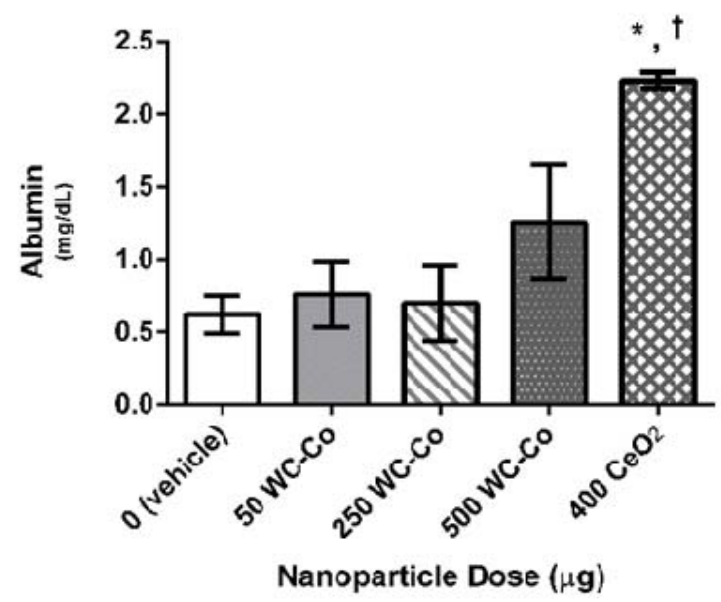

Figure 4.1. Pulmonary inflammation parameters assessed in the BAL fluid following 24-hr exposure to WC-Co and $\mathrm{CeO}_{2}$ NPs: A) LDH activity, B) albumin and C) AM chemiluminescence. Values presented as mean $\pm \mathrm{SD}$. $(* \mathrm{P}<0.05, \ddagger \mathrm{P}<0.001$ compared to the vehicle control and $+\mathrm{P}<0.01$ compared to WC-Co NP exposed groups) 
The activation state of AM was determined via zymogen-stimulated chemiluminescence assay, where no significant differences were found in AM activation in WC-Co NP exposed animals at all the doses studied compared to the vehicle control group. A significant increase in AM activation was observed when the $\mathrm{CeO}_{2} \mathrm{NP}$ exposed group was compared to the vehicle control and to all of the WC-Co NP exposed groups (Figure 1C). Moreover, the number of AMs in the BAL fluid samples was similar across the vehicle control and all WC-Co NP exposed animals, where a relatively higher number of AMs was found in the $\mathrm{CeO}_{2} \mathrm{NP}$ exposed group compared to the vehicle control and WC-Co NP exposed groups; however, the differences were not significant (Figure 2A). Additionally, no significant differences in the number of PMNs were found between the WC-Co NP exposed groups and the vehicle control group; however, a significant increase in the number of PMNs was detected in the $\mathrm{CeO}_{2} \mathrm{NP}$ exposed group compared to the vehicle control and the WC-Co NP exposed groups (Figure 2B).

Further, no significant differences were detected in the levels of inflammatory cytokines (i.e. TNF- $\alpha$ and IFN- $\gamma$ ) in BAL fluid among the $\mathrm{WC}-\mathrm{Co}, \mathrm{CeO}_{2}$, and vehicle control groups (Figure 3A) with the exception of IL-6, where a significant increase in IL-6 was observed for the $\mathrm{CeO}_{2} \mathrm{NP}$ group compared to the vehicle control and WC-Co NP exposed groups (Figure 3A).

Systemic Inflammation: The levels of inflammatory cytokines including TNF- $\alpha$, IL-6, and IFN$\gamma$ were determined in blood plasma samples to examine the potential systemic inflammatory response to WC-Co and $\mathrm{CeO}_{2} \mathrm{NP}$ exposures. No significant differences were observed in TNF- $\alpha$ and IFN- $\gamma$ levels among all the animal groups studied (i.e. Control, WC-Co NP, and $\mathrm{CeO}_{2} \mathrm{NP}$ groups), but significantly higher IL-6 was found in the $\mathrm{CeO}_{2} \mathrm{NP}$ exposed group compared to the vehicle control and WC-Co NP exposed groups (Figure 3B). 


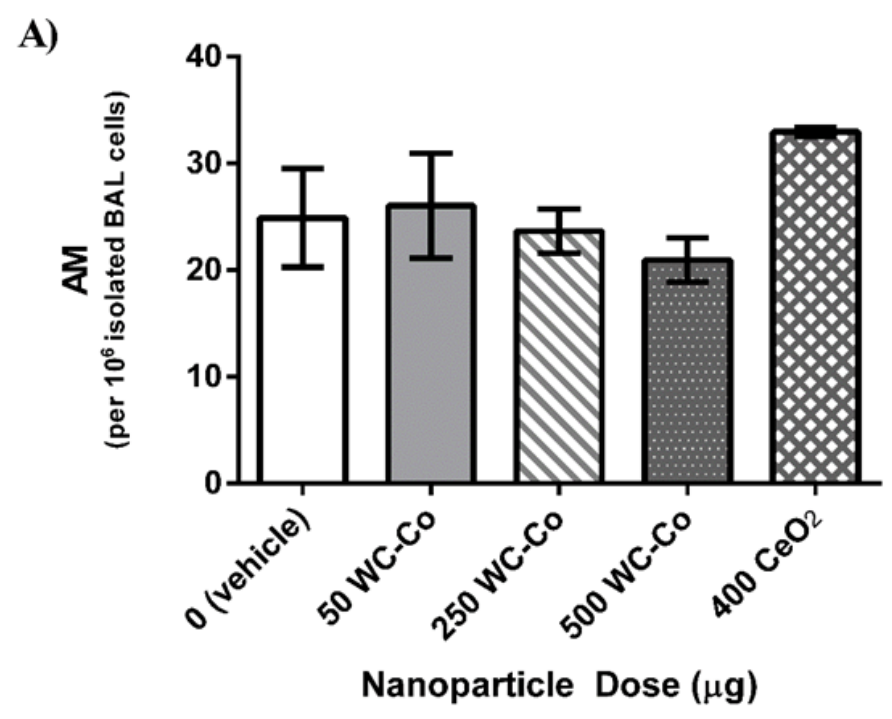

B)

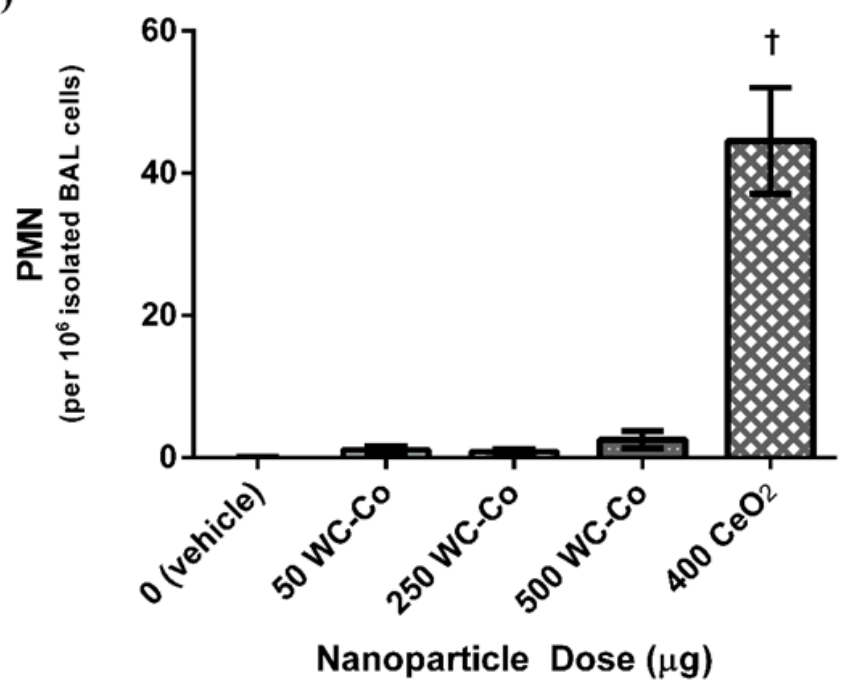

Figure 4.2. Inflammatory cells quantified in BAL fluid samples following 24-hr exposure to WC-Co and $\mathrm{CeO}_{2}$ NPs: A) alveolar macrophages (AM) and B) polymorphonuclear leukocytes (PMN), represented as the total number of $\mathrm{AM} / \mathrm{PMN}$ per $10^{6}$ isolated BAL cells per rat. Values presented as mean $\pm \mathrm{SD} .(+\mathrm{P}<$ 0.01 compared to the vehicle control and WC-Co NP exposed groups)

Isolated BAL Cell Histology: Histological examination of the cytospin cell preparations revealed a population of AMs present in both the vehicle control (Figure 4A) and WC-Co NP 
exposed groups (Figure 4B) and AM containing NPs were visible in WC-Co exposed groups (Figure 4B). These data suggest that AM were capable of phagocytizing the WC-Co NP; however, the overall lack of inflammation observed in the other pulmonary parameters suggests that the WC-Co NPs were recognized as 'inert' by the AM and did not cause significant AM activation.

A)

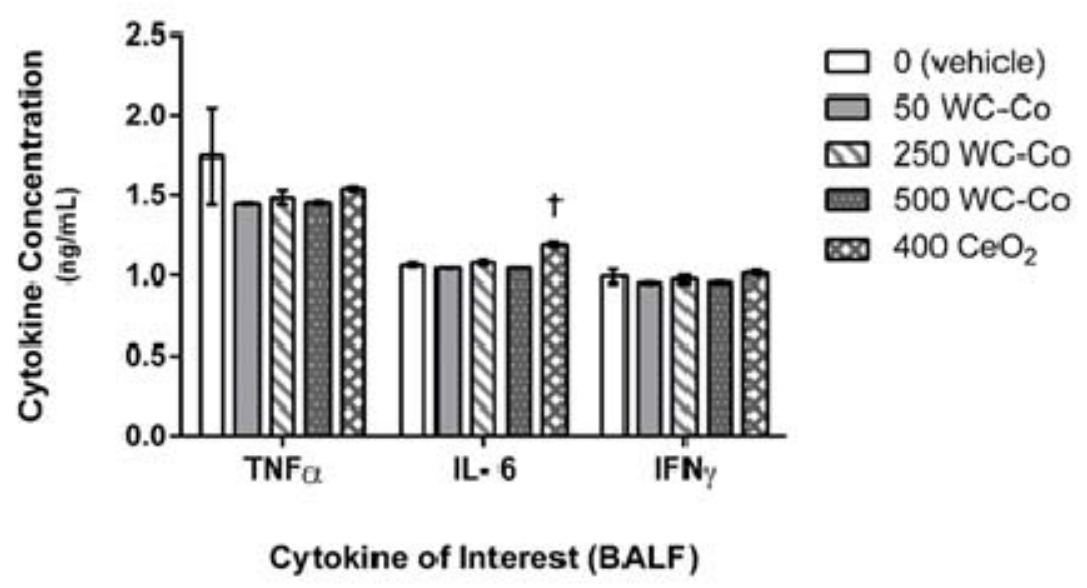

B)

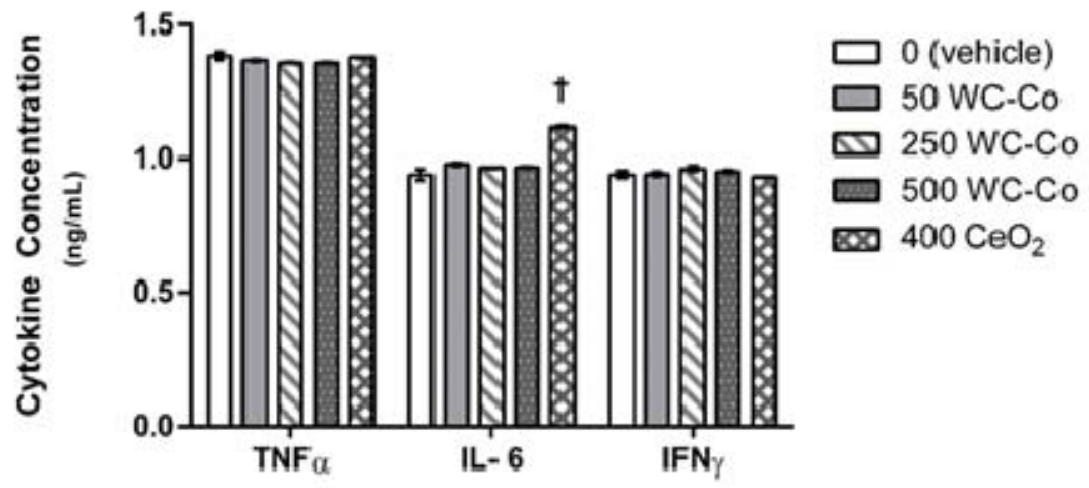

Cytokine of Interest (Plasma)

Figure 4.3. Inflammatory cytokine concentrations in A) BAL fluid and B) blood plasma. $(† P<0.01$ compared to the vehicle control and WC-Co NP exposed groups) 
A)

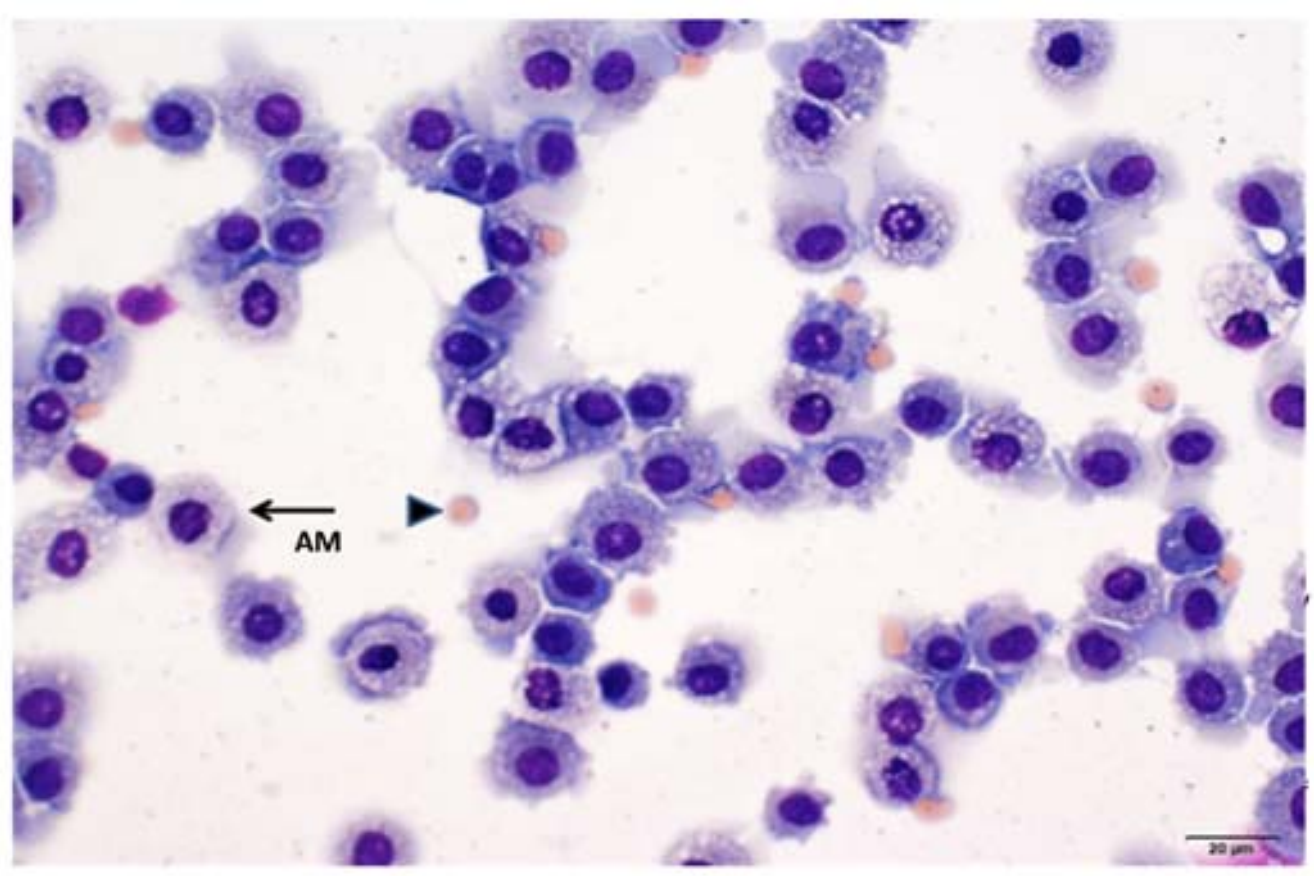

B)

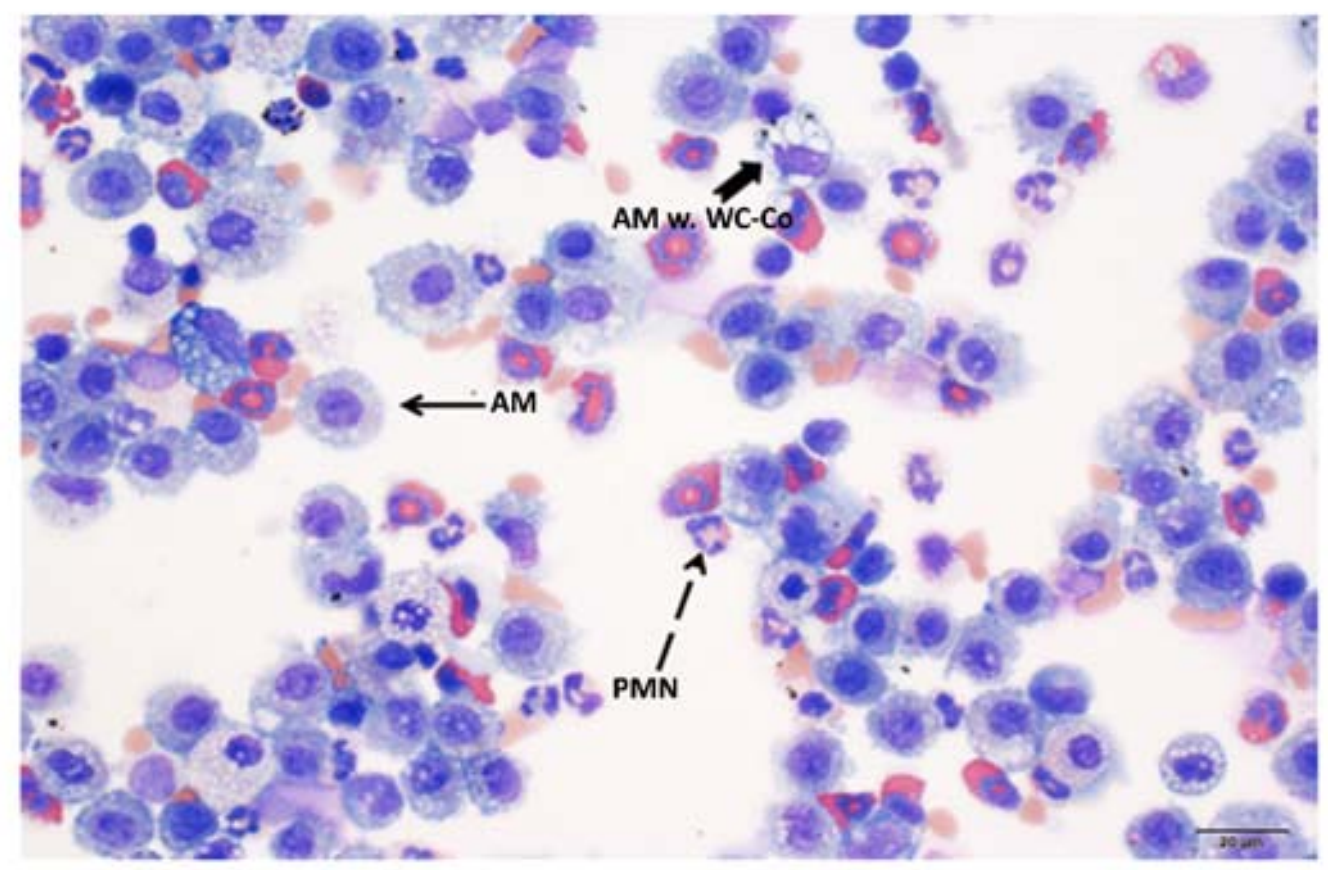

Figure 4.4. Histology of isolated BAL fluid cells from a representative A) control (vehicle only) rat and B) $500 \mu \mathrm{g} \mathrm{WC}-\mathrm{Co} \mathrm{NP}$ exposed rat. Scale bars $=20 \mu \mathrm{m}$. (black arrow = alveolar macrophage, AM; arrow head = erythrocyte; dotted arrow $=$ polymorphonuclear leukocyte, PMN; wide arrow = AM with WC-Co NPs) 


\section{DISCUSSION}

In this study, we determined the acute inflammatory effects of WC-Co and $\mathrm{CeO}_{2} \mathrm{NP}$ exposure in terms of local pulmonary responses via assessment of BAL fluid and the acute systemic effects via quantification of important inflammatory mediators in the blood.

In general, the presence of particles in the lungs, including NPs, is thought to promote the recruitment of macrophages, increase macrophage phagocytic activity and thereby stimulate particle clearance from the lung [41, 205-207] as part of the normal physiological response. Macrophage recruitment and phagocytosis of deposited particles is rapid, usually occurring within $24 \mathrm{hr}$ of exposure for most animal species [205]. In this study, WC-Co NPs were phagocytized by AMs after $24 \mathrm{hr}$, evidenced by histological examination, which is consistent with reports demonstrating the uptake of other NPs such as graphene [41], titanium dioxide [248, 249] and magnetite [250] by AMs in vivo. Interestingly, WC-Co NPs were also "phagocytized" by lung bronchial epithelial cells in vitro [222], which suggests that NP internalization may not be exclusive to macrophages and is of particular interest, since hard metal (WC-Co) deposits have been found in workers diagnosed with HMLD $[113,114,124]$. In the present study, WCCo NPs did not induce significant acute pulmonary inflammation, compared to the vehicle control, in the assessment of LDH activity and albumin content in the BAL fluid following 24-hr exposure at doses of 50-500 $\mathrm{mg}$ per rat. The lack of acute pulmonary inflammation is further supported by the observation that WC-Co NP exposure caused little change in the number of AM and PMN cells and did not increase macrophage activation following 24-hr WC-Co NP exposure. This outcome is similar to that reported for instilled titanium dioxide NPs, which do not cause any substantial acute pulmonary inflammation after $24 \mathrm{hr}$ at a dose up to $200 \mu \mathrm{g}$ per rat $[248,249]$. 
It is known that particle size may play a major role in the depth of tissue penetration and toxicity. Compared to micron-sized particles, NPs are smaller and have higher surface area (that is available for tissue interaction) and are thereby capable of deeper penetration and possessing higher toxicity $[238,251-256]$. However, no significant alterations in LDH activity and albumin levels were observed in this study following WC-Co NP exposure, while significant increases in LDH and albumin were reported in a similar IT rat model following 24-hr exposure of WC-Co in the $2 \mu \mathrm{m}$ size range [155-157]. Two factors may have contributed to the differences observed between this study and the previous ones: particle dose and chemical composition. In this study, we elected to dose our animals (50-500 $\mu$ g per rat) based on total lung burden in the microgram range, which were identified in vitro to be significantly toxic against lung epithelial cells [222] and are known to cause significant inflammation in $\mathrm{CeO}_{2} \mathrm{NP}$ exposed animals [65]. This is in stark contrast to the previous WC-Co NP studies [155-157], which used a mg per $100 \mathrm{~g}$ body weight dosing scheme with total WC-Co NP doses ranging from 3-30 mg per rat in a single IT exposure. As a result, the previous studies most likely overloaded the lung and led to significant inflammation. Moreover, the WC-Co NPs in the previous studies were obtained from a hard metal manufacturing facility and contained a significant amount of iron [155-157], which is not found in our WC-Co NPs. Iron has recently been identified as a pulmonary irritant [64, 174, 257] and could have contributed to the observed inflammatory responses in the previous studies.

In this study, no significant differences in inflammatory cytokines (i.e. TNF- $\alpha$, IL-6, IFN$\gamma$ ) were found in plasma or BAL fluid samples for WC-Co NP exposed animals compared to the vehicle control. These findings indicate that WC-Co NPs did not induce acute systemic inflammation after 24-hr pulmonary exposure at the doses studied. By contrast, within the emerging body of literature regarding NP toxicity in vivo, it is reported that cadmium oxide [63], 
titanium dioxide [220] and silver [221] NPs are capable of inducing systemic inflammation after acute pulmonary exposure, marked by increased inflammatory cytokine levels. For example, a three-fold increase in the pulmonary levels of TNF- $\alpha$ and IFN- $\gamma$ were observed in mice exposed to cadmium oxide NPs for $24 \mathrm{hr}$ [63]. Similarly, a significant increase in pulmonary IL-6 was reported in rats exposed to silver NPs for $24 \mathrm{hr}$ [221]. While cadmium oxide and silver NPs increased the pulmonary levels of these inflammatory cytokines, titanium dioxide is capable of inducing a significant increase in both the pulmonary and systemic levels of IL-6 and IFN- $\gamma$ after 24-48 $\mathrm{hr}$ of exposure in a rat IT model [220]. Together, these reports demonstrate the capacity of pulmonary NP exposure to initiate systemic inflammation and highlights the potential influence that systemic inflammatory cascades may have on the outcomes of pulmonary NP exposure.

In contrast to the WC-Co NPs, $\mathrm{CeO}_{2} \mathrm{NPs}$ induced significant acute pulmonary and systemic responses in our intra-tracheal instillation rat model. After 24-hr exposure, we observed significant acute inflammation in our $\mathrm{CeO}_{2} \mathrm{NP}$ exposed group compared to the vehicle control in terms of LDH activity, albumin content, and macrophage activation state. These findings are consistent with a previous study in Nurkiewicz's laboratory [65], where significantly higher LDH, albumin, and number of activated AMs were observed after 24-hr exposure to 100-400 $\mu \mathrm{g}$ $\mathrm{CeO}_{2} \mathrm{NPs}$, which might have contributed to microvascular dysfunction [65]. The significant increases in $\mathrm{AM}$ activation and number of PMNs in this study indicated that $\mathrm{CeO}_{2} \mathrm{NPs}$ stimulated the activation of macrophages and promoted the recruitment of PMNs. Furthermore, in this study we found a significant increase in IL-6 levels in both the plasma and BAL fluid of $\mathrm{CeO}_{2} \mathrm{NP}$ exposed animals compared to the vehicle control. This is most likely because IL-6 is primarily secreted by activated macrophages to stimulate inflammation in response to pulmonary tissue damage caused by the presence of NPs in the lung [207]. Overall, the outcomes reported 
here for $\mathrm{CeO}_{2} \mathrm{NPs}$ are consistent with the earlier studies regarding the systemic effects of exposure [65] and other in vivo [164, 170,242] and in vitro [24, 258-262] reports concerning $\mathrm{CeO}_{2} \mathrm{NP}$ toxicity in the literature.

In the current in vivo study, WC-Co NPs did not induce significant acute pulmonary and systemic inflammation, which is likely because we limited our investigation to a single IT dose (i.e. 50-500 $\mu \mathrm{g}$ per rat) and a short exposure time (i.e. $24 \mathrm{hr}$ ). It is possible that multiple doses of WC-Co NP could cause significant inflammation in a delayed response (beyond $24 \mathrm{hr}$ ). Future studies that explore multiple WC-Co NP doses and/or longer exposure times are warranted to further examine the pulmonary and systemic inflammatory response to WC-Co NPs in vivo.

\section{CONCLUSIONS}

In this study, we examined the acute local pulmonary and systemic inflammatory responses to WC-Co NPs using an intra-tracheal instillation rat model. No significant differences between WC-Co exposed animals and vehicle control were observed in terms of LDH activity, albumin concentration, or cell differentials. Macrophages isolated from WC-Co animals also did not show significant activation when compared to macrophages from vehicle control animals. In addition, no significant differences in inflammatory cytokines were observed for WC-Co exposed animals. These findings indicated a lack of acute local pulmonary and systemic inflammatory responses after 24-hr exposure to WC-Co NPs in an IT dose in the range of 0-500 $\mu \mathrm{g}$ per rat. 


\section{ACKNOWLEDGEMENT}

The authors thank Caroll McBride and Michael Wolfarth for their expert technical assistance during the completion of this study. A. Armstead acknowledges the American Foundation for Pharmaceutical Education (AFPE) Pre-Doctoral Fellowship in Pharmaceutical Sciences for support (2012-14). V. Minarchick acknowledges the West Virginia NANOSAFE graduate fellowship program (NSF-1003907) and T. Nurkiewicz acknowledges NSF-1003907, R01-ES015022 and DGE-1144676 for financial support.

\section{REFERENCES (See Chapter 7)}




\section{CHAPTER 5:}

Toxicity of Cobalt Chromium Molybdenum (CoCrMo) Particles Toward Lung Epithelial Cells in vitro

A Summary of Original Research Findings 


\section{ABSTRACT}

Metal-on-metal (MoM) joint implants are used routinely during total hip and knee replacement surgeries and are typically composed of cobalt chromium molybdenum (CoCrMo) alloy. While these implants are more successful than previous technologies, recent evidence indicates that CoCrMo "wear particles", in the nano- and micro-size range, can be generated in situ and may cause toxicity and inflammation in patients. Meanwhile, occupational exposure to CoCrMo particles has been associated with the development of industrial dental worker's pneumoconiosis and pulmonary exposure to CoCrMo particles is therefore a relevant concern in the manufacturing of MoM implant devices. In this study, we examined the pulmonary toxicity of nano- and micro-CoCrMo particles in vitro using a lung epithelial cell model and compared the outcomes with tungsten carbide cobalt (WC-Co) particles, which are known to cause toxicity and lung disease in exposed workers. We found that CoCrMo particles induced a time and dosedependent toxicity. There was no significant increase in the toxicity of nano-CoCrMo compared to micro-CoCrMo particles; however, nano-CoCrMo caused significantly greater levels of oxidative stress than micro-CoCrMo particles. Compared to WC-Co, CoCrMo particles caused significantly less cellular toxicity and oxidative stress under the conditions tested. These in vitro findings suggest that the pulmonary toxicity and oxidative stress associated with CoCrMo particle exposure in occupational settings may contribute to the development of lung disease.

Keywords: implant wear, joint replacement, cobalt chromium, occupational lung disease, pulmonary exposure, nanoparticle, nanotoxicity 


\section{INTRODUCTION}

Over a million total hip replacement procedures are performed each year; one-third of these surgeries use metal-on-metal (MoM) implant devices composed of cobalt chromium molybdenum (CoCrMo) alloys [263]. While MoM implant devices offer advantages, such as increased strength and resistance to wear over previous implants composed of polymeric and/or ceramic articulating surfaces, they are not without their faults or risks [28, 39]. In particular, new evidence is emerging that these MoM CoCrMo implants generate particles in situ, within the micro- and nano-size range, as a result of wear between the articulating joint surfaces [26, 28, 29, 38, 39, 264-266]. The generation of wear particles increases when the implant is improperly aligned, causing aseptic loosening of the joint, uneven wear and damage to the implant area [26, 28]. The current literature suggests that CoCrMo wear particles released locally within the joint area and surrounding tissues may cause toxicity and a subsequent inflammatory response [26, 28, 39, 266].

Given this evidence and emerging concerns regarding the long term effects of CoCrMo particle exposure in joint replacement patients, the toxicity of CoCrMo wear particles has recently been explored in vitro $[29,39,48-50,263-278]$ and in vivo [67, 279, 280]. CoCrMo toxicity has been reported in osteoblasts, osteoclasts, fibroblasts, leukocytes and macrophages, where oxidative stress and DNA damage are cited as common mechanisms of toxicity amongst these studies [29, 48-50, 264, 267, 268, 271, 272, 274, 276-278]. Additionally, CoCrMo particle exposure has been found to cause reproductive toxicity $[68,281]$, genotoxicity and inflammatory immune reactions in exposed mice [38, 67, 279]. Together, these studies demonstrate that CoCrMo particles possess toxic properties under in vitro and in vivo conditions. 
In addition to "internal" CoCrMo particle exposure via MoM implant wear, it is important to consider alternative routes of exposure such as inhalation, which could occur during the manufacturing and production of MoM implants. Industrial exposures to cobalt-containing metal "dusts" have been well-associated with the development of pneumoconiosis, occupational asthma and lung disease in a number of settings [86, 88, 96, 178, 181, 182, 282-289]. Although occupational exposure to CoCrMo particles has not been directly reported in orthopedic implant manufacturing settings, pulmonary exposure to CoCrMo "dusts", similar in composition to orthopedic implant materials, have been reported in dental implant manufacturing settings [290]. Inhalation of CoCrMo particles has been attributed as the cause of "dental technician's pneumoconiosis" (DTP) [290-296], which has a similar clinical presentation to hard metal lung disease resulting from tungsten carbide cobalt (WC-Co) exposure [26, 296, 297].

Given the risk of CoCrMo pulmonary exposure through inhalation of CoCrMo dusts in manufacturing settings and the lack of data regarding CoCrMo pulmonary toxicity, the goal of the current study was to determine the toxicity and oxidative stress response to nano- and microCoCrMo particle exposure in a lung epithelial cell culture model recently established in our lab [222]. Based on the literature, we hypothesized that nano- and micro-CoCrMo particles would exert time and dose-dependent toxicity and induce high levels of oxidative stress in BEAS-2B lung epithelial cells.

\section{MATERIALS and METHODS}

Materials and Reagents: CoCrMo particles were obtained as a gift from T.A. Simoes (University of Leeds, Institute for Materials Research, Leeds, UK). BEAS-2B lung epithelial cells were obtained from the laboratory of Yon Rojansakul (West Virginia University, 
Morgantown, WV, USA). Dulbecco's Modified Eagle Media (DMEM), sterile phosphate buffered saline (PBS), $0.25 \%$ trypsin/ethylenediaminetetraacetic acid (EDTA), fetal bovine serum (FBS) and penicillin/streptomycin were purchased from Lonza (Allendale, NJ). The MTT cell viability kit (TOX-1), 2',7'-dichlorofluorescein diacetate (DCF) and dihydroethidium (DHE) were purchased from Sigma-Aldrich (St. Louis, MO).

Particle Preparation: Briefly, CoCrMo nanoparticles were prepared from micro-sized ASTM F75 cobalt chromium atomized powder for surgical implants using mechanochemical milling in a high energy SPEX mill (Metuchen, NJ) [298]. For cell-based assays, CoCrMo particles were prepared in a phosphate buffered saline (PBS) solution containing 10\% fetal bovine serum (FBS) as a stabilization agent and sonicated using an Omni International Sonic Ruptor 250 Ultrasonic Homogenizer (Kennesaw, GA). A stock concentration of $5 \mathrm{mg} / \mathrm{mL}$ CoCrMo particles was prepared by sonication ( $2 \mathrm{~min}, 120$ watts power output, frequency $20 \mathrm{kHz}$ ) in an ice bath, to minimize heating of the sample during particle dispersion. Dilute particle suspensions, ranging from 0.1 to $1000 \mu \mathrm{g} / \mathrm{mL}$, were prepared in DMEM containing 10\% FBS and used immediately on the day of each experiment.

Particle Characterization: Micro- and nano-CoCrMo particles were characterized for size and morphology by scanning electron microscopy and elemental composition was determined via energy-dispersive x-ray (SEM/EDX; JEOL JSM 7600F, Jeol USA, Inc., Peabody, MA). The average size of CoCrMo particles in suspension for cell culture was determined using dynamic light scattering (DLS). Additional details provided in the Supplementary Material.

CoCrMo Particle Assay Interference: Prior to execution of the cell viability and oxidative stress assays, the potential interference of CoCrMo particles was examined under the 
experimental conditions. To test compatibility with the MTT-based cell viability assay, $200 \mu \mathrm{L}$ of CoCrMo suspensions (0.1 to $1000 \mathrm{ug} / \mathrm{mL}$ in DMEM) was added to duplicate wells in a 96well plate. The plate was briefly centrifuged $(500 \times \mathrm{g}, 5 \mathrm{~min})$ to pellet the particles at the bottom of the wells. The supernatant was then aspirated and $100 \mu \mathrm{L}$ of plain (un-supplemented) DMEM was added to each well containing CoCrMo particles, along with $10 \mu \mathrm{L}$ of MTT dye reagent. After $2 \mathrm{hr}$ incubation at $37^{\circ} \mathrm{C}, 100 \mu \mathrm{L}$ of solubilization solution was added to each well and the absorbance was determined at $570 \mathrm{~nm}$. Any auto-reduction of the MTT dye reagent to formazan by the CoCrMo particles themselves would have been detected as an increase in absorbance compared to the blank wells, containing only media, MTT dye reagent and solubilization solution. Similarly, for the oxidative stress assay, we tested whether the CoCrMo particles caused increased fluorescence of either DCF or DHE dye under our assay conditions. CoCrMo particle suspensions were plated and centrifuged in duplicate wells of a 96-well plate as described above. The supernatant was then aspirated and replaced with $100 \mu \mathrm{L}$ of $10 \mu \mathrm{M}$ DCF or DHE working solution prepared in PBS. Plates were incubated for $15 \mathrm{~min}$ in the dark and then fluorescence intensity of each well was quantified every $5 \mathrm{~min}$, up to one hour, at $520 \mathrm{~nm}$ for DCF or $620 \mathrm{~nm}$ for DHE, to identify any potential particle/dye interference compared to the blank (dye solution only) wells.

Cell Culture and Exposure to CoCrMo Particles: BEAS-2B cells were cultured in DMEM supplemented with $10 \%$ FBS and $1 \%$ penicillin-streptomycin and maintained at $37^{\circ} \mathrm{C}$ and $5 \%$ $\mathrm{CO}_{2}$. Briefly, confluent monolayers were rinsed with $\mathrm{PBS}$, trypsinized, transferred to $5 \mathrm{~mL}$ polystyrene tubes and centrifuged at $1200 \mathrm{rpm}$ for $7 \mathrm{~min}$ to pellet. The cell pellet was resuspended at the desired plating density of $1.5 \times 10^{5}$ cells $/ \mathrm{mL}$, transferred to a 96-well tissue 
culture plate and allowed to adhere overnight prior to conducting the cell viability and oxidative stress assays.

Cell Viability Assay: For the viability assay, cells were exposed to either nano- or microCoCrMo particles at concentrations of $0.1,1,10,100$ and $1000 \mu \mathrm{g} / \mathrm{mL}$ for exposure periods of 6 , 12, 24 and $48 \mathrm{hr}$. Following particle treatment, cells were rinsed once with sterile PBS to remove traces of media and excess particles. The MTT cell viability assay was performed per kit instructions (TOX-1, Sigma-Aldrich). The absorbance of each well was recorded at $570 \mathrm{~nm}$ using a Bio-Tek $\mu$ Quant microplate reader (Winooski, VT). Blank values were subtracted from absorbance readings. Cell viability was calculated by dividing the absorbance of particle treated cells (AbsExpt) by the absorbance of the negative control cells (media treatment only; Abscontrol) and converted to percentage according to the following equation: Cell Viability $(\%)=($ AbsExptl $/$ Abscontrol) $\times 100 \%$.

Oxidative Stress Assay: Oxidative stress was examined at the same concentration and exposure range described for the viability assay (above). Following particle treatment, cells were rinsed once with sterile PBS to remove traces of media and excess particles. Oxidative stress was then determined by the addition of $10 \mu \mathrm{M}$ DCF or DHE in PBS following particle treatment. Plates were incubated for $15 \mathrm{~min}$ in the dark and then fluorescence intensity of each well was quantified at $520 \mathrm{~nm}$ for DCF or $620 \mathrm{~nm}$ for DHE. The relative fluorescence of particle-treated cells was calculated as fold over control.

Statistical Analyses: All experiments were performed in triplicate and data are presented as mean \pm standard deviation. Statistical analysis was carried out by 2-way analysis of variance 
(ANOVA) using GraphPad Prism software (La Jolla, CA). P values $<0.05$ were considered significant.

\section{RESULTS}

CoCrMo Particle Characterization and Assay Interference: Morphological examination of nano- and micro-CoCrMo particles by SEM revealed distinct differences between the two particle types (Figure 1). Micro-CoCrMo particles demonstrated spherical morphology sized in the 5-6 $\mu \mathrm{m}$ range (Figure 1B) whereas nano-CoCrMo particles demonstrated a more irregular particle shape and size range, from a half-micron down to 100-200 nm (Figure 1A). DLS analysis indicated that nano-CoCrMo averaged $54 \mathrm{~nm}$ and micro-CoCrMo particles averaged $5.04 \mu \mathrm{m}$ in in suspension, similar to our WC-Co particles characterized previously [222]. We did not find any CoCrMo particle interference in our assay tests; no auto-reduction of the MTT dye was identified and no changes in DCF/DHE fluorescence were observed under the assay conditions tested (see Supplementary Material).
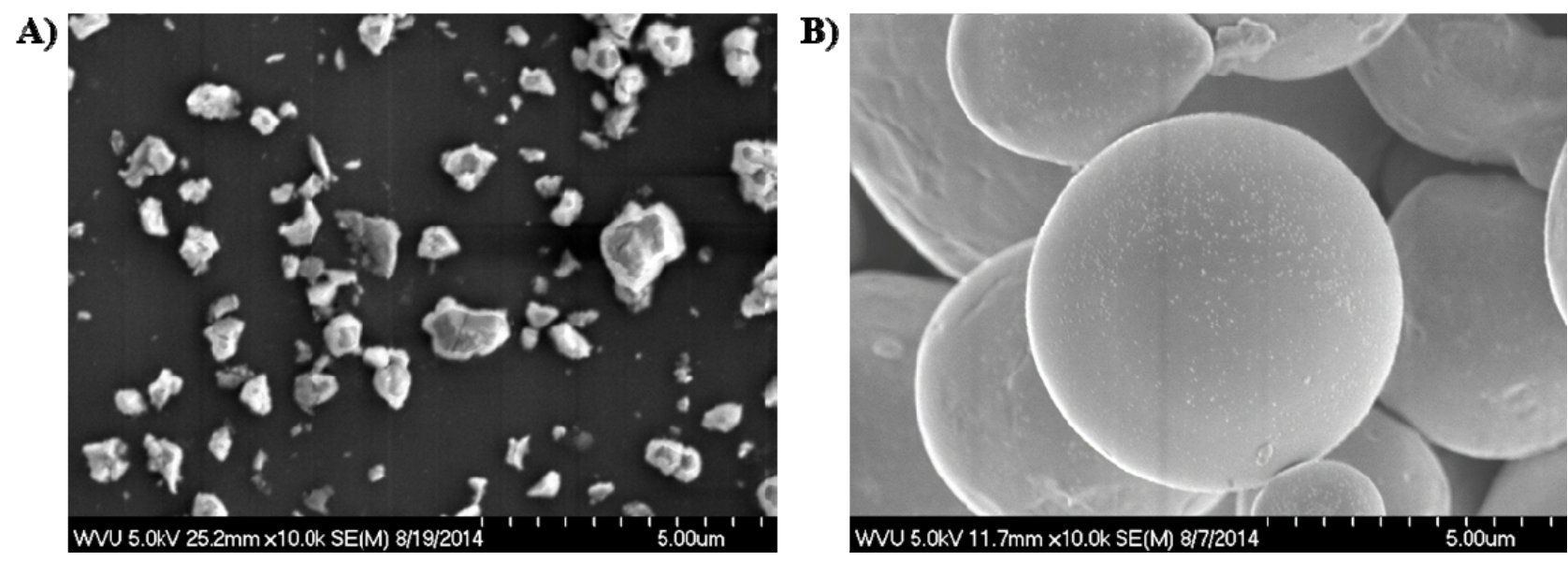

Figure 5.1. SEM images showing size and morphology of A) nano-CoCrMo and B) micro-CoCrMo particles. 
CoCrMo Effects on Cell Viability: BEAS-2B cells were exposed to nano- and micro-CoCrMo particles at concentrations of $0.1,1,10,100$ and $1000 \mu \mathrm{g} / \mathrm{mL}$ for durations of $6,12,24$ and $48 \mathrm{hr}$. BEAS-2B average cell viability was about $90-98 \%$ (vs. control of $100 \%$ ) for all cells exposed at concentrations of $0.1,1$ and $10 \mu \mathrm{g} / \mathrm{mL}$ for durations of $6-48 \mathrm{hr}$; the cell viability tended to decrease with increasing particle exposure time from $6 \mathrm{hr}$ to $48 \mathrm{hr}$ at concentrations of both 100 and $1000 \mu \mathrm{g} / \mathrm{mL}$ (Figure 2).

In cells exposed to nano-CoCrMo particles (Figure 2A), a significant reduction in viability (compared to control) was only observed at the highest concentration of $1000 \mu \mathrm{g} / \mathrm{mL}$ for 24 and $48 \mathrm{hr}$ exposure periods; the other concentrations and exposures tested did not cause a statistically significant change in cell viability for nano-CoCrMo.

In cells exposed to micro-CoCrMo particles (Figure 2B), a significant reduction in viability (compared to control) was observed at a concentration of $1000 \mu \mathrm{g} / \mathrm{mL}$ at 12,24 and 48 hr of exposure. There were no significant differences observed in toxicity between the nano- and micro-CoCrMo; however, when we compared the viability after CoCrMo treatment with our previous study on WC-Co particles [222], significant differences in toxicity were noted. We identified that nano-CoCrMo caused significantly less toxicity than nano-WC-Co at 1, 10, 100 and $1000 \mu \mathrm{g} / \mathrm{mL}$ after $48 \mathrm{hr}$ of exposure (Figure 3). Similarly, we observed that micro-CoCrMo caused significantly less toxicity than micro-WC-Co at 1,10,100 and $1000 \mu \mathrm{g} / \mathrm{mL}$ after $48 \mathrm{hr}$ of exposure (Figure 3). At a low particle concentration (i.e. $0.1 \mu \mathrm{g} / \mathrm{mL}$ ), no significant differences in cell viability were found between nano-CoCrMo and nano-WC-Co or between micro-CoCrMo and micro-WC-Co particles (Figure 3). 

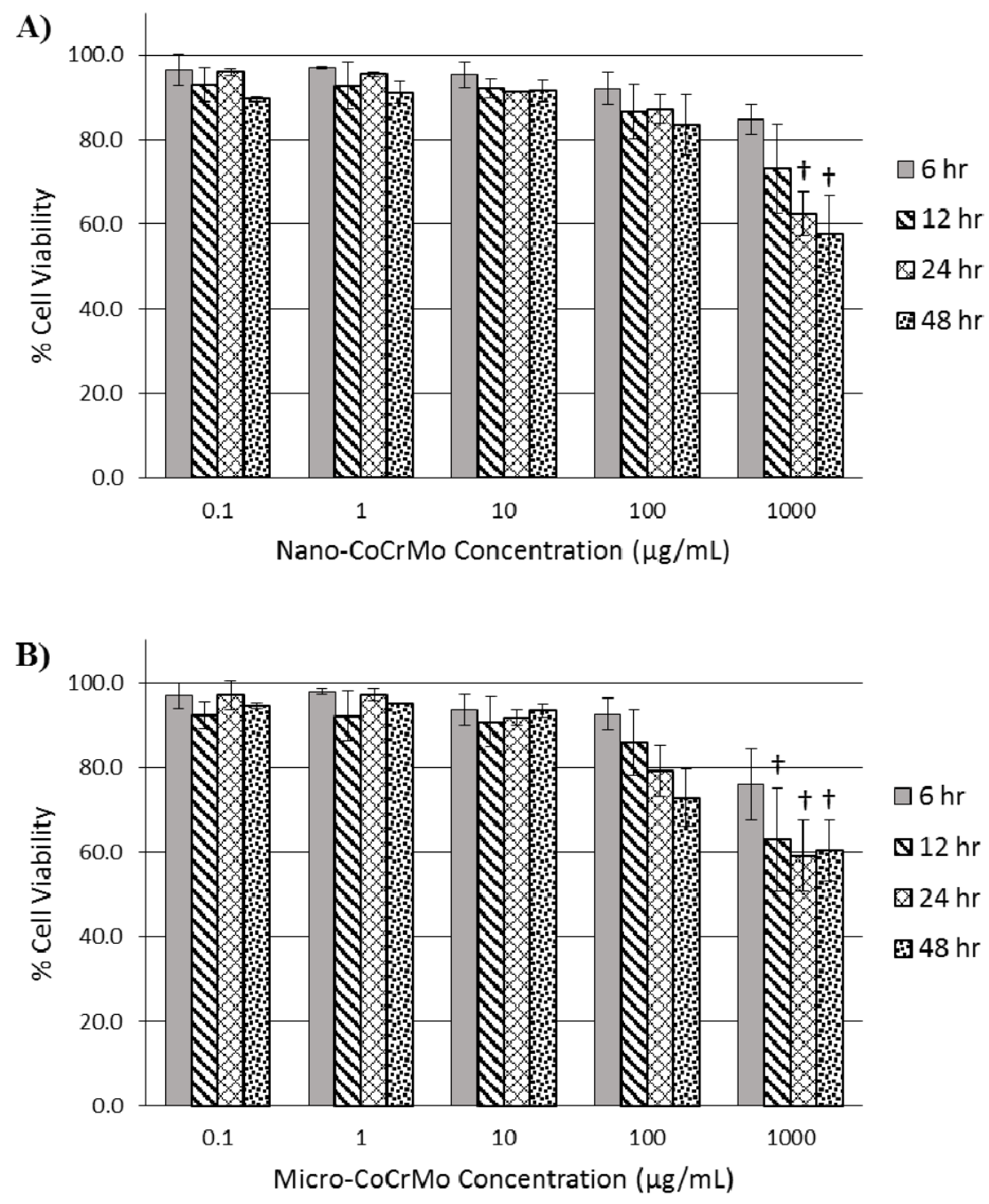

Figure 5.2. Cell viability measured by the MTT assay after exposure to A) Nano-CoCrMo and B) MicroCoCrMo particles. $(\dagger \mathrm{P}<0.01$ compared to controls with $100 \%$ viability)

CoCrMo Effects on Oxidative Stress: Oxidative stress was measured in the form of DCF/DHE fluorescence after exposure to nano- and micro-CoCrMo particles at 0.1, 1, 10, 100 and 1000 $\mu \mathrm{g} / \mathrm{mL}$ under identical exposure conditions in the viability assay. Compared to control, there was a significant increase in DCF fluorescence in cells exposed to $100 \mu \mathrm{g} / \mathrm{mL}$ nano-CoCrMo after 6 , 12 and $24 \mathrm{hr}$ of exposure and at $1000 \mu \mathrm{g} / \mathrm{mL}$ after $6,12,24$ and $48 \mathrm{hr}$ of exposure; a 3.5 fold 


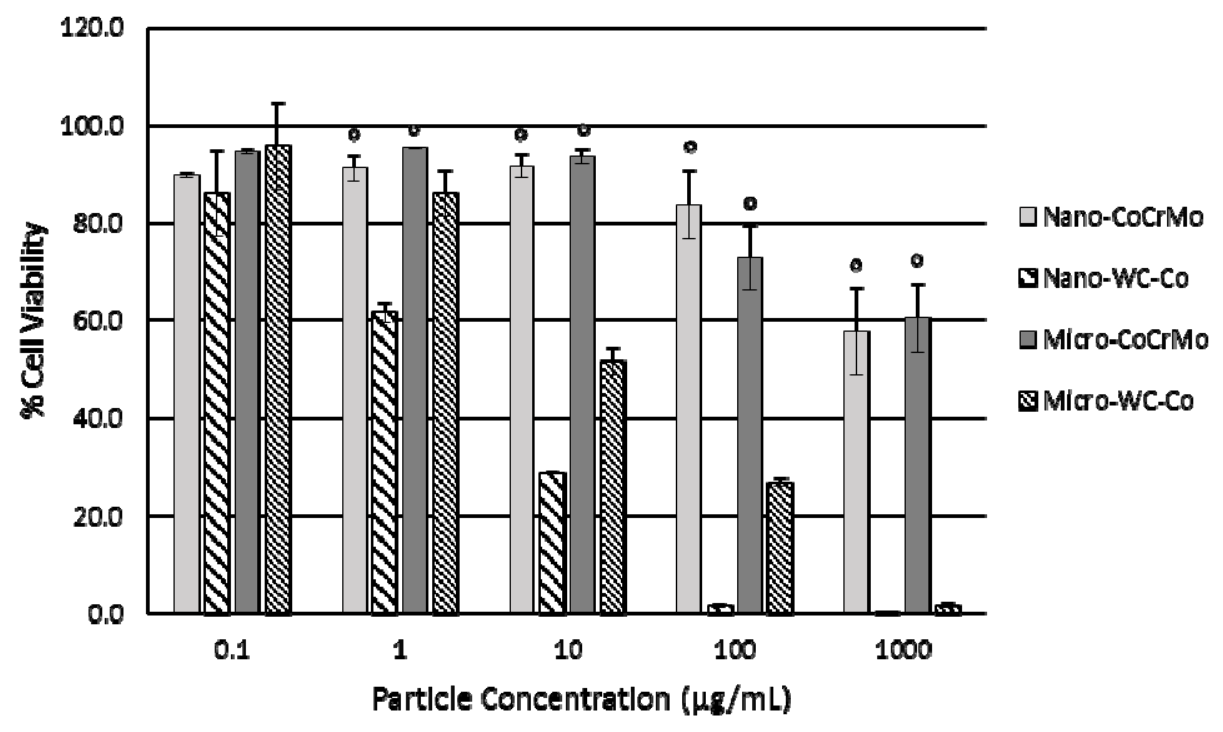

Figure 5.3. Comparison of cell viability after $48 \mathrm{hr}$ exposure to nano-CoCrMo, nano-WC-Co, microCoCrMo and micro-WC-Co. $\left({ }^{\circ} \mathrm{P}<0.001\right.$ vs. WC-Co)

increase in DCF fluorescence was observed in cells exposed to $1000 \mu \mathrm{g} / \mathrm{mL}$ nano-CoCrMo after $6 \mathrm{hr}$ of exposure and after which DCF fluorescence decreased with increasing exposure time (Figure 4A). In cells exposed to micro-CoCrMo, a significant increase in DCF fluorescence was observed after $6 \mathrm{hr}$ exposure to 10 and $100 \mu \mathrm{g} / \mathrm{mL}$ and after $6,12,24$ and $48 \mathrm{hr}$ exposure to 1000 $\mu \mathrm{g} / \mathrm{mL}$ micro-CoCrMo; a 2.3 fold increase in DCF fluorescence was observed in cells exposed to $1000 \mu \mathrm{g} / \mathrm{mL}$ micro-CoCrMo after $6 \mathrm{hr}$ of exposure (Figure 4B). In addition, nano-CoCrMo particles caused a significantly higher change in DCF fluorescence compared to micro-CoCrMo particles after 6, 12 and $24 \mathrm{hr}$ exposure to $100 \mu \mathrm{g} / \mathrm{mL}$ and after $6,12,24$ and $48 \mathrm{hr}$ at 1000 $\mu \mathrm{g} / \mathrm{mL}$ (Figure 4).

For DHE, no significant differences, compared to control, were observed in fluorescence after exposure to nano-CoCrMo (Figure 5A) or micro-CoCrMo (Figure 5B) particles, and the DHE fluorescences in cells exposed to both nano- and micro-CoCrMo particles were about the 
same as the controls at all concentrations $(0.1-1000 \mu \mathrm{g} / \mathrm{mL})$ and exposure times (i.e. 6-48 hr) studied.
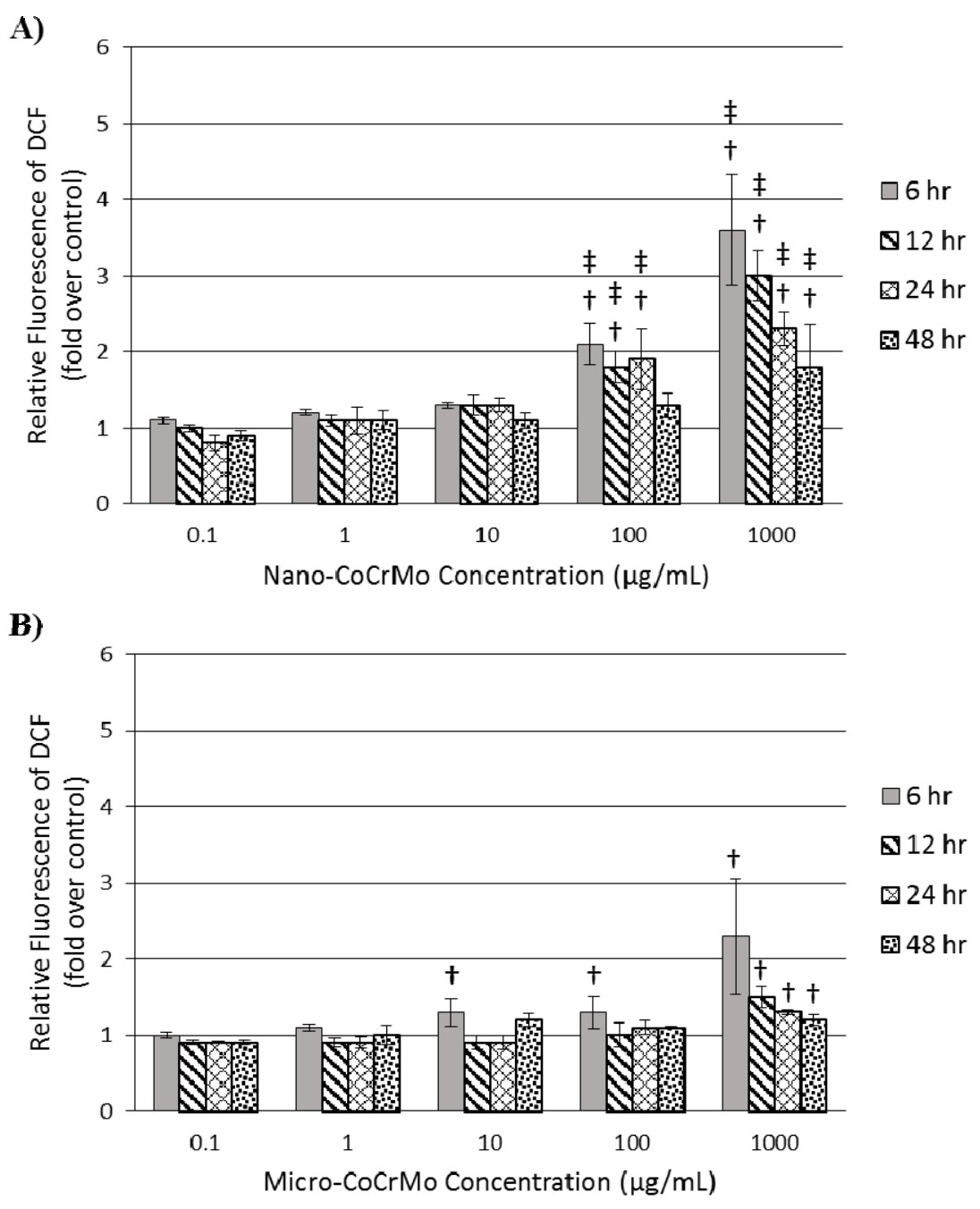

Figure 5.4. Oxidative stress measured via fluorescence intensity of DCF after exposure to A) nanoCoCrMo and B) micro-CoCrMo particles. ( $+\mathrm{P}<0.01$ compared to control; $\ddagger \mathrm{P}<0.05$ vs. micro-CoCrMo)

Compared to nano-WC-Co particles, nano-CoCrMo particles caused significantly less DCF fluorescence at 6 and $12 \mathrm{hr}$ of exposure but significantly higher DCF fluorescence at 24 and $48 \mathrm{hr}$ of exposure at the $1000 \mu \mathrm{g} / \mathrm{mL}$ concentration (Figure 6A). Compared to micro-WC-Co 
particles, micro-CoCrMo particles caused significantly higher levels of DCF fluorescence at $6 \mathrm{hr}$ exposure but significantly lower DCF fluorescence at $12 \mathrm{hr}$ of exposure at the $1000 \mu \mathrm{g} / \mathrm{mL}$ (Figure 6B). Compared to WC-Co particles, there was a significant increase in DHE fluorescence after exposure to both nano- and micro-CoCrMo at $1000 \mu \mathrm{g} / \mathrm{mL}$ after 6, 12, 24 and $48 \mathrm{hr}$ of exposure (Figure 6B).
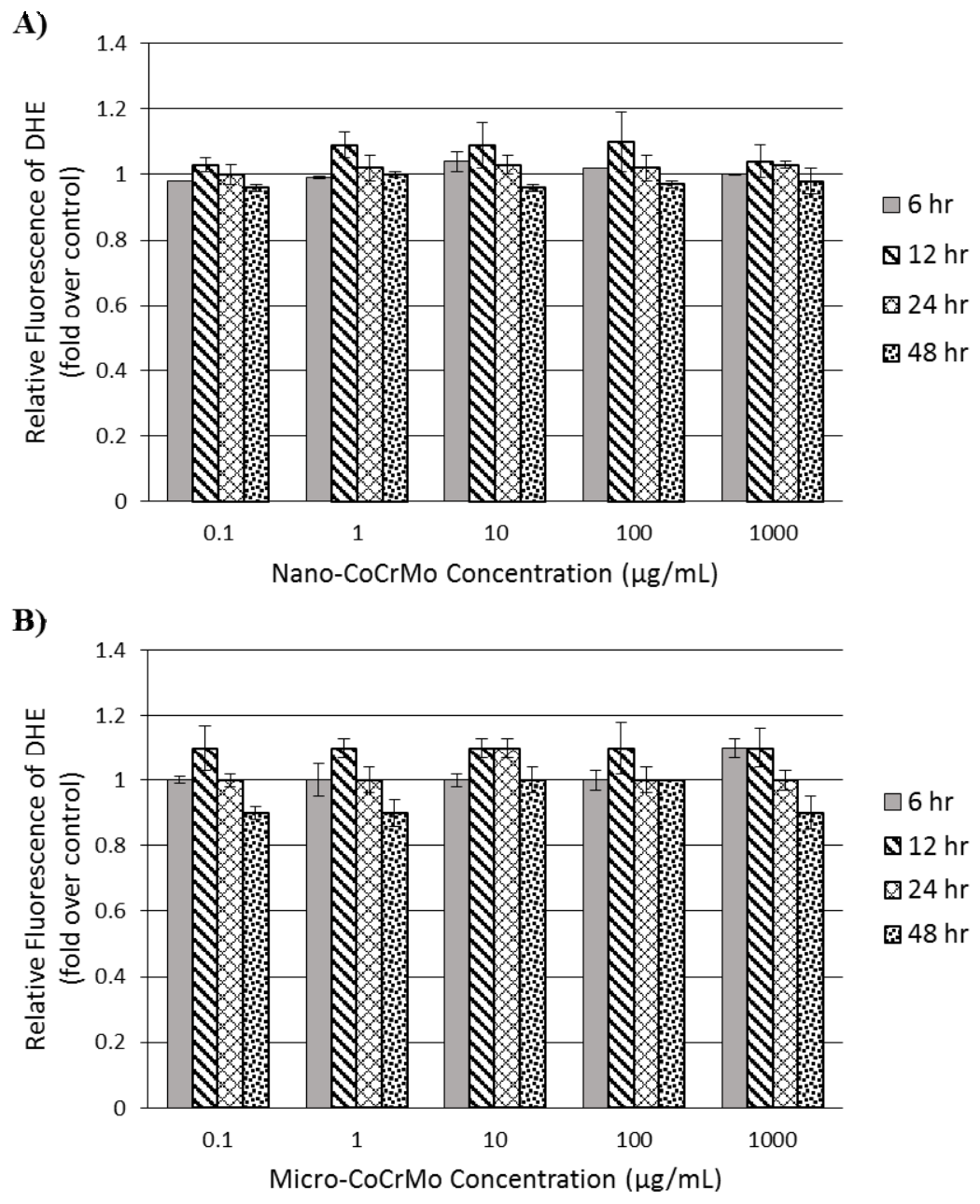

Figure 5.5. Oxidative stress measured via fluorescence intensity of DHE after exposure to A) nanoCoCrMo and B) micro-CoCrMo particles. 

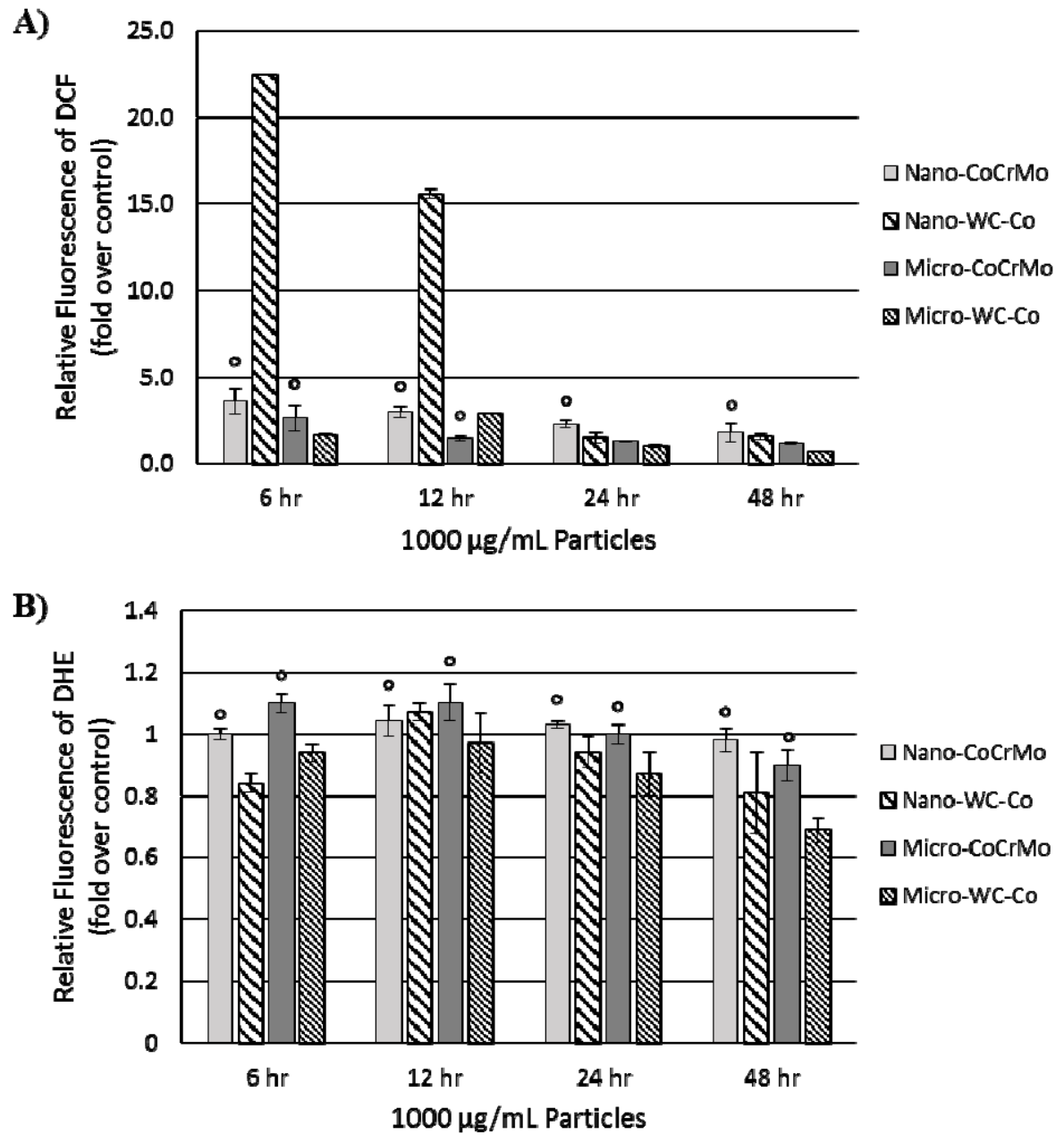

Figure 5.6. Comparison of oxidative stress measured via fluorescence intensity of A) DCF and B) DHE after $48 \mathrm{hr}$ exposure to nano-CoCrMo, nano-WC-Co, micro-CoCrMo and micro-WC-Co particles at 1000 $\mu \mathrm{g} / \mathrm{mL} .\left({ }^{\circ} \mathrm{P}<0.001\right.$ vs. WC-Co)

\section{DISCUSSION}

Inhalation of cobalt-containing metal particles is a known occupational risk in certain industries and has been associated with the development of hard metal lung disease following exposure to WC-Co particles [85, 93, 125, 199, 282, 299] and dental technician's pneumoconiosis after exposure to CoCrMo particles [290-292, 294, 296, 297]. Exposure to CoCrMo particles may also occur under other conditions, such as orthopedic joint implant wear 
$[26,39,265]$; advancements in our understanding of nanoparticle toxicity $[35,37,168]$ lead us to question the potential impacts of CoCrMo implant wear particles on tissues and organs beyond the affected joint area. Due to their small size, nanoparticles have the capacity to enter the circulatory system and deposit in secondary tissues such as the liver, spleen, kidney, lymph nodes or lungs $[26,27,31,32,238]$. In humans whom have undergone MoM joint replacement surgery, translocation and deposition of CoCrMo wear particles has been reported in lymph nodes, liver and spleen $[26,38,265,300]$; therefore, the potential secondary, systemic effects of CoCrMo particle exposure cannot be ignored [175, 295, 301].

In the current study, we focused on the pulmonary toxicity associated with CoCrMo inhalation in industrial settings using an in vitro lung epithelial cell model. Here, the toxicity of nano- and micro-sized CoCrMo particles, originating from ASTM F75 orthopedic implant material, was compared with the toxicity of nano- and micro-WC-Co particles in BEAS-2B cells. Pulmonary exposure to WC-Co particles is known to cause "hard metal lung disease", with characteristic multi-nucleated giant cells, reduced lung function, progressive inflammation and fibrosis of the lung in exposed workers [99-101, 107, 113, 114, 117, 124, 129, 302]. Therefore, the pulmonary toxicity of WC-Co has been well studied in a number of relevant models including bronchial epithelial cells, alveolar macrophages and lung carcinoma cells [132, 141143, 152, 222]. WC-Co nanoparticles are reported to cause significant cellular toxicity in bronchial epithelial cells after as little as $2 \mathrm{hr}$ of exposure to WC-Co concentrations $\geq 10 \mu \mathrm{g} / \mathrm{mL}$ [222] and in A549 lung carcinoma cells after 3 days exposure to a low concentration of $8 \mu \mathrm{g} / \mathrm{mL}$ WC-Co [132]. In alveolar macrophages, WC-Co exerts toxicity after as little as $2 \mathrm{hr}$ exposure to $\geq 83 \mu \mathrm{g} / \mathrm{mL}[141,142]$. By contrast, very little is known about the pulmonary toxicity of CoCrMo particles. Since occupational exposure to both CoCrMo and WC-Co particles is known 
to cause similar types of lung diseases, we hypothesized that the toxicity of CoCrMo particles would be similar to that of WC-Co particles in our BEAS-2B cell model.

While a distinct dose- and time-dependent toxicity was observed for nano- and microCoCrMo particles (Figure 2), we did not note any significant increase in the toxicity of nanoCoCrMo compared to micro-CoCrMo. This outcome was somewhat surprising, as there is a clear association between particle size and toxicity in the literature $[25,31,35,59,187,238,295$, 303]; nanoparticles typically exert greater toxic effects than microparticles of the same composition, due to their smaller size and increased surface area available for cellular interaction and chemical reactions. This result is in contrast to our findings regarding WC-Co particle toxicity, where nano-WC-Co was significantly more toxic than micro-WC-Co in lung epithelial cells at concentrations $\geq 10 \mu \mathrm{g} / \mathrm{mL}$ [222]. We speculate that there was little difference in nanoand micro-CoCrMo toxicity due to the fact that CoCrMo has caused significantly less toxicity compared to WC-Co particles at doses of 1-1000 $\mu \mathrm{g} / \mathrm{mL}$ under identical conditions (Figure 3), and CoCrMo has been implemented as a "bio-compatible" material, hence its prevalent use in the orthopedic community [26]. However, these results demonstrate that CoCrMo particles can be toxic toward BEAS-2B cells.

Oxidative stress has been implicated in the reported toxicity of CoCrMo particles in other cell types, such as fibroblasts $[48,50,264,274,304]$. Oxidative stress may also play a role in the progression of lung diseases [305], such as those caused by cobalt-containing metal exposures [139], so we examined the capacity of nano- and micro-CoCrMo particles to cause oxidative stress in our BEAS-2B cell model. The results of our DCF assay indicated that nano-CoCrMo caused significantly higher levels of oxidative stress compared to micro-CoCrMo particles at concentrations of 100 and $1000 \mu \mathrm{g} / \mathrm{mL}$ (Figure 4), which would be consistent with the expected 
size-dependent effect due to the increased reactive surface area of nano-CoCrMo compared to micro-CoCrMo. These results are consistent with fibroblast studies in the literature [48, 274], which found high levels of oxidative stress, marked by increased levels of DCF fluorescence, after as little as $2 \mathrm{hr}$ of exposure [274] and increased levels of 8OHdG staining, a marker of oxidative stress induced DNA damage, after $24 \mathrm{hr}$ of exposure to nano-CoCrMo particles [48]. Although CoCrMo particles could cause high levels of oxidative stress compared to control, we noted that nano-CoCrMo caused less oxidative stress than nano-WC-Co at $1000 \mu \mathrm{g} / \mathrm{mL}$ after 6 and $12 \mathrm{hr}$ of exposure (Figure 6). Beyond $12 \mathrm{hr}$, nano-CoCrMo caused higher levels of oxidative stress than nano-WC-Co; however, we attributed this phenomenon to the enhanced toxicity of WC-Co over CoCrMo. At $24 \mathrm{hr}$ exposure and beyond, nano-WC-Co caused such substantial toxicity that no live cells remained to generate a signal in the oxidative stress assay. These data indicated that, while less toxic than nano-WC-Co at high concentrations in the cell viability assay, CoCrMo particles caused greater levels of oxidative stress upon long-term exposure (i.e. $48 \mathrm{hr}$ ), which could ultimately lead to downstream effects such as DNA damage and genotoxicity upon long-term exposure [48-50, 271].

In the case of occupational WC-Co exposure, there is a two-fold increased risk of developing lung cancer [97, 100]; however, no such link between CoCrMo particle exposure and cancer has yet been identified [270]. It is worth noting, however, that only the relationship between local implant wear particles and systemic cancer occurrence was examined during the systematic review of in vitro and in vivo research regarding CoCrMo cancer occurrence [270]. Human clinical data pertaining to the occurrence and progression of DTP in CoCrMo exposed technicians was not included in the study [290-294, 296, 297]. Currently, due to small sample size and lack of clinical follow-up, there is little information regarding the long-term progression 
of DTP and occurrence of lung cancer in affected patients, so it remains unknown whether DTP patients have an increased risk of lung cancer similar to that reported for HMLD patients.

Taken together, the results of our study demonstrated that CoCrMo particles cause toxicity toward BEAS-2B cells at a high concentration $(1000 \mu \mathrm{g} / \mathrm{mL})$ but remain relatively nontoxic at concentrations $\leq 100 \mu \mathrm{g} / \mathrm{mL}$, in stark contrast to WC-Co particles which exhibit high toxicity at concentrations $\geq 10 \mu \mathrm{g} / \mathrm{mL}$. These findings are intriguing, since both types of "dusts" are reported to cause similar lung diseases following chronic occupational exposures. At least in the case of WC-Co, the combination of WC with Co is highly toxic in vitro and in vivo, whereas the components themselves are relatively non-toxic when administered alone [128, 140-144, 146, $154-156,160,161,284]$. It is thought that the release of cobalt ions from the composite particle may enhance the toxicity of the constituent WC components $[134,140,144,146,306,307]$. There is also some evidence which suggests that the speciation of cobalt released from MoM CoCrMo hip implants plays a role in the associated toxicity and inflammation state [263], so it seems plausible that similar mechanisms of toxicity may occur during CoCrMo and WC-Co particle exposure. While the results of our preliminary study indicated that CoCrMo caused high oxidative stress and toxicity toward lung epithelial cells, studies which further examine the mechanism responsible for CoCrMo-mediated toxicity are warranted.

\section{CONCLUSION}

This study examined the toxicity of nano- and micro-CoCrMo particles and determined whether their exposure caused oxidative stress in a lung epithelial cell model. Nano- and microCoCrMo caused significant toxicity at a high concentration (i.e. $1000 \mu \mathrm{g} / \mathrm{mL}$ ), but there was no enhancement of toxicity of the nano-CoCrMo compared to the micro-CoCrMo. However, nanoCoCrMo induced significantly higher levels of oxidative stress than micro-CoCrMo at high 
concentrations (i.e. 100 and $1000 \mu \mathrm{g} / \mathrm{mL}$ ). The results presented here demonstrated, for the first time, that CoCrMo particles cause pulmonary toxicity in vitro, which may contribute toward the development of occupational dental technician's pneumoconiosis (lung disease) in industrial settings.

\section{ACKNOWLEDGEMENT}

The authors thank TA Simoes for providing particle samples and Xianfeng Wang for performing particle characterization via SEM/EDX. The authors also acknowledge Dale Porter for assistance with dynamic light scattering analysis. A.Armstead thanks the American Foundation for Pharmaceutical Education for her Pre-Doctoral Fellowship in Pharmaceutical Sciences award 2012-14.

\section{REFERENCES (See Chapter 7)}




\section{SUPPLEMENTARY MATERIAL}

\section{MATERIALS and METHODS}

S1.1 CoCrMo Particle Characterization: Milled nano- and micro-CoCrMo particles were analyzed using scanning electron microscopy with energy-dispersive $\mathrm{x}$-ray (SEM/EDX) to determine the morphology and elemental composition. Dynamic light scattering (DLS) was used to determine the average particle/aggregate size in suspension.

For DLS, stock particle suspensions $(5 \mathrm{mg} / \mathrm{mL})$ were prepared by adding $25 \mathrm{mg}$ dry particle powder to a $20 \mathrm{~mL}$ vial containing $5 \mathrm{~mL}$ sterile PBS with $10 \%$ FBS. The particles were then sonicated using an Omni International Sonic Ruptor (Kennesaw, GA) for two intervals of $30 \mathrm{sec}$ each to ensure particle dispersion. Dilute particle suspension was prepared in DMEM supplemented with 10\% FBS and analyzed via DLS using a Malvern Zetasizer 7.01 (Malvern Instruments Ltd., Malvern, UK). Background absorbance of DMEM containing 10\% FBS only was used to 'blank' the instrument prior to measurement of the WC-Co particle suspensions.

For SEM/EDX, raw particle powder was imaged on a JEOL JSM 7600F setup equipped with an Oxford Instruments energy dispersive x-ray (EDX) system for chemical analysis. EDX measurements were carried out in the Point \& ID mode with spectrum acquisition time of $120 \mathrm{~s}$ and spectrum range of $0-10 \mathrm{keV}$. 


\section{FIGURES}

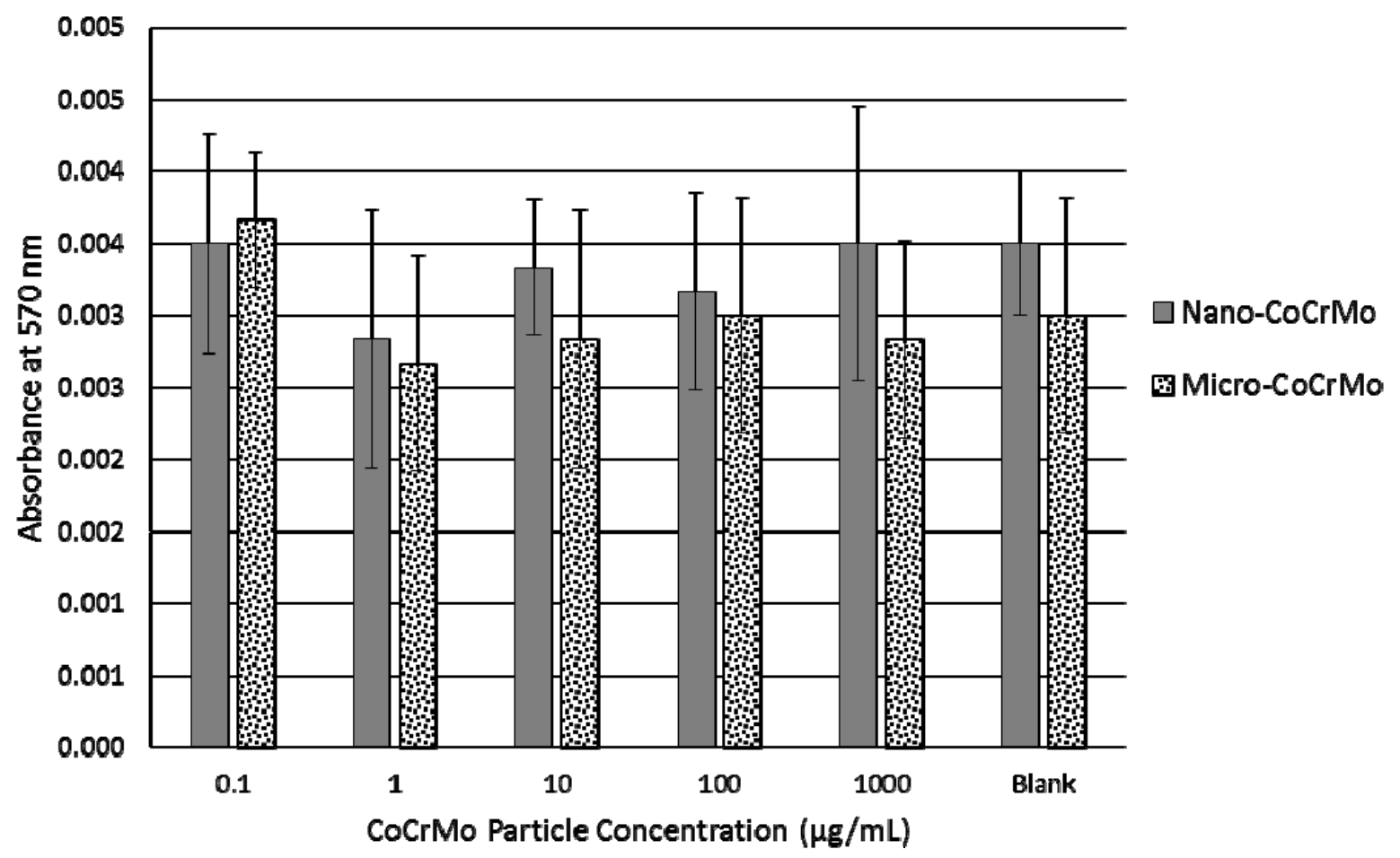

Figure S1. Background absorbance of DMEM containing MTT reagent (tetrazolinium salt) under assay conditions in the presence of CoCrMo particles or blank (control) to confirm the absence of artifacts at $570 \mathrm{~nm}$, the primary absorbance wavelength for formazan detection used in the MTT viability assay. 

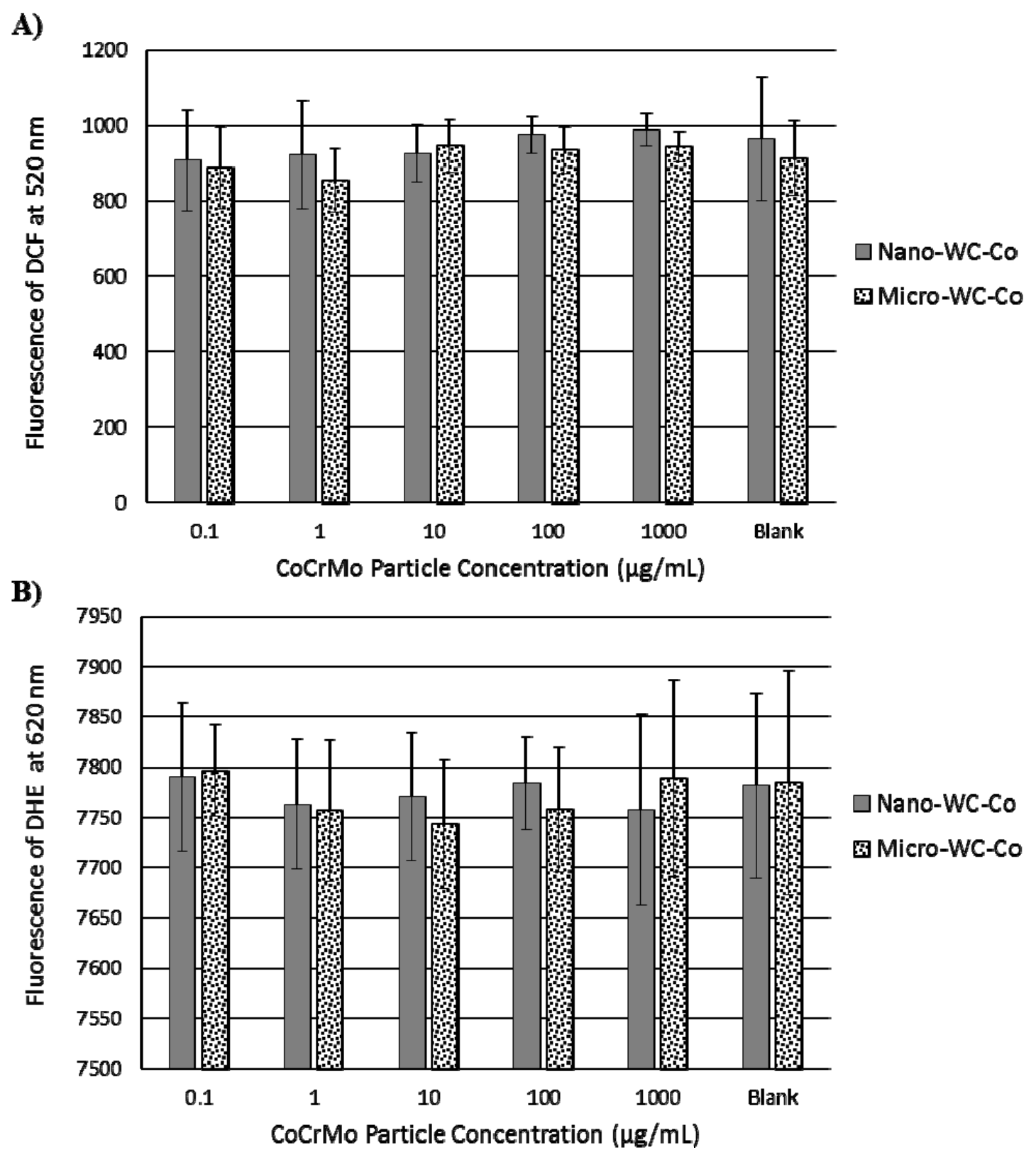

Figure S2. Background fluorescence of blank (PBS + dye only) and WC-Co particle suspensions in the absence of cells to confirm the absence of artifacts at the primary emission wavelengths for A) DCF at $520 \mathrm{~nm}$ and B) DHE at $620 \mathrm{~nm}$. 


\section{CHAPTER 6: \\ Research Summary and General Discussion}

A summary of our findings regarding nano-WC-Co toxicity and suggestions for future work 


\section{SUMMARY \& DISCUSSION}

Occupational exposure to hard metals such as WC-Co is an important concern in the field of nanotoxicology, since inhalation of WC-Co dusts and particles is known to cause hard metal lung disease (HMLD), marked by progressive lung inflammation, fibrosis and an increased risk of lung cancer $[101,102,105,110,111]$. Although WC-Co exposure is attributed as the cause of HMLD, the relationship between acute WC-Co toxicity and disease progression remains poorly understood. Previous in vitro studies focused on identifying the toxicity of micro-sized WC-Co particles and determined that the combination of WC with $\mathrm{Co}$ is responsible for the observed toxic effects, which are greater than that of the components (W, WC or Co) alone $[128,130-$ 153]; however, the mechanism underlying the enhanced toxicity of the WC-Co composite over W, WC or Co alone has not been identified. Additionally, the toxicity of micro-sized WC-Co has been verified in vivo, although these studies mainly focused on the local pulmonary effects of WC-Co exposure $[130,154-161]$. In general, there are fewer reports regarding the toxicity of nano-sized WC-Co [132-134, 137, 138, 150, 151], especially in vivo, which is concerning since nano-sized particles are generally thought to be more toxic and are capable of deeper airway penetration than their micro-sized counterparts during inhalation.

Therefore, the goal of my dissertation research project was to examine the toxic effects of nano-WC-Co, using relevant cell culture and animal models, to determine the toxicity of nanoWC-Co and shed light on potential mechanisms underlying disease progression. To achieve this goal, we systematically examined the toxicity of WC-Co using a variety of in vitro and in vivo models. In Specific Aim 1, we focused on the in vitro effects of nano-WC-Co particles on lung epithelial cells which line the upper and middle respiratory tract. This model is highly relevant due to the risk of pulmonary WC-Co exposure in industrial settings and the effects of WC-Co 
have yet to be reported in a non-carcinoma lung cell line. Here, we identified that nano-WC-Co was capable of inducing greater cellular toxicity and higher levels of oxidative stress than microWC-Co particles of the same composition under identical conditions. These results were consistent with the literature, where the enhanced toxicity of nano-sized over micro-sized particles has been clearly established $[25,31,32,44,205,238]$. Oxidative stress has been reported in human cells after exposure to micro-sized WC-Co in vitro, so our findings here seem consistent with earlier reports [132, 137, 140-144].

We further determined that cellular toxicity and death following WC-Co exposure occurs via induction of cellular apoptosis rather than necrosis, using flow cytometry, which indicated that WC-Co particles are capable of stimulating apoptotic signaling in lung epithelial cells. This finding is consistent with a previous study, where apoptosis was reported in human peripheral blood monocytes after as little as $6 \mathrm{hr}$ of WC-Co exposure [148]. Determining the primary apoptosis signaling cascade activated after exposure to WC-Co particles was beyond the scope of our study and remains to be identified; however, since high levels of oxidative stress can cause DNA damage, we speculate that apoptosis may occur in cells exposed to WC-Co due to reactive oxygen species-induced DNA damage and subsequent activation of caspases involved in apoptosis signaling $[52,136]$.

In HMLD patients, large deposits of WC-Co are often found in histological specimens, but the origin of these deposits is unknown. One theory suggests that these WC-Co deposits are due to macrophage phagocytosis of WC-Co particles [84, 299]: once the macrophage has engulfed the WC-Co particle, the macrophage is unable to eliminate the WC-Co particle via its normal lysosomal degradation process and as a result, WC-Co persists within the macrophage thereby forming a 'deposit'. Due to their small size, nano-WC-Co particles have been reportedly 
internalized by other non-phagocytic cell types such as neurons, colon and skin cells [132]. Consistent with this previous report, we found that lung epithelial cells are capable of internalizing WC-Co particles up to $500 \mathrm{~nm}$ in diameter in our study; therefore, we speculate that the origins of WC-Co deposits in HMLD patients may be multi-cellular in nature and could be due to the interaction of WC-Co with both lung epithelial cells and alveolar macrophages.

Since one of the hallmarks of HMLD is pulmonary inflammation, in Specific Aim 2, we examined the inflammatory response toward nano-WC-Co particles in macrophages and determined the toxicity of WC-Co using a co-culture of lung epithelial cells and macrophages to more closely represent the dynamic tissue environment of the lung. In our study, nano-WC-Co exposure stimulated an inflammatory response in macrophages, marked by high levels of IL-12 and IL-1 $\beta$ secretion. In HMLD, lung inflammation and fibrosis occur in a progressive fashion, so we speculate that the induction of a pro-inflammatory response in macrophages may be an important factor in HMLD. This idea is supported by literature which indicates that IL-1 in particular may play a role in pulmonary fibrosis [308], so it seems reasonable to suggest that WC-Co may induce a similar type of pulmonary inflammatory response which promotes lung fibrosis after inhalation.

Macrophages attenuated the toxicity of nano-WC-Co in our co-culture model compared to lung epithelial cells alone. This "protective" effect was attributed to the engulfment of nanoWC-Co by the macrophages, which confined the WC-Co particles to the intracellular environment of the macrophage itself, which thereby prevented direct interaction and toxicity of the nano-WC-Co toward lung epithelial cells. Although phagocytosis of WC-Co particles is part of the natural physiological macrophage response and seemed to play a protective role in our in vitro study, the long-term effects of WC-Co internalization in macrophages have not yet been 
reported and could potentially have a more detrimental effect. As mentioned earlier, WC-Co may not be degraded within the phago-lysosomal compartments inside the macrophage; the inability to eliminate WC-Co may exacerbate the inflammatory response of the macrophage over long term exposure and may play a role in the progressive inflammatory and fibrotic reaction due to chronic secretion of cytokines such as IL-1 [308].

In addition to exerting local toxicity at the site of exposure, emerging evidence in the field of nanotoxicology suggests that pulmonary NP exposure may cause systemic effects beyond the site of exposure in the lung $[37,66,164-175]$. Animal studies regarding the toxicity of WC-Co particles are limited, and in fact, the toxicity of nano-sized WC-Co has not yet been reported in vivo. Therefore, in Specific Aim 3, we conducted a preliminary in vivo study to investigate the local toxicity and potential systemic effects resulting from pulmonary nano-WCCo exposure in rats. Based on our in vitro outcomes in reported for Aims 1 and 2, we hypothesized that exposure to nano-WC-Co would cause pulmonary toxicity, inflammation and may cause an increase in the levels of circulating pro-inflammatory cytokines. However, we found an overall lack of toxicity and pulmonary inflammation after $24 \mathrm{hr}$ exposure to a single dose of nano-WC-Co.

This outcome was perplexing, as all of the evidence regarding the effects of WC-Co exposure thus far suggests that nano-WC-Co should cause acute toxicity both in vivo and in vitro. In this case, we speculate that we may have missed the inflammatory response since only a single exposure time $(24 \mathrm{hr}$ ) was used. While we selected our dosages based on the toxicity of WC-Co in vitro, it is possible that a single exposure at these concentrations in vivo simply did not generate enough pulmonary toxicity/inflammation to be effectively detected via the bronchoalveolar lavage technique; toxicity and inflammation may have occurred but not at detectable 
levels after the $24 \mathrm{hr}$ exposure time. It is also possible that the effects of nano-WC-Co exposure may occur in a cumulative fashion (i.e. toxicity is observed after repeated or chronic exposures) in vivo, so multiple/repeated exposure may be a prerequisite for WC-Co toxicity in whole animals. The outcomes of our preliminary in vivo nano-WC-Co study highlight the need for future studies to examine the systemic inflammatory effects of repeated or chronic nano-WC-Co exposure, which would more closely represent an actual occupational WC-Co NP exposure.

Overall, the results of this dissertation project confirm the toxic potential of WC-Co particles in the respiratory tract and highlight the importance of understanding the mechanism of WC-Co toxicity as it relates to HMLD. Based on our findings reported herein, we speculate that HMLD may be caused by the simultaneous acute toxicity of WC-Co in lung epithelial cells and the rapid inflammatory response generated by macrophages upon WC-Co internalization. The presence of apoptotic cells and secretion of inflammatory cytokines in the lung may stimulate an immune response designed to promote tissue repair; however, the persistence of WC-Co in the pulmonary region and likelihood for repeated exposures may shift this response toward a chronic inflammatory state which, in turn, may promote the fibrosis and therefore lead to the development of HMLD. This study, along with the existing body of literature regarding microWC-Co toxicity, highlights the detrimental effects of WC-Co NP exposure in occupational settings, including hard metal manufacturing facilities and mining and drilling industries and highlights the importance of defining occupational WC-Co exposure limits so that future generations of workers are protected from this harmful disease. Studies which examine the effects of chronic nano-WC-Co exposure in vitro and in vivo are warranted in the future, so that the link between WC-Co acute toxicity and development of a chronic inflammatory state observed in HMLD patients may be elucidated. 


\section{CHAPTER 7:}

References for Chapters 1-6 


\section{REFERENCES}

1. Schrand, A.M., et al., Toxicity testing of nanomaterials. Adv Exp Med Biol, 2012. 745: p. 58-75.

2. Song, Y., et al., Nanomaterials in humans: identification, characteristics, and potential damage. Toxicol Pathol, 2011. 39(5): p. 841-9.

3. Adlakha-Hutcheon, G., et al., NANOMATERIALS, NANOTECHNOLOGY Applications, Consumer Products, and Benefits. Nanomaterials: Risks and Benefits, 2009: p. 195-207.

4. Hansen, S.F., et al., NANOMATERIALS IN CONSUMER PRODUCTS Categorization and Exposure Assessment. Nanomaterials: Risks and Benefits, 2009: p. 359-367.

5. Stamm, H., N. Gibson, and E. Anklam, Detection of nanomaterials in food and consumer products: bridging the gap from legislation to enforcement. Food Additives and Contaminants Part a-Chemistry Analysis Control Exposure \& Risk Assessment, 2012. 29(8): p. 1175-1182.

6. $\quad$ Chekman, I.S., et al., The prospects of medical application of metal-based nanoparticles and nanomaterials. Lik Sprava, 2011(1-2): p. 3-21.

7. Cormode, D.P., et al., Nanotechnology in medical imaging: probe design and applications. Arterioscler Thromb Vasc Biol, 2009. 29(7): p. 992-1000.

8. de Silva, M.N., Nanotechnology and nanomedicine: a new horizon for medical diagnostics and treatment. Arch Soc Esp Oftalmol, 2007. 82(6): p. 331-4.

9. Lin, H. and R.H. Datar, Medical applications of nanotechnology. Natl Med J India, 2006. 19(1): p. 27-32.

10. Zhao, J. and V. Castranova, Toxicology of nanomaterials used in nanomedicine. J Toxicol Environ Health B Crit Rev, 2011. 14(8): p. 593-632.

11. Blynskaya, E.V., K.V. Alekseev, and R.N. Alyautdin, Perspectives of the development of pharmaceutical nanotechnology. Russian Journal of General Chemistry, 2012. 82(3): p. 519-526.

12. Chapman, P., Nanotechnology in the pharmaceutical industry. Expert Opinion on Therapeutic Patents, 2005. 15(3): p. 249-251.

13. Crommelin, D.J.A., K. Park, and A. Florence, Pharmaceutical nanotechnology: Unmet needs in drug delivery. Journal of Controlled Release, 2010. 141(3): p. 263-264.

14. Stolarczyka, E.U. and K. Stolarczyk, Perspectives of nanotechnology in medicine and pharmacy and its influence on pharmaceutical industry. Przemysl Chemiczny, 2007. 86(8): p. 797-799.

15. Cassee, F.R., et al., Exposure, health and ecological effects review of engineered nanoscale cerium and cerium oxide associated with its use as a fuel additive. Crit Rev Toxicol, 2011. 41(3): p. 213-29.

16. Lynam, D.R., et al., Environmental assessment of MMT fuel additive. Sci Total Environ, 1990. 93: p. 107-14.

17. Park, B., et al., Hazard and risk assessment of a nanoparticulate cerium oxide-based diesel fuel additive - a case study. Inhal Toxicol, 2008. 20(6): p. 547-66.

18. Madl, A.K., et al., Health Risk Ranking Framework for the Life Cycle of NanomaterialContaining Products: Comparison of Industrial Versus Consumer Application Settings. International Journal of Toxicology, 2013. 32(1): p. 65-69.

19. $\quad$ http://www.nanotechproject.org/cpi/about/analysis/. 2014. 
20. Arvidsson, R., S. Molander, and B.A. Sanden, Review of Potential Environmental and Health Risks of the Nanomaterial Graphene. Human and Ecological Risk Assessment, 2013. 19(4): p. 873-887.

21. Hristovski, K.D., et al., Environmental releases of engineered nanomaterial resulting from biosolids disposal to land and air. Abstracts of Papers of the American Chemical Society, 2012. 244.

22. Luo, X.Z.J., Nanomaterial Registry A resource for biological and environmental interactions of nanomaterials. 2012 Ieee International Conference on Bioinformatics and Biomedicine Workshops (Bibmw), 2012.

23. Eckelman, M.J., et al., New perspectives on nanomaterial aquatic ecotoxicity: production impacts exceed direct exposure impacts for carbon nanotoubes. Environ Sci Technol, 2012. 46(5): p. 2902-10.

24. Gaiser, B.K., et al., Assessing exposure, uptake and toxicity of silver and cerium dioxide nanoparticles from contaminated environments. Environ Health, 2009. 8 Suppl 1( Suppl 1): p. S2.

25. Buzea, C., I.I. Pacheco, and K. Robbie, Nanomaterials and nanoparticles: Sources and toxicity. Biointerphases, 2007. 2(4): p. Mr17-Mr71.

26. Keegan, G.M., I.D. Learmonth, and C.P. Case, A systematic comparison of the actual, potential, and theoretical health effects of cobalt and chromium exposures from industry and surgical implants. Crit Rev Toxicol, 2008. 38(8): p. 645-74.

27. Parry, M.C., et al., Blood levels of cobalt and chromium are inversely correlated to head size after metal-on-metal resurfacing arthroplasty. Hip International, 2013. 23(6): p. 529534.

28. Pourzal, R., et al., Characterization of Wear Particles Generated from CoCrMo Alloy under Sliding Wear Conditions. Wear, 2011. 271(9-10): p. 1658-1666.

29. Sansone, V., D. Pagani, and M. Melato, The effects on bone cells of metal ions released from orthopaedic implants. A review. Clin Cases Miner Bone Metab, 2013. 10(1): p. 3440.

30. Simeonova, P.P. and A. Erdely, Engineered nanoparticle respiratory exposure and potential risks for cardiovascular toxicity: predictive tests and biomarkers. Inhal Toxicol, 2009. 21 Suppl 1: p. 68-73.

31. Cattaneo, A.G., et al., Nanotechnology and human health: risks and benefits. J Appl Toxicol, 2010. 30(8): p. 730-44.

32. Castranova, V., Overview of current toxicological knowledge of engineered nanoparticles. J Occup Environ Med, 2011. 53(6 Suppl): p. S14-7.

33. Nurkiewicz, T.R., et al., Systemic microvascular dysfunction and inflammation after pulmonary particulate matter exposure. Environ Health Perspect, 2006. 114(3): p. 412-9.

34. Stapleton, P.A., et al., Xenobiotic particle exposure and microvascular endpoints: a call to arms. Microcirculation, 2012. 19(2): p. 126-42.

35. Nel, A.E., et al., Understanding biophysicochemical interactions at the nano-bio interface. Nat Mater, 2009. 8(7): p. 543-57.

36. Nurkiewicz, T.R., et al., Particulate matter exposure impairs systemic microvascular endothelium-dependent dilation. Environ Health Perspect, 2004. 112(13): p. 1299-306.

37. Nurkiewicz, T.R., et al., Pulmonary particulate matter and systemic microvascular dysfunction. Res Rep Health Eff Inst, 2011. 164: p. 3-48. 
38. Gill, H.S., et al., Molecular and immune toxicity of CoCr nanoparticles in MoM hip arthroplasty. Trends Mol Med, 2012. 18(3): p. 145-55.

39. Ingham, E. and J. Fisher, Biological reactions to wear debris in total joint replacement. Proceedings of the Institution of Mechanical Engineers Part H-Journal of Engineering in Medicine, 2000. 214(H1): p. 21-37.

40. Song, Y., X. Li, and X. Du, Exposure to nanoparticles is related to pleural effusion, pulmonary fibrosis and granuloma. . Eur Respir J, 2009. 34: p. 559-567.

41. Donaldson, K., et al., The biologically effective dose in inhalation nanotoxicology. Acc Chem Res, 2013. 46(3): p. 723-32.

42. Hubbs, A.F., et al., Nanotoxicology--a pathologist's perspective. Toxicol Pathol, 2011. 39(2): p. 301-24.

43. Lison, D., G. Vietti, and S. van den Brule, Paracelsus in nanotoxicology. Part Fibre Toxicol, 2014. 11(1): p. 35.

44. Boverhof, D.R. and R.M. David, Nanomaterial characterization: considerations and needs for hazard assessment and safety evaluation. Anal Bioanal Chem, 2010. 396(3): p. 953-61.

45. Richman, E.K. and J.E. Hutchison, The nanomaterial characterization bottleneck. ACS Nano, 2009. 3(9): p. 2441-6.

46. Bohnsack, J.P., et al., The primacy of physicochemical characterization of nanomaterials for reliable toxicity assessment: a review of the zebrafish nanotoxicology model. Methods Mol Biol, 2012. 926: p. 261-316.

47. Takhar, P. and S. Mahant, In vitro methods for nanotoxicity assessment: advantages and applications. Arch Appl Sci Res, 2011. 3(2): p. 389-403.

48. Papageorgiou, I., et al., The effect of nano- and micron-sized particles of cobaltchromium alloy on human fibroblasts in vitro. Biomaterials, 2007. 28(19): p. 2946-2958.

49. Papageorgiou, I., et al., Macrophages detoxify the genotoxic and cytotoxic effects of surgical cobalt chrome alloy particles but not quartz particles on human cells in vitro. Mutat Res, 2008. 643(1-2): p. 11-9.

50. Papageorgiou, I., et al., Genotoxic effects of particles of surgical cobalt chrome alloy on human cells of different age in vitro. Mutat Res, 2007. 619(1-2): p. 45-58.

51. Sun, L., et al., Cytotoxicity and mitochondrial damage caused by silica nanoparticles. Toxicol In Vitro, 2011. 25(8): p. 1619-29.

52. Park, E.J., et al., Oxidative stress and apoptosis induced by titanium dioxide nanoparticles in cultured BEAS-2B cells. Toxicol Lett, 2008. 180(3): p. 222-9.

53. Wilhelmi, V., et al., Evaluation of apoptosis induced by nanoparticles and fine particles in RAW 264.7 macrophages: facts and artefacts. Toxicol In Vitro, 2012. 26(2): p. 32334.

54. Guadagnini, R., et al., Toxicity screenings of nanomaterials: challenges due to interference with assay processes and components of classic in vitro tests. . Nanotoxicology, 2013. Epub ahead of print: p. DOI 0.3109/17435390.2013.829590.

55. Holder, A.L., et al., Particle-induced artifacts in the MTT and LDH viability assays. Chem Res Toxicol, 2012. 25(9): p. 1885-92.

56. Kroll, A., et al., Interference of engineered nanoparticles with in vitro toxicity assays. Arch Toxicol, 2012. 86(7): p. 1123-36. 
57. Lupu, A.R. and T. Popescu, The noncellular reduction of MTT tetrazolium salt by TiO(2) nanoparticles and its implications for cytotoxicity assays. Toxicol In Vitro, 2013. 27(5): p. 1445-50.

58. Guadagnini, R., et al., Toxicity screenings of nanomaterials: challenges due to interference with assay processes and components of classic in vitro tests. Nanotoxicology, 2013. epub ahead of print: p. DOI 10.3109/17435390.2013.829590.

59. Fischer, H.C. and W.C.W. Chan, Nanotoxicity: the growing need for in vivo study. Current Opinion in Biotechnology, 2007. 18(6): p. 565-571.

60. Rizzo, L.Y., et al., In vivo nanotoxicity testing using the zebrafish embryo assay. Journal of Materials Chemistry B, 2013. 1(32): p. 3918-3925.

61. Shelley, M.L., et al., Modeling the In Vivo Case with In Vitro Nanotoxicity Data. International Journal of Toxicology, 2008. 27(5): p. 359-367.

62. Henderson, R.F., et al., A comparison of the inflammatory response of the lung to inhaled versus instilled particles in F344 rats. Fundam Appl Toxicol, 1995. 24(2): p. 183-97.

63. Blum, J.L., et al., Short-term inhalation of cadmium oxide nanoparticles alters pulmonary dynamics associated with lung injury, inflammation, and repair in a mouse model. Inhal Toxicol, 2014. 26(1): p. 48-58.

64. Pauluhn, J., Subchronic inhalation toxicity of iron oxide (magnetite, $\mathrm{Fe}(3) \mathrm{O}(4)$ ) in rats: pulmonary toxicity is determined by the particle kinetics typical of poorly soluble particles. J Appl Toxicol, 2012. 32(7): p. 488-504.

65. Minarchick, V.C., et al., Pulmonary cerium dioxide nanoparticle exposure differentially impairs coronary and mesenteric arteriolar reactivity. Cardiovasc Toxicol, 2013. 13(4): p. 323-37.

66. Choi, M., et al., Chitosan nanoparticles show rapid extrapulmonary tissue distribution and excretion with mild pulmonary inflammation to mice. Toxicol Lett, 2010. 199(2): p. 144-52.

67. Brown, C., et al., Consequences of exposure to peri-articular injections of micro- and nano-particulate cobalt-chromium alloy. Biomaterials, 2013. 34(34): p. 8564-80.

68. Wang, Z., et al., Reproductive toxicity in adult male rats following intra-articular injection of cobalt-chromium nanoparticles. Journal of Orthopaedic Science, 2013. 18(6): p. 1020-1026.

69. Gaiser, B.K., et al., Effects of silver and cerium dioxide micro- and nano-sized particles on Daphnia magna. J Environ Monit, 2011. 13(5): p. 1227-35.

70. Yao, Z., J. Stiglich, and T. Sudarshan, Nanosized WC-Co holds promise for the future. Metal Powder Report, 1998. 53(3): p. 26-33.

71. Yao, Z., J. Stiglich, and T. Sudarshan, Nano-grained Tungsten Carbide-Cobalt (WC/Co). Materials Modification Inc., 1995. http://www.matmod.com/publications/armor_1.pdf: p. 1-27.

72. Linnainmaa, M., J. Kangas, and P. Kalliokoski, Exposure to airborne metals in the manufacture and maintenance of hard metal and stellite blades. Am Ind Hyg Assoc J, 1996. 57(2): p. 196-201.

73. Balmes, J.R., Respiratory effects of hard-metal dust exposure. Occup Med, 1987. 2(2): p. 327-44.

74. Broding, H.C., et al., Comparison between exhaled breath condensate analysis as a marker for cobalt and tungsten exposure and biomonitoring in workers of a hard metal alloy processing plant. Int Arch Occup Environ Health, 2009. 82(5): p. 565-73. 
75. Day, G.A., M.A. Virji, and A.B. Stefaniak, Characterization of exposures among cemented tungsten carbide workers. Part II: Assessment of surface contamination and skin exposures to cobalt, chromium and nickel. J Expo Sci Environ Epidemiol, 2009. 19(4): p. 423-34.

76. Guffey, S.E., et al., Hard metal exposures. Part 1: Observed performance of three local exhaust ventilation systems. Appl Occup Environ Hyg, 2000. 15(4): p. 331-41.

77. Kraus, T., et al., Exposure assessment in the hard metal manufacturing industry with special regard to tungsten and its compounds. Occup Environ Med, 2001. 58(10): p. 6314.

78. Stefaniak, A.B., M.A. Virji, and G.A. Day, Characterization of exposures among cemented tungsten carbide workers. Part I: Size-fractionated exposures to airborne cobalt and tungsten particles. J Expo Sci Environ Epidemiol, 2009. 19(5): p. 475-91.

79. Stefaniak, A.B., et al., Characteristics of dusts encountered during the production of cemented tungsten carbides. Ind Health, 2007. 45(6): p. 793-803.

80. National Toxicology, P., Cobalt-tungsten carbide: powders and hard metals. Rep Carcinog, 2011. 12: p. 115-20.

81. Demedts, M. and J.L. Ceuppens, Respiratory diseases from hard metal or cobalt exposure. Solving the enigma. Chest, 1989. 95(1): p. 2-3.

82. Kumagai, S., Y. Kusaka, and S. Goto, Cobalt exposure level and variability in the hard metal industry of Japan. Am Ind Hyg Assoc J, 1996. 57(4): p. 365-9.

83. Kusaka, Y. and S. Goto, Is there an occupational exposure limit (TLV) present for cobalt? A lesson from hard metal disease in Japan. Advances in the Prevention of Occupational Respiratory Diseases, 1998. 1153: p. 388-392.

84. Anttila, S., et al., Hard metal lung disease: a clinical, histological, ultrastructural and Xray microanalytical study. Eur J Respir Dis, 1986. 69(2): p. 83-94.

85. Chiappino, G., Hard metal disease: clinical aspects. Sci Total Environ, 1994. 150(1-3): p. 65-8.

86. Cullen, M.R., Respiratory diseases from hard metal exposure. A continuing enigma. Chest, 1984. 86(4): p. 513-4.

87. Fischbein, A., et al., Hard metal disease: a multidisciplinary evaluation of two cases. N Y State J Med, 1986. 86(11): p. 600-3.

88. Galy, P., et al., Pulmonary disorders in the hard metal industry. Rev Inst Hyg Mines (Hasselt), 1974. 29(3): p. 130-7.

89. Hartmann, A., B. Wuthrich, and G. Bolognini, Occupation-related lung diseases in hard metal production and manufacturing. An allergic process? Schweiz Med Wochenschr, 1982. 112(33): p. 1137-41.

90. Hartung, M., Etiology, pathogenesis and clinical aspects of hard metal fibrosis of the lung. Pneumologie, 1990. 44(2): p. 49-54.

91. Hartung, M. and H. Valentin, Pulmonary fibrosis caused by hard-metal dusts. Zentralbl Bakteriol Mikrobiol Hyg B, 1983. 177(3-4): p. 237-50.

92. Kishimoto, T., I. Yamadori, and Y. Kawabata, Interstitial pneumonia induced by the inhalation of hard metal. Nihon Kokyuki Gakkai Zasshi, 1999. 37(9): p. 704-9.

93. Kitaichi, M. and Y. Kitagawa, Hard metal disease. Ryoikibetsu Shokogun Shirizu, 1994(3): p. 566-8.

94. Kusaka, Y., et al., Bronchopulmonary diseases due to ultra-hard metal dust, with special reference to the result of the dust analysis. Sangyo Igaku, 1983. 25(3): p. 155-60. 
95. Kusaka, Y., O. Kuwabara, and H. Kitamura, A case of diffuse lung disease associated with lung cancer in a hard metal worker. Nihon Kyobu Shikkan Gakkai Zasshi, 1984. 22(9): p. 804-8.

96. Kusaka, Y., et al., Bronchopulmonary diseases due to the hard metal dust. Sangyo Igaku, 1982. 24(6): p. 636-48.

97. Lasfargues, G., et al., Lung cancer mortality in a French cohort of hard-metal workers. Am J Ind Med, 1994. 26(5): p. 585-95.

98. Meyer-Bisch, C., et al., Respiratory hazards in hard metal workers: a cross sectional study. Br J Ind Med, 1989. 46(5): p. 302-9.

99. Montero, M.A., J. de Gracia, and F. Morell, Hard metal interstitial lung disease. Arch Bronconeumol, 2010. 46(9): p. 489-91.

100. Moulin, J.J., et al., Lung cancer risk in hard-metal workers. Am J Epidemiol, 1998. 148(3): p. 241-8.

101. Nemery, B. and J.L. Abraham, Hard metal lung disease: still hard to understand. Am J Respir Crit Care Med, 2007. 176(1): p. 2-3.

102. Nemery, B., E.K. Verbeken, and M. Demedts, Giant cell interstitial pneumonia (hard metal lung disease, cobalt lung). Semin Respir Crit Care Med, 2001. 22(4): p. 435-48.

103. Ott, G. and G. Mikuz, Hard metal pulmonary fibrosis. Dtsch Med Wochenschr, 1982. 107(37): p. 1396-9.

104. Rivolta, G., et al., Hard metal lung disorders: analysis of a group of exposed workers. Sci Total Environ, 1994. 150(1-3): p. 161-5.

105. Rizzato, G., et al., The differential diagnosis of hard metal lung disease. Sci Total Environ, 1994. 150(1-3): p. 77-83.

106. Rochat, T., et al., Rapidly progressive interstitial lung disease in a hard metal coating worker undergoing hemodialysis. Eur J Respir Dis, 1987. 71(1): p. 46-51.

107. Ruokonen, E.L., et al., A fatal case of hard-metal disease. Scand J Work Environ Health, 1996. 22(1): p. 62-5.

108. Scherrer, M. and J.M. Maillard, Hard metal pneumopathies. Schweiz Med Wochenschr, 1982. 112(6): p. 198-207.

109. Scherrer, M., et al., 3 cases of hard metal dust lung disease. Schweiz Med Wochenschr, 1970. 100(52): p. 2251-5.

110. Forni, A., Bronchoalveolar lavage in the diagnosis of hard metal disease. Sci Total Environ, 1994. 150(1-3): p. 69-76.

111. Kinoshita, M., et al., Giant cell interstitial pneumonia in two hard metal workers: the role of bronchoalveolar lavage in diagnosis. Respirology, 1999. 4(3): p. 263-6.

112. Bezerra, P.N., et al., Hard metal lung disease in an oil industry worker. J Bras Pneumol, 2009. 35(12): p. 1254-8.

113. Dunlop, P., et al., Hard metal lung disease: high resolution CT and histologic correlation of the initial findings and demonstration of interval improvement. J Thorac Imaging, 2005. 20(4): p. 301-4.

114. Moriyama, H., et al., Two-dimensional analysis of elements and mononuclear cells in hard metal lung disease. Am J Respir Crit Care Med, 2007. 176(1): p. 70-7.

115. Potolicchio, I., et al., Susceptibility to hard metal lung disease is strongly associated with the presence of glutamate 69 in HLA-DP beta chain. Eur J Immunol, 1997. 27(10): p. 2741-3. 
116. Rizzato, G., et al., Trace of metal exposure in hard metal lung disease. Chest, 1986. 90(1): p. 101-6.

117. Tanaka, J., et al., An observational study of giant cell interstitial pneumonia and lung fibrosis in hard metal lung disease. BMJ Open, 2014. 4(3): p. e004407.

118. Wahbi, Z.K., A.G. Arnold, and A.J. Taylor, Hard metal lung disease and pneumothorax. Respir Med, 1997. 91(2): p. 103-5.

119. Nureki, S., et al., Hard metal lung disease successfully treated with inhaled corticosteroids. Intern Med, 2013. 52(17): p. 1957-61.

120. Enriquez, L.S., et al., Hard metal pneumoconiosis: a case of giant-cell interstitial pneumonitis in a machinist. Respir Care, 2007. 52(2): p. 196-9.

121. Kaneko, Y., et al., Upper lobe-dominant pulmonary fibrosis showing deposits of hard metal component in the fibrotic lesions. Intern Med, 2010. 49(19): p. 2143-5.

122. Okuno, K., et al., A case of hard metal lung disease resembling a hypersensitive pneumonia in radiological images. Intern Med, 2010. 49(12): p. 1185-9.

123. Blanc, P.D., Is giant cell interstitial pneumonitis synonymous with hard metal lung disease? Am J Respir Crit Care Med, 2007. 176(8): p. 834; author reply 834-5.

124. Naqvi, A.H., et al., Pathologic spectrum and lung dust burden in giant cell interstitial pneumonia (hard metal disease/cobalt pneumonitis): review of 100 cases. Arch Environ Occup Health, 2008. 63(2): p. 51-70.

125. Ohori, N.P., et al., Giant-cell interstitial pneumonia and hard-metal pneumoconiosis. A clinicopathologic study of four cases and review of the literature. Am J Surg Pathol, 1989. 13(7): p. 581-7.

126. Tabatowski, K., et al., Giant cell interstitial pneumonia in a hard-metal worker. Cytologic, histologic and analytical electron microscopic investigation. Acta Cytol, 1988. 32(2): p. 240-6.

127. Wada, M., et al., A case report of hard metal lung with giant cell interstitial pneumonia. Nihon Kyobu Shikkan Gakkai Zasshi, 1986. 24(6): p. 703-9.

128. Lison, D., et al., Experimental research into the pathogenesis of cobalt/hard metal lung disease. Eur Respir J, 1996. 9(5): p. 1024-8.

129. Ruediger, H.W., Hard metal particles and lung disease: coincidence or causality? Respiration, 2000. 67(2): p. 137-8.

130. Huaux, F., et al., Lung toxicity of hard metal particles and production of interleukin-1, tumor necrosis factor-alpha, fibronectin, and cystatin-c by lung phagocytes. Toxicol Appl Pharmacol, 1995. 132(1): p. 53-62.

131. Antonini, J.M., et al., Changes in F-actin organization induced by hard metal particle exposure in rat pulmonary epithelial cells using laser scanning confocal microscopy. In Vitr Mol Toxicol, 2000. 13(1): p. 5-16.

132. Bastian, S., et al., Toxicity of tungsten carbide and cobalt-doped tungsten carbide nanoparticles in mammalian cells in vitro. Environ Health Perspect, 2009. 117(4): p. 530-6.

133. Busch, W., et al., Tungsten carbide cobalt nanoparticles exert hypoxia-like effects on the gene expression level in human keratinocytes. BMC Genomics, 2010. 11: p. 65.

134. De Boeck, M., et al., In vitro genotoxic effects of different combinations of cobalt and metallic carbide particles. Mutagenesis, 2003. 18(2): p. 177-86.

135. Edel, J., et al., Trace metal lung disease: in vitro interaction of hard metals with human lung and plasma components. Sci Total Environ, 1990. 95: p. 107-17. 
136. Fenoglio, I., et al., The oxidation of glutathione by cobalt/tungsten carbide contributes to hard metal-induced oxidative stress. Free Radic Res, 2008. 42(8): p. 437-45.

137. Kuhnel, D., et al., Agglomeration of tungsten carbide nanoparticles in exposure medium does not prevent uptake and toxicity toward a rainbow trout gill cell line. Aquat Toxicol, 2009. 93(2-3): p. 91-9.

138. Kuhnel, D., et al., Comparative evaluation of particle properties, formation of reactive oxygen species and genotoxic potential of tungsten carbide based nanoparticles in vitro. J Hazard Mater, 2012. 227-228: p. 418-26.

139. Lison, D., Human toxicity of cobalt-containing dust and experimental studies on the mechanism of interstitial lung disease (hard metal disease). Crit Rev Toxicol, 1996. 26(6): p. 585-616.

140. Lison, D., et al., Physicochemical mechanism of the interaction between cobalt metal and carbide particles to generate toxic activated oxygen species. Chem Res Toxicol, 1995. 8(4): p. 600-6.

141. Lison, D. and R. Lauwerys, In vitro cytotoxic effects of cobalt-containing dusts on mouse peritoneal and rat alveolar macrophages. Environ Res, 1990. 52(2): p. 187-98.

142. Lison, D. and R. Lauwerys, Biological responses of isolated macrophages to cobalt metal and tungsten carbide-cobalt powders. Pharmacol Toxicol, 1991. 69(4): p. 282-5.

143. Lison, D. and R. Lauwerys, Study of the mechanism responsible for the elective toxicity of tungsten carbide-cobalt powder toward macrophages. Toxicol Lett, 1992. 60(2): p. 203-10.

144. Lison, D. and R. Lauwerys, Evaluation of the role of reactive oxygen species in the interactive toxicity of carbide-cobalt mixtures on macrophages in culture. Arch Toxicol, 1993. 67(5): p. 347-51.

145. Lison, D. and R. Lauwerys, Cobalt bioavailability from hard metal particles. Further evidence that cobalt alone is not responsible for the toxicity of hard metal particles. Arch Toxicol, 1994. 68(8): p. 528-31.

146. Lison, D. and R. Lauwerys, The interaction of cobalt metal with different carbides and other mineral particles on mouse peritoneal macrophages. Toxicol In Vitro, 1995. 9(3): p. 341-7.

147. Lombaert, N., et al., Hard-metal (WC-Co) particles trigger a signaling cascade involving p38 MAPK, HIF-1alpha, HMOX1, and p53 activation in human PBMC. Arch Toxicol, 2012. 87(2): p. 259-68.

148. Lombaert, N., et al., Evaluation of the apoptogenic potential of hard metal dust (WC-Co), tungsten carbide and metallic cobalt. Toxicol Lett, 2004. 154(1-2): p. 23-34.

149. Lombaert, N., et al., In vitro expression of hard metal dust (WC-Co)--responsive genes in human peripheral blood mononucleated cells. Toxicol Appl Pharmacol, 2008. 227(2): p. 299-312.

150. Anard, D., et al., In vitro genotoxic effects of hard metal particles assessed by alkaline single cell gel and elution assays. Carcinogenesis, 1997. 18(1): p. 177-84.

151. Ding, M., et al., Size-dependent effects of tungsten carbide-cobalt particles on oxygen radical production and activation of cell signaling pathways in murine epidermal cells. Toxicol Appl Pharmacol, 2009. 241(3): p. 260-8.

152. Roesems, G., et al., In vitro cytotoxicity of various forms of cobalt for rat alveolar macrophages and type II pneumocytes. Toxicol Appl Pharmacol, 2000. 162(1): p. 2-9. 
153. Zhang, X.D., et al., Tungsten carbide-cobalt particles activate Nrf2 and its downstream target genes in JB6 cells possibly by ROS generation. J Environ Pathol Toxicol Oncol, 2010. 29(1): p. 31-40.

154. Kitamura, H., et al., Effects of cemented tungsten carbide dust on rat lungs following intratracheal injection of saline suspension. Acta Pathol Jpn, 1980. 30(2): p. 241-53.

155. Lasfargues, G., et al., The delayed lung responses to single and repeated intratracheal administration of pure cobalt and hard metal powder in the rat. Environ Res, 1995. 69(2): p. 108-21.

156. Lasfargues, G., et al., Comparative study of the acute lung toxicity of pure cobalt powder and cobalt-tungsten carbide mixture in rat. Toxicol Appl Pharmacol, 1992. 112(1): p. 4150 .

157. De Boeck, M., et al., In vivo genotoxicity of hard metal dust: induction of micronuclei in rat type II epithelial lung cells. Carcinogenesis, 2003. 24(11): p. 1793-800.

158. Fedan, J.S. and D. Cutler, Hard metal-induced disease: effects of metal cations in vitro on guinea pig isolated airways. Toxicol Appl Pharmacol, 2001. 174(3): p. 199-206.

159. Rengasamy, A., et al., Effects of hard metal on nitric oxide pathways and airway reactivity to methacholine in rat lungs. Toxicol Appl Pharmacol, 1999. 157(3): p. 178-91.

160. Kerfoot, E.J., W.G. Fredrick, and E. Domeier, Cobalt metal inhalation studies on miniature swine. Am Ind Hyg Assoc J, 1975. 36(1): p. 17-25.

161. Adamis, Z., et al., A study on lung toxicity of respirable hard metal dusts in rats. Ann Occup Hyg, 1997. 41(5): p. 515-26.

162. Hartung, M., K.H. Schaller, and E. Brand, On the question of the pathogenetic importance of cobalt for hard metal fibrosis of the lung. Int Arch Occup Environ Health, 1982. 50(1): p. 53-7.

163. Migliori, M., et al., Hard metal disease: eight workers with interstitial lung fibrosis due to cobalt exposure. Sci Total Environ, 1994. 150(1-3): p. 187-96.

164. Geraets, L., et al., Tissue distribution of inhaled micro- and nano-sized cerium oxide particles in rats: results from a 28-day exposure study. Toxicol Sci, 2012. 127(2): p. 46373.

165. He, X., et al., Lung deposition and extrapulmonary translocation of nano-ceria after intratracheal instillation. Nanotechnology, 2010. 21(28): p. 285103.

166. Kang, G.S., et al., Long-term inhalation exposure to nickel nanoparticles exacerbated atherosclerosis in a susceptible mouse model. Environ Health Perspect, 2011. 119(2): p. 176-81.

167. Kang, G.S., et al., Comparative pulmonary toxicity of inhaled nickel nanoparticles; role of deposited dose and solubility. Inhal Toxicol, 2011. 23(2): p. 95-103.

168. Knuckles, T.L., et al., Nanoparticle inhalation alters systemic arteriolar vasoreactivity through sympathetic and cyclooxygenase-mediated pathways. Nanotoxicology, 2012. 6(7): p. 724-35.

169. LeBlanc, A.J., et al., Nanoparticle inhalation impairs coronary microvascular reactivity via a local reactive oxygen species-dependent mechanism. Cardiovasc Toxicol, 2010. 10(1): p. 27-36.

170. Ma, J.Y., et al., Cerium oxide nanoparticle-induced pulmonary inflammation and alveolar macrophage functional change in rats. Nanotoxicology, 2011. 5(3): p. 312-25. 
171. McKinney, W., et al., Pulmonary and cardiovascular responses of rats to inhalation of a commercial antimicrobial spray containing titanium dioxide nanoparticles. Inhal Toxicol, 2012. 24(7): p. 447-57.

172. Nurkiewicz, T.R., et al., Pulmonary nanoparticle exposure disrupts systemic microvascular nitric oxide signaling. Toxicol Sci, 2009. 110(1): p. 191-203.

173. Sriram, K., et al., Neurotoxicity following acute inhalation exposure to the oil dispersant COREXIT EC9500A. J Toxicol Environ Health A, 2011. 74(21): p. 1405-18.

174. Zhu, M.T., et al., Particokinetics and extrapulmonary translocation of intratracheally instilled ferric oxide nanoparticles in rats and the potential health risk assessment. Toxicol Sci, 2009. 107(2): p. 342-51.

175. Oberdorster, G., Lung particle overload: implications for occupational exposures to particles. Regul Toxicol Pharmacol, 1995. 21(1): p. 123-35.

176. Li, J.J., et al., Nanoparticle-induced pulmonary toxicity. Exp Biol Med (Maywood), 2010. 235(9): p. 1025-33.

177. Cugell, D.W., The hard metal diseases. Clin Chest Med, 1992. 13(2): p. 269-79.

178. Trautmann, H., Pneumoconiosis due to inhaltion of hard metal dusts. Hefte Unfallheilkd, 1958. 56: p. 99-103.

179. Bech, A.O., M.D. Kipling, and J.C. Heather, Hard metal disease. Br J Ind Med, 1962. 19: p. 239-52.

180. Heuer, W., Pulmonary fibrosis in hard metal-production workers. Int Arch Gewerbepathol Gewerbehyg, 1962. 19: p. 613-32.

181. Beritic, T., et al., Pheumoconiosis Caused by Hard Metal Dust. Arh Hig Rada Toksikol, 1963. 14: p. 261-8.

182. Joseph, M., Hard metal pneumoconiosis. Australas Radiol, 1968. 12(2): p. 92-5.

183. Schutze, S., et al., Inhibition of receptor internalization by monodansylcadaverine selectively blocks p55 tumor necrosis factor receptor death domain signaling. J Biol Chem, 1999. 274(15): p. 10203-12.

184. Nunez, J., et al., Competitive inhibition of colchicine binding to tubulin by microtubuleassociated proteins. Proc Natl Acad Sci U S A, 1979. 76(1): p. 86-90.

185. Cooper, J.A., Effects of cytochalasin and phalloidin on actin. J Cell Biol, 1987. 105(4): p. $1473-8$.

186. Val, S., et al., Carbon black and titanium dioxide nanoparticles induce pro-inflammatory responses in bronchial epithelial cells: need for multiparametric evaluation due to adsorption artifacts. Inhal Toxicol, 2009. 21 Suppl 1: p. 115-22.

187. Canton, I. and G. Battaglia, Endocytosis at the nanoscale. Chem Soc Rev, 2012. 41(7): p. 2718-39.

188. Champion, J.A. and S. Mitragotri, Role of target geometry in phagocytosis. Proc Natl Acad Sci U S A, 2006. 103(13): p. 4930-4.

189. dos Santos, T., et al., Effects of transport inhibitors on the cellular uptake of carboxylated polystyrene nanoparticles in different cell lines. PLoS One, 2011. 6(9): p. e24438.

190. Wu, Y.-L., et al., Biophysical Responses upon the Interaction of Nanomaterials with Cellular Interfaces. Acc Chem Res, 2012. 46(3): p. 782-91.

191. Zhang, L.W. and N.A. Monteiro-Riviere, Mechanisms of quantum dot nanoparticle cellular uptake. Toxicol Sci, 2009. 110(1): p. 138-55.

192. Shivapurkar, N., et al., Apoptosis and lung cancer: a review. J Cell Biochem, 2003. 88(5): p. 885-98. 
193. Stieber, P. and S. Holdenrieder, Lung cancer biomarkers - Where we are and what we need. Cancer Biomark, 2010. 6(3-4): p. 221-4.

194. Holdenrieder, S. and P. Stieber, Circulating apoptotic markers in the management of non-small cell lung cancer. Cancer Biomark, 2010. 6(3-4): p. 197-210.

195. Stearns, R.C., J.D. Paulauskis, and J.J. Godleski, Endocytosis of ultrafine particles by A549 cells. Am J Respir Cell Mol Biol, 2001. 24(2): p. 108-15.

196. Gotway, M.B., et al., Hard metal interstitial lung disease: high-resolution computed tomography appearance. J Thorac Imaging, 2002. 17(4): p. 314-8.

197. Mariano, A., P. Sartorelli, and A. Innocenti, Evolution of hard metal pulmonary fibrosis in two artisan grinders of woodworking tools. Sci Total Environ, 1994. 150(1-3): p. 21921.

198. Matejka, M.H., et al., Heavy metal deposits in pathologically modified hard tissues. Clinical and experimental studies. Wien Med Wochenschr, 1985. 135(21): p. 523-5.

199. Rizzato, G., et al., Multi-element follow up in biological specimens of hard metal pneumoconiosis. Sarcoidosis, 1992. 9(2): p. 104-17.

200. Armstead, A. and B. Li, Nanomedicine as an emerging approach against intracellular pathogens. International Journal of Nanomedicine, 2011. 6(1): p. 3281-3293.

201. Luo, H., et al., Kaempferol nanoparticles achieve strong and selective inhibition of ovarian cancer cell viability. Int J Nanomedicine, 2012. 7: p. 3951-9.

202. Wang, X.F., B. Ding, and B.Y. Li, Biomimetic electrospun nanofibrous structures for tissue engineering. Materials Today, 2013. 16(6): p. 229-241.

203. Goddette, D.W. and C. Frieden, Actin polymerization. The mechanism of action of cytochalasin D. J Biol Chem, 1986. 261(34): p. 15974-80.

204. Elkjaer, M.L., et al., Effects of microtubule disruption on endocytosis, membrane recycling and polarized distribution of Aquaporin-1 and gp330 in proximal tubule cells. Eur J Cell Biol, 1995. 67(1): p. 57-72.

205. Geiser, M., Morphological aspects of particle uptake by lung phagocytes. Microsc Res Tech, 2002. 57(6): p. 512-22.

206. Muhlfeld, C., et al., Interactions of nanoparticles with pulmonary structures and cellular responses. Am J Physiol Lung Cell Mol Physiol, 2008. 294(5): p. L817-29.

207. Miyata, R. and S.F. van Eeden, The innate and adaptive immune response induced by alveolar macrophages exposed to ambient particulate matter. Toxicol Appl Pharmacol, 2011. 257(2): p. 209-26.

208. Gosens, I., et al., Impact of agglomeration state of nano- and submicron sized gold particles on pulmonary inflammation. Part Fibre Toxicol, 2010. 7(1): p. 37.

209. Niwa, Y., et al., Inhalation exposure to carbon black induces inflammatory response in rats. Circ J, 2008. 72(1): p. 144-9.

210. Azad, N., Y. Rojanasakul, and V. Vallyathan, Inflammation and lung cancer: roles of reactive oxygen/nitrogen species. J Toxicol Environ Health B Crit Rev, 2008. 11(1): p. 115.

211. Sica, A. and A. Mantovani, Macrophage plasticity and polarization: in vivo veritas. J Clin Invest, 2012. 122(3): p. 787-95.

212. Mosser, D.M., The many faces of macrophage activation. J Leukoc Biol, 2003. 73(2): p. 209-12.

213. Mantovani, A., et al., The chemokine system in diverse forms of macrophage activation and polarization. Trends Immunol, 2004. 25(12): p. 677-86. 
214. Aron-Wisnewsky, J., et al., Human adipose tissue macrophages: $m 1$ and $m 2$ cell surface markers in subcutaneous and omental depots and after weight loss. J Clin Endocrinol Metab, 2009. 94(11): p. 4619-23.

215. Daigneault, M., et al., The identification of markers of macrophage differentiation in PMA-stimulated THP-1 cells and monocyte-derived macrophages. PLoS One, 2010. 5(1): p. e8668.

216. Chao, J., J.G. Wood, and N.C. Gonzalez, Alveolar macrophages initiate the systemic microvascular inflammatory response to alveolar hypoxia. Respir Physiol Neurobiol, 2011. 178(3): p. 439-48.

217. Martinez, F.O., et al., Transcriptional profiling of the human monocyte-to-macrophage differentiation and polarization: new molecules and patterns of gene expression. $\mathrm{J}$ Immunol, 2006. 177(10): p. 7303-11.

218. Hao, N.B., et al., Macrophages in tumor microenvironments and the progression of tumors. Clin Dev Immunol, 2012. 2012: p. 948098.

219. Quatromoni, J.G. and E. Eruslanov, Tumor-associated macrophages: function, phenotype, and link to prognosis in human lung cancer. Am J Transl Res, 2012. 4(4): p. 376-89.

220. Gustafsson, A., et al., Lung exposure of titanium dioxide nanoparticles induces innate immune activation and long-lasting lymphocyte response in the Dark Agouti rat. J Immunotoxicol, 2011. 8(2): p. 111-21.

221. Haberl, N., et al., Cytotoxic and proinflammatory effects of PVP-coated silver nanoparticles after intratracheal instillation in rats. Beilstein J Nanotechnol, 2013. 4: p. 933-40.

222. Armstead, A.L., C.B. Arena, and B. Li, Exploring the potential role of tungsten carbide cobalt (WC-Co) nanoparticle internalization in observed toxicity toward lung epithelial cells in vitro. Toxicol Appl Pharmacol, 2014. 278(1): p. 1-8.

223. Meissner, T., et al., Physical-chemical characterization of tungsten carbide nanoparticles as a basis for toxicological investigations. Nanotoxicology, 2010. 4(2): p. 196-206.

224. Takashiba, S., et al., Differentiation of monocytes to macrophages primes cells for lipopolysaccharide stimulation via accumulation of cytoplasmic nuclear factor kappaB. Infect Immun, 1999. 67(11): p. 5573-8.

225. Maess, M.B., et al., Reduced PMA enhances the responsiveness of transfected THP-1 macrophages to polarizing stimuli. J Immunol Methods, 2014. 402(1-2): p. 76-81.

226. Napierska, D., et al., Cytokine production by co-cultures exposed to monodisperse amorphous silica nanoparticles: the role of size and surface area. Toxicol Lett, 2012. 211(2): p. 98-104.

227. Wottrich, R., S. Diabate, and H.F. Krug, Biological effects of ultrafine model particles in human macrophages and epithelial cells in mono- and co-culture. Int J Hyg Environ Health, 2004. 207(4): p. 353-61.

228. Antonios, J.K., et al., Macrophage polarization in response to wear particles in vitro. Cell Mol Immunol, 2013. 10(6): p. 471-82.

229. Pfeffer, K., Biological functions of tumor necrosis factor cytokines and their receptors. Cytokine Growth Factor Rev, 2003. 14(3-4): p. 185-91.

230. Dinarello, C.A., Immunological and Inflammatory Functions of the Interleukin-1 Family. Annual Review of Immunology, 2009. 27: p. 519-550. 
231. Dinarello, C.A., Interleukin-1 beta and the Autoinflammatory Diseases. New England Journal of Medicine, 2009. 360(23): p. 2467-2470.

232. Gee, K., et al., The IL-12 family of cytokines in infection, inflammation and autoimmune disorders. Inflamm Allergy Drug Targets, 2009. 8(1): p. 40-52.

233. Trinchieri, G., Interleukin-12: a proinflammatory cytokine with immunoregulatory functions that bridge innate resistance and antigen-specific adaptive immunity. Annu Rev Immunol, 1995. 13: p. 251-76.

234. Hamza, T., J.B. Barnett, and B. Li, Interleukin 12 a Key Immunoregularoty Cytokine in Infection Applications. International Journal of Molecular Sciences, 2010. 11: p. 789-806.

235. Li, B., et al., Evaluation of local MCP-1 and IL-12 nanocoatings for infection prevention in open fractures. J Orthop Res, 2010. 28(1): p. 48-54.

236. Boyce, B.M., et al., Additive effects of exogenous IL-12 supplementation and antibiotic treatment in infection prophylaxis. J Orthop Res, 2012. 30(2): p. 196-202.

237. Li, B., et al., Multilayer polypeptide nanoscale coatings incorporating $I L-12$ for the prevention of biomedical device-associated infections. Biomaterials, 2009. 30(13): p. 2552-8.

238. Albanese, A., P.S. Tang, and W.C. Chan, The effect of nanoparticle size, shape, and surface chemistry on biological systems. Annu Rev Biomed Eng, 2012. 14: p. 1-16.

239. Du, Z., et al., Cardiovascular toxicity of different sizes amorphous silica nanoparticles in rats after intratracheal instillation. Cardiovasc Toxicol, 2013. 13(3): p. 194-207.

240. Porter, D.W., et al., Pulmonary toxicity of Expancel microspheres in the rat. Toxicol Pathol, 2007. 35(5): p. 702-14.

241. Sjogren, I., et al., Hard metal lung disease: importance of cobalt in coolants. Thorax, 1980. 35(9): p. 653-9.

242. Toya, T., et al., Pulmonary toxicity induced by intratracheal instillation of coarse and fine particles of cerium dioxide in male rats. Ind Health, 2010. 48(1): p. 3-11.

243. Porter, D.W., et al., Mouse pulmonary dose- and time course-responses induced by exposure to multi-walled carbon nanotubes. Toxicology, 2010. 269(2-3): p. 136-47.

244. Dulin, A.M., M.J. Paape, and B.T. Weinland, Cytospin centrifuge in differential counts of milk somatic cells. J Dairy Sci, 1982. 65(7): p. 1247-51.

245. Porter, D.W., et al., Nitric oxide and reactive oxygen species production causes progressive damage in rats after cessation of silica inhalation. Toxicol Sci, 2006. 90(1): p. 188-97.

246. Castranova, V., et al., Enhancement of nitric oxide production by pulmonary cells following silica exposure. Environ Health Perspect, 1998. 106 Suppl 5: p. 1165-9.

247. Allen, R.C., Evaluation of serum opsonic capacity by quantitating the initial chemiluminescent response from phagocytizing polymorphonuclear leukocytes. Infect Immun, 1977. 15(3): p. 828-33.

248. Renwick, L.C., et al., Increased inflammation and altered macrophage chemotactic responses caused by two ultrafine particle types. Occup Environ Med, 2004. 61(5): p. 442-7.

249. Silva, R.M., et al., Biological response to nano-scale titanium dioxide (TiO2): role of particle dose, shape, and retention. J Toxicol Environ Health A, 2013. 76(16): p. 953-72.

250. Tada, Y., et al., Acute phase pulmonary responses to a single intratracheal spray instillation of magnetite (fe(3)o(4)) nanoparticles in Fischer 344 rats. J Toxicol Pathol, 2012. 25(4): p. 233-9. 
251. Nel, A., et al., Toxic potential of materials at the nanolevel. Science, 2006. 311: p. 622627.

252. Seale-Goldsmith, M.M. and J.F. Leary, Nanobiosystems. Wiley Interdiscip Rev Nanomed Nanobiotechnol, 2009. 1(5): p. 553-67.

253. Srimok, B. and M.S. Yim, Examining the importance of the particle size effect in inhalation dose assessment for short-term radiological events. Radiat Prot Dosimetry, 2011. 147(3): p. 439-50.

254. Kim, K.P., et al., Influence of particle size distribution on inhalation doses to workers in the Florida phosphate industry. Health Phys, 2006. 91(1): p. 58-67.

255. Bernstein, D., A review of the influence of particle size, puff volume, and inhalation pattern on the deposition of cigarette smoke particles in the respiratory tract. Inhal Toxicol, 2004. 16(10): p. 675-89.

256. Cassee, F.R., et al., Particle size-dependent total mass deposition in lungs determines inhalation toxicity of cadmium chloride aerosols in rats. Application of a multiple path dosimetry model. Arch Toxicol, 2002. 76(5-6): p. 277-86.

257. Pauluhn, J. and M. Wiemann, Siderite (FeCO(3)) and magnetite (Fe(3)O(4)) overloaddependent pulmonary toxicity is determined by the poorly soluble particle not the iron content. Inhal Toxicol, 2011. 23(13): p. 763-83.

258. Courbiere, B., et al., Ultrastructural interactions and genotoxicity assay of cerium dioxide nanoparticles on mouse oocytes. Int J Mol Sci, 2013. 14(11): p. 21613-28.

259. Gaiser, B.K., et al., Interspecies comparisons on the uptake and toxicity of silver and cerium dioxide nanoparticles. Environ Toxicol Chem, 2012. 31(1): p. 144-54.

260. Hussain, S., et al., Cerium dioxide nanoparticles induce apoptosis and autophagy in human peripheral blood monocytes. ACS Nano, 2012. 6(7): p. 5820-9.

261. Verstraelen, S., et al., Gene expression profiles reveal distinct immunological responses of cobalt and cerium dioxide nanoparticles in two in vitro lung epithelial cell models. Toxicol Lett, 2014. 228(3): p. 157-169.

262. Zhou, X., et al., Uptake of cerium oxide nanoparticles and their influences on functions of A549 cells. J Nanosci Nanotechnol, 2013. 13(1): p. 204-15.

263. Goode, A.E., et al., Chemical speciation of nanoparticles surrounding metal-on-metal hips. Chemical Communications, 2012. 48(67): p. 8335-8337.

264. Germain, M.A., et al., Comparison of the cytotoxicity of clinically relevant cobaltchromium and alumina ceramic wear particles in vitro. Biomaterials, 2003. 24(3): p. 469-479.

265. Hosman, A.H., et al., Effects of metal-on-metal wear on the host immune system and infection in hip arthroplasty. Acta Orthop, 2010. 81(5): p. 526-34.

266. Ogunwale, B., et al., Investigating the immunologic effects of CoCr nanoparticles. Clin Orthop Relat Res, 2009. 467(11): p. 3010-6.

267. Allen, M.J., et al., The effects of particulate cobalt, chromium and cobalt-chromium alloy on human osteoblast-like cells in vitro. Journal of Bone and Joint Surgery-British Volume, 1997. 79B(3): p. 475-482.

268. Behl, B., et al., Biological effects of cobalt-chromium nanoparticles and ions on dural fibroblasts and dural epithelial cells. Biomaterials, 2013. 34(14): p. 3547-58.

269. Bhabra, G., et al., Nanoparticles can cause DNA damage across a cellular barrier. Nature Nanotechnology, 2009. 4(12): p. 876-883. 
270. Christian, W.V., et al., Toxicology-based cancer causation analysis of CoCr-containing hip implants: a quantitative assessment of genotoxicity and tumorigenicity studies. Journal of Applied Toxicology, 2014. 34(9): p. 939-967.

271. Figgitt, M., et al., The genotoxicity of physiological concentrations of chromium (Cr(III) and $\mathrm{Cr}(\mathrm{VI})$ ) and cobalt (Co(II)): An in vitro study. Mutation Research-Fundamental and Molecular Mechanisms of Mutagenesis, 2010. 688(1-2): p. 53-61.

272. Landsiedel, R., et al., Genotoxicity investigations on nanomaterials: Methods, preparation and characterization of test material, potential artifacts and limitationsMany questions, some answers. Mutation Research-Reviews in Mutation Research, 2009. 681(2-3): p. 241-258.

273. Potnis, P.A., D.K. Dutta, and S.C. Wood, Toll-like receptor 4 signaling pathway mediates proinflammatory immune response to cobalt-alloy particles. Cellular Immunology, 2013. 282(1): p. 53-65.

274. Raghunathan, V.K., et al., Influence of particle size and reactive oxygen species on cobalt chrome nanoparticle-mediated genotoxicity. Biomaterials, 2013. 34(14): p. 3559-3570.

275. Sood, A., et al., Signalling of DNA damage and cytokines across cell barriers exposed to nanoparticles depends on barrier thickness. Nature Nanotechnology, 2011. 6(12): p. 824833.

276. Tan, H.C., et al., Covalently grafted BMP-7 peptide to reduce macrophage/monocyte activity: An in vitro study on cobalt chromium alloy. Biotechnology and Bioengineering, 2013. 110(3): p. 969-979.

277. Tan, H.C., et al., Anti-fibrosis effect of BMP-7 peptide functionalization on cobalt chromium alloy. Journal of Orthopaedic Research, 2013. 31(6): p. 983-990.

278. Thomas, I.T. and E.J. Evans, The Effect of Cobalt Chromium Molybdenum Powder on Collagen Formation by Fibroblasts Invitro. Biomaterials, 1986. 7(4): p. 301-304.

279. Hosman, A.H., et al., The influence of Co-Cr and UHMWPE particles on infection persistence: an in vivo study in mice. J Orthop Res, 2012. 30(3): p. 341-7.

280. Scharf, B., et al., Molecular analysis of chromium and cobalt-related toxicity. Sci Rep, 2014. 4: p. 5729.

281. Taylor, U., et al., Impact of Metal Nanoparticles on Germ Cell Viability and Functionality. Reproduction in Domestic Animals, 2012. 47: p. 359-368.

282. Nielsen, J., J.R. Jepsen, and F. Egede, The hard-metal lung. Cobalt-induced pneumoconiosis. Ugeskr Laeger, 1986. 148(21): p. 1311-2.

283. Kusaka, Y., et al., Effect of hard metal dust on ventilatory function. Br J Ind Med, 1986. 43(7): p. 486-9.

284. Demedts, M., Cobalt and hard metal. Chest, 1986. 89(2): p. 316.

285. Rystedt, I. and T. Fischer, Relationship between nickel and cobalt sensitization in hard metal workers. Contact Dermatitis, 1983. 9(3): p. 195-200.

286. Perdrix, A., et al., Cobalt and sintered metal carbides. Value of the determination of cobalt as a tracer of exposure to hard metals. Toxicol Eur Res, 1983. 5(5): p. 233-40.

287. Hillerdal, G. and M. Hartung, On cobalt in tissues from hard metal workers. Int Arch Occup Environ Health, 1983. 53(1): p. 89-90.

288. Fischer, T. and I. Rystedt, Cobalt allergy in hard metal workers. Contact Dermatitis, 1983. 9(2): p. 115-21.

289. Lundgren, K.D. and H. Ohman, Pneumoconiosis in hard metal industry; technical and medical problems. Virchows Arch, 1954. 325(3): p. 259-84. 
290. Morgenroth, K., et al., Morphology and pathogenesis of pneumoconiosis in dental technicians. Pathol Res Pract, 1985. 179(4-5): p. 528-36.

291. Rom, W.N., et al., Pneumoconiosis and exposures of dental laboratory technicians. Am J Public Health, 1984. 74(11): p. 1252-7.

292. Sherson, D., N. Maltbaek, and O. Olsen, Small Opacities among Dental Laboratory Technicians in Copenhagen. British Journal of Industrial Medicine, 1988. 45(5): p. 320324.

293. Sherson, D., N. Maltbaek, and K. Heydorn, A dental technician with pulmonary fibrosis: a case of chromium-cobalt alloy pneumoconiosis? Eur Respir J, 1990. 3(10): p. 1227-9.

294. Choudat, D., Occupational lung diseases among dental technicians. Tuber Lung Dis, 1994. 75(2): p. 99-104.

295. Oberdorster, G., J. Ferin, and B.E. Lehnert, Correlation between particle size, in vivo particle persistence, and lung injury. Environ Health Perspect, 1994. 102 Suppl 5: p. 173-9.

296. Selden, A., et al., Three cases of dental technician's pneumoconiosis related to cobaltchromium-molybdenum dust exposure. Chest, 1996. 109(3): p. 837-42.

297. Selden, A.I., et al., Exposure to cobalt chromium dust and lung disorders in dental technicians. Thorax, 1995. 50(7): p. 769-72.

298. Simoes, T., et al., Synthesis and characterization of Cobalt Chromium nanoparticles by mechanochemical milling route.

299. Fischbein, A., et al., Clinical findings among hard metal workers. Br J Ind Med, 1992. 49(1): p. 17-24.

300. Gatti, A.M. and F. Rivasi, Biocompatibility of micro- and nanoparticles. Part I: in liver and kidney. Biomaterials, 2002. 23(11): p. 2381-7.

301. Oberdorster, G., Pulmonary effects of inhaled ultrafine particles. Int Arch Occup Environ Health, 2001. 74(1): p. 1-8.

302. Moreira, M.A., et al., Hard metal pneumoconiosis with spontaneous bilateral pneumothorax. J Bras Pneumol, 2010. 36(1): p. 148-51.

303. Oberdorster, G., E. Oberdorster, and J. Oberdorster, Nanotoxicology: an emerging discipline evolving from studies of ultrafine particles. Environ Health Perspect, 2005. 113(7): p. 823-39.

304. Tsaousi, A., E. Jones, and C.P. Case, The in vitro genotoxicity of orthopaedic ceramic (Al2O3) and metal (CoCr alloy) particles. Mutat Res, 2010. 697(1-2): p. 1-9.

305. Brody, J.S. and A. Spira, State of the art. Chronic obstructive pulmonary disease, inflammation, and lung cancer. Proc Am Thorac Soc, 2006. 3(6): p. 535-7.

306. Scansetti, G., et al., Absorption and excretion of cobalt in the hard metal industry. Sci Total Environ, 1994. 150(1-3): p. 141-4.

307. Zanetti, G. and B. Fubini, Surface interactions between metallic cobalt and tungsten carbide particles as a primary cause of hard metal disease. J Mater Chem, 1997. 7: p. 1647-1654.

308. Gauldie, J., M. Jordana, and G. Cox, Cytokines and pulmonary fibrosis. Thorax, 1993. 48(9): p. 931-5. 


\title{
APPENDIX I:
}

\author{
Curriculum Vitae
}

Andrea Lynn Armstead 


\section{Andrea Lynn Armstead, PhD.}

140 Hoffman Avenue

Morgantown, WV 26505
Phone: (304) 906-6138

Email: aarmstead@hsc.wvu.edu

\section{Education}

Washburn University (2003-09)

College of Liberal Arts \& Sciences

Department: Biochemistry

Degree: B.S.

GPA: 3.82

West Virginia University (2009-present)

School of Pharmacy

Department: Pharmaceutical \& Pharmacological

Sciences

Degree: Doctor of Philosophy

GPA: 3.86

\section{Awards and Honors}

- Outstanding Graduate Student Achievement Award, School of Pharmacy, West Virginia University (2014)

- $\quad 3^{\text {rd }}$ Place "Chapter of the Year”, Chapter Chair, American Association of Pharmaceutical Scientists (AAPS) West Virginia University Student Chapter (2013)

- West Virginia University School of Pharmacy Graduate Student Travel Award (\$500; 2013)

- West Virginia University Research and Graduate Education Student Travel Award (\$400; 2013)

- American Foundation for Pharmaceutical Education (AFPE) Pre-Doctoral Fellowship in Pharmaceutical Sciences (2013-14)

- $\quad$ E.J. Van Liere Research Day, West Virginia University, $2^{\text {nd }}$ Place Poster Award (2013)

- $4^{\text {th }}$ Annual AAPS Pittsburgh Chapters Student Research Symposium, “Most Outstanding Research Presentation” (Podia; 2012)

- American Foundation for Pharmaceutical Education (AFPE) Pre-Doctoral Fellowship in Pharmaceutical Sciences (2012-13) 
- Rho Chi Pharmacy Scholarship Society Induction (2012)

- WV Nano Graduate Research Fellowship (2010-11, 2011-12)

- American Chemical Society “Undergraduate Analytical Chemistry” Award (2009)

- Washburn University “Analytical Chemistry Student of the Year” Award (2009)

- Kansas Academy of Sciences, “First Place Oral Competition” Award (2009)

- KINBRE Research Training Scholarship (2008-09)

- Dean’s Honor Roll, Washburn University (2004, 2008-09)

- Washburn University Academic Scholarship (2003-04, 2006, 2008)

\section{Leadership and Service}

- Chair: American Association of Pharmaceutical Scientists (AAPS) West Virginia University Student Chapter (2013-14)

- Pharmaceutical Sciences Graduate Student Representative, School of Pharmacy, West Virginia University Chancellor’s Health Sciences Center Student Advisory Board (201314)

- Student Volunteer, “Science Days” at the Children’s Discovery Museum, Morgantown, WV (2013)

- Student Committee Chair: Inaugural West Virginia University School of Pharmacy American Association of Pharmaceutical Scientists (AAPS) Regional Meeting \& Research Forum (2013)

- Treasurer: American Association of Pharmaceutical Scientists (AAPS) West Virginia University Student Chapter (2012-13)

- Graduate Student Representative, Organizational Committee: Center for Drug Discovery and Therapeutics Retreat, Morgantown, WV (2012)

- Medical Student Research Mentor (Ketu Patel): West Virginia University E.J. Van Liere Summer Medical Student Research Program (2011)

- Medical Student Research Mentor (Christopher Arena): West Virginia University E.J. Van Liere Summer Medical Student Research Program (2010)

- Student volunteer, “Nano Days” at the Children’s Discovery Museum, Morgantown, WV (2012) 


\section{Dissertation Research Summary}

- Identifying the toxicity of hard metal tungsten carbide cobalt (WC-Co) nano- and microparticles using in vitro cell culture models to assess cell viability, oxidative stress and induction of apoptosis

- Examining WC-Co nanoparticle internalization using cytoskeletal inhibitor assays and transmission electron microscopy (TEM)

- Determining the effects of WC-Co particle exposure in vitro on immune functions such as cytokine secretion and macrophage activation in a co-culture model

- Establishing an in vivo rat model for the assessment of potential systemic effects induced by WC-Co nanoparticle exposure via intra-tracheal instillation

\section{Laboratory Experience and Techniques}

- Mammalian cell culture and aseptic technique

- Cell viability assays (MTT-based, lactate dehydrogenase (LDH)-based)

- Flow cytometry (cell preparation, staining and sample analysis)

- Phase-contrast and fluorescence microscopy

- Dynamic light scattering analysis and nano/micro-particle suspension

- Limited in vivo experience with animal anesthesia, exsanguination, bronchio-alveolar lavage

\section{Dissertation Committee}

- Dr. Bingyun Li (Mentor): Department of Orthopedics, School of Medicine, West Virginia University

- Dr. Rae Matsumoto: Dean, School of Pharmacy, Touro University California

- Dr. Peter Gannett: Department of Basic Pharmaceutical Sciences, School of Pharmacy, West Virginia University

- Dr. Yon Rojanasakul: Department of Basic Pharmaceutical Sciences, School of Pharmacy, West Virginia University

- Dr. Tim Nurkiewicz: Department of Physiology \& Pharmacology, School of Medicine, West Virginia University 


\section{Publications}

\section{Peer Reviewed Manuscripts}

- Armstead, A.L; Arena, C.B and B. Li. Exploring the potential role of tungsten carbide cobalt (WC-Co) nanoparticle internalization in observed toxicity toward lung epithelial cells in vitro. Tox App Pharmacol 2014: 278 (1): 1-8. http://dx.doi.org/10.1016/j.taap.2014.04.008

- Armstead, A.L. and B. Li. Nanomedicine as an Emerging Approach against Intracellular Pathogens. Int J Nanomedicine 2011: 6; 3281-3293. http://www.dovepress.com/articles.php?article_id=8838

- Armstead, A.L; Minarchick, V; Porter, D; Nurkiewicz, T and B. Li. Acute inflammatory responses of nanoparticles in an intra-tracheal instillation rat model. PLoS One (under review 11/2014)

- Armstead, A.L; Wang, X and B. Li. Toxicity of cobalt chromium molybdenum orthopedic implant wear nanoparticles in human cells. PLoS One. (to be submitted)

\section{Workshop Participation}

- Science and Technology Entrepreneurship Academy, August 7-12, 2011. Erickson Alumni Center, Morgantown, WV.

- Science: Becoming the Messenger Workshop, presented by the National Science Foundation. October 11, 2011. Erickson Alumni Center, Morgantown, WV.

- Succeeding in the People Business, presented by the WV Nano Initiative. January 12, 2012. Chestnut Ridge Research Building, Morgantown, WV.

- Creating Elevator Pitches that Pack a Punch, presented by Ninja Communications, July 12, 2014. WestVaco Center, Morgantown, WV.

\section{Memberships}

- Association for Women in Science (2013-present)

- American Association for the Advancement of Science, Excellence in Science Program (2013-present)

- Society of Toxicology, Allegheny-Erie Regional Chapter (2012-present)

- Rho Chi Society (2012-present) 
- American Association of Pharmaceutical Sciences (2010-present)

- American Chemical Society (2010-present)

\section{Presentations}

\section{Seminars and Podia presentations:}

- West Virginia University Graduate Student Seminar Series, Fall 2014: “Understanding Hard Metal (WC-Co) Toxicity: In vitro Studies and In vivo Exploration"

- West Virginia University Graduate Student Seminar Series, Spring 2014: "Hard Metal (WC-Co) Particle Exposure: In Vitro Toxicity and Potential Role of Macrophage Polarization"

- West Virginia University Graduate Student Seminar Series, Fall 2013: "Exploring the systemic effects of WC-Co nanoparticle exposure in vivo using an intra-tracheal instillation model"

- West Virginia University Graduate Student Seminar Series, Spring 2013: “Hard Metal Toxicity: from in vitro studies to in vivo exploration"

- $4^{\text {th }}$ Annual Pittsburgh AAPS Student Research Symposium, November 2012: “Hard Metal (WC-Co) Nano-particles Induce Cellular Toxicity and Apoptosis in a DoseDependent Manner" (Abstract one of six selected for podia presentation; received "Most Outstanding Research Presentation” award)

- West Virginia University Graduate Student Seminar Series, Fall 2012: "Toxicity and Inflammatory Response to Hard Metal (WC-Co) Particles in a Co-culture Model"

- West Virginia University Graduate Student Seminar Series, Spring 2012: “Nanoparticle Internalization contributes to Nano-Toxicity"

- Interdisciplinary Research Team (IRT3) Meeting, 2012: “BEAS-2B Cellular Response to Organic and Inorganic Particle Exposure"

- West Virginia University Graduate Student Seminar Series, Fall 2011: “Cellular Response to Organic and Inorganic Particle Exposure"

- West Virginia Nano Brown Bag Lunch Seminar Series, Spring 2011: "Nanomedicine: An Emerging Therapeutic Strategy against Intracellular Pathogens" 
- Interdisciplinary Research Team (IRT3) Meeting, 2011: “Examining Cell-Nanoparticle Interactions"

- West Virginia University Graduate Student Seminar Series, Spring 2011: “Examining Cell-Nanoparticle Interactions"

- West Virginia University Graduate Student Seminar Series, Fall 2010: “Treating Intracellular Pathogens: Nanoparticles as an Alternative Therapeutic Approach”

- Kansas Academy of Science Annual Meeting, 2009: “Benzylic Oxidation of Pyrroles by Oxone $^{\circledR}$ ", (first place winner, oral competition)

\section{Poster presentations:}

- E.J Van Liere Research Day, West Virginia University, 2013: “Examining the Inflammatory Response to Hard Metal (WC-Co) Nanoparticle Exposure in Vivo”

- American Association of Pharmaceutical Scientists (AAPS) Annual Meeting, 2013: “Understanding Hard Metal (WC-Co) Toxicity: Potential Role of Nanoparticle Internalization"

- $\quad 5^{\text {th }}$ Annual Pittsburgh Chapters AAPS Student Research Symposium, 2013: “Exploring the Systemic Effects of Hard Metal (WC-Co) Nanoparticle Exposure in vivo",

- Allegheny-Erie Society of Toxicology Regional Meeting, 2013: “Hard metal (WC-Co) Nanoparticles Induce Cellular Toxicity and Apoptosis in a Dose-Dependent Manner”

- E.J Van Liere Research Day, West Virginia University, 2013: "Hard metal (WC-Co) Nanoparticles Induce Cellular Toxicity and Apoptosis in a Dose-Dependent Manner” (2nd place winner, poster competition)

- NanoBio Seattle, Seattle WA, 2012: “Heavy metal (WC-Co) Nanoparticles Induce Cellular Toxicity and Apoptosis in a Dose-Dependent Manner",

- E.J Van Liere Research Day, West Virginia University, 2012: Co-presentation with Christopher Arena “Cellular Responses to Heavy Metal Particle Exposure” (first place winner, poster competition)

- E.J Van Liere Research Day, West Virginia University, 2012: "Potential Role of WC-Co Nano-Particle Internalization in Hard Metal Lung Disease” 
- E.J. Van Liere Research Day, West Virginia University, 2010: Co-Presentation with Therwa Hamza “In vitro models for intracellular S. aureus infections of osteoblasts and macrophages"

- School of Pharmacy Research Day, West Virginia University, 2010: Co-Presentation with Therwa Hamza "In vitro models for intracellular S. aureus infections of osteoblasts and macrophages"

- KINBRE Regional Meeting, 2009: “Further Studies on the Benzylic Oxidation of Pyrroles by Oxone ${ }^{\circledR,}$

- Kansas Academy of Science Annual Meeting, 2009: “Benzylic Oxidation of Pyrroles by Oxone $^{\circledR,}$ 


\section{APPENDIX II:}

Nanomedicine as an Emerging Approach against Intracellular Pathogens

\section{Supplemental Literature Review}

Original Review Article

Armstead, A.L and Li, B. 2011. Nanomedicine as an emerging approach against intracellular pathogens. Int J Nanomedicine 6, 3281-3293. http://dx.doi.org/10.2147/IJN.S27285 


\begin{abstract}
Diseases such as tuberculosis, hepatitis and HIV/AIDS are caused by intracellular pathogens and are a major burden to the global medical community. Conventional treatments for these diseases typically consist of long-term therapy with a combination of drugs which may lead to side effects and contribute to low patient compliance. The pathogens reside within intracellular compartments of the cell which provide additional barriers to effective treatment. Therefore, there is a need for improved and more effective therapies for such intracellular diseases. This review will summarize, for the first time, the intracellular compartments in which pathogens can reside and discuss how nanomedicine has the potential to improve intracellular disease therapy by offering properties such as targeting, sustained drug release and drug delivery to the pathogen's intracellular location. The characteristics of nanomedicine may prove advantageous in developing improved or alternative therapies for intracellular diseases.
\end{abstract}

Keywords: intracellular pathogen; infection; nanomedicine; nanoparticle; drug delivery 


\section{INTRODUCTION}

Worldwide, a number of diseases (eg HIV/AIDS, hepatitis and tuberculosis) are caused by intracellular pathogens. Such diseases can be due to viral [1-8], bacterial [9-16], fungal [17, 18] or other parasitic [19-21] infection as summarized in Table 1. The prevalence of each disease may differ geographically but the intracellular nature of these pathogens, which may protect them from a variety of antibiotic therapies and host immune responses, presents a treatment challenge for the global medical community. Some antibiotic drugs like aminoglycosides and beta-lactams have limited cellular penetration, while others such as fluoroquinolones or macrolides have the ability to penetrate host cells but are poorly retained and therefore inefficient [22]. Therapeutic drugs targeting the intracellular pathogens should overcome the cell membrane barriers, and release and retain the drug intracellularly at the therapeutic level for a desired time period. Moreover, multi-drug resistance is increasing [23-29] and is making intracellular disease treatment more challenging. Therefore, there is a need for the development of advanced treatment methods to better control intracellular infections. This review will summarize the status of intracellular disease treatments, the current therapeutic strategies against common intracellular diseases and present how nanomedicine is emerging as an attractive platform for advanced intracellular drug therapy. Note that therapeutic treatments that tune the cell-mediated immune responses against intracellular pathogens are important but will not be discussed here.

INTRACELLULAR PATHOGENS AND CURRENT TREATMENT APPROACHES 
A wide variety of pathogens are capable of causing intracellular diseases such as HIV/AIDS, hepatitis and tuberculosis (see Table 1). In this section, a brief description of selected viral and bacterial diseases is given along with a discussion of the current therapeutic strategies against the causative pathogens.

\section{Table 1: Summary of Disease-Causing Intracellular Pathogens}

\section{Associated Disease(s)}

\section{Viral Pathogens}

\begin{tabular}{|l|l|l|}
\hline Herpes simplex & $\begin{array}{l}\text { Type I: oral herpes (cold sore, fever } \\
\text { blister) } \\
\text { Type II: genital herpes (warts, ulcers) }\end{array}$ & {$[1,8]$} \\
\hline Hepatitis C & $\begin{array}{l}\text { Liver cirrhosis, hepatocellular carcinoma } \\
\text { (HCC) }\end{array}$ & {$[2,6]$} \\
\hline Respiratory syncytial virus & Pediatric viral respiratory disease & {$[4,7]$} \\
\hline Human immunodeficiency virus (HIV) & Acquired immunodeficiency syndrome & {$[3,5]$} \\
\hline
\end{tabular}

\section{Bacterial Pathogens}

Mycobacterium tuberculosis

Tuberculosis

$[9,10]$

Salmonella enterica serovars Typhi,

Typhoid fever Paratyphi

Brucella species B. melitensis, B. abortus, B. Malta fever or undulant fever suis 
Table 1: Summary of Disease-Causing Intracellular Pathogens (continued)

\section{Associated Disease(s)}

\section{Fungal Pathogens}

Candidia albicans

Multiple cutaneous and mucosal forms: frequently encountered oral form is thrush

Aspergillus fumigatus

Pulmonary aspergillosis

\section{Other Pathogens}

Leishmania (parasite)

Cutaneous or tegumentary

[19, leishmaniasis

Plasmodium species (protist) $P$. vivas, $P$. Malaria ovale, $P$. malariae, $P$. falciparum, $P$. knowlesi

Table A2.1. Summary of disease-causing intracellular pathogens.

\section{Tuberculosis (TB)}

Tuberculosis (TB) is a disease caused by Mycobacterium tuberculosis (M. tuberculosis).

It is estimated that up to 2.2 billion people carry latent TB infections worldwide [30]. Exposure to TB does not necessarily lead to an active infection, as normal human immune systems are able to effectively control bacteria and most people remain in a symptom-free latent stage of infection [30]. However, susceptible individuals with poor immune response or complicating factors such as HIV infection may develop an active TB infection [31]. People with active infections typically experience pain in the chest and a cough with blood or sputum (phlegm) lasting more than three 
weeks [32]. These symptoms could also be accompanied by fatigue, weight loss, fever, chills or night sweats [33]. M. tuberculosis is a gram-positive bacterium with a very thick cell wall characteristic of the Mycobacterium species. The thick cell wall provides an excellent permeability barrier, making Mycobacteria resistant to a wide variety of antimicrobial agents [23]. M. tuberculosis bacteria may reside and duplicate within macrophages of the lung [34]; a full description of M. tuberculosis pathogenesis is beyond the scope of this discussion and is reviewed elsewhere [35, 36]. However, an important factor is the bacteria's ability to avoid the cell-mediated immune response through granuloma formation [10], such that treatment of TB remains a challenge.

At present, the treatment of choice for an active TB infection is long-term antibiotic therapy, with an initial "intensive phase" consisting of the four first-line anti-tuberculosis drugs (isoniazid, rifampicin, ethambutol and pyrazinamide) followed by a typical four month course of rifampicin and isoniazid alone [37]. This has been the most effective treatment to date although, due to the length of antibiotic therapy, side effects frequently develop [38] and the cost is high [39]. These factors may lead to low patient compliance and contribute to the development of drug resistant bacteria [40].

\section{Human Immunodeficiency Virus (HIV)}

Infection with human immunodeficiency virus (HIV) is a significant ongoing problem worldwide. As HIV infection progresses, infected individuals develop acquired immunodeficiency syndrome (AIDS). According to the latest statistics from the World Health Organization (WHO), there are 33.3 million people living with HIV/AIDS [41]. Many of those infected live in sub-saharan Africa, where access to treatment is extremely costly or unavailable. 
There have been major developments in the treatment of HIV/AIDS since the approval of Retrovir ${ }^{\circledR}$ (zidovudine) in 1987 [5]. Current therapeutic efforts consist of a combination of several drugs [42], typically from different classes of antiviral drugs [43, 44]. This regimen is referred to as "highly active anti-retroviral therapy" or HAART and has become the standard of care for those infected with HIV. There are five classes of drugs available for HIV/AIDS treatment, including: nucleoside reverse transcriptase inhibitors, nucleotide reverse transcriptase inhibitors, non-nuceloside reverse transcriptase inhibitors, protease inhibitors and viral fusion and integrase inhibitors. Typical regimens are combinations of three or four drugs, with subsequent modifications made based on the patient's response to therapy [45]. Changes made to a patient's regimen are often based on drug resistance testing, and take into consideration toxicity and tolerability of the new treatment strategy [45]. Although HAART has increased the median survival time of HIV/AIDS patients from less than a year to about ten years [29], patients often develop multi-drug resistant strains of the virus [41] over the course of therapy, leading to poor treatment outcomes [46].

\section{Hepatitis C Virus (HCV)}

It is estimated that at least three percent of the world's population is infected with HCV [2, 47]. The virus only affects humans and is considered a "silent" disease, as infected individuals are usually symptom free until later stages of infection when liver inflammation [48] occurs. HCV can cause liver scarring and cirrhosis, which ultimately leads to hepatocarcinoma (liver cancer) and death [2, 48]. Unfortunately, there is no effective vaccine [49] against HCV and the "gold-standard" of HCV treatment is combination antiviral therapy with ribavirin and interferon alpha [6]; however, both of these compounds are highly toxic and may cause severe side effects. Several months of treatment are usually required to eradicate a chronic infection and 
the cost of therapy is high [49]. These factors contribute to low patient compliance, making therapy less effective and potentially contributing to the development of viral resistance [29].

\section{Typhoid Fever}

Typhoid fever is an acute illness caused by the bacterium Salmonella enterica serovar Typhi (S. Typhi) or Paratyphi that cause about 20 million cases of illness per year [50]. These bacteria are usually ingested by consuming contaminated food or water [51]. Once ingested, the bacteria translocate across intestinal epithelial cells and establish an intracellular growth environment within macrophages [52]. The bacteria survive within 'Salmonella-containing vacuoles' in infected macrophages and later spread to organs such as the liver and spleen [11, 12, 53]. Infected individuals often experience sustained high fevers (up to $103^{\circ} \mathrm{F}$ ), stomach pains, headache, weakness and appetite loss [51]. Several vaccines against S. Typhi have been developed [54] although they provide only short-term protection against the disease due to failure of the immune system to build a lasting response [50,54]. Typhoid fever is endemic in many developing countries [55], where access to vaccines and antibiotic drugs is limited and expensive even if available. Standard treatment for S. Typhi infection is the antibiotic chloramphenicol, although resistance has been reported [50]. Newer antibiotics like the fluoroquinolones have also proven effective in treating typhoid fever, but the widespread use of these drugs for a range of febrile illnesses in developing countries is contributing to the development of more drug-resistant strains of the bacterium [55]. 


\section{MAJOR CHALLENGES IN TREATING INTRACELLULAR PATHOGENS}

Tables 2A and 2B summarize the common intracellular viruses and bacteria and their related current therapeutic approaches. One can see that intracellular treatment approaches generally involve long-term therapy with a combination of drugs. Side effects can develop due to the drug's inherent toxicity or due to the length of drug exposure. One of the critical challenges in treating these types of infections is to get enough drugs to reach the pathogens within their intracellular compartments. After reviewing the literature, we found evidence that intracellular pathogens reside in phagosomes $[15,34,56]$, vacuoles $[52,53]$, cytosol $[16,57,58]$, nucleus $[1$, 59, 60], and may interact with the golgi apparatus [61] and endoplasmic reticulum [62-66] of host cells (Figure 1). The host cell membranes make it a challenge for many drugs to reach the invading pathogens. Moreover, some antiviral and antibiotic medications have short half-lives, requiring frequent and large doses to obtain a therapeutic effect which may lead to high cost, low patient compliance, and severe side effects. In addition, drug resistance may be developed when patients do not fully comply with their treatment regimens [28] or when pathogens are exposed to drugs at sub-optimal concentrations [67] for an extended time period. An alerting new phenomenon is that some pathogens, that have been traditionally considered extracellular, are emerging as intracellular pathogens and may lead to new types of intracellular diseases. As an example, Staphylococcus aureus (S. aureus) has long been considered an extracellular pathogen although recent evidence in the literature demonstrates that this bacterium is capable of being internalized and surviving within host cells (e.g. osteoblasts [68-72]), and may contribute to recurrent infections [73]. In order to reduce side effects, improve patient compliance, and reduce the development of drug-resistance, more effective therapeutic approaches need to be developed. 
An ideal drug treatment method to eradicate intracellular pathogens is one that has the following characteristics: the ability to penetrate host cells and reach the pathogens, high efficacy and low toxicity and sustained and site-specific drug release [22]. Recent evidence from the literature shows that nanomedicine is emerging as a promising potential treatment for intracellular pathogens, as nanomedicine has the capacity to address these specific challenges.

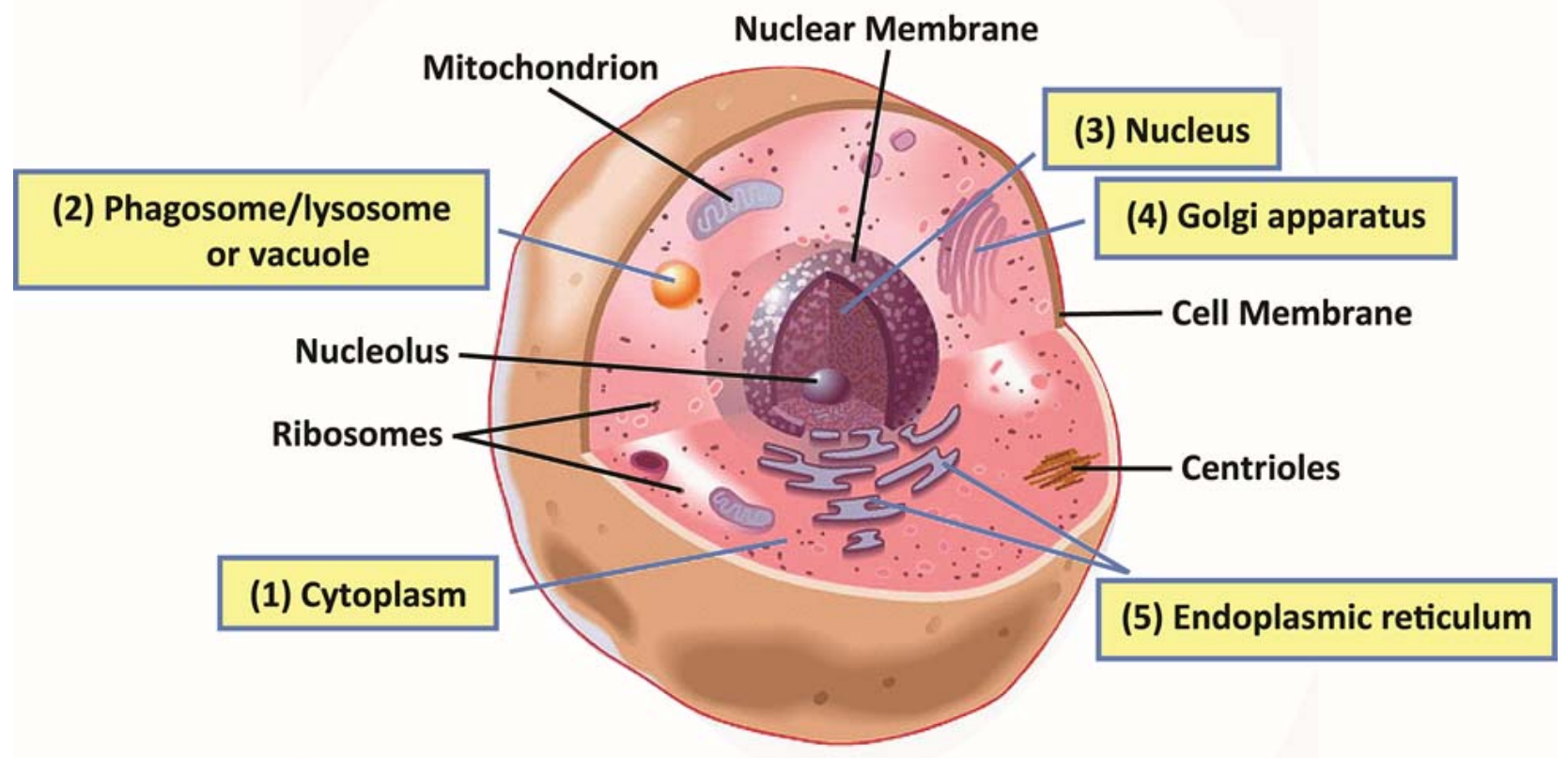

Figure A2.1. Potential Locations of Intracellular Pathogens. In a typical eukaryotic cell, pathogens may be internalized via endocytic mechanisms before establishing their intracellular life cycle. Pathogens may reside in various locations, including: the cytosol, phagosome, lysosome or vacuole compartments, the nucleus, and some may associate with the golgi apparatus or endoplasmic reticulum. ${ }^{(1)}$ Cytosol ( $F$. tularensis [57], L. monocytogenes [58], Shigella [64]) ${ }^{(2)}$ Phagosome/lysosome or vacuole (M. tuberculosis [43, 45], Brucella species [15], Salmonella [52, 53], Leigonella [56]), ${ }^{(3)}$ Nucleus (Herpes Simplex virus [1, 60], HIV [59]), ${ }^{(4)}$ Golgi apparatus (Chlamydia [61]) and ${ }^{(5)}$ Endoplasmic reticulum (Hepatitis C virus [65], Brucella [63], T. gondii [66], L. pneumophilia [62, 64]). 


\begin{tabular}{|c|c|c|c|c|c|}
\hline Virus Name & $\begin{array}{l}\text { Type of } \\
\text { Virus }\end{array}$ & $\begin{array}{l}\text { Current Treatment } \\
\text { Options }\end{array}$ & $\begin{array}{c}\text { Drugs } \\
\text { Commonly } \\
\text { Prescribed } \\
\end{array}$ & Drug Class/Mode of Action & [Ref] \\
\hline \multirow[b]{2}{*}{$\begin{array}{l}\text { Hepatitis C } \\
\text { Virus (HCV) }\end{array}$} & \multirow{2}{*}{$\begin{array}{l}\text { RNA virus } \\
\text { (single } \\
\text { strand, } \\
\text { positive } \\
\text { sense) }\end{array}$} & \multirow{2}{*}{$\begin{array}{l}\text { Combination } \\
\text { treatment with } \\
\text { interferon and } \\
\text { broad-spectrum } \\
\text { antiviral drugs. } \\
\text { Treatment duration } \\
\text { is several months. }\end{array}$} & \multirow{2}{*}{$\begin{array}{l}\text { pegylated } \\
\text { interferon 2- } \\
\text { alpha and } \\
\text { ribavirin }\end{array}$} & $\begin{array}{l}\text { PEG-IFN is an } \\
\text { immunomodulatory drug } \\
\text { and helps enhance natural } \\
\text { anti-viral mechanisms } \\
\text { (degradation of viral RNA, } \\
\text { translation inhibition, etc.) } \\
\text { although the exact } \\
\text { mechanism is unkown. }\end{array}$ & \multirow{2}{*}{$\begin{array}{l}{[5,} \\
42- \\
45]\end{array}$} \\
\hline & & & & $\begin{array}{l}\text { ribavirin is a purine analog } \\
\text { and is incorporated into the } \\
\text { genome of the virus, } \\
\text { causing lethal mutations. It } \\
\text { is ineffective against HCV } \\
\text { when administered alone; it } \\
\text { must be administered } \\
\text { concomitantly with PEG- } \\
\text { IFN. }\end{array}$ & \\
\hline \multirow{2}{*}{$\begin{array}{l}\text { Respiratory } \\
\text { syncytial } \\
\text { virus (RSV) }\end{array}$} & \multirow{2}{*}{$\begin{array}{l}\text { RNA virus } \\
\text { (single } \\
\text { strand, } \\
\text { negative } \\
\text { sense) }\end{array}$} & \multirow{2}{*}{$\begin{array}{l}\text { Prophylactic } \\
\text { administration of } \\
\text { antibodies as disease } \\
\text { prevention, or } \\
\text { disease treatment } \\
\text { with broad-spectrum }^{\text {antiviral drugs. }}{ }^{\text {C }}\end{array}$} & \multirow{2}{*}{$\begin{array}{l}\text { Ribavirin or } \\
\text { palvizumab }\end{array}$} & $\begin{array}{l}\text { Ribavirin is a broad- } \\
\text { spectrum antiviral drug that } \\
\text { has shown some clinical } \\
\text { benefit in FSV infections. It } \\
\text { is the only FDA-approved } \\
\text { drug for RSV treatment. }\end{array}$ & \multirow[t]{2}{*}[4,7]{} \\
\hline & & & & $\begin{array}{l}\text { Palivizumab is a monoclonal } \\
\text { anti-RSV antibody (mAb). It } \\
\text { targets the RSV F } \\
\text { glycoprotein, inhibiting viral } \\
\text { entry into host cells. }\end{array}$ & \\
\hline \multirow{3}{*}{$\begin{array}{c}\text { Herpes } \\
\text { Simplex } \\
\text { Virus (HSV) }\end{array}$} & \multirow{3}{*}{$\begin{array}{l}\text { DNA virus } \\
\text { (double } \\
\text { stranded) }\end{array}$} & \multirow{3}{*}{$\begin{array}{l}\text { Antiviral drug } \\
\text { administration until } \\
\text { symptoms and viral } \\
\text { shedding are } \\
\text { reduced. Suppressive } \\
\text { therapy is often } \\
\text { recommended. }\end{array}$} & $\begin{array}{l}\text { acyclovir, } \\
\text { valacyclovir, } \\
\text { famiclovir, } \\
\text { ganciclovir }\end{array}$ & $\begin{array}{l}\text { guanosine analog; these are } \\
\text { potent inhibitors of the viral } \\
\text { DNA polymerase. Requires } \\
\text { phosphorylation by viral } \\
\text { thymidine kinase. }\end{array}$ & \multirow{3}{*}[1,8]{} \\
\hline & & & cidofovir & $\begin{array}{l}\text { competitive inhibitor of } \\
\text { viral DNA polymerase; } \\
\text { reserved for cases of } \\
\text { acyclovir resistance due to } \\
\text { high toxicity. }\end{array}$ & \\
\hline & & & foscarnet & $\begin{array}{l}\text { pyrophosphate; inhibits } \\
\text { viral DNA polymerase. }\end{array}$ & \\
\hline
\end{tabular}




\begin{tabular}{|c|c|c|c|c|c|}
\hline Virus Name & $\begin{array}{l}\text { Type of } \\
\text { Virus }\end{array}$ & $\begin{array}{l}\text { Current } \\
\text { Treatment } \\
\text { Options } \\
\end{array}$ & $\begin{array}{c}\text { Drugs } \\
\text { Commonly } \\
\text { Prescribed } \\
\end{array}$ & $\begin{array}{c}\text { Drug Class/Mode of } \\
\text { Action }\end{array}$ & [Ref] \\
\hline \multirow{6}{*}{$\begin{array}{c}\text { Human } \\
\text { Immunodeficiency } \\
\text { Virus (HIV) }\end{array}$} & \multirow{6}{*}{$\begin{array}{l}\text { Retrovirus } \\
\text { (lentivirus) }\end{array}$} & \multirow{6}{*}{$\begin{array}{l}\text { Highly active } \\
\text { anti-retroviral } \\
\text { therapy (HAART; } \\
\text { combination } \\
\text { therapy using } \\
\text { three or more } \\
\text { antivirals } \\
\text { simutaneously). } \\
\text { Drugs may be } \\
\text { administered } \\
\text { individually or as } \\
\text { combination } \\
\text { pills. }{ }^{A} \text { Treatment } \\
\text { duration is often } \\
\text { lifetime of the } \\
\text { patient. }\end{array}$} & $\begin{array}{l}\text { nevirapine, } \\
\text { delavirdine, } \\
\text { efavirenz, } \\
\text { etravirine }\end{array}$ & $\begin{array}{l}\text { non-nucleoside reverse } \\
\text { transcriptase inhibitior } \\
\text { (NNRTI) }\end{array}$ & \multirow{6}{*}{$\begin{array}{l}{[5,} \\
42- \\
45]\end{array}$} \\
\hline & & & $\begin{array}{l}\text { tenofovir } \\
\text { disoprozil } \\
\text { fumarate (TDF), } \\
\text { azidothymidine, } \\
\text { abacavir, } \\
\text { lamivudine, } \\
\text { zalcitabine, } \\
\text { didanosine, } \\
\text { stavudine }\end{array}$ & $\begin{array}{l}\text { nucleoside/nucleotide } \\
\text { reverse transcriptast } \\
\text { inhibitor (NRTI) }\end{array}$ & \\
\hline & & & $\begin{array}{l}\text { atazanavir, } \\
\text { darunavir, } \\
\text { fosamprenavir, } \\
\text { lopinavir, } \\
\text { tipranavir, } \\
\text { indinavir, } \\
\text { entricitabine, } \\
\text { saquinavir, } \\
\text { lopinavir, } \\
\text { ritonivir, } \\
\text { nelfinavir }\end{array}$ & protease inhibitor (PI) & \\
\hline & & & enfuvirtide & $\begin{array}{l}\text { entry/fusion inhibitor } \\
\text { (FI) }\end{array}$ & \\
\hline & & & maraviroc & CCR5 antagonist & \\
\hline & & & raltegravir & integrase inhibitor & \\
\hline \multicolumn{6}{|c|}{$\begin{array}{l}\text { Notes: }{ }^{\mathrm{A}} \text { Examples of combination pills include: Combivir, Kaletra, Truvada, Trizivir, Atripla, } \\
\text { Epizicom/Kivexa (all registered trademarks of their respective companies); }{ }^{\mathrm{B}} \mathrm{HCV} \text {-specific antivirals are } \\
\text { currently under development in clinical trials. None have been FDA-approved to date; }{ }^{\mathrm{C}} \text { There are } \\
\text { multiple RSV-targeted therapies currently under development, including: improved mAb preparations } \\
\text { (motavizumab), antisense anti-RSV siRNAs, fusion inhibitors and other small molecule RSV viral epitope } \\
\text { inhibitors. A variety of vaccine options are being explored as well (live, attenuated vaccines, vector } \\
\text { vaccines and subunit vaccines). }\end{array}$} \\
\hline
\end{tabular}

Table 2.2A. Current therapeutic strategies against selected viral pathogens. 


\begin{tabular}{|c|c|c|c|c|c|}
\hline Bacteria & $\begin{array}{l}\text { Associated } \\
\text { Disease(s) }\end{array}$ & $\begin{array}{c}\text { Current Treatment } \\
\text { Options }\end{array}$ & $\begin{array}{l}\text { Drugs } \\
\text { Commonly } \\
\text { Prescribed }\end{array}$ & $\begin{array}{l}\text { Drug Class/Mode } \\
\text { of Action }\end{array}$ & [Ref] \\
\hline \multirow[b]{2}{*}{$\begin{array}{c}\text { Mycobacterium } \\
\text { tuberculosis }\end{array}$} & \multirow[b]{2}{*}{ Tuberculosis } & \multirow{2}{*}{$\begin{array}{l}\text { Long-term antibiotic } \\
\text { treatment in two } \\
\text { phases: intensive 2- } \\
\text { month initial phase } \\
\text { (four first-line drugs) } \\
\text { then 4-month follow } \\
\text { up (isoniazid and } \\
\text { rifampicin only). } \\
\text { Drug resistant strains } \\
\text { require additional } \\
\text { treatment for up to } \\
12 \text { months. }\end{array}$} & $\begin{array}{l}\text { isoniazid, } \\
\text { pyrazinamide, } \\
\text { rifampicin, } \\
\text { ethambutol }\end{array}$ & $\begin{array}{l}\text { first-line drugs } \\
\text { effective against } \\
\text { non-resistant } M \text {. } \\
\text { tuberculosis } \\
\text { infections. (non- } \\
\text { MDR-TB) }\end{array}$ & \multirow{2}{*}{$\begin{array}{l}{[30,} \\
31 \\
34, \\
37, \\
38]\end{array}$} \\
\hline & & & $\begin{array}{l}\text { ethionamide, } \\
\text { prothionamide, } \\
\text { cycloserine, } \\
\text { capreomycin, } \\
\text { para- } \\
\text { aminosalicylic } \\
\text { acid, } \\
\text { fluorquinolones }\end{array}$ & $\begin{array}{l}\text { second-line drugs } \\
\text { effective against } \\
\text { multi-drug } \\
\text { resistant strains } \\
\text { of } M \text {.tuberculosis. } \\
\text { (MDR-TB) }\end{array}$ & \\
\hline \multirow{4}{*}{$\begin{array}{c}\text { Salmonella } \\
\text { enterica } \\
\text { (Serovars Typhi, } \\
\text { Paratyphi) }\end{array}$} & \multirow{4}{*}{$\begin{array}{l}\text { Typhoid } \\
\text { fever }\end{array}$} & \multirow{4}{*}{$\begin{array}{l}\text { Best therapy is } \\
\text { prevention through } \\
\text { vaccination. } \\
\text { Chloramphenicol is a } \\
\text { first-line drug of } \\
\text { choice, although } \\
\text { there is increasing } \\
\text { bacterial resistance } \\
\text { to this drug. Other } \\
\text { recommendations } \\
\text { include treatment } \\
\text { with cephalosporins, } \\
\text { fluorquinolones or } \\
\text { azithromycin in the } \\
\text { case of highly drug } \\
\text { resistant strains of } \\
\text { Salmonella. }\end{array}$} & chloramphenicol & $\begin{array}{l}\text { broad-spectrum } \\
\text { protein synthesis } \\
\text { inhibitor; } \\
\text { emerging } \\
\text { bacterial } \\
\text { resistance to this } \\
\text { antibiotic }\end{array}$ & \multirow{4}{*}{$\begin{array}{l}{[50,} \\
52, \\
54, \\
55, \\
74]\end{array}$} \\
\hline & & & ciprofloxacin & $\begin{array}{l}\text { fluoroquinolones } \\
\text { (inhibit bacterial } \\
\text { DNA replication) }\end{array}$ & \\
\hline & & & $\begin{array}{l}\text { ceftriaxone, } \\
\text { cefotaxime }\end{array}$ & $\begin{array}{l}\text { cephalosporins } \\
\text { (inhibit cell wall } \\
\text { synthesis; a type } \\
\text { of beta-lactam } \\
\text { antibiotic) }\end{array}$ & \\
\hline & & & azithromycin & $\begin{array}{l}\text { macrolide } \\
\text { antibiotic } \\
\text { (inhibits bacterial } \\
\text { protein synthesis) }\end{array}$ & \\
\hline $\begin{array}{c}\text { Brucella } \\
\text { (melitensis, } \\
\text { abortus, suis, } \\
\text { canis) }\end{array}$ & $\begin{array}{l}\text { Brucellosis, } \\
\text { Malta fever }\end{array}$ & $\begin{array}{l}\text { Long-term antibiotic } \\
\text { treatment; } \\
\text { combination therapy } \\
\text { more effective than } \\
\text { monotherapy. }\end{array}$ & $\begin{array}{l}\text { doxycycline with } \\
\text { streptomycin, } \\
\text { gentamicin or } \\
\text { rifampicin }\end{array}$ & $\begin{array}{l}\text { tetracycline- } \\
\text { aminoglycoside } \\
\text { combination } \\
\text { (protein synthesis } \\
\text { inhibitors) }\end{array}$ & $\begin{array}{c}{[13-} \\
15]\end{array}$ \\
\hline
\end{tabular}

Table 2.2B. Current therapeutic strategies against common intracellular bacterial pathogens. 


\section{NANOMEDICINE AS AN EMERGING THERAPEUTIC APPROACH}

Conventional therapies for the treatment of intracellular diseases have existed for many years. These treatments may be further improved as we enter a new era of therapies based on nanomedicine. Nanomedicine can be most succinctly defined as "the application of nanotechnology to medicine” [75]. There are many potential advantages of using nanomedicine over the conventional therapies previously described. Combining new knowledge of nanomaterials with our current understanding of cellular and molecular functions may allow for the development of novel and advanced nanomedicines. As discussed below, nanomedicine has the capacity to incorporate, encapsulate or conjugate a variety of drugs, to target specific cell populations and to offer tunable and site-specific drug release; nanomedicine could be advantageous in treating intracellular diseases.

\section{Biocompatibility and Nanotoxicity}

Biocompatibility is an important feature of any drug delivery system and the goal is to minimize nonspecific cytotoxic effects to healthy tissues while maximizing drug effects at the target tissue or against invasive pathogens [76]. Nanoparticles have been fabricated using a variety of materials including poly(lactide-co-glycolide) or PLGA [77-82], poly-lactic acid (PLA) [78, 83, 84], polymethacrylic acid (PMA) [85, 86], polyethylene glycol (PEG) [87, 88], “natural” polymers such as chitosan [89, 90], gelatin [91, 92] or alginate [93, 94], and other materials such as lipids [95-97], gold [76, 98] and silica [99-102].

PLGA has been approved by the US Food and Drug Administration (FDA) for several biomedical applications including surgical sutures, implants and prosthetic devices [79]. PLGA micro- or nano-particles have also been used for a variety of drug-delivery applications [80]. 
PLGA displays good biocompatibility, biodegradability, suitable degradation kinetics and mechanical properties and is easy to process. For this reason, PLGA is an attractive candidate for nanoparticle-based drug delivery systems and there is a large body of ongoing research in this area. Other polymers such as PLA, PMA, PEG, chitosan, gelatin and alginate also show promise as drug delivery vehicles due to their biocompatible properties. PEG may be used as a "coating" to prevent the rapid removal of nanoparticles from the blood stream by the mononuclear phagocytic system, which may increase nanoparticle circulation time and theoretically improve the therapeutic capacity of the nanoparticle [84, 87]. Chitosan and alginate are polymers derived from natural sources and may offer more "friendly" conditions for the encapsulation or incorporation of DNA or peptides since the use of organic solvents can be avoided [94].

Lipids are also being explored as potential nano-delivery systems, either as liposomes or lipid nanocapsules (LNCs). Liposomes are composed of lipid bi-layers surrounding a hydrophilic "core" and can be designed to incorporate hydrophobic drugs within the lipid bilayer or hydrophilic drugs within the aqueous core [95]. Liposome-encapsulated aminoglycosides (such as gentamicin) have shown higher therapeutic efficacy than conventional amingoglycoside preparations in the liver and spleen using a murine S. typhi infection model[95]. Amphotercin B (an anti-fungal) has also been encapsulated in lipids and administered to mice with an Aspergillus fumigatis infection [96]. Liposome-treated mice have survived longer than mice treated with other amphotercin B preparations, with reduced renal toxicity and a prolonged drug circulation time[96]. These liposome formulations could be a better treatment for diseases affecting the liver or spleen (eg typhoid fever, hepatitis). LNCs are another type of lipid mediated delivery system under exploration. LNCs are considered a "hybrid" between a polymer nanoparticle and a liposome, with an oily core surrounded by a 
membrane composed of PEGylated surfactants [97]. LNCs have shown promise in in vitro and some animal models encapsulating anti-cancer drugs such as paclitaxel, doxorubicin, and etoposide [97]. The results of these studies have indicated higher intracellular drug delivery and reduced tumor size in vivo when LNC formulations were administered.

In contrast to these "soft" polymer-based nanoparticle systems, metals such as gold have also been explored as potential drug delivery vectors. Gold is an attractive drug delivery vector due to the ease with which biomolecules, such as protein or DNA, can be attached to the gold surface using thiol chemistry [76]. This process can also allow attachment of multiple targeting or functional groups to the nanoparticle surface to produce a multifunctional nanoparticle. Although gold nanoparticles can be easily functionalized, these nanoparticles may accumulate in tissues over time because they are not biodegradable. The effects of long-term nanoparticle accumulation are unknown, so in many cases it may be better to use a material that is fully biodegradable. Silica-based compounds are another option, as the biodegradation of silica avoids tissue-accumulation concerns [99] and it has been demonstrated that a variety of agents have been successfully incorporated into silica-based nanoparticles [100-102] for drug delivery applications.

Although each of these materials offers its own set of characteristics and biocompatible properties, some materials may be more suited to certain applications than others. It is important to determine the desired properties of the nanomedicine for defined applications.

\section{Cellular Penetration and Intracellular Delivery}

One critical challenge in treating intracellular pathogens is to get enough drugs to reach the pathogen within an intracellular compartment. Nanoparticles can be internalized by endocytic 
mechanisms which include receptor-mediated or clathrin-coated pit endocytosis [103]. Nanoparticles may reside within acidic endo-lysosome compartments following endocytosis [80] and premature drug release within this acidic compartment may cause drug degradation and render treatment ineffective. It is therefore important for the nanoparticle to escape this compartment and gain access to the cytosol where either the drug cargo may be directly released or the nanoparticle goes on to further target a specific organelle. For instance, PLGA nanoparticles carrying doxorubicin are reportedly capable of escape of the endo-lysosomal compartment by a reversal of their surface charge. This allows the particles to interact with the membrane and escape into the cytosol where the doxorubicin is released [80].

There are a number of sources which report time and concentration-dependent uptake of nanoparticles by a variety of cell types such as smooth muscle cells [80], endothelial cells [104, 105], macrophages [40, 106-108] and tumor cells [109-114]. The uptake of PLGA nanoparticles containing bovine serum albumin as a model drug was found to be concentration dependent in human vascular endothelial cells, approaching first order kinetics [104]. An in vitro uptake and cellular trafficking study using mesoporous hybrid silica nanoparticles demonstrated that the particles were internalized by receptor-mediated endocytosis, localized in the endocytic compartment and then released their cargo within the cytosol [101]. Another in vitro study examined the uptake of drug-loaded thiolated PMA hydrogel capsules [114]. The tracking experiments revealed that nanocapsules were taken up by endocytic mechanisms in a timedependent manner and the drug was released throughout the cell. Collectively, these studies demonstrate that nanoparticles are capable of cellular penetration and are capable of intracellular drug release. This is an important characteristic of a nanomedicine that targets intracellular 
pathogens and promotes direct killing, as the drug must be able to effectively reach the invading pathogens within the intracellular compartment.

\section{Targeting to Specific Cell Types}

The goal of targeting nanomedicines to specific cell populations is to increase the therapeutic efficacy of the drug while minimizing damage to healthy cells and tissues, thereby reducing the incidence and severity of side effects. Presently, the majority of experiments demonstrating the targeting of nanoparticles are related to cancer/tumor targeting although these same concepts can be applied to pathogen-infected cells and the intracellular compartments [99] where the pathogens reside. Nanoparticles can be targeted toward specific cell populations by conjugating targeting ligands to the surface of the nanoparticles. These targeting ligands can be attached directly to nanoparticle surfaces or attached via a spacer (eg PEG), which acts to enhance the flexibility of the targeting ligand and increase the likelihood it will bind the appropriate receptor on the target cell $[111,115]$. There are a variety of methods available to attach ligands to nanoparticle surfaces [116, 117]. Targeting ligands can include antibodies (whole or fragment), receptors or receptor ligands, peptides, aptamers or other small molecules [115]. A few examples are presented below.

When incorporating antibodies on nanoparticle surfaces, it is important to consider whether attachment will affect the binding site or structure of the antibody. Hybrid lipid nanoparticles composed of PLGA, phospholipids and an outer PEG layer have shown targeting capacity to pancreatic cancer cells when coupled with an anti-carcinoembryonic antigen (CEA) half-antibody [113]. Nanoparticles incubated with CEA-presenting pancreatic cancer cells showed selective uptake of targeted nanoparticles over non-targeted control nanoparticles. 
Receptor ligands can also act as targeting moieties. It has been recently reported that nanosized poly(ethylene glycol)-block-poly( $\varepsilon$-caprolactone) (PEG- $b$-PCL) micelles bearing a surface epidermal growth factor (EGF) have been targeted to breast cancer cells over-expressing the epidermal growth factor receptor (EGFR) in vitro and in vivo [109]. The uptake of the nanomicelles was two-fold higher using EGFR over-expressing cells compared to cells which express low levels of EGFR. These results were confirmed using a xenograft mouse model, with mice bearing EGFR over-expressing tumors demonstrating increased tumor uptake of the particles compared to mice bearing low EGFR expressing tumors.

Polyester nanoparticles carrying paclitaxel can be targeted to irradiated tumor cells with a short peptide, Gly-Ile-Arg-Leu-Arg-Gly (GIRLRG), which binds specifically to GRP78 receptors expressed by glioma and breast tumor cells in response to radiation therapy [110]. In vitro and in vivo studies were used to compare tumor volumes following treatment with control and targeted nanoparticles. Mice treated with nanoparticles bearing the targeting component had a significant decrease in tumor volume compared to control.

Conjugation of an A10 aptamer to PLGA/PEG nanoparticles has also been shown to be an effective targeting strategy [117]. The A10 aptamer binds to the prostate-specific membrane antigen (PSMA) on the surface of prostate cancer cells, and the A10 aptamer conjugated nanoparticles showed higher uptake by PSMA positive cells than by PSMA negative cells.

\section{$\underline{\text { Site-Specific and Tunable Drug Release }}$}

In order to effectively eradicate intracellular pathogens, drugs that are intended to kill the pathogens directly should reach the intracellular locations of infected host cells. As we have summarized in Figure 1, locations may include phagosomes [15, 34, 56], vacuoles [52, 53], 
cytosol $[16,57,58]$, nucleus $[1,59,60]$, and may interact with the golgi apparatus [61] or endoplasmic reticulum [62-66]. With proper engineering and design, nanoparticles can be tailored to carry their drug payloads into the infected cells and then release the drug within specific intracellular compartments. One way to accomplish site-specific drug release is to use $\mathrm{pH}$-responsive polymers. In one study, short peptides were conjugated to $\mathrm{pH}$-responsive polymers designed specifically to disrupt the endosomal membrane at $\mathrm{pH} 5.5$ and subsequently release the peptide into the cytosol [118]. The polymers had no membrane disruptive activity at pH 7.4 due to a "masking” PEG group, which is later cleaved to expose the membrane disruption domain at pH 5.5. Peptide-polymer conjugates demonstrated a diffuse cytosolic distribution after one hour, the time normally required for macrophage endosomes to mature into lysosomes. Unconjugated peptide was located primarily in the lysosome after the same time period, indicating the peptide itself was unable to escape into the cytosol. This polymer technology may allow for local drug delivery to the cytosol, although it is more critical to reach the specific intracellular location of the pathogen, such as a vacuole or the nucleus.

It has been demonstrated that nanoparticles can be specifically targeted to mitochondria [119] or nucleus [120] and may be capable of entering vacuoles [121] where pathogens such as Salmonella may reside during an infection process. Although intracellular pathogens do not typically live within mitochondria, pathogens such as Listeria monocytogenes can secrete toxins which interfere with normal mitochondrial function [122]. So, the ability to target mitochondria may provide a means to treat these types of infection and attenuate the effects of secreted toxins. One study successfully localized fluorescent nanodiamonds conjugated with mitochondrial protein antibodies to mitochondria in live cells [119]. The inherent fluorescence of these nanodiamonds allowed for tracking the localization of the nanoparticles, and the microscopy 
experiments revealed that these nanodiamonds were capable of specifically binding the mitochondria compared to control nanodiamonds without conjugated antibody.

Nuclear targeting has been demonstrated in a similar manner, by conjugating nuclear localization signal (NLS) peptides on the surface of PLGA nanoparticles for the nuclear delivery of doxorubicin to cancer cells [120]. The NLS-targeted nanoparticles demonstrated a 6-fold increase in uptake compared to free doxorubicin in solution, and also a 2.5-fold increase in uptake over non-targeted nanoparticles. Cells treated with NLS-targeted nanoparticles also showed a higher toxicity than control nanoparticles, which was expected due to the increased delivery of drug to its nuclear target site. Nuclear targeting would be especially useful in viral infections such as HIV and HSV, as these viruses must enter the nucleus to begin their replicative life cycles.

There is also evidence that demonstrates nanoparticles loaded with ampicillin are capable of entering cells and delivering the drug within Salmonella-containing vacuoles (SCV) [121]. Ampicillin was tritium-labeled and found to localize within both the cytosol and SCV's using ultrastructural autoradiography. The co-localization of the drug with the bacteria led to enhanced bacterial killing and elimination compared to control cells treated with ampicillin in solution. The co-localization of the drug within the SCV is an important step in effectively targeting intracellular pathogen compartments.

Another issue plaguing intracellular pathogen treatments is the lower concentration of drug at the target site and the short duration of efficacy of the drug administered. Large and frequent doses of the drugs are often required to obtain a therapeutic effect. Nanoparticles have the potential to overcome this issue by offering sustained release of drugs, which would lower the required dose and decrease the frequency of administration [123]. As an example, polymer-based 
nanoparticles composed of PLGA are able to sustain release of a variety of drugs, such as rolipram for seven days [124], gentamicin for 25 days [125, 126] and dexamethasone for 15 days [127]. Hyperbranched poly(amine-ester)-PLGA nanoparticles have also demonstrated sustained release of isoniazid, an important anti-TB drug, up to 14 days [82]. Another study targeted gelatin nanoparticles loaded with rifampicin, another anti-TB drug, to macrophages [92]. Test results indicated that the rifampicin-loaded gelatin nanoparticles were capable of localizing in the lungs and reducing bacterial loads in a mouse model of TB. In addition, nanoparticle treatment was as effective as traditional daily oral rifampicin at a reduced dosing frequency (every three days), due to the sustained release of rifampicin from the gelatin matrix [92].

\section{PERSPECTIVES FOR THE FUTURE}

We have reviewed the current therapeutic strategies against commonly encountered intracellular pathogens like viruses and bacteria, and have evaluated the potential of nanomedicine to improve upon the current treatments. When treating intracellular diseases, it is important to avoid or prevent further development of pathogen resistance, which is becoming a major problem for the management of TB [23]. Generally speaking, the success of an antibiotic drug relies on its ability to penetrate the bacterial cell wall and membranes and to bind to its target site (protein, enzyme, etc) [128]. Bacteria may develop resistance by mutating various drug target sites [27], and viruses may also develop drug resistance through genetic mutation and recombination events [29] that can render our current treatments ineffective. For this reason, there is a need for new drugs with novel mechanisms of action that may slow or stop the development of pathogen resistance. 
As an example, recent literature has emerged touting the potential of cationic antimicrobial peptides (CAMPs) to serve as an alternative to conventional antibiotic therapy [129-133]. Antimicrobial peptides are short, positively charged peptides which are produced endogenously by human epithelial tissues where they function to prevent invasion of pathogens, demonstrating broad-spectrum killing activity against bacteria, yeast and fungi [130, 134]. The complete mechanism of CAMP action is yet to be fully understood, but one proposed mechanism suggests that the CAMPs interact electrostatically with the negatively charged molecules on the outer surface of bacteria, where they can insert themselves into the membrane and form a pore [130]. Such a disruption in the bacterial cell wall and membranes will affect the osmolytic balance of the bacterium and ultimately cause cell death. Because CAMPs do not have a specific molecular target per se, pathogens may have more difficulty in developing resistance to these peptides. There is also some evidence indicating that CAMPs can help modulate exogenous antibiotic action against several strains of S. aureus [135]. Bacterial cultures treated with both CAMPs and antibiotics had lower antibiotic "minimum inhibitory concentration” (MIC) values than for cultures treated with antibiotics alone, indicating complementary action between the CAMPs and antibiotics.

As a result, these CAMPs are attractive targets for the development of novel nanomedicines to treat intracellular diseases. It may be possible to design nanoparticles capable of carrying CAMPs into the cell, or to develop self-assembled CAMP nanoparticles. The development of such nanoparticles may greatly improve intracellular drug therapy by offering high efficacy against a variety of pathogens, and also offer very high biocompatibility, as endogenous CAMPs can be used. We anticipate that CAMP nanoparticles will be a potential advanced nanomedicine for intracellular disease treatments. 
Another potential strategy to improve intracellular disease treatments is to take advantage of the preferential accumulation of nanoparticles by the reticuloendothelial system (RES). The RES can also be referred to as the "mononuclear phagocytic system" and is composed of macrophages residing in the liver, spleen and lungs. Normally, this phenomenon is avoided in nanomedicine, as the RES removes the nanoparticles from circulation and may prevent drugs from reaching target tissues. However, this treatment modality may be particularly useful in treating intracellular diseases such as TB (affecting the lungs) or typhoid fever (affecting the liver and spleen), as these pathogens primarily live and duplicate within macrophages of the affected organs. Using nanoparticles to deliver drugs of interest to fight these diseases may be aided by the natural tendency of these cells to internalize nanoparticles, which would help reduce unnecessary tissue exposure and likely decrease the amount of drug required since it is being delivered to the appropriate cell.

To create the "perfect" intracellular drug delivery system for fighting infections, certain characteristics of nanoparticles or nanomedicine must be successfully incorporated such that the medicine exhibits acceptable biocompatibility, possesses targeting capacity and offers efficient and sustained drug release at the target site. Figure 2 illustrates an "ideal" nanoparticle drug delivery system with such characteristics suited to treat intracellular diseases. The nanomaterial used will vary with each application, but there are a variety of biocompatible materials available as summarized in Table 3. 


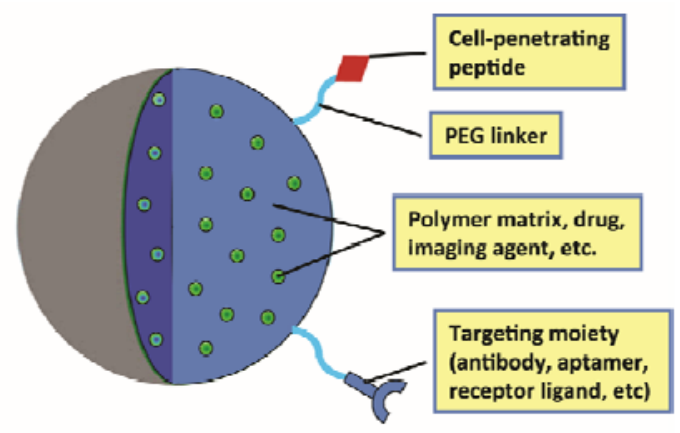

Figure A2.2. Components of an "ideal” nanoparticle for intracellular drug delivery. The important components of a nanoparticle used for intracellular drug delivery include: choice of nanomaterials (polymer, gold, etc), targeting molecules, cell penetrating peptides (to promote internalization) and the incorporated drug molecules of interest.

The drug may be used to form the nanoparticle, encapsulated within a polymer matrix, or attached to the surface of a solid "carrier" nanoparticle. The incorporation of surface targeting components to help localize to the affected tissue may improve therapeutic efficacy, along with the presence of molecules to enhance cellular penetration such as cell penetrating peptides (CPPs). CPPs are short, cationic peptides, typically derived from the HIV TAT proteins [136] which have been shown to readily translocate through cell membranes. The addition of CPPs, such as TAT, to the surface of a nanoparticle can increase the efficiency with which the nanoparticles are delivered intracellularly [137, 138]; although the mechanism by which these CPPs are able to enter cells is currently under debate. It is suggested that either the CPPs promote direct translocation through the membrane via electrostatic interactions, or the CPPs bind to specific receptors on the membrane and induce rapid receptor-mediated endocytosis [138]. In either case, promoting efficient cellular penetration is critical for the treatment of intracellular diseases.

Nanomedicine meets the requirements for an "ideal” drug delivery system to improve intracellular disease therapy; however, we are still exploring this relatively new field. It is early 
to assess how quickly nanomedicine will be adopted and integrated into the mainstream healthcare. Research on nanomedicine is relatively well-funded[139], so it is likely that many new treatment methods will be approved and available in the future. However, this investment cost for drug development is still high from an economic standpoint [140], and the price will probably be passed down to patients via high prescription co-pays and may not be available for years in developing areas where these improved therapies are needed most. Initially, this may be a deterrent to promoting nanomedicine, but over the long-term with new cost-effective technologies, higher drug efficacy, and better treatment outcomes, the price will become acceptable.

\begin{tabular}{|c|c|c|}
\hline Type of Nanoparticle & Materials Used & [Ref] \\
\hline \multirow{4}{*}{ Synthetic or Man-made Polymers } & Poly (lactide-co-glycolide) (PLGA) & {$[77-81]$} \\
\hline & Poly-lactic acid (PLA) & {$[78,83,84]$} \\
\hline & Polymethacrylic acid (PMA) & {$[85,86]$} \\
\hline & Polyethylene glycol (PEG) & {$[78,87,88]$} \\
\hline \multirow{4}{*}{ Natural Polymers } & Chitosan & {$[89,90]$} \\
\hline & Gelatin & {$[91,92]$} \\
\hline & Alginate & {$[93,94]$} \\
\hline & Lipids & [95-97] \\
\hline \multirow{2}{*}{ Other Types of Nanoparticles } & Gold & {$[76,98]$} \\
\hline & Silica-based compounds & [99-102] \\
\hline
\end{tabular}

Table A2.3. Examples of biocompatible nanoparticles. 


\section{CONCLUDING REMARKS}

The burden of treating intracellular diseases is continually increasing due to the sheer number of people living with diseases such as HIV/AIDS, hepatitis and tuberculosis worldwide, along with the increasing incidence of drug resistance. We have summarized the locations where these pathogens reside, such as phagosomes [15, 34, 56], vacuoles [52, 53], cytosol $[16,57,58]$, nucleus [1, 59, 60], golgi apparatus [61] or endoplasmic reticulum [62-66]. The major challenges in treating these invasive pathogens include getting enough drugs to penetrate the host cell and reach the pathogen, having high drug efficacy and low toxicity, and maintaining sustained, sitespecific drug release throughout the duration of treatment. In the future, it may be possible to improve disease treatment by utilizing the uptake of nanoparticles by the reticuloendothelial system, especially in the case of TB or hepatitis which affects macrophages. Additionally, looking to endogenous sources such as CAMPs or other immunomodulatory compounds such as interleukins (not covered) may further improve upon current therapies.

The literature presented here shows the potential for nanomedicine to address these challenges and improve upon the current therapeutic strategies. The incorporation of nanomedicine into mainstream healthcare is a lofty, but achievable, goal. Researchers from multiple disciplines must work together, push the boundaries of science at the nanoscale and incorporate concepts from biology, engineering and drug design in order to make this goal a reality. 


\section{REFERENCES}

1. Akhtar, J. and D. Shukla, Viral entry mechanisms: cellular and viral mediators of herpes simplex virus entry. FEBS Journal, 2009. 276(24): p. 7728-7236.

2. Alter, M.J., Epidemiology of hepatitis c virus infection. World Journal of Gastroenterology, 2007. 13: p. 2436-2441.

3. Chatterjee, K., Host genetic factors in susceptibility to HIV and prgression to AIDS. Journal of Genetics, 2010. 89(1): p. 109-116.

4. Empey, K.M., J. R Stokes Peebles, and J.K. Kolls, Pharmacological advances in the treatment and prevention of Respiratory Syncytial Virus. Clinical Infectious Diseases, 2010. 50: p. 1258-1267.

5. Este, J.A. and T. Cihlar, Current status and challenges of antiretroviral research and therapy. Antiviral Research, 2010. 85: p. 25-33.

6. Sharma, S.D., Hepatitis C Virus: Molecular biology \& current therapeutic options. Indian J Med Res, 2010. 131: p. 17-34.

7. Welliver, R.C., Pharmacotherapy of respiratory syncytial virus. Current Opinion in Pharmacology, 2010. 10: p. 289-293.

8. Wilson, S.S., E. Fakiogly, and B.C. Herold, Novel approaches in fighting herpes simplex virus infections. Expert Rev Anti Infect Ther, 2009. 7(5): p. 559-568.

9. LoBue, P.A., D.A. Enarson, and T.C. Thoen, Tuberculosis in humans and its epidemiology, diagnosis and treatment in the United States. Int J Tuberc Lung Dis, 2010. 14(10): p. 1126-1232.

10. Flynn, J.L. and J. Chan, Immunology of Tuberculosis. Annu Rev Immunol, 2001. 19: p. 93-129.

11. Lahiri, A., et al., Visiting the cell biology of Salmonella infection. Microbes and Infection, 2010. 12: p. 809-818.

12. Watson, K.G. and D.W. Holden, Dynamics of growth and dissemination of Salmonella in vivo. Cellular Microbiology, 2010. 12(10): p. 1389-1397.

13. Franco, M.P., et al., Human brucellosis. The Lancet Infectious Diseases, 2007. 7(12): p. 775-786.

14. Gamazo, C., et al., Chemical and biological factors in the control of Brucella and brucellosis. Current Drug Delivery, 2006. 3: p. 359-365.

15. Roop, R.M., et al., Adaptation of the brucellae to their intracellular niche. Molecular Microbiology, 2004. 52(3): p. 621-630.

16. Theirot, J.A., The cell biology of infection by intracellular bacterial pathogens. Annu Rev Cell Dev Biol, 1995. 11: p. 213-239.

17. Lopez-Martinez, R., Candidosis, a new challenge. Clinics in Dermatology, 2010. 28: p. 178-184.

18. Balloy, V. and M. Chignard, The innate immune response to Aspergillus fumigatis Microbes and Infection, 2009. 11: p. 919-927.

19. Gomez, M.A. and M. Olivier, Proteases and phosphatases during Leishmaniamacrophage interaction: Paving the road for pathogenesis. Virulence, 2010. 1(4): p. 314-318.

20. Goto, H., J. Angelo, and L. Lindoso, Current diagnosis and treatment of cutaneous and mucocutaneous leishmaniasis. Expert Rev Anti Infect Ther, 2010. 8(4): p. 419-433. 
21. Sadanand, S., Malaria: An evaluation of the current state of research on pathogenesis and antimalarial drugs. Yale J Biol Med, 2010. 83(4): p. 185-191.

22. Briones, E., C.I. Colino, and J.M. Lanao, Delivery systems to increase the selectivity of antibiotics in phagocytic cells. Journal of Controlled Release, 2008. 125: p. 210-227.

23. Chiang, C.Y. and H.S. Schaaf, Management of drug-resistant tuberculosis. Int J Tuberc Lung Dis, 2010. 14(6): p. 672-682.

24. Nguyen, H.M. and C.J. Graber, Limitations of antibiotic options for invasive infections caused by methicillin-resistant Staphylococcus aureus: is combination therapy the answer? Journal of Antimicrobial Chemotherapy, 2009. 65: p. 24-36.

25. Woodford, N. and D.M. Livermore, Infections caused by Gram-Positive bacteria: a review of the global challenge. Journal of Infection, 2009. 59: p. S4-S16.

26. Finch, R., Bacterial resistance- the clinical challenge. Clinical Microbiology and Infection, 2002. 8 (Supp 3): p. 21-32.

27. Hawkey, P.M. and A.M. Jones, The changing epidemiology of resistance. Journal of Antimicrobial Chemotherapy, 2009. 64(Supp 1): p. 3-10.

28. Goossens, H., Antibiotic consumption and link to resistance. Clinical Microbiology and Infection, 2009. 15(Supp 3): p. 12-15.

29. Margeridon-Thermet, S. and R.W. Shafer, Comparison of the mechanisms of drug resistance among HIV, Hepatitis B and Hepatitis C. Viruses, 2010. 2(12): p. 2696-2739.

30. Kaufmann, S.H.E., Future vaccination strategies against tuberculosis: Thinking outside the box. Immunity, 2010. 33: p. 567-577.

31. Lalloo, U.G. and A. Ambaram, New antituberculosis drugs in development. Curr HIV/AIDS Rep, 2010. 7: p. 143-151.

32. Signs and symptoms of TB disease. Atlanta, GA: Centers for Disease Control and Prevention; 2010. Available from: http://www.cdc.gov/tb/topic/basis/signsandsymptoms.htm Accessed November 10, 2011.

33. Tuberculosis: general information. Atlanta, GA: Centers for Disease Control and Prevention; 2010. Available from:

http://www.cdc.gov/tb/publications/factsheets/general/tb.htm Accessed November 10, 2011.

34. Ahmad, S., Pathogenesis, immunity, and diagnosis of latent Mycobacterium tuberculosis infection. Clin Dev Immunol, 2011(2011:814943).

35. Lin, P.L. and J.L. Flynn, Understanding latent tuberculosis: A moving target. The Journal of Immunology, 2010. 185: p. 15-22.

36. Kumar, D. and K.V.S. Rao, Regulation between survival, persistence, and elimination of intracellular mycobacteria: a nested equilibrium of delicate balances. Microbes and Infection, 2011. 13: p. 121-133.

37. Gaspar, M., et al., Developments on drug delivery systems for the treatment of mycobacterial infections. Current Topics in Medicinal Chemistry, 2008. 8: p. 579-591.

38. Garner, P., et al., Promoting adherence to tuberculosis treatment. Bulletin of the World Health Organization, 2007. 85(5): p. 404-406.

39. Aspler, A., et al., Cost of tuberculosis diagnosis and treatment from the patient perspective in Lusaka, Zambia. Int J Tuberc Lung Dis, 2008. 12(8): p. 928-935.

40. Onoshita, T., et al., The behaivor of PLGA microspheres containing rifampicin in alveolar macrophages. Colloids and Surfaces B: Biointerfaces, 2010. 76: p. 151-157. 
41. Global summary of the AIDS epidemic; 2009. Geneva, Switzerland: World Health Organization; 2009. Available from:

http://www.who.int/hiv/data/2009 gloval summary.png Accessed November 20, 2011.

42. Wohl, D.A., Deconstructing most recent antitretroviral recommendations. Curr HIV/AIDS Rep, 2010. 7: p. 77-84.

43. Clercq, E.D., Highlights in the discovery of antiviral drugs: A personal retrospective. $\mathrm{J}$ Med Chem, 2010. 53: p. 1438-1450.

44. Zolopa, A.R., The evolution of HIV treatment guidelines: Current state-of-the-art of ART. Antiviral Research, 2010. 85: p. 241-244.

45. Gupta, U. and N.K. Jain, Non-polymeric nano-carriers in HIV/AIDS drug delivery and targeting. Advanced Drug Delivery Reviews, 2010. 62: p. 478-490.

46. Waters, L. and M. Nelson, Why do patients fail HIV therapy? Int J Clin Pract, 2007. 61(6): p. 983-990.

47. Lavanchy, D., Evolving epidemiology of Hepatitis C Virus. Clinical Microbiology and Infection, 2011. 17(2): p. 107-115.

48. Castello, G., et al., HCV-related hepatocellular carcinoma: From chronic inflammation to cancer. Clinical Immunology, 2010. 130: p. 237-250.

49. $\quad \mathrm{Yu}, \mathrm{C} . \mathrm{I}$. and B.-L. Chiang, $A$ new insight into Hepatitis $C$ vaccine development. Journal of Biomedicine and Biotechnology, 2010. 2010: p. 548280-548292.

50. Zhang, X.-L., V.T. Jeza, and Q. Pan, Salmonella Typhi: from a human pathogen to a vaccine vector. Cellular and Molecular Immunology, 2008. 5: p. 91-97.

51. Typhoid fever: general information. Atlanta, GA: Centers for Disease Control and Prevention; 2010. Available from:

http://www.cdc.gov/nczved/divisions/dfbmb/diseases/typhoid fever. Accessed November 10, 2011.

52. Trebichavsky, I., I. Splichal, and A. Splichalova, Innate immune response in the gut against Salmonella - review. Folia Microbiol, 2010. 55(3): p. 295-300.

53. Buchmeier, N.A. and F. Heffron, Inhibition of macrophage phagosome-lysosome fusion by Salmonella typhimurium. Infection and Immunity, 1991. 59(7): p. 2232-2238.

54. Guzman, C.A., et al., Vaccines against typhoid fever. Vaccine, 2006. 24: p. 3804-3811.

55. Thaver, D., et al., A comparison of fluoroquinolones versus other antibiotics for treating enteric fever: meta-analysis. BMJ, 2009. 338: p. 11.

56. Lawlor, C., et al., Cellular targeting and trafficking of drug delivery systems for the prevention and treatment of MTb. Tuberculosis, 2011. 91(1): p. 93-97.

57. Al-Khodor, S. and Y.A. Kwalk, Triggering Ras signalling by intracellular Francisella tularensis through recruitment of PKC-alpha and beta-I to the SOS2/GrB2 complex is essential for bacterial proliferation in the cytosol. Cellular Microbiology, 2010. 12(11): p. 1604-1621.

58. Collins, C.A. and E.J. Brown, Cytosol as a battleground: ubiquitiation as a weapon for both host and pathogen. Trends in Cell Biology, 2010. 20(4): p. 205-213.

59. D'Orsogna, M.R. and T. Chou, Optimal cytoplasmic transport in viral infections. PLoS One, 2009. 4(12): p. 8165-72.

60. Calder, J.M., E.C. Stow, and N.D. Stow, On the cellular localization of the components of the herpes simplex virus type 1 helicase-primase complex and the viral origin-binding protein. Journal of General Virology, 1992. 73: p. 531-538. 
61. Heuer, D., et al., Chlamydia causes fragmentation of the golgi compartment to ensure reproduction. Nature 2009. 457: p. 731-735.

62. Tilney, L.G., et al., How the parasitic bacterium Legionella pneumophilia modifies its phagosome and transforms it into rough ER: implications for conversion of plasma membrane to the ER membrane. J Cell Sci, 2001. 114: p. 4637-4650.

63. Celli, J., et al., Brucella evades macrophage killing via VirB-dependent sustained interactions with the endoplasmic reticulum. J Exp Med, 2003. 198: p. 545-556.

64. Roy, C.R., S.P. Salcedo, and J.-P.E. Gorvel, Pathogen-endoplasmic-reticulum interactions: in through the out door. Nat Rev Immunol, 2006. 6: p. 136-147.

65. Moradpour, D., et al., Membrane association of hepatitis $C$ virus nonstructural proteins and identification of the membrane alteration that harbors the viral replication complex. Antiviral Research, 2003. 60: p. 103-109.

66. Sinai, A.P., P. Webster, and K.A. Joiner, Association of host cell endoplasmic reticulum and mitochondria with the Toxoplasma gondii parasitophorous vacuole membrane: a high affinity interactions. Journal of Cell Science, 1997. 110: p. 2117-2128.

67. Sandegren, L. and D.I. Andersson, Bacterial gene amplification: implications for the evolution of antibiotic resistance. Nat Rev Microbiol, 2009. 7(8): p. 578-88.

68. Sendi, P. and R.A. Proctor, Staphylococcus aureus as an intracellular pathogen: the role of small colony variants. Trends in Microbiology, 2009. 17: p. 54-58.

69. Garzoni, C. and W.L. Kelley, Staphylococcus aureus: new evidence for intracellular persistence. Trends in Microbiology, 2009. 17: p. 59-65.

70. Hudson, M.C., et al., Internalization of Staphylococcus aureus by cultured osteoblasts. Microbial Pathogenesis, 1995. 19: p. 409-419.

71. Jevon, M., et al., Mechanisms of internalization of Staphylococcus aureus by cultured human osteoblasts. Infect Immun, 1999. 67(5): p. 2677-81.

72. Sinha, B. and M. Fraunholz, Staphylococcus aureus host cell invasion and post-invasion events. International Journal of Medical Microbiology, 2010. 300: p. 170-175.

73. Ellington, J., et al., Intracellular Staphylococcus aureus: A mechanism for the indolence of osteomyelitis. Journal of Bone and Joint Surgery Br, 2003. 85: p. 918-921.

74. http://www.cdc.gov/nczved/divisions/dfbmd/diseases/typhoid_fever/, Centers for Disease Control and Prevention, Typhoid Fever: General Information [Internet] Atlanta, GA, [updated 2010 Oct 5, cited 2011 Jan 23]. c2010.

75. Freitas, R.A., What is nanomedicine? Nanomedicine, 2005. 1(1): p. 2-9.

76. Seale-Goldsmith, M.M. and J.F. Leary, Nanobiosystems. Wiley Interdiscip Rev Nanomed Nanobiotechnol, 2009. 1(5): p. 553-67.

77. Astete, C.E. and C.M. Sabliov, Synthesis and characterization of PLGA nanoparticles. J Biomater Sci Polymer Edn, 2006. 17(3): p. 247-289.

78. Avgoustakis, K., Pegylated poly(lactide) and poly(lactide-co-glycolide) nanoparticles: preparation, properties and possible applications in drug delivery. Current Drug Delivery, 2004. 1: p. 321-333.

79. Lu, J.-M., et al., Current advances in research and clinical applications of PLGA-based nanotechnology. Expert Rev Mol Diagn, 2009. 9(4): p. 325-341.

80. Panyam, J., et al., Rapid endo-lysosomal escape of poly(DL-lactide-co-glycolide) nanoparticles: implications for drug and gene delivery. FASEB J, 2002. 16: p. 1217-26. 
81. Qaddoumi, M.G., et al., The characteristics and mechanisms of uptake of PLGA nanoparticles in rabbit conjunctival epithelial cell layers. Pharm Res, 2004. 21(4): p. 641-8.

82. Kohane, D.S., et al., Biodegradable polymeric microspheres and nanospheres for drug delivery in the peritoneum. J Biomed Mater Res A, 2006. 77(2): p. 351-61.

83. Wang, G., et al., The release of cefazolin and gentamicin from biodegradable PLA/PGA beads. Int J Pharm, 2004. 273(1-2): p. 203-12.

84. Xiao, R.Z., et al., Recent advances in PEG-PLA block copolymer nanoparticles. Int J Nanomedicine, 2010. 5: p. 1057-1065.

85. Lorenz, S., et al., The softer and more hydrophobic the better: Influence of the side chain of polymethacrylate nanoparticles for cellular uptake. Macromolecular Bioscience, 2010. 10(9): p. 1034-1042.

86. Sajeesh, S. and C.P. Sharma, Cyclodextrin-insulin complex encapsulated polymethacrylic acid based nanoparticles for oral insulin delivery. Int J Pharm, 2006. 325: p. 147-154.

87. Joralemon, M.J., S. McRae, and T. Emrick, PEGylated polymers for medicine: from conjugation to self-assembled systems. Chem Comm, 2010. 46(1377-1393).

88. Vlerken, L.E.v., T.K. Vyas, and M.M. Amiji, Poly(ethylene glycol)-modified nanocarriers for tumor-targeted and intracellular delivery. Pharmaceutical Research, 2007. 24(8): p. 1405-1415.

89. Panos, I., N. Acosta, and A. Heras, New drug delivery systems based on chitosan. Current Drug Discovery Technologies, 2008. 5: p. 333-341.

90. Park, J.H., et al., Targeted delivery of low molecular drugs using chitosan and its derivatives. Advanced Drug Delivery Reviews, 2009. 62(1): p. 28-41.

91. Kumari, A., S.K. Yadav, and S.C. Yadav, Biodegradable polymers nanoparticles based drug delivery systems. Colloids and Surfaces B: Biointerfaces, 2010. 75: p. 1-18.

92. Saraogi, G.K., et al., Gelatin nanocarriers as potential vectors for effective management of tuberculosis. International Journal of Pharmaceutics, 2009. 385: p. 143-149.

93. Hamidi, M., A. Azadi, and P. Rafiei, Hydrogel nanoparticles in drug delivery. Advanced Drug Delivery Reviews, 2008. 60: p. 1638-1649.

94. Reis, C.P., et al., Review and current status of emulsions/dispersions technologogy using an internal gelation process for the design of alginate particles. Journal of Microencapsulation, 2006. 23(3): p. 245-257.

95. Schiffelers, R., G. Storm, and I. Bakker-Woudenberg, Liposome-encapsulated aminoglycosides in pre-clinical and clinical studies. J Antimicrob Chemother, 2001. 48(3): p. 333-44.

96. Jung, S.H., et al., Amphotercin B-entrapping lipid nanoparticles and their in vitro and in vivo characteristics. European Journal of Pharmaceutical Sciences, 2009. 37: p. 313-320.

97. Huynh, N.T., et al., Lipid nanocapsules: A new platform for nanomedicine. Int J Pharm, 2009. 379: p. 201-209.

98. Pissuwan, D., et al., Functionalized gold nanoparticles for controlling pathogenic bacteria. Trends in Biotechnology, 2010. 28: p. 207-213.

99. Seleem, M.N., et al., Silica-antibiotic hybrid nanoparticles for targeting intracellular pathogens. Antimicrobial Agents and Chemotherapy, 2009. 53(10): p. 4270-4274.

100. Izquierdo-Barba, I., et al., Incorporation of amtimicrobial compounds in mesoporous silica film monolith. Biomaterials, 2009. 30: p. 5729-5736. 
101. Rosenholm, J.M., et al., Targeted intracellular delivery of hydrophobic agents using mesoporous hybird silica nanoparticles as carrier systems. Nano Letters, 2009. 9(9): p. 3308-3311.

102. Wan, X., D. Wang, and S. Liu, Fluorescent pH-sensing organic/inorganic hybrid mesoporous silica nanoparticles with tunable redox-responsive release capability. Langmuir, 2010. 26(19): p. 15574-79.

103. Vasir, J.K. and V. Labhasetwar, Biodegradable nanoparticles for cytosolic delivery of therapeutics. Advanced Drug Delivery Reviews, 2007. 59: p. 718-728.

104. Davda, J. and V. Labhasetwar, Characterization of nanoparticle uptake by endothelial cells. Int J Pharm, 2002. 233(1-2): p. 51-9.

105. Ferrati, S., et al., Intracellular trafficiking of silicon particles and logic-embedded vectors. Nanoscale 2010. 2: p. 1512-1520.

106. Martins, M., et al., Targeting human macrophages for enhanced killing of intracellular $X D R-T B$ and MDR-TB. Int J Tuberc Lung Dis, 2009. 13(5): p. 569-573.

107. Lecaroz, C., et al., Intracellular killing of Brucella melitensis in human macrophages with microsphere encapsulated gentamicin. Journal of Antimicrobial Chemotherapy, 2006. 58: p. 549-556.

108. Kamat, M., et al., Hyaluronic acid immobilized magnetic nanoparticles for active targeting and imaging of macrophages. Bioconjugate Chem, 2010. 21: p. 2128-2135.

109. Lee, H., et al., The effects of particle size and molecular targeting on the intratumoral and subcellular distribution of polymeric nanoparticles. Mol Pharm, 2010. 7(4): p. 1195208.

110. Passarella, R.J., et al., Targeted nanoparticles that deliver a sustained, specific release of paclitaxel to irradiated tumors. Cancer Research, 2010. 70(11): p. 4550-4559.

111. Ruoslahti, E., S.N. Bhatia, and M.J. Sailor, Targeting of drugs and nanoparticles to tumors. Journal of Cell Biology, 2010. 188(6): p. 759-769.

112. Vazquez, E., et al., Internalization and kinetics of nuclear migration of protein-only, arginine-rich nanoparticles. Biomaterials, 2010. 31(35): p. 9333-9.

113. Hu, C.-M.J., et al., Half-antibody functionalized lipid-polymer hybrid nanoparticles for targeted drug delivery to carcinoembryonic antigen presenting pancreatic cancer cells. Molecular Pharmaceutics, 2010. 7(3): p. 914-920.

114. Yan, Y., et al., Uptake and intracellular fate of disulfide-bonded polymer hydrogel capsules for Doxorubicin delivery to colorectal cancer cells. ACS Nano, 2010. 4(5): p. 2928-36.

115. Wang, M. and M. Thanou, Targeting nanoparticles to cancer. Pharmacological Research, 2010. 62: p. 90-99.

116. Nobs, L., et al., Current methods for attaching targeting ligands to liposomes and nanoparticles. Journal of Pharmaceutical Sciences, 2004. 90(8): p. 1980-1992.

117. Gu, F., et al., Precise engineering of targeted nanoparticles by using self-assembled biointegrated block copolymers. PNAS, 2008. 105(7): p. 2586-2591.

118. Murthy, N., et al., Bio-inspired pH-responsive polymers for the intracellular delivery of biomolecular drugs. Bioconjugate Chemistry, 2003. 14: p. 412-419.

119. Mkandawire, M., et al., Selective targeting of green fluorescent nanodiamond conjugates to mitochondria in HeLa cells. Journal of Biophotonics, 2009. 2: p. 596-606. 
120. Misra, R. and S.K. Sahoo, Intracellular trafficking of nuclear localization signal conjugated nanoparticles for cancer therapy. European Journal of Pharmaceutical Sciences, 2010. 39: p. 152-163.

121. Balland, O., et al., Intracellular distribution of ampicillin in murine macrophages infected with Salmonella typhimurium and treated with $\left({ }^{\beta} H\right)$ ampicillin-loaded nanoparticles. Journal of Antimicrobial Chemotherapy, 1996. 37: p. 105-115.

122. Stavru, F., et al., Listeria monocytogenes transiently alters mitochondrial dynamics during infection. PNAS, 2011. 108: p. 3612-3617.

123. Zhang, L., et al., Nanoparticles in medicine: Therapeutic applications and developments. Clinical Pharmacology \& Therapeutics, 2008. 83(5): p. 761-769.

124. Lamprecht, A., et al., Biodegradable nanoparticle for targeted drug delivery in treatment of inflammatory bowel disease. Journal of Pharmacology and Experimental Therapeutics, 2001. 299: p. 775-781.

125. Lecaroz, C., et al., Biodegradable micro- and nanoparticles as long-term delivery vehicles for gentamicin. Journal of Microencapsulation, 2006. 23(7): p. 782-792.

126. Blanco-Prieto, M.J., et al., In vitro evaluation of gentamicin resleased from microparticles. International Journal of Pharmaceutics, 2002. 242: p. 203-206.

127. Panyam, J. and V. Labhasetwar, Sustained cytoplasmic delivery of drugs with intracellular receptors using biodegradable nanoparticles. Mol Pharm, 2004. 1(1): p. $77-$ 84.

128. Cloutier, M.J., Antibiotics: Mechanisms of action and the acquisition of resistance- when magic bullets lose thier magic. American Journal of Pharmaceutical Education, 1995. 59: p. $167-172$.

129. Wang, H., et al., The efficacy of self-assembled cationic antimicrobial peptide nanoparticles against Cryptococcus neoformans for the treatment of meningitis. Biomaterials, 2010. 31: p. 2874-2881.

130. Bucki, R., et al., Cathelicidin LL-37: A multitask antimicrobial peptide. Arch Immunol Ther Exp, 2010. 58: p. 15-25.

131. Eby, D.M., K.E. Farrington, and G.R. Johnson, Synthesis of bioinorganic antimicrobial peptide nanoparticles with potential therapeutic properties. Biomacromolecules, 2008. 9: p. 2481-2494.

132. Liu, L., et al., Self-assembled cationic peptide nanoparticles as an efficient antimicrobial agent. Nature Nanotechnology, 2009. 4: p. 457-463.

133. Cho, W.-M., et al., Design and synthesis of novel antibacterial peptide-resin conjugates. Medicinal Chemistry Letters, 2007. 17: p. 5772-5776.

134. Durr, U.H.N., U.S. Sudheendra, and A. Ramamoorthy, LL-37, the only human member of the cathelicidin family of antimicrobial peptides. Biochimica et Biophysica Acta, 2006. 1758: p. 1408-1425.

135. Leszczynska, K., et al., Modulation of exogenous antibiotic activity by host cathelicidin LL-37. APIMS, 2010. 118: p. 830-836.

136. Fonseca, S.B., M.P. Pereira, and S.O. Kelley, Recent advances in the use of cellpenetrating peptides for medical and biological applications. Adv Drug Deliv Rev, 2009. 61(11): p. 953-64.

137. Juliano, R.L., et al., Cell-targeting and cell-penetrating peptides for delivery of therapeutic and imaging agents. Wiley Interdiscip Rev Nanomed Nanobiotechnol, 2009. 1(3): p. 324-35. 
138. Schmidt, N., et al., Arginine-rich cell-penetrating peptides. FEBS Lett, 2010. 584(9): p. 1806-13.

139. Murday, J.S., et al., Translational nanomedicine: status assessment and opportunities. Nanomedicine, 2009. 5(3): p. 251-73.

140. Allhoff, F., The coming era of nanomedicine. Am J Bioeth, 2009. 9(10): p. 3-11. 